\title{
Kapitel 3. Folgen der teleologischen Subsidiarität von § 241 II BGB - Lückenfüllung in der Subsumtion
}

\section{A. Rechtsmethodische Konsequenz der teleologischen Subsidiarität schuldverhältnisbedingter Nebenpflichten: Doppelfunktionalität von § 241 II BGB}

Nachdem herausgearbeitet wurde, dass Nebenpflichten bei teleologischer Auslegung des $\S 241$ II BGB aus rechtspraktischer Perspektive Haftungslücken im Deliktsrecht füllen sollen, kann der Zweck des § 241 II BGB nun weiter untersucht werden. Erstere Erkenntnis hilft schließlich bei der Subsumtion in dem Moment nicht mehr weiter, in dem eine Haftungslücke im Deliktsrecht festgestellt wurde. Die Entscheidung, ob diese Lücke dann durch eine Nebenpflicht und eine korrespondierende Haftung aus $\S \S 280$ I, 241 II BGB - geschlossen werden soll oder gänzlich offen bleibt, muss sich letztlich ebenfalls aus dem Zweck von $\S 241$ II BGB heraus erklären lassen. ${ }^{1203}$

\section{Blankettcharakter des $\S 241$ II BGB}

$\S 241$ II BGB wird von der Literatur zu Recht als Blankettnorm eingeordnet, die der näheren Ausfüllung bedarf. ${ }^{1204}$ Die Untersuchung hat aber bislang gezeigt, dass die Konkretisierung des $\S 241$ II BGB durch die bislang häufig deskriptiven Ansätze in der Literatur ${ }^{1205}$ oder gänzlich theoretischen Konstrukte ${ }^{1206}$ noch nicht entscheidend ,vor[ge]prägt ${ }^{\text {(1207 }}$ wurde. Die bislang untersuchten Haftungsgrün-

1203 Das Vorgehen ist dabei der methodischen Begründung einer Analogie nicht unähnlich: Zunächst muss eine Regelungslücke festgestellt werden (i.e. die Haftungslücke im Deliktsrecht). Anschließend muss untersucht werden, ob diese Regelungslücke auch planwidrig ist. Der Plan, gegen den ohne Annahme einer Nebenpflicht verstoßen werden würde, wird dann entsprechend vom Normzweck des § 241 II BGB repräsentiert.

1204 Vgl. HKK/Dorn, 2007, § 241 Rn. 109; Palandt/Grüneberg, 77. Aufl. 2018, § 241 Rn. 7; Tröger, Arbeitsteilung, 2012, S. 520f. Der Erlass einer solchen Generalklausel lässt sich als „Übertragung von Rechtssetzungsbefugnis" auf die Rechtsprechung deuten, zutreffend C. Kirchner, FS Schäfer, 2008, S. 37, 39.

1205 Z.B. „Rechtskreiseröffnung“ (Frost, Schutzpflichten, 1981, S. 64), Kriterium der „sozialen Nähe" (Teichmann, JA 1984, 709, 713) etc.

1206 Z.B. Gebot des neminem laedere, s. Katzenstein, Jura 2004, 584, 586; HKK/Schermaier, 2007, $\S \S 280-285$ Rn. 34; Unberath, Vertragsverletzung, 2007, S. $186 f$.

1207 Treffend Tröger, Arbeitsteilung, 2012, S. 521. 
de konnten also mit anderen Worten nicht wesentlich zur Präzisierung und Begrenzung der Nebenpflicht beitragen. Naheliegend erscheint deshalb die Überlegung, dass die bisher vorgetragenen Haftungsgründe sich für die sinnvolle Begrenzung der Nebenpflichten nicht nutzbar machen lassen und ein gänzlich anderer Weg eingeschlagen werden muss. Deshalb ist eine funktionale Betrachtung sinnvoll: Nur diese kann sich nämlich völlig von den deskriptiven Ansätzen lösen und die entscheidende Frage stellen: Welches Haftungsergebnis soll mit Nebenpflichten erreicht werden? Zur besseren Handhabung in der Subsumtion wird die Funktion im Folgenden zweigeteilt.

1. Nebenpflichten als Handlungsanreiz zur Vermeidung von Fahrlässigkeit

Nebenpflichten dienen dem Integritätsschutz. Sie sollen also bestimmte Interessen schützen. Sie können auf (grob) fahrlässige Weise oder vorsätzlich verletzt werden. Wird die Integrität von absolut geschützten Rechtsgütern vorsätzlich verletzt, so steht regelmäßig auch eine Straftat ${ }^{1208}$ im Raum. Wird das Vermögen vorsätzlich geschädigt, so ist - neben ebenfalls denkbaren Straftaten ${ }^{1209}$ - auch $\S 826$ BGB einschlägig. Bei der vorsätzlichen Verletzung einer Nebenpflicht wird mit dem Verbot der Vorsatzschädigung ${ }^{1210}$ also stets auch ein allgemeines Rechtsprinzip beeinträchtigt. Das verdrängt in diesem Fall eine etwaige Eigendynamik der verletzten Nebenpflicht. Die originäre dogmatische Struktur einer Nebenpflicht lässt sich daher nur im Rahmen fahrlässiger Verletzungen freilegen.

1208 Für die Verletzung der körperlichen Integrität steht exemplarisch § 223 I StGB, für die Verletzung der sachlichen Integrität $\S 303$ I StGB.

1209 Hier ist insbesondere an einen Betrug nach $\S 263$ StGB oder eine Untreue nach $\S 266$ StGB zu denken.

1210 Vgl. Bamberger-Roth/Spindler, 3. Aufl. 2012, § 826 Rn. 1; MüKo-BGB/Wagner, 7. Aufl. $2017, \S 826$ Rn. 6, die allerdings in $\S 826$ BGB keine „Diskriminierung von Vorsatztätern“ sehen wollen; a.A. insoweit Staudinger/Oechsler, Neubearbeitung 2014, § 826 Rn. 12ff.; näher hierzu Rödl, Gerechtigkeit, 2015, S. 140ff. 


\section{Notwendigkeit einer Abgrenzung zwischen Tun und Unterlassen?}

In der Diskussion zu Nebenpflichten wird auf die Unterscheidung von Tun und Unterlassen einigen Wert gelegt. ${ }^{1211}$ So wird es regelmäßig als schwerere Belastung für den Schuldner empfunden, wenn ihm durch die Nebenpflicht ein positives Tun abverlangt wird. ${ }^{1212}$ Die Belastung durch eine Unterlassungspflicht wird entsprechend weniger intensiv wahrgenommen. ${ }^{1213}$ Diese Unterscheidung kann nicht überzeugen: Unabhängig von der Qualität der abverlangten Handlung wird der Schuldner in jedem Fall mit einem Mehraufwand belastet. ${ }^{1214}$ Bei einer Pflicht zum aktiven Handeln ist dies offensichtlich: Der Schuldner muss hier die Kosten des konkreten Tuns schultern. ${ }^{1215}$ Auch bei einer Pflicht zum Unterlassen treffen den Schuldner indes positive Handlungsanforderungen ${ }^{1216}$ : Er muss die Abläufe innerhalb seiner Sphäre derart gestalten, dass die verbotene Handlung unterbleibt. ${ }^{1217}$ Dies erfordert regelmäßig die Aufwendung von Zeit und/oder Geld. In beiden Fällen werden dem Schuldner also im Regelfall „Investitionen

1211 Aus historischer Sicht lässt sich dies auch damit erklären, dass Staub, Vertragsverletzungen, 1904, S. 6 als „,der“ Begründer des Vorläufers der Nebenpflicht - der positiven Forderungsverletzung - für eine schuldverhältnisbedingte Schadensersatzhaftung wegen Integritätsverletzungen ein positives Tun verlangte. Dass gegen $\S 241$ II BGB auch durch Unterlassen verstoßen werden kann, ist mittlerweile unumstritten, vgl. nur Larenz, Schuldrecht AT, 14. Aufl. 1987, S. 367f. Dennoch mag es erklären, warum zwischen Tun und Unterlassen heute überhaupt noch differenziert wird.

1212 BGH, Urt. v. 29.4.2008 - XI ZR 221/07, Rn. 17, 19f.; NK-BGB/Krebs, 3. Aufl. 2016, § 241 Rn. 60 (,aktive Schutzpflicht bedarf der Begründung“); Staudinger/Olzen, Neubearbeitung 2015, § 241 Rn. 449 (,Informationsbeschaffungspflicht [...] wird [...] ohne ein dem Schuldverhältnis immanentes besonderes Fürsorge-oder Beratungselement abgelehnt"), 498 (,Pflicht zum aktiven Schutz der Gegenseite [...] sowie [...] sonstige Erhaltungspflichten [...] bedürfen stets besonderer Rechtfertigung").

1213 Grigoleit, FS Canaris, Bd. I, 2007, S. 275, 285 (für den Schuldner „nicht mit einem besonderen Aufwand verbunden“); NK-BGB/Krebs, 3. Aufl. 2016, § 241 Rn. 59 („Schädigungsvermeidungspflicht belastet den Verpflichteten weniger").

1214 So auch Tröger, Arbeitsteilung, 2012, S. 522; für eine grundsätzliche Differenzierung zwischen Nebenpflichten, die ein Tun zum Gegenstand haben und solchen, die ,nur" ein Unterlassen fordern, hingegen Krebs, Sonderverbindungen, 2000, S. 504ff.; Staudinger/Olzen, Neubearbeitung 2015, § $241 \mathrm{Rn} .489,498$.

1215 Das umfasst auch die Kosten einer etwaig notwendigen Vorbereitung für das „Tun“, wie zum Beispiel die Beschaffung einer mitzuteilenden Information.

1216 Treffend Träger, FG Enneccerus, 1913, S. 1, 7 („Unterlassen heißt nicht „nichts tun“, sondern „etwas nichttun“"“).

1217 Vgl. Träger, FG Enneccerus, 1913, S. 1, 8f. (Unterlassen als „Nichtvornahme einer [...] Handlung"). 
zur Vermeidung des pflichtwidrigen Verhaltens “ ${ }^{1218}$ abverlangt. ${ }^{1219}$ Zwar mögen Pflichten, die vom Schuldner ein Tun fordern, ihm häufig einen größeren Aufwand zuweisen als Unterlassungspflichten. Das muss aber nicht zwingend so sein. Zudem wäre es bloß eine graduelle Differenzierung. Der Unterschied zwischen Tätigkeits- und Unterlassungspflichten ist also - sofern es denn überhaupt einen gibt - nur quantitativer nicht qualitativer Natur. In der Lückenfüllung mittels § 241 II BGB sollen Handlungspflichten demnach einheitlich erfasst werden, ohne dass es es eine Rolle spielt, ob dem Schuldner nur ein Unterlassen abverlangt wird.

\section{Zur rechtspraktischen Funktion}

Wie oben dargelegt besteht der Zweck von § 241 II BGB darin, Haftungslücken im Deliktsrecht zu schließen. Der Zweck - also die Funktion - einer Nebenpflicht ist damit aus einer praktischen Perspektive der Ersatz eines anderweitig nicht ersatzfähigen Schadens, der nichtsdestotrotz ersatzwürdig ist. Nach welchen Maßstäben der Schaden ersatzwürdig sein muss, bleibt offen. Der notwendige Vergleich mit der Situation im Jedermannsrecht macht aber schon deutlich, dass es weniger um spezifisch schuldverhältnisbedingte Fragen geht als vielmehr um ein (darzulegendes) allgemeines Bedürfnis nach Haftung (Soll A für einen B gegenüber verursachten Schaden prinzipiell haften?). ${ }^{1220}$ Dabei wird jeder Haf-

1218 Die Phrase stammt von Tröger, Arbeitsteilung, 2012, S. 522.

1219 Ähnlich Köndgen/von Randow, Travemünder Symposium, 1989, S. 122, 124; Kötz, FS Steindorff, 1990, S. 643, 666. Für die ökonomische Analyse spielt die finanzielle Belastung des Schuldners durch eine Verhaltensanforderung dabei eine größere Rolle in der Subsumtion als für die rechtswissenschaftliche Abwägung, treffend M. Müller/Hempel, AcP 205 (2005), 246, 247 (Fn. 4). In Nuancen wird dies deutlich bei der instruktiven Abhandlung von E. Schmidt, JA 1978, 597, 599f., der ,den dem Schuldner [durch Nebenpflichten] abverlangten finanziellen Aufwand“" innerhalb der gesonderten Überschrift „Die ökonomische Situation“ würdigt, noch plakativer bei der Einschätzung zu Nebenpflichten von Dölle, ZgStW 103 (1943), 67, 102 (,eine Vermögensleistung fordern sie von dem Gebotsunterworfenen nicht" ${ }^{*}$ ). Taupitz, AcP 196 (1996), 114, 145 sieht es als große Chance der ökonomischen Analyse an, dass sie „,er Rechtsprechung verdeutlichen kann, welche ökonomischen Folgen ihre Entscheidungen haben können".

1220 HKK/Dorn, 2007, § 241 Rn. 77 (Nebenpflichten „systembedingter Weg, die als billig anerkannte Haftung bestimmter Personen für bestimmte Schäden" durchzusetzen); ähnlich auch Tröger, Arbeitsteilung, 2012, S. 52, der Nebenpflichten - anders als das sonstige Leistungsstörungsrecht - eher als ein ,überindividuell[es]“" Haftungssystem sieht. 
tungsvorteil gegenüber dem Jedermannsrecht, welcher mit der Haftung aus Nebenpflichtverletzung angestrebt wird, separat untersucht. ${ }^{1221}$ Dieser Aspekt des Normzwecks von $\S 241$ II BGB soll im Folgenden als die rechtspraktische Funktion einer Nebenpflicht bezeichnet werden.

Zunächst wird innerhalb der rechtspraktischen Funktion versucht, den telos des jeweiligen Haftungsvorteils mit bestehenden rechtswissenschaftlichen Ansätzen zu ermitteln. Anschließend wird der Zweck des jeweils angestrebten Haftungsvorteils aus der Perspektive der ökonomischen Analyse betrachtet. ${ }^{1222}$ Das Bedürfnis nach Haftung weniger aus einer schuldverhältnisbedingten Perspektive, sondern vielmehr aus einer ganzheitlich-rechtssystemischen Perspektive auszuleuchten ermuntert nämlich zur Berücksichtigung der ökonomischen Analyse des Rechts. ${ }^{1223}$ Nebenpflichten werden von der herrschenden Lehre unabhängig von der konkreten dogmatischen Verortung als gesetzliche Haftung mit heterono-

1221 Vgl. - mit Ausnahme der nunmehr angeglichenen Verjährung - die Übersicht bei Michael Lehmann, Bürgerliches Recht, 1983, S. 97. Die Intensität der Analyse verhält sich dabei linear zu der Quantität der im ersten Teil festgestellten Haftungsunterschiede: Dem Aspekt des Vermögensschutzes wird folglich am meisten Raum eingeräumt, anschließend folgt die Verantwortlichkeit für Dritte. Die Beweislastumkehr wird aufgrund der geringen, verbleibenden Unterschiede nur noch kursorisch behandelt.

1222 Tröger, Arbeitsteilung, 2012, S. 66 hält eine rein rechtswissenschaftliche Problemanalyse im Schuldverhältnisrecht mittlerweile für ausgeschlossen, weil die ökonomische Analyse bereits die „Denkstrukturen“ verändert habe. Das mag mit Blick auf viele Ergebnisse der Rechtspraxis stimmen. Solange indes der Ansatz der ökonomischen Analyse nicht in der Subsumtion explizit gewürdigt wird, bleibt für die Schnittstellenwissenschaft die wichtige Aufgabe, für methodische Transparenz zu sorgen.

1223 Diese liefert abstrakte Kriterien, mit denen Haftungsrisiken zugewiesen werden können. Haftung, die aus einer abstrakten Perspektive für notwendig erklärt wird, muss aber stets im Ansatz fremdbestimmt sein, weil sie nicht vom Willen des Einzelnen abhängen darf, Picker, FS Medicus, 1999, S. 397, 411. Dieser könnte schließlich das als sinnvoll ausgemachte Haftungsniveau eigenmächtig herabsenken. Dieser Gedanke steht zunächst einmal im klaren Widerspruch zum Primat des Parteiwillens innerhalb rechtsgeschäftlicher Schuldverhältnisse. So ist die Akzeptanz der ökonomischen Analyse im Deliktsrecht auch größer als im Vertragsrecht. Die Risikozuweisung nach Effizienzgedanken meidet im Jedermannsrecht zumindest den Konflikt mit der Privatautonomie. Es bleibt weiterhin ein potentieller Konflikt mit Gedanken der Gerechtigkeit sowie mit dem teilweise vertretenen Grundsatz, dass Zivilrecht - anders als das öffentliche Recht oder das Strafrecht - frei von Verhaltenssteuerung zu sein habe, vgl. präzise hierzu Wagner, AcP 206 (2006), 352, 360 (,heiße Kartoffel des Rechtssystems“), 431 (,mitunter behauptet, die Verfolgung präventiver Ziele mit Hilfe zivilrechtlicher Schadensersatzdrohungen sei verfassungswidrig), 454 (zivilrechtliche Haftung in jedem Fall unmissverständliches "Signal an sämtliche Akteure, die künftig in dieselbe Situation geraten“ wie der Schädiger). 
mem Haftungsgrund eingeordnet. ${ }^{1224}$ Damit nehmen sie (auch) in einem rechtsgeschäftlichen Schuldverhältnis eine Sonderstellung ein. In welcher Weise die Heteronomie der Nebenpflichten materiell-rechtlich auszufüllen ist, hat der Gesetzgeber der Wissenschaft überlassen. ${ }^{1225}$ Damit steht auch der Anwendung der ökonomischen Analyse kein prinzipielles Hindernis entgegen. ${ }^{1226}$

\section{Zur schuldverhältnisspezifischen Funktion}

Schon der Wortlaut des $\S 241$ II BGB gibt vor, dass sich die Nebenpflicht (auch) aus dem jeweiligen Schuldverhältnis speisen muss (,Schuldverhältnis [...] nach seinem Inhalt $\left.{ }^{\circ}\right)$. Zweck einer Nebenpflicht ist damit auch immer die dienende Unterstützung eines konkreten Schuldverhältnisses. Im Vergleich zur obigen rechtspraktischen liegt hier der Fokus auf der Frage, ob das konkrete Schuldverhältnis den Ersatz des jeweiligen Schadens aus einer situativen Perspektive rechtfertigen kann (Lässt sich eine Haftung von A gegenüber B darauf stützen, dass beide durch ein Schuldverhältnis verbunden sind?). Dieser Aspekt des Normzwecks von $\S 241$ II BGB soll im Folgenden als die schuldverhältnisspezifische Funktion einer Nebenpflicht bezeichnet werden. ${ }^{1227}$

\section{Funktionale Zweiteilung}

Um im Einzelfall eine Nebenpflicht überzeugend auf dem Normzweck des $§ 241$ II BGB stützen zu können, müssen beide (Teil-)Funktionen einschlägig sein. Die

1224S.o., S. 169 (Fn. 688).

1225 Vgl. BT-Drs. 14/6040, SchRModG, Gesetzesbegründung, S. 125f.

1226 Nebenpflichten sind schließlich aus einer pragmatischen Perspektive lediglich Instrumente zum ausschnittweisen Ersatz von Vermögensschäden unter Berücksichtigung gesellschaftlicher Entwicklungen, Schäfer/Ott, Ökonomische Analyse, 5. Aufl. 2012, S. 325. Als kontemporäre Spielart des „Vertragsfunktionalismus" bietet sich die ökonomische Analyse für einen funktionalen Ansatz im Schuldverhältnisrecht deshalb in besonderer Weise an, Oechsler, Vertragsgerechtigkeit, 1997, S. 133; s. bereits Fezer, JZ 1986, 817, 822f.

1227 Diese soll primär der Begrenzung dienen. Anders als die rechtspraktische Funktion kann sie eine Nebenpflicht nicht mit vorhersehbaren Maßstäben begründen, sie soll aber das Feld, auf dem die Nebenpflicht gesucht wird, klar abstecken. Die für die Subsumtion entscheidende Frage ist damit, wann sich eine Haftung von A gegenüber B eben gerade nicht mehr auf das Schuldverhältnis stützen lässt und eine schuldverhältnisbedingte Nebenpflicht deshalb ausscheidet. 
Aufspaltung des Normzwecks in zwei separate Prüfungspunkte ist nicht zwingend, soll aber die Subsumtion zur Existenz einer Nebenpflicht entzerren und damit differenzierter werden lassen. Zudem soll sie deutlich machen, dass die Natur einer Nebenpflicht nach heutigem Stand der Dogmatik ohnehin zweigespalten ist ${ }^{1228}$ : Zum einen lässt sich ein gewisser Rückbezug auf das konkrete Schuldverhältnis in der Begründung schon wegen des Wortlauts des § 241 II BGB sowie der Einbettung in einen konkret schuldverhältnisbedingten Sachverhalt nicht vermeiden. Zum anderen steht aber häufig der Gedanke, prinzipiell aus verschiedensten, nicht immer rechtlichen Gründen - eine Verhaltenssteuerung durch eine Nebenpflicht zu ermöglichen, bei der Subsumtion im Vordergrund. $^{1229}$

1228 Die Zweiteilung innerhalb des Verständnisses von Nebenpflichten findet sich in einigen, wenigen Varianten nämlich auch bereits in der Literatur: So stellt etwa Lüsing fest, dass schuldverhältnisbedingten Nebenpflichten ein „hybrider Charakter" innewohnt: Zum einen verfolgen sie ein Schutzinteresse gegenüber dem jeweils betroffenen Rechtsgut, zum anderen ist Teil ihrer Regelungsaufgabe auch die Förderung des Güteraustausches, Lüsing, Schutzpflichten, 2010, S. 165f. Ähnlich sieht dies Fleischer, der zum einen den konkreten Güterschutz sowie zum anderen den Schutz des Schuldverhältnisses auf lange Sicht aus einer makrojuristischen Perspektive als Aufgabe der Nebenpflichten sieht, Fleischer, Informationsasymmetrie, 2001, S. 427; Fleischer, Schuldrechtsreform, 2001, S. 243, 256f. Haftungsgrund der Nebenpflichten sei die Funktionsfähigkeit des Geschäftsverkehrs durch Schutz von ,Systemvertrauen" (Begriff von Luhmann, Vertrauen, 2. Aufl. 1973, S. 50ff.), Fleischer, Informationsasymmetrie, 2001, S. 423f. Durch eine Standardisierung der Verkehrserwartungen lasse sich das Kriterium der Effizienz berücksichtigen, Fleischer, Informationsasymmetrie, 2001, S. 423. Das ,generalisierte Vertrauen" wiederum ist schutzwürdig, um makrojuristisch das jeweils betroffene Schutzinteresse langfristig zu sichern. Das „,klassische Vertragsmodell“ das die sachgerechte Abwicklung des einzelnen Schuldverhältnisses gewährleisten soll - wird damit von Fleischer um den Institutionsschutz des Rechtsgeschäfts ,an sich“ ergänzt, vgl. bereits die Begründung von Nebenpflichten aus einem „Korrelat privatautonomer Gestaltungsfreiheit" heraus bei Frotz, GS Gschnitzer, 1969, S. 163, 172f. (,Privatrecht [hat] notwendig eine überindividuelle Sozialfunktion zu erfüllen"). Im Ergebnis weisen Nebenpflichten damit auch nach seinem Ansatz ein hybrides Schutzgut auf: Auf der einen Seite steht der Schutz des individuell betroffenen Schutzinteresses - in concreto war dies für Fleischer die (rechtsgeschäftliche) Entscheidungsfreiheit - und auf der anderen Seite steht der Institutionsschutz eines reibungslosen Rechtsverkehrs, Fleischer, Informationsasymmetrie, 2001, S. 427; Fleischer, Schuldrechtsreform, 2001, S. 243, 256f. Der jeweils als zweites genannte Aspekt lässt sich als „überindivividuelles“ Schutzgut erfassen, vgl. zur „ökonomisch-sozialen Funktion des Vertrages" bereits Raiser, FS DJT, Bd. I, 1960, S. 101, 119f. Dabei soll der systemische Schutz auch die Position des konkreten Rechtsguts auf lange Sicht verbessern und damit einen Rückbezug der beiden Funktionen aufeinander ermöglichen, vgl. Fleischer, Informationsasymmetrie, 2001, S. 423f.; Fleischer, Schuldrechtsreform, 2001, S. 243, $256 \mathrm{f}$.

1229 Vgl. zur culpa in contrahendo Fleischer, Schuldrechtsreform, 2001, S. 243, 251 (,verhaltenssteuernde Funktion im Vordergrund“) sowie allgemein Köndgen/von Randow, Travemünder 


\section{Zur Prüfungsreihenfolge}

Als prinzipielle, von Schuldverhältnis-spezifischen Einzelheiten befreite Frage bietet es sich aus einer theoretischen Perspektive - und somit auch in dieser Arbeit - an, mit der Prüfung nach der Haftungsnotwendigkeit dem Grunde nach zu beginnen. Allerdings ist es aus praktischer Perspektive wenig zielführend, zunächst die Ersatzwürdigkeit eines Schadens nach allgemeinen Grundsätzen festzustellen, um sodann festzustellen, dass es einer entsprechenden Nebenpflicht an jeglichem Bezug zum konkreten Schuldverhältnis fehlt. Da § 241 II BGB ein Schuldverhältnis voraussetzt und in seinen Voraussetzungen an ein solches anknüpft, wäre folglich in der Rechtspraxis die spezifisch schuldverhältnisbedingte Voraussetzung - obgleich spezieller - als erste zu prüfen.

\section{Zwischenergebnis: Doppelfunktionales Verständnis von § 241 II BGB}

Ist die auf Verletzung einer Nebenpflicht gestützte Haftung nicht wegen der teleologischen Subsidiarität von $\S 241$ II BGB verdrängt, so wird zur Subsumtion ein doppelfunktionales Verständnis schuldverhältnisbedingter Nebenpflichten vorgeschlagen. Eine Nebenpflicht lässt sich demnach nur dann aus $\S 241$ II BGB ableiten, wenn sie (1) als Ausgleich für unerwünschte Haftungslücken im Jedermannsrecht eine rechtspraktische Funktion erfüllt und (2) als sachdienliche Stütze des konkreten Schuldverhältnisses dem konkreten Schuldverhältnis gegenüber eine schuldverhältnisspezifische Funktion erfüllt.

Symposium, 1989, S. 122, 123 („Haftungsregeln verhaltenssteuernd“); Wagner, AcP 206 (2006), 352, 454 („Wahl des maßgeblichen Sorgfaltsstandards“ als „Signal an sämtliche Akteure, die künftig in dieselbe Situation geraten"); plakativ Matthias Lehmann, ZEuP 2009, 693, 694 (Nebenpflichten als Baustein für ",social engineering“). Indem diesem prinzipiellen Bedürfnis nach Verhaltenssteuerung durch Anerkennung einer Nebenpflicht Rechnung getragen wird, lässt sich häufig sogar eine gewisse Entkopplung von den Spezifika der Schuldverhältnis-spezifischen Situation feststellen. 


\section{B. Ausfüllung der rechtspraktischen Funktion von Nebenpflichten}

Aus rechtspraktischer Perspektive soll eine Nebenpflicht aus § 241 II BGB Haftungslücken des Deliktsrechts schließen. ${ }^{1230}$ Lässt sich der Schadensposten nicht über das Jedermannsrecht liquidieren, so beginnt der originäre Anwendungsbereich der Nebenpflichten. Als zweiter Schritt ist deshalb zu fragen, welcher der drei primären Vorteile des Schuldverhältnisrechts gegenüber dem Jedermannsrecht - Schutz vermögenswerter Interessen, Haftung für das Verhalten Dritter oder die Beweislastumkehr - im konkreten Fall für einen Anspruch des Anspruchsstellers notwendig ist. Fällt die Wahl auf einen - oder mehrere - der drei elementaren Haftungsvorteile des Schuldverhältnisrechts, so gilt es zu ermitteln, ob die Anwendung des jeweiligen Vorteils im konkreten Einzelfall angemessen scheint. Dafür bedarf es für jeden Vorteil haftungsausfüllender Kriterien, welche die Teleologie des jeweiligen Bereichs in abstrakter Hinsicht offenlegen. Nur so kann aus ex-ante-Perspektive vorhersehbare Haftungsreichweite garantiert werden. Der Schutzzweck des angestrebten Haftungsvorteils gegenüber dem Jedermannsrecht begründet und begrenzt damit die rechtspraktische Funktion einer Nebenpflicht.

\section{Ausgleich haftungsrechtlicher Lücken im Bereich des Vermögensschutzes}

Der wichtigste Anwendungsbereich von Nebenpflichten ist der Schutz vermögenswerter Interessen.

1230 Für die Frage ob innerhalb eines bestehenden Schuldverhältnisses eine Nebenpflicht in Betracht kommt, ist nach hier vertretener Ansicht bei teleologischer Auslegung des § 241 II BGB in einem ersten Schritt zu fragen, ob sich der gewünschte Schadensposten nicht prozessual und materiell-rechtlich in gleichwertigem Maße über das Jedermannsrecht liquidieren lässt. Ist dies der Fall, so entfällt die rechtspolitische Begründung für Nebenpflichten. Weil die Nebenpflichten nach allgemeiner Ansicht nur mit großer Mühe in die Dogmatik des allgemeinen Schuldrechts einzufügen sind, besteht dann keine Notwendigkeit mehr, über das Schuldverhältnisrecht eine dritte Spur zwischen Vertrags- und Deliktsrecht aufrechtzuerhalten, s.o., S. $275 \mathrm{ff}$. 


\section{Frage nach der Reichweite von Vermögensschutz}

a) Eignung als Haftungsgrund?

Der Gesetzgeber hat sich bei Erlass des BGB gegen eine große Generalklausel für den Ersatz aller vermögenswerter Interessen entschieden. ${ }^{1231}$ Dies tat er vor allem, um einer übermäßigen Einschränkung der allgemeinen Handlungsfreiheit des Einzelnen vorzubeugen. ${ }^{1232}$ Dieser würde durch die unbegrenzte Anzahl möglicher Gläubiger bei einem Unfall schließlich im Alltag in seiner grundgesetzlich verbürgten Handlungsfreiheit (Art. 2 I GG) unangemessen eingeschränkt. Zudem wäre damit jeder ein potentieller Schuldner einer vermögensschützenden Sorgfaltspflicht gegenüber seinen Mitbürgern, ohne jedwede Kenntnis von den konkreten Vermögensinteressen zu haben. ${ }^{1233}$ Im Umkehrschluss hierzu ließe sich als Ausfluss des neminem laedere-Gebots formulieren, dass vermögenswerte Interessen immer dann zu schützen seien, wenn im Verhältnis zum Anspruchsgegner die Anzahl der möglichen Anspruchssteller fest-

1231 Canaris, FS Larenz, 1983, S. 27, 35. Der BGB-Gesetzgeber hatte hierbei vor französischen Auswüchsen Angst, die entstehen könnten, wenn der Rechtsprechung mit einer solchen Generalklausel „,carte blanche“ erteilt würde, vgl. Mugdan, Materialien, Bd. II, 1899, S. 1075; von Caemmerer, FS DJT, Bd. II, 1960, S. 49, 65. In Frankreich gibt es eine „große“ Generalklausel im Jedermannsrecht, welche den Ersatz jedweder vermögenswerter Interessen ermöglichen kann: Nach Art. 1382 Code civil ist jeder für den Schaden haftbar, den er einem anderen durch schuldhaftes Verhalten zufügt, vgl. hierzu Fleischer, Informationsasymmetrie, 2001, S. 733ff.; Nirk, RabelsZ 18 (1953), 310, 342f. Nach Art. 1383 Code civil wird nicht nur für positives Tun gehaftet, sondern auch für schuldhaftes Unterlassen und Fahrlässigkeit, Faenger, Nebenpflichten, 2012, S. 74f.; näher zur historischen Entwicklung Schlechtriem, Gutachten, Band II, 1981, S. 1591, 1611f. sowie zur Beweislastverteilung Sonnenberger, FS Medicus, 1999, S. 621, 630ff. Zusammengenommen erlauben die beiden Normen einen im Ansatz und der Auswahl schützenswerter Interessen unbeschränkten Schutz durch das Jedermannsrecht, näher - auch zu den faktisch durchaus vorhandenen Grenzen - von Bar, Gutachten, Band II, 1981, S. 1681, 1724 1727f., 1733f.; von Caemmerer, FS DJT, Bd. II, 1960, S. 49, 50f.; Wagner, Grundstrukturen, 2003, S. 189, 225ff.; Wagner, Schuldrecht, 2003, S. 203, 205.

1232 Die „Rechtskreise der Einzelnen, innerhalb deren sie ihre individuelle Freiheit entfalten und ihre Interessen verfolgen dürfen" sollten maßvoll voneinander abgegrenzt werden, Mugdan, Materialien, Bd. II, 1899, S. 1073; vgl. auch Canaris, FS Larenz, 1983, S. 27, 36f.; Hassemer, Heteronomie, 2007, S. 264; Honsell, FS Medicus, 1999, S. 211, 213f.; Lobinger, Verpflichtung, 1999, S. 36 (Gefahr ,eine[s] [die] [...] allgemeine Handlungsfreiheit nahezu erstickenden Haftungsrisiko[s]“); HKK/Schiemann, 2013, §§ 823-830, 840, 842-853 Rn. 14 („floodgates argument").

1233 Treffend Lobinger, Verpflichtung, 1999, S. 36 („Folgen einer Handlung von vornherein jeder Kalkulierbarkeit entzogen"). 
steht oder zumindest ex ante bestimmbar ist. ${ }^{1234}$ Zudem sollte der potentielle Anspruchsgegner seine Schuldnerposition erkennen können. Ist die Haftungsgefahr für den Schuldner zumindest erkennbar, so ist das Kernargument gegen den umfassenden Vermögensschutz im Jedermannsrecht entkräftet. ${ }^{1235}$ Innerhalb

1234 So Picker, AcP 183 (1983), 369, 491f.; Picker, JZ 1987, 1041, 1053; Picker, FS Medicus, 1999, S. 397, 437; zust. Lobinger, Verpflichtung, 1999, S. 36ff.; vgl. auch Canaris, FS Larenz, 1983, S. 27, 37f.; Wendelstein, AcP 215 (2015), 70, 101f. Im Ansatz nicht unähnlich versucht Schur, Leistung, 2001, S. 216ff., Nebenpflichten aus der „Personalität“ des Schuldverhältnisses heraus zu begründen. Er stellt damit ebenfalls die mengenmäßige Fixierung von Schuldner und Gläubiger im Vorhinein der Schädigung in den Mittelpunkt.

1235 So auch Hassemer, Heteronomie, 2007, S. 264. Dieser Ansatz mag in theoretischer Abstraktheit attraktiv wirken, aber welche Anspruchsgrundlage den Vermögensschutz gewährleisten soll, geht aus ihm nicht hervor, ähnlich Hassemer, Heteronomie, 2007, S. 264f. Deshalb muss er sich am geltenden Recht messen lassen: Das Deliktsrecht soll nach allgemeiner Ansicht mit der Integrität den status quo schützen. Bei absoluten Rechtsgütern ist der Schutzzweck klar: Jedes rechtswidrige und schuldhafte Verhalten, das eine Beeinträchtigung des Rechtsguts herbeiführt, verpflichtet zur Naturalrestitution nach § 249 I BGB. Ist aber wie im Fall des Vermögens das Schutzgut amorph, so darf eben nicht jede Beeinträchtigung zum Schadensersatz führen. Vielmehr muss das zu sanktionierende Verhalten bereits vor der Schädigung genau umrissen und begrenzt sein. Im Jedermannsrecht liegt die Konturierung regelmäßig darin, dass aktiv auf einen fremden Gegenstand eingewirkt wird und dem Gegenstand nicht nur Nutzungsvorteile entzogen werden, zutreffend Picker, NJW 2015, 2304, 2305f. Anderenfalls könnte auch der Abschluss eines nur für die eine Seite wirtschaftlich vorteilhaften Geschäfts zum Schadensersatz berechtigen. Abschreckung würde dann die Durchführung vermögensrelevanter Interaktionen zwischen Menschen insgesamt behindern. Hebt man die Nicht-Ersatzfähigkeit reiner Vermögensschäden im Deliktsrecht auf, so bleibt zunächst völlig unklar, welches Verhalten sanktioniert werden soll und welches nicht. Außerhalb eines Schuldverhältnisses ließe sich der hier dargestellte Ansatz daher für die Begründung vermögensschützender Verkehrssicherungspflichten im Sinne von $\S 823$ I BGB gebrauchen. Schließlich kommen nur die ex ante bestimmbaren Adressaten der Verkehrssicherungspflicht als Schuldner eines Anspruchs in Betracht. Auch das jeweils betroffene vermögenswerte Interesse wäre beim Aufstellen der Verkehrspflicht näher zu konkretisieren. Zumindest die Schuldnerposition sowie das Schutzgut der Verkehrspflicht sind damit ex ante bestimmbar, was die die oben beschriebene Gefahr der unüberschaubaren Haftungsausweitung zumindest erheblich verringert. Auch Medicus, FS Kern, 1968, S. 313, 328f. war der Auffassung, dass das Deliktsrecht mit dem Instrument der Verkehrssicherungspflichten in der Lage wäre, sinnvoll begrenzten Vermögensschutz zu leisten; vgl. zudem Lüsing, Schutzpflichten, 2010, S. 94 (Fn. 39). De lege lata hat sich der Gesetzgeber aber gegen den Erlass einer vermögensschützenden Generalklausel im Jedermannsrecht entschieden. So wollte schon der BGB-Gesetzgeber den Gerichten ,einen gewissen objektiven Maßstab an die Hand [...] geben“, weil ,es der im deutschen Volke herrschenden Auffassung von der Stellung des Richteramtes" nicht entspreche, den Gerichten mit einer großen Generalklausel eine ,autoritative[...] Stellung“ hinsichtlich der grundsätzlichen Reichweite des Jedermannsrechts einzuräumen, Mugdan, Materialien, Bd. II, 1899, S. 1075. Diese Entscheidung würde man aushöhlen, würde man der Rechtsprechung erlauben, vermögensschützende Verkehrssicherungspflichten zu kreieren, entschieden Canaris, FS Larenz, 1983, S. 27, 83; vgl. auch Picker, AcP 183 (1983), 369, 445 (,nicht allein aus Traditionsbefangenheit kurios"); Hans Stoll, RabelsZ 58 (1994), 96, 98 („,expansive Sprengkraft hypostasierender Gene- 
eines Schuldverhältnisses ist die Anzahl möglicher Gläubiger auf den oder die Schuldverhältnis-Partner sowie auf solche Dritte beschränkt, an deren Einbeziehung dem Gläubiger für den Schuldner erkennbar gelegen ist. Damit ist die Anzahl möglicher Gläubiger aus der Sicht des Schuldners ex ante bestimmbar. ${ }^{1236}$

Im Umkehrschluss zu den Bedenken des BGB-Gesetzgebers lässt sich die Annahme einer Nebenpflicht nach § 241 II BGB zum Schutz vermögenswerter Interessen deshalb darauf stützen, dass der Gläubiger eines etwaigen Schadensersatzanspruches durch das Schuldverhältnis bereits im Vorfeld der Schädigung bestimmt ist. ${ }^{1237}$

ralklauseln"); dafür aber von Bar, Verkehrspflichten, 1980, S. 220ff.; K. Huber, FS von Caemmerer, 1978, S. 359, 378ff.; Mertens, AcP 178 (1978), 227, 251ff.; Replik wiederum von Steffen, VersR 1980, 409, 409ff. Selbst wenn man mit der obigen Argumentation davon ausginge, dass die Furcht des Gesetzgebers vor Übermaßhaftung in bestimmten Konstellationen grundlos gewesen sei, so muss dem Gesetzgeber die Einschätzungsprärogative zugebilligt werden, in welchen konkreten Fällen Vermögensschutz gewährt werden soll. Diese Entscheidung würde aber hier den Richtern als Teil der Judikative zukommen. Sie wären schließlich diejenigen, die über die Existenz einer im Streitfall relevanten vermögensschützenden Verkehrssicherungspflicht zu urteilen hätten. Da die Richter mangels vorgegebener Maßstäbe bei der Prüfung einer vermögensschützenden Verkehrspflicht nicht zwingend zum gleichen Ergebnis kommen müssen, kann es zu einem verwirrenden Haftungsausmaß kommen, Picker, JZ 1987, 1041, 1047 („Gerichte [...] institutionell überfordert"); Schäfer/Ott, Ökonomische Analyse, 5. Aufl. 2012, S. 318 (Fn. 3) m.w.N.; Steffen, VersR 1980, 409, 409; Teichmann, JA 1984, 709, 712. Obwohl er dem Ansatz Pickers aus einer theoretischen Perspektive nicht abgeneigt ist, lehnt auch Hassemer, Heteronomie, 2007, S. 266 es aus diesem Grund ab, hieraus eine konkrete Haftung abzuleiten. In jedem Fall würde aber durch vermögensschützende Verkehrssicherungspflichten die gesetzgeberische Einschätzungsprärogative beschnitten, Canaris, FS Larenz, 1983, S. 27, 83; Picker, AcP 183 (1983), 369, 498ff.; Soergel/Spickhoff, 13. Aufl. 2005, Vor $\S 823$ Rn. 15f. Deshalb kann der Ansatz nur innerhalb eines Schuldverhältnisses überzeugen. Dort sind Schuldner und Gläubiger bereits im Vorhinein fixiert.

1236 So auch Katzenstein, Jura 2004, 584, 595 (Fn. 157); Picker, AcP 183 (1983), 369, 478f. Ob der Vertrag mit Schutzwirkung zugunsten Dritter in der Handhabung durch die Gerichte für den Schuldner erkennbare Ergebnisse produziert, wird z.T. durchaus bezweifelt, näher MüKoBGB/Gottwald, 7. Aufl. 2016, § 328 Rn. 165.

1237 Ähnlich Picker, FS Medicus, 1999, S. 397, 437. 


\section{b) Eignung als Haftungsgrenze?}

Wie weit ein aus dem neminem-laedere-Gebot ${ }^{1238}$ abgeleiteter Vermögensschutz reichen soll, geht aus dem Gedanken selbst nicht hervor. ${ }^{1239}$ Durch die ex-anteBegrenzung potentieller Gläubiger innerhalb eines Schuldverhältnisses sollen der Vermögensschutz des Gläubigers und der Schutz der Handlungsfreiheit des Schuldners in einen maßvollen Ausgleich gebracht werden. Korrespondierend müsste umfassender Vermögensschutz gewährleistet werden. Auch im Schuldverhältnisrecht werden vermögenswerte Interessen der Beteiligten indes nicht vorbehaltlos geschützt. Eine der hier erörterten Fragen ist ja gerade, inwieweit das Vermögen des Gläubigers zu schützen ist. Die ex ante Beschränkung möglicher Gläubiger hebt zwar die grundsätzlich bestehende Barriere ${ }^{1240}$ auf, welche der BGB-Gesetzgeber gegen die Haftungsflut für Vermögensschäden errichtet hat. ${ }^{1241}$ Welche Beeinträchtigungen des Vermögens dann aber im Einzelnen zu ersetzen sind - an welcher Stelle der Flut also wieder Einhalt zu gebieten ist -, ist unter Rückgriff auf ein einschränkendes Kriterium separat zu begründen. Dieses caveat wird in der Diskussion regelmäßig ausgelassen. ${ }^{1242}$ Unmittelbar lassen sich mit dem Gedanken, dass innerhalb eines Schuldverhältnisses die

1238 Picker, AcP 183 (1983), 369, 466 („Rückgriff auf das Prinzip des „,neminem laeder“ als Idealpostulat jeder rechtlichen Ordnung").

1239 Vgl. Picker, AcP 183 (1983), 369, 509 (Ansatz „,beschränkt sich also auf die Methode der Haftungsbegrenzung"). Aus einer dogmatischer Perspektive soll der Ansatz wohl auch eher den Haftungsgrund für Nebenpflichten bilden, ohne konkrete Grenzen aufzustellen, vgl. Katzenstein, Jura 2004, 584, 586. Zudem scheint der Ansatz auch eher ein Gebot im Jedermannsrecht - und damit im Kern eine deliktsrechtliche Anspruchsgrundlage - aufstellen zu wollen, vgl. Picker, NJW 2015, 2304, 2305f.; eindeutiger Bezug zur Haftung nach § 280 I BGB hingegen bei Katzenstein, Jura 2004, 584, 586. Damit entfernt sich der Ansatz aber von der hier thematisierten Auslegung des $§ 241$ II BGB. Rückt man mit Schur das Kriterium der „Personalität" des Schuldverhältnisses in den Vordergrund, so ist zumindest gewährleistet, dass die Haftung nicht aus dem Jedermannsrecht folgen soll. Gleichzeitig lässt sich hiermit keine Grenze für schützenswerte Vermögensinteressen ziehen. Wo genau die „Personalität“ endet, gibt der Ansatz nicht vor. Zudem sind durchaus Fälle aus dem Jedermannsrecht vorstellbar, in denen die ,persönliche“ Komponente zwischen Schädiger und Geschädigtem ausgeprägter ist, ohne dass eine Haftung aus $\S \S 280$ I, 241 II BGB in Betracht käme, in diese Richtung Paßmann, Schutzpflichtverletzungen, 2010, S. 159.

1240 Vgl. Schlechtriem, FS Medicus, 1999, S. 529, 538 („Schleusentore“).

1241 So auch Katzenstein, Jura 2004, 584, 595 (Fn. 157); Wendelstein, AcP 215 (2015), 70, $101 \mathrm{f}$.

1242 Arg e contrario Picker, FS Medicus, 1999, S. 397, 445, der als Subsumtionskriterium vorschlägt, „ob aufgrund individualisierbarer Beziehungen der Parteien der Kreis der möglichen Gläubiger schon vorweg abstrakt-generell begrenzt werden kann"; deshalb skeptisch auch Medicus, Schuldverhältnis, 1987, S. 24. 
Gläubigeranzahl ex ante abgegrenzt ist, Nebenpflichten demnach nicht rechtssicher im Hinblick auf die Reichweite von Vermögensschutz begrenzen.

Aus der ursprünglichen Befürchtung des BGB-Gesetzgebers lässt sich aber zumindest ableiten, dass die Haftungsgefahr für den Schuldner im weitesten Sinne überschaubar sein soll. ${ }^{1243}$ Die Anzahl der Gläubiger ist im Schuldverhältnis bereits beschränkt. Wie gezeigt erlaubt diese Voraussetzung den Vermögensschutz nur dem Grunde nach. Welche Bestandteile des Vermögens aber in concreto schützenswert sind, muss aus dem Ansatz ableitbar sein. Für eine sinnvolle Begrenzung kann man aber erneut auf den BGB-Gesetzgeber zurückgreifen: Diesem war es wichtig, dass der einzelne sein Haftungsrisiko nicht als potentiell existenzvernichtendes Damoklesschwert unerkannt mit sich tragen muss. ${ }^{1244}$ Soll ein vermögenswertes Interesse geschützt werden, so muss es folglich dem Schuldner gegenüber erkennbar sein. Der Schutz vermögenswerter Interessen innerhalb eines Schuldverhältnisses wird damit - in tatbestandlicher Hinsicht, nicht aber auf Rechtsfolgenseite ${ }^{1245}$ - sinnvollerweise durch das Kriterium der Erkennbarkeit begrenzt. ${ }^{1246}$

1243 Vgl. auch Reischl, FS Musielak, 2004, S. 411, 420f.; Schur, Leistung, 2001, S. $263 f$.

1244 Vgl. Mugdan, Materialien, Bd. I, 1899, S. 1073, 1075; Reischl, FS Musielak, 2004, S. 411, 420.

1245 Dort gilt schließlich, ebenso wie im Jedermannsrecht, der Grundsatz der Totalreparation aller aus der Pflichtverletzung herrührenden Schäden, vgl. Soergel/Ekkenga/Kuntz, 13. Aufl. 2014, Vor $\$ 249$ Rn. 14.

1246 Ähnlich, wenn auch mitunter in anderem Kontext Reischl, FS Musielak, 2004, S. 411, 420f. (Kriterium für die ,Allzweckwaffe“ eines Schuldverhältnisses nach § 311 II Nr. 3 BGB); Schlechtriem, FS Medicus, 1999, S. 529, 539; Trimarchi, ZHR 136 (1972), 118, 127 (,Schuldner [nur bei Erkennbarkeit der Haftung] in die Lage versetzt [...], den von ihm geschuldeten Aufwand zu kalkulieren, um sich diesem im Bewußtsein seiner Verpflichtung unterziehen und eine entsprechende Gegenleistung fordern zu können"); vgl. auch Paßmann, Schutzpflichtverletzungen, 2010, S. 173, der aber in verkehrter Reihenfolge argumentiert: Weil die Gläubigerzahl im Schuldverhältnis ex ante begrenzt und die jeweiligen Vermögensinteressen erkennbar seien, könne die ratio der Begrenzung des Vermögensschutzes aus dem Jedermannsrecht im Schuldverhältnis nicht einschlägig sein. Korrespondierend sei der Schutz des Vermögens des Gegenübers angemessen. Auch im Schuldverhältnis gibt es aber durchaus vermögenswerte Interessen des Gläubigers, die dem Schuldner nicht bekannt und auch nicht erkennbar waren. Der Schutz jedes vermögenswerten Interesses des Gläubigers käme eben jener freiheitserdrosselnden Haftung gleich, die der BGB-Gesetzgeber zu verhindern suchte. Einziger Unterschied wäre, dass zumindest die Person des Gläubigers bekannt ist. Deshalb ist die Erkennbarkeit des vermögenswerten Interesses nicht Grund sondern Voraussetzung einer Haftung aus $\S \S 280$ I, 241 II BGB, vgl. insoweit auch Picker, FS Medicus, 1999, S. 397, 445f. Weil Nebenpflichten die Durchführung des Schuldverhältnisses situativ absichern sollen, muss diese 


\section{c) Besonderheiten bei der Informationsverantwortlichkeit}

Zielen Nebenpflichten auf den Schutz des Vermögens, so geht es häufig um die Beeinträchtigung vermögenswerter Interessen durch fehlerhafte oder unzureichende Information durch die Gegenseite. Zentral für ein einheitliches Verständnis der Teleologie von Informationspflichten ist, dass man sie als fremdbestimmt einordnet: Sie lassen sich also auch in rechtsgeschäftlichen Schuldverhältnissen nicht auf den Parteiwillen zurückführen. ${ }^{1247}$ Schon der Gesetzgeber stand indes einer einheitlichen Begründungsgrundlage für vermögensschützende Aufklärungspflichten bei Erlass des BGB skeptisch gegenüber. ${ }^{1248}$ Die Rechtsprechung nimmt mittlerweile tatbestandlich eine Aufklärungspflicht für solche Umstände an, die für die andere Partei erkennbar von wesentlicher Bedeutung sind und auf deren Mitteilung sie nach Treu und Glauben vertrauen kann. ${ }^{1249}$ Subsumtionsleitender Zweck jeder Nebenpflicht, welche die Informationsverantwortlichkeit verlagert, ist bei einer Rundschau über Rechtspraxis und Wissen-

Erkennbarkeit nicht schon bei Begründung des Schuldverhältnisses vorliegen. Das vom Schuldner zu schützende Interesse muss aber vor dem Moment erkennbar sein, in welchem ihm über die Nebenpflicht eine Handlung abverlangt wird.

1247 So auch Tröger, Arbeitsteilung, 2012, S. 60f.

1248 Mugdan, Materialien, Bd. I, 1899, S. 467 („Frage, inwieweit eine Rechtspflicht besteht, dem anderen Theile Umstände mitzuteilen, von denen vorauszusetzen ist, daß sie auf seine Entschließung von Einfluss sein würden, entzieht sich der gesetzlichen Lösung“). Auch Medicus, Gutachten, Bd. I, 1981, S. 479, 539 hielt 1981 eine dogmatisch einheitliche Rückführung der Informationspflichten auf einen gemeinsamen Nenner für „fast ausgeschlossen“. Breidenbach, Informationspflichten, 1989, S. 62ff. versuchte 1989 dann drei Abwägungskriterien zu entwickeln, mit denen sich jede Informationspflicht begründen lassen sollte: Der Bedarf des Gläubigers an der Information, die (faktische) Möglichkeit des Schuldners zur Information, sowie der „Funktionskreis“ der Information sollten die Leitlinien in der Subsumtion darstellen. Auch Lorenz versuchte Gemeinsamkeiten der Aufklärungspflichten aufzudecken, vgl. Lorenz, Schutz, 1997, S. 436f. mit einem Entwurf zu § 305f BGB als konkrete Kodifikation der vorvertraglichen Aufklärungspflicht; noch weitergehend Roth, Information, 2006, S. 179ff. („These vom einheitlichen Recht auf Information als dogmatische Grundlage aller Informationsansprüche“).

1249 RG, Urt. v. 1.3.1928 - VI 258/27, RGZ 120, 249, 252; BGH, Urt. v. 20.2.1967 - III ZR 134/65, Rn. 14 a.E. (BGHZ 47, 207, 210f.); BGH, Urt. v. 27.11.1985 - VIII ZR 316/84, Rn. 54 (BGHZ 96, 302, 311); BGH, Urt. v. 14.3.2003 - V ZR 308/02, Rn. 12; BGH, Urt. v. 25.3.2009 - XII ZR 117/07, Rn. 12; BGH, Urt. v. 1.2.2013 - V ZR 72/11, Rn. 8; vgl. Faust/Grigoleit, Verbraucher-acquis, 2011, S. 193, 198 (,generalklauselartige Formel"); Klinck, Information, 2013, S. 103, 105 („Wertungsblankette“); Staudinger/Olzen, Neubearbeitung 2015, § 241 Rn. 447; Tröger, Arbeitsteilung, 2012, S. 475 (Fn. 205) m.w.N. 
schaft ein Informationsgefälle zwischen den Parteien auszugleichen. ${ }^{1250}$ Nebenpflichten lassen sich also für die Verlagerung der Informationsverantwortlichkeit spezifisch auf das Ziel stützen, Informationsgefälle zu beheben.

Ob sich Nebenpflichten mit dem inneren Zweck der Verlagerung von Informationsverantwortlichkeit sinnvoll begrenzen lassen, hängt davon $a b$, wie man den Begriff des Informationsgefälles selbst begrenzt. In der Rechtspraxis wird der Begriff insbesondere mit den Kriterien der Erkennbarkeit, der Entscheidungserheblichkeit, der Schutzwürdigkeit und der Zumutbarkeit konturiert. ${ }^{1251}$ Wegen der Vielzahl von hochnormativen Begriffen lassen sich Nebenpflichten so zwar im Einzelfall durchaus sinnvoll begrenzen. Eine ex ante erkennbare Haftungsreichweite können die Kriterien wegen ihrer Vagheit aber nicht garantieren. ${ }^{1252}$

\section{d) Zwischenergebnis: Vermögensschutz muss erkennbar sein}

Nebenpflichten zum Schutz vermögenswerter Interessen auf einen einzigen Zweck zurückzuführen - und damit dann zu begrenzen - gestaltet sich wie erwartet schwierig. Nebenpflichten zum Schutz vermögenswerter Interessen lassen sich aber zumindest insofern auf die Teleologie des Vermögensschutzes im BGB stützen, als in einem Schuldverhältnis keine grundsätzlichen Bedenken gegen umfassenden Vermögensschutz bestehen. Ab welchem Punkt vermögenswerte Interessen nicht mehr mittels einer Pflicht aus § 241 II BGB zu schützen sind, sollte mit Blick auf die Intentionen des BGB-Gesetzgebers vor allem das Kriterium der Erkennbarkeit des vermögenswerten Interesses entscheiden.

1250 Staudinger/Olzen, Neubearbeitung 2015, § 241 Rn. 447f.; Teichmann, JA 1984, 545, 547; Tröger, Arbeitsteilung, 2012, S. 476 (Fn. 209) m.w.N.

1251 Staudinger/Olzen, Neubearbeitung 2015, § 241 Rn. 450ff. m.w.N.; Teichmann, JA 1984, 545, 547; vgl. beispielsweise BAG, Urt. v. 14.1.2009 - 3 AZR 71/07, Rn. 29, das auf die „erkennbaren Informationsbedürfnisse [...] einerseits und die Beratungsmöglichkeiten [...] andererseits" als entscheidende Subsumtionskriterien abstellt.

1252 Provokant, aber treffend Honsell, FS Medicus, 2009, S. 181, 183 (Grenzen der Aufklärungspflichten nach dem Maßstab der Rechtsprechung als „Gretchenfrage“). 
2. Bestimmung der Reichweite von Vermögensschutz nach Ansätzen der ökonomischen Analyse

a) Kein Widerspruch zwischen richterlicher Aufgabe und ökonomischer Analyse

Im Ausgangspunkt muss eine richterliche Entscheidung ein interessengerechtes Ergebnis im Einzelfall herbeiführen. Diese Aufgabe stellt nicht zwingend einen Widerspruch zur Berücksichtigung von Gedanken der ökonomischen Analyse dar. ${ }^{1253}$ Das Zivilrecht hat nämlich nicht nur einen einzelnen Fall interessengerecht zu lösen, sondern muss den Sachverhalt auch als ein Muster für zukünftige, ähnlich gelagerte Konstellationen würdigen. ${ }^{1254}$ Auch in der Rechtswissenschaft wird dabei darauf hingewiesen, dass das Privatrecht Anreize für volkswirtschaftlich sinnvolles Handeln setzen sollte. ${ }^{1255}$ Der Grundansatz einer an der Rechtspraxis orientierten ökonomischen Analyse ist ganz ähnlich: So soll ein Richter bei seiner Entscheidung - vereinfacht gesagt - nicht nur die Parteiinteressen, sondern auch das kollektive Interesse der Gesellschaft im Blick haben. ${ }^{1256}$

1253 Vgl. Heusinger, Rechtsfortbildung, 1975, S. 5 (Rechtsanwendung durch den Richter ist ,finales Handeln, ausgerichtet auf ein vernünftiges Ergebnis, wie es der Gerechtigkeit entspricht“.). Die „Vernünftigkeit" eines Ergebnisses kann dabei auch von Determinanten beeinflusst werden, die über den einzelnen Sachverhalt hinausgehen, vgl. Heusinger, Rechtsfortbildung, 1975, S. 5 (,Richter [...] bei der Suche nach der Entscheidung in erster Linie von dem Streben geleitet, [...] etwas zu tun, wovon für Gegenwart und [!] Zukunft etwas Sinnvolles [...] zu erwarten ist" ${ }^{*}$; Kübler, FS Steindorff, 1990, S. 687, 693f. So sieht beispielsweise Coleman, Ariz. L. Rev. 37 (1995), 15, 29 den haftungszuweisenden Begriff des cheapest cost avoider im Einklang mit dem Gedanken kompensatorischer Gerechtigkeit, wenn sich die Gesellschaft als Kollektiv darauf einigen kann, die Kosten der Schadensvermeidung möglichst gering zu halten; krit. indes Rödl, Gerechtigkeit, 2015, S. 78ff., 97f.

1254 Vgl. bereits Coase, J. Law \& Econ. 3 (1960), 1, 27 („In a world in which there are costs of rearranging the rights establishes by the legal system, the courts $[\ldots]$ are, in effect, making a decision on the economic problem and determining how ressources are to be employed."). Schließlich hat jede Entscheidung über Sorgfaltsstandards aus einer rein faktischen Perspektive Signalwirkung, überzeugend Wagner, AcP 206 (2006), 352, 424, 454; verhalten Eidenmüller, AcP 197 (1997), 80, 86 (,typisch für das Rechtsanwendungsverständnis der ökonomischen Analyse").

1255 Hassemer, Heteronomie, 2007, S. 232; Kübler, FS Steindorff, 1990, S. 687, 693f. (Rechtspraxis ,kann sich der Verantwortung für die Folgen ihres Tuns oder Unterlassens nicht länger entziehen“); Tröger, Arbeitsteilung, 2012, S. 39, 55 (Fn. 116f.); ausf. zur „Verhaltenssteuerung als Privatrechtsprinzip" Wagner, AcP 206 (2006), 352, 422ff.

1256 Schäfer/Ott, Ökonomische Analyse, 5. Aufl. 2012, S. 4; vgl. aber gleichwohl das vernichtende Verdikt von Taupitz, AcP 196 (1996), 114, 120 (,keine einzige gerichtliche Entscheidung, in der das Ergebnis ausdrücklich auf die ökonomische Analyse gestützt worden wäre"). 


\section{aa) Grundgedanke der Rechtsökonomie}

Was steckt hinter der Idee, die ökonomische Analyse auf Nebenpflichten aus einem Schuldverhältnis anzuwenden? Funktion des Schuldrechts im Allgemeinen ist nach rechtswissenschaftlicher Auffassung die Ermöglichung und Erleichterung von Güterverschiebungen zwischen Rechtspersonen. ${ }^{1257}$ Nebenpflichten sollen hierbei der Funktion des Schuldrechts flankierend dienen, indem im Rahmen eines Schuldverhältnisses auch Rechtsgüter der Beteiligten geschützt werden, die zwar nicht zum Leistungsgegenstand werden, aber trotzdem unmittelbar an etwaigen Gefahren des Schuldverhältnisses teilhaben. ${ }^{1258}$ Weil Ressourcen (Geld, Wirtschaftsgüter, Zeit etc.) endlich sind, ${ }^{1259}$ müssen sie aus wirtschaftswissenschaftlicher Perspektive - zur Mehrung des gesamtgesellschaftlichen Wohlstands - mit größtmöglicher Sorgfalt verteilt werden. ${ }^{1260}$ Aufgabe und Ziel der ökonomischen Analyse des Rechts ist eine Symbiose von Rechts- und Wirtschaftswissenschaften. ${ }^{1261}$ Maßstab der ökonomischen Analyse für die Reichwei-

1257 Bydlinski, Prinzipien, 1996, S. 172f.; Larenz, Schuldrecht AT, 14. Aufl. 1987, S. 4.

1258 Vgl. Medicus/Lorenz, Schuldrecht AT, 21. Aufl. 2015, Rn. 520f.

1259 Prämisse der Ressourcenknappheit, s. J. Schmidt, Vertragsfreiheit, 1985, S. 192; Schäfer/Ott, Ökonomische Analyse, 5. Aufl. 2012, S. 45f.

1260 Hieraus folgt die wirtschaftswissenschaftliche Forderung nach Allokationseffizienz, welche einen Zustand bezeichnet, in dem alle Ressourcen zum größtmöglichen Nutzen verteilt sind, näher Mankiw/Taylor, Volkswirtschaftslehre, 5. Aufl. 2012, S. 184f.; R. Posner, Economic Analysis, 9. Aufl. 2014, S. 8, 30; Schäfer/Ott, Ökonomische Analyse, 5. Aufl. 2012, S. 14ff.

1261 Staudinger/Honsell, Neubearbeitung 2013, Einl zum BGB Rn. 199; Schäfer/Ott, Ökonomische Analyse, 5. Aufl. 2012, S. XXXIII. Hierum machte sich insbesondere der amerikanische Wirtschaftswissenschaftler und Nobelpreisträger Richard Coase verdient. Er stellte die - später als sog. Coase-Theorem bekannt gewordene - These auf, dass in einer Welt, in der Rechtsgüter ohne (Transaktions-)Kosten (Notargebühren, Beratungskosten, Austauschkosten etc.) getauscht werden können und die Durchsetzung individueller Rechte keine Kosten (Gerichtskosten, Rechtsanwaltskosten etc.) verursacht, die Menschen durch den Austausch der Rechtsgüter (Ressourcenallokation) eine effiziente Verteilung dieser Rechtsgüter (Zustand der Allokationseffizienz) erreichen werden, die keinerlei negative Auswirkungen auf unbeteiligte Marktteilnehmer (sog. negative Externalitäten) hat, näher Coase, J. Law \& Econ. 3 (1960), 1, 13, 19. Prämisse dieser These ist aber ein stets rational im eigenen Interesse agierender Marktteilnehmer, der von (negativen) Stimuli wie Gruppenzwang, Neid, Gier, etc. unbeeinflusst bleibt (sog. homo oeconomicus). Der homo oeconomicus versucht dabei als rationales Individuum seine eigenen Präferenzen möglichst umfassend nach der REM-Theorie (,resourceful, evaluating, maximising“" [individual]) durchzusetzen und prägt als solcher das gesamtgesellschaftliche Erscheinungsbild, näher zu alldem Tröger, Arbeitsteilung, 2012, S. 40f. (Fn. 47, 51) m.w.N. Dies wird insbesondere von den Verhaltenswissenschaften scharf kritisiert, vgl. knapp Staudinger/Honsell, Neubearbeitung 2013, Einl zum BGB Rn. 199 sowie ausf. Drexl, Selbstbestimmung, 1998, S. 169ff. Mittlerweile konnten empirisch nachweisbare Verhaltensmuster festgestellt werden, die das Modell des homo oeconomicus zum Teil widerlegen, näher M.- 
te von Nebenpflichten sind damit die Fragen, zu welchem Ressourceneinsatz die Schaffung einer Verhaltensanforderung in einem Schuldverhältnis führt (deskriptive Komponente) und ob dieser (neue) Umgang mit Ressourcen effizient(er) ${ }^{1262}$ ist (wertende Komponente). ${ }^{1263}$

\section{bb) Rezeption der ökonomischen Analyse des Rechts im Zivilhaftungsrecht}

Zur ökonomischen Analyse des Rechts in Bezug auf zivilrechtliche Haftungsfragen gibt es - neben der Fülle an US-amerikanischer Literatur ${ }^{1264}$ - mittlerweile auch einige deutsche Publikationen. ${ }^{1265}$ Viele monographische Werke integrieren

P. Weller, Vertragstreue, 2009, S. 362; aus einer systemischen Perspektive J. Schmidt, Vertragsfreiheit, 1985, S. 203; schon früh das „Menschenbild eines schieren Nutzenmaximierers“ ablehnend Fezer, JZ 1986, 817, 822. Beispiele sind die sogenannten bias, also eine rational nicht zu erklärende Abneigung oder Präferenz für ein bestimmtes Verhalten sowie bestimmte Formen von rational nicht erklärbarem sozial-empathischen Verhalten, vgl. instruktiv zu alldem aus der Perspektive der Verhaltensökonomie Eidenmüller, JZ 2005, 216, 218f.; Falk/Alles, ZIP 2014, 1209, 1210, 1212ff.; Kahnemann, Denken, 2012, S. 508ff.; Schäfer/Ott, Ökonomische Analyse, 5. Aufl. 2012, S. 105ff. sowie spezifisch zu einer mit Risikoaversion zusammenhängenden ,omission bias“, welche bei Beweislastfragen relevant wird, Zamir/ Ritov, J. Leg. Stud. 41 (2012), 165, $192 \mathrm{f}$.

1262 Was genau Effizienz bedeutet, ist in der ökonomischen Analyse umstritten. Nach dem ParetoKriterium ist ein prospektiver Zustand erstrebenswert, wenn zumindest eine Person ihn bevorzugt und niemand ihn ablehnt, näher Calabresi, Yale L.J. 100 (1991), 1211, 1215f.; Schäfer/Ott, Ökonomische Analyse, 5. Aufl. 2012, S. 13; Unberath, Vertragsverletzung, 2007, S. 125. Nach dem Kaldor-Hicks-Kriterium ist eine Zustandsveränderung erstrebenswert, wenn der Vorteil der Profiteure theoretisch ausreichen würde, um den Nachteil der den Zustand Ablehnenden auszugleichen, Calabresi, Yale L.J. 100 (1991), 1211, 1221f.; Oechsler, Vertragsgerechtigkeit, 1997, S. 137; Unberath, Vertragsverletzung, 2007, S. 127f. Dass der Nachteil der von dem Zustand Beeinträchtigten auch tatsächlich ausgeglichen wird, ist nicht Voraussetzung der Kaldor-Hicks-Effizienz. Deshalb wird ein Zustand, der dem Kriterium genügt, auch „potentielle Paretoverbesserung“ genannt, Schäfer/Ott, Ökonomische Analyse, 5. Aufl. 2012, S. 20 (Fn.11); krit. deshalb Faust, Vorhersehbarkeit, 1996, S. 205f. (Fn. 44); Grundmann/ Hoernig, X. Travemünder Symposium, 2007, S. 420, 427. Gegen jedes Festklammern an einer der beiden (starren) Hypothesen und für eine rein normativ-abwägende Auseinandersetzung mit dem Begriff der Effizienz eindringlich und überzeugend Calabresi, Yale L.J. 100 (1991), $1211,1229 \mathrm{ff}$.

1263 Verneint man letzteres, so spricht zumindest die ökonomische Analyse gegen eine derartige Nebenpflicht. Bejaht man es, so bliebe in einem juristischen Gutachten zu überprüfen, ob andere Wertungen trotzdem gegen eine solche Nebenpflicht sprechen. Eine alleinige Maßgeblichkeit des Effizienzbegriffs würde in der Rechtspraxis auf Ablehnung stoßen.

1264 R. Posner, Economic Analysis, 9. Aufl. 2014, S. 26f, 35, 155f. m.w.N.

1265 Beispielsweise Baumann, RNotZ 2007, 297ff.; Brüggemeier, AcP 182 (1982), 385ff.; Doobe, Vermögensschäden, 2014; Fezer, JZ 1986, 817ff.; Gottwald, FS Fasching, 1988, S. 181ff.; 
mittlerweile Grundannahmen der ökonomischen Analyse in einer theoretischen Einführung. ${ }^{1266}$ Unmittelbare praktische Konsequenzen werden hieraus aber selten gezogen. ${ }^{1267}$ Insgesamt bleibt die ökonomische Analyse damit in der deutschen Zivilrechtswissenschaft - und insbesondere im Schuldverhältnisrecht ${ }^{1268}$ ausbaufähig. ${ }^{1269}$

Köhler, ZHR 144 (1980), 589ff.; Kötz, FS Steindorff, 1990, S. 496ff.; Kübler, FS Steindorff, 1990, S. 687ff.; Michael Lehmann, Vertragsanbahnung, 1981, S. 226ff.; M. Müller/Hempel, AcP 205 (2005), 246ff. Riha, Sachmängelgewährleistungsrecht, 2007; Taupitz, AcP 196 (1996), 114ff.; Trimarchi, ZHR 136 (1972), 118ff.; Unberath/Cziupka, AcP 209 (2009), 37ff.; Wagner, AcP 206 (2006), 352, 424ff., 451ff.; vgl näher Grechenig/Gelter, RabelsZ 72 (2008), 513, 516ff. m.w.N.

1266 S. beispielsweise Brors, Nebenpflichten, 2002, S. 67ff.; Drexl, Selbstbestimmung, 1998, S. 162ff.; Michael Lehmann, Vertragsanbahnung, 1981, S. 226ff.; Rehm, Aufklärungspflichten, 2003, S. 23ff.; Riha, Sachmängelgewährleistungsrecht, 2007, S. 19ff.; Unberath, Vertragsverletzung, 2007, S. 122ff.; M.-P. Weller, Vertragstreue, 2009, S. $348 \mathrm{ff}$.

1267 Zutreffend Doobe, Vermögensschäden, 2014, S. 236f. („,Es existieren keine höchstrichterlichen Entscheidungen, die sich eindeutig mit der ökonomischen Analyse des Rechts [...] auseinandergesetzt haben."). Auch wenn er die ökonomische Analyse im Grundsatz für überzeugend hält, kritisiert beispielsweise Faust, Oxford Handbook, 2006, S. 837, 849f., dass ihre abstrakten Konstrukte sich in der Rechtspraxis nicht einsetzen lassen, weil die notwendige Modifizierung der Ansätze für die Praxis unterbleibt. Damit weist er letztlich der Wissenschaft die Aufgabe zu, die theoretischen Instrumente der ökonomischen Analyse auch tatsächlich am Einzelfall auszuprobieren, vgl. Faust, Oxford Handbook, 2006, S. 837, 850 („economic analysis $[. .$.$] must come down to earth and sacrifice exactitude in order to get closer to real life");$ ebenfalls in diese Richtung Tröger, Arbeitsteilung, 2012, S. 31. Soweit ersichtlich unternahm lediglich Brors 2002 einen (monographischen) Versuch, die ökonomische Analyse des Rechts auf den Bereich der Nebenpflichten anzuwenden. Deren Arbeit fokussierte sich aber auf den spezifischen Kosmos des Arbeitsrechts, dessen Besonderheiten (v.a. strukturelle Unterlegenheit des Arbeitnehmers) dazu führten, dass die ökonomische Analyse nach Ansicht der Autorin nur eingeschränkt einsetzbar war, vgl. Brors, VII. Travemünder Symposium, 2001, S. 215, 219f., 225f.; Brors, Nebenpflichten, 2002, S. 84f., 103. Vor allem wandte sich Brors gegen die Berücksichtigung der ökonomischen Analyse des Rechts als Rechtsprinzip mit eigenem Wertungsspielraum. Zudem lag der hauptsächliche Fokus dieser Arbeit auf den leistungsbezogenen Nebenpflichten eines spezifischen rechtsgeschäftlichen Schuldverhältnisses und ließ für den Bereich der nichtleistungsbezogenen Nebenpflichten im allgemeinen Schuldrecht weiteren Forschungsbedarf, vgl. Brors, Nebenpflichten, 2002, S. $41 \mathrm{ff} ., 143 \mathrm{ff}$.; s. auch den Kommentar von Salje, VII. Travemünder Symposium, 2001, S. 234, 235 zu einem Aufsatz von Brors im selben Band zum gleichen Thema.

1268 Eine längere, deutsche Historie hat nämlich vor allem die ökonomische Analyse des Deliktsrechts, wohingegen die Haftung aus einem Schuldverhältnis erst später von der ökonomischen Analyse aufgegriffen wurde, vgl. noch Köhler, ZHR 144 (1980), 589, 589f.; Trimarchi, ZHR 136 (1972), 118, 118.

1269 Vgl. Baumann, RNotZ 2007, 297, 297 (,unter deutschen Juristen (vor allem Praktikern) wenig bekannte Theorie"); Doobe, Vermögensschäden, 2014, S. 236f.; Grechenig/Gelter, RabelsZ 72 (2008), 513, 516 (,vergleichsweise schwache Stellung der ökonomischen Analyse des Rechts 
b) Methodische Möglichkeiten, die ökonomische Analyse in Bezug auf Nebenpflichten anzuwenden

Im Grundsatz hat die ökonomische Analyse des Rechts zwei voneinander unabhängige Funktionen: Die Folgenanalyse als deskriptive Komponente sowie die Folgenbewertung als normative Komponente. ${ }^{1270}$

\section{aa) Ökonomische Folgenanalyse von $\S 241$ II BGB}

Die erste und einfachste Methode, die ökonomische Analyse anzuwenden, ist die rein deskriptive Untersuchung des Bereichs der Nebenpflichten auf die Berücksichtigung ökonomischer Gesichtspunkte. ${ }^{1271}$ Trotz Kritik an den Wertungen der ökonomischen Analyse steht ein Großteil der Rechtswissenschaft einer Folgenanalyse bei der Rechtsanwendung einzelner Normen prinzipiell offen gegenüber. ${ }^{1272}$ Auch die Gerichte berücksichtigen bei der Subsumtion die möglichen Folgen der Entscheidung auf zukünftige Fälle. ${ }^{1273}$ Soll eine Folgenanalyse um-

im deutschsprachigen Rechtsdiskurs“); Kötz, FS Drobnig, 1998, S. 563, 564 („,[d]en meisten Juristen in Deutschland ist die ökonomische Analyse des Rechts noch ganz unbekannt"); Rückert/Seinecke/Laudenklos, Methodik, 3. Aufl. 2017, Rn. 1210, 1244ff; Michael Lehmann, Vertragsanbahnung, 1981, S. 228 (,Schule der wirtschaftswissenschaftlichen Untersuchung des Rechts [...] in Deutschland noch nicht einmal rudimentär vorhanden"); Taupitz, AcP 196 (1996), 114, 120 (,,[k]eine Rezeption, aber partieller Begründungsgleichklang“); symptomatisch die (zu) knappe, kritische Darstellung bei Staudinger/Honsell, Neubearbeitung 2013, Einl zum BGB Rn. 199 sowie die lapidare Nennung bei Staudinger/Olzen, Neubearbeitung 2015, Einl zum SchuldR Rn. 330 (Ökonomische Analyse gehe ,von anderen Wertungen [...] als das $B G B^{\prime \prime}$ aus); zu möglichen historisch bedingten Gründen für die unterschiedliche Behandlung der ökonomischen Analyse in Deutschland und den USA instruktiv Grechenig/Gelter, RabelsZ 72 (2008), 513, 522ff. ("divergente Evolution des Rechtsdenkens").

1270 Schäfer/Ott, Ökonomische Analyse, 5. Aufl. 2012, S. 4; ähnlich Tröger, Arbeitsteilung, 2012, S. 39 (zunächst „Ermittlung der [zu erwartenden] Resultate“, anschließend „Vergleich mit einem [...] sozialen Optimum").

1271 Näher Ott, FS Kübler, 1997, S. 21, 27f. Ob und inwieweit die Rechtsanwendung sich bei der Bestimmung von Nebenpflichten auf wirtschaftliche Erwägungen stützt, wäre dann Fokus der Untersuchung, vgl. Oechsler, Vertragsgerechtigkeit, 1997, S. 136.

1272 S. Schwarze, Leistungsstörungen, 2. Aufl. 2017, S. 8 (,kann [...] die Ermittlung der Tatsachen verbessern“); Tröger, Arbeitsteilung, 2012, S. 35; Unberath, Vertragsverletzung, 2007, S. $128 \mathrm{f}$.

1273 Vgl. exemplarisch BGH, Urt. v. 3.3.1988 - X ZR 54/86, Rn. 37 (sachlich überzeugendes, aber erkennbar über den Einzelfall hinausdeutendes Argument, „, daß der der Werft durch den Abschlu $\beta$ einer umfassenden Haftpflichtversicherung entstehende zusätzliche Prämienaufwand die Eigner unterschiedlich risikogefährdeter Schiffe gleichermaßen treffen würde. Dadurch 
fassend sein, muss sie aber auch die wirtschaftlichen Auswirkungen abbilden können. ${ }^{1274}$ Hierfür wird die ökonomische Analyse mit ihren Instrumenten vorgeschlagen. Die analytische Transparenz der ökonomischen Analyse in der Folgenanalyse ist ein Vorteil, der unabhängig davon besteht, ob man der ökonomischen Analyse auch im Ergebnis wertenden Vorrang einräumt. ${ }^{1275}$ Damit ist die Berücksichtigung der deskriptiven Komponenten der ökonomischen Analyse logische Konsequenz der rechtswissenschaftlich anerkannten Folgenanalyse.

bb) Ökonomische Folgenbewertung von $\S 241$ II BGB

Instrumente der normativen ökonomischen Analyse dienen der Verwirklichung objektiver, abstrakt definierter Ziele. Nebenpflichten sollen ein bestimmtes Schuldverhältnis näher ausgestalten. Mit einem rechtsgeschäftlichen Schuldverhältnis und dem Primat des Parteiwillens lassen sich inhaltlich fremdbestimmte (Neben-)Pflichten zunächst kaum vereinen. Selbst wenn ein Schuldverhältnis willentlich begründet wird, muss sich der subjektive Wille des Antragenden aber noch am objektivierten Verständnis des Adressaten messen und gegebenenfalls modifizieren lassen. ${ }^{1276}$ Auch Nebenpflichten sind von „heteronomen Zielvor-

würden nicht nur solche Kunden zusätzlich belastet, deren Interessen bereits ausreichend gewahrt seien, diese Kunden müßten vielmehr einen Teil der Reparaturkosten für besonders risikogeneigte Schiffe mittragen, während die Eigner dieser Schiffe dadurch einen sachlich nicht gerechtfertigten Vorteil hätten.") (BGHZ 103, 316, 327); Schäfer/Ott, Ökonomische Analyse, 5. Aufl. 2012, S. 4f., 7f.; Wagner, AcP 206 (2006), 352, 388f.

1274 Vgl. Fleischer, Informationsasymmetrie, 2001, S. 178ff. („makrojuristisches Vertragsmodell").

1275 Kötz, FS Drobnig, 1998, S. 563, 576f.; Taupitz, AcP 196 (1996), 114, 145; Tröger, Arbeitsteilung, 2012, S. 40f. (deskriptive ökonomische Analyse „rechtliche[r] Institute“ in jedem Fall gewinnbringend), 43. Zwar werden die Begriffe der Effizienz und des homo oeconomicus sowie die ihnen zugrundeliegenden Hypothesen bisweilen kritisiert, Drexl, Selbstbestimmung, 1998, S. 169ff.; Fezer, JZ 1986, 817, 821ff.; zum Begriff des homo oeconomicus aber deutlich Eidenmüller, JZ 2005, 216, 217ff. (,nach wie vor das leistungsfähigste derartige Modell"). Kritik am Effizienzbegriff - und anderen Hypothesen - kann sich sinnvollerweise aber nur auf die Folgenbewertung mittels der Ökonomik beziehen. Darauf zu verzichten, alle Facetten eines Problems auszuleuchten, nur, weil es Kritik an den Bewertungsmaßstäben gibt, erschiene kurzsichtig.

1276 Auch ein Vertrag spiegelt damit ungeachtet des Geltungsprimats vom Parteiwillen ,heterono$m e^{\text {“ Elemente wider, Oechsler, Vertragsgerechtigkeit, 1997, S. } 239 f .}$ 
stellungen“ geprägt. ${ }^{1277}$ Selbst in einem Vertrag teilen sie also nicht dessen dogmatischen Ursprung - den Parteiwillen. ${ }^{1278}$ Ansätze der ökonomischen Analyse des Rechts sind deshalb zur Bestimmung der Reichweite von Nebenpflichten in einem Schuldverhältnis unabhängig von dessen Natur grundsätzlich geeignet.

\section{(1) Widerspruch zwischen Effizienz und Rechtsssystem?}

Disziplinen wie die ökonomische Analyse, die nicht unmittelbar dem positiven Rechtsssystem oder der juristischen Dogmatik entspringen, können sinnvollerweise - wenn überhaupt - nur innerhalb der teleologischen Auslegung einer Norm berücksichtigt werden. ${ }^{1279}$ Über die rein deskriptive Folgenanalyse hinaus ließe sich ökonomische Analyse des Rechts demnach innerhalb von § 241 II BGB womöglich als eigenes Rechtsprinzip mit Wertungsspielraum integrieren. ${ }^{1280}$ Diese Herangehensweise ist in der rechtswissenschaftlichen Literatur aber auf erhebliche Kritik ${ }^{1281}$ gestoßen: So wird zum Teil die Eignung der ökonomischen Analyse für die Rechtspraxis angezweifelt ${ }^{1282}$, andere sehen in der

1277 Tröger, Arbeitsteilung, 2012, S. 60f., 517.

1278 Grigoleit, FS Canaris, Bd. I, 2007, S. 275, 283f.

1279 Drexl, Selbstbestimmung, 1998, S. 167; Schwarze, Leistungsstörungen, 2. Aufl. 2017, S. 8 (,,angebunden an die „objektive Teleologie“"'); Tröger, Arbeitsteilung, 2012, S. 33 (Fn. 14) m.w.N.

1280 Faust, Vorhersehbarkeit, 1996, S. 205, 207; Ott, FS Kübler, 1997, S. 21, 30f. Ähnlich wird auch die Konkretisierung des Maßstabs einer ergänzenden Vertragsauslegung über Instrumente der ökonomischen Analyse des Rechts vorgeschlagen, Salje, VII. Travemünder Symposium, 2001, S. 234, 239. Nebenpflichten werden aber nach hier vertretener Ansicht nicht über das Instrument der ergänzenden Vertragsauslegung festgestellt, s.o., S. 185ff. Demnach scheidet die Berücksichtigung der ökonomischen Analyse auf diesem Wege aus.

1281 Repräsentativ Assmann, Travemünder Symposium, 1989, S. 45, 45ff.; Fezer, JZ 1986, 817, $821 \mathrm{ff} ., 824$ („,̈konomische Rechtstheorie [...] ein Irrweg, den zu beschreiten, das Recht sich hüten sollte“); dezidierte Replik auf die häufigsten Kritikpunkte bei Kübler, FS Steindorff, 1990, S. 687, 690ff.

1282 Tröger, Arbeitsteilung, 2012, S. 64 (Fn. 164) m.w.N. zeigt die Gefahr auf, dass sich Wissenschaft und Praxis wegen der inhaltlichen Komplexität der ökonomischen Analyse voneinander entfremden könnten, Weitergehend will Luhmann die Judikative als Teil der Rechtsanwendung nicht mit einer folgenfokussierten Problemanalyse beschweren, sondern diese Aufgabe ausschließlich der Rechtssetzung überlassen, Luhmann, Rechtssystem, 1974, S. $31 \mathrm{ff.,} 48$ (,Auftauchen von folgenorientierten Scheinkriterien außerjuristischer Provenienz" als Zeichen, dass rechtssicherheitsgefährdende Vermischung von Wertung und Kriterium droht). Eidenmüller weist die Rechtsanwendung der ökonomischen Analyse ebenfalls generell und entschieden unter Verweis auf die unzureichende „Kompetenz“ des einzelnen Rechtsanwenders sowie Systemschwächen der Einzelfallanalyse zurück, näher Eidenmüller, AcP 197 


\section{Maßgeblichkeit von Effizienzgedanken in der Rechtsanwendung einen grund- sätzlichen Wertungswiderspruch ${ }^{1283}$.}

(1997), 80, $103 \mathrm{ff}$. („Richter sind keine Ökonomen.“), 111 („,Für eine umfassende ökonomische Folgenanalyse fehlt den Gerichten die Kompetenz, für eine umfassende ökonomische Folgenbewertung fehlt ihnen [darüber hinaus] die Legitimation."), 119f. (,Reale Akteure [in einem Schuldverhältnis sind keine] homines oeconomici“"); skeptisch auch Drexl, Selbstbestimmung, 1998, S. 168f.; Raiser, FS DJT, Bd. I, 1960, S. 101, 120; Taupitz, AcP 196 (1996), 114, 165f. (,gefährlich und verfehlt, [die ökonomische Analyse] [...] unter Abstraktion ihrer idealisierenden, abstrahierenden und isolierenden Prämissen unmittelbar zur Auslegung, Bewertung und Kritik rechtlicher Regelungen heranzuziehen"). Als Alternativkonzept zur ökonomischen Analyse durch den häufig nur mit begrenzten ökonomischen Kenntnissen ausgestatteten Rechtsanwender schlägt Eidenmüller vor, die ökonomische Analyse des Rechts als Gesetzgebungstheorie anzuwenden, näher Eidenmüller, AcP 197 (1997), 80, $93 \mathrm{ff} . ;$ Eidenmüller, Effizienz, 2. Aufl. 1998, S. 414ff; ähnlich Luhmann, Rechtssystem, 1974, S. 48, 53 (,funktional abstrahierende dogmatische Begriffsarbeit [impliziert] in stärkerem Maße Fragen und Appelle an den Gesetzgeber"); Taupitz, AcP 196 (1996), 114, 144 (,ökonomische Analyse des Rechts in erster Linie eine Gesetzgebungstheorie“). Weil die Arbeit sich aber auf die Rechtsanwendung - und nicht auf die Rechtssetzung - beschränken will, wird auf diese Funktion nur der $\mathrm{Ab}$ grenzung halber hingewiesen.

1283 Oechsler, Vertragsgerechtigkeit, 1997, S. 136 hält einen absoluten Vorrang des Effizienzkriteriums in wertender Hinsicht für unangebracht; so auch Assmann, Travemünder Symposium, 1989, S. 45, 47 (,keine konsenstheoretische Begründung dafür in Sicht, daß sich ein Sozialvertragspartner darauf einlassen müßte, den „Reichtum einer Gesellschaft “ auf der Grundlage gegebener Verteilungslagen zum „ethischen Maximand“ zu erheben“); Drexl, Selbstbestimmung, 1998, S. 169 (,Gefahr, daß sich das Recht [...] zu sehr am Kriterium der wirtschaftlichen Effizienz orientiert"). Oechsler, Vertragsgerechtigkeit, 1997, S. 136 hält den Begriff der „Effizienz" auch für unscharf definiert, s. auch Fehling, Ringvorlesung K. Schmidt, 2011, S. 39, 43 („Verdacht bloßer Scheinrationalität"); Fezer, JZ 1986, 817, 823 („Gefahr der Scheinpräzision"); Murphy/Coleman, Philosophy of Law, 1990, S. 250 (,objection that has secured the greatest currency [...] is that the economics of law involves an insidious, unpalatable idelogy"). Zudem bemängelt Oechsler, Vertragsgerechtigkeit, 1997, S. 13, dass sich in der ökonomischen Analyse mikro- und makroökonomische Betrachtungen ohne erkennbare Systematik abwechseln. Die Nutzenprognosen, auf die sich die ökonomische Analyse stütze, ließen sich regelmäßig nicht belegen, vgl. dagegen allerdings das eindrucksvolle Plädoyer zur Ersatzfähigkeit reiner Vermögensschäden aus mathematischer Perspektive von Schweizer, Spieltheorie, 2015, S. 107ff. Dies alles führe laut Oechsler, Vertragsgerechtigkeit, 1997, S. $138 \mathrm{zu}$ einer praxisfernen ,Abstraktheit" und ,fehlenden teleologischen Präzision" der ökonomischen Analyse, ähnlich auch Larenz/Canaris, Schuldrecht BT 2, 13. Aufl. 1994, S. 417 (,Mehraufwand an schwieriger Terminologie häufig außer Verhältnis zum Ertrag an sachhaltigen Argumenten"). Speziell in Bezug auf Nebenpflichten ist auch Brors, Nebenpflichten des Arbeitgebers, 2002, S. 76ff. dem Versuch kritisch gegenüber eingestellt, der ökonomischen Analyse des Rechts einen eigenen Wertungsspielraum einzuräumen. Die Kritik fußt jedoch auf der dem Arbeitsrecht eigenen, funktionalen Machtasymmetrie der beiden SchuldverhältnisParteien sowie der drohenden Gefahr einer Erosion von Arbeitnehmerrechten und ist deshalb nicht ohne weiteres auf alle Schuldverhältnisse übertragbar, vgl. Ott, FG Kübler, 1997, S. 21, 29; deshalb beispielsweise für die Berücksichtigung der Ökonomik (nur) im geschäftlichen 
Der Ressourcenverteilung nach dem Kriterium der Effizienz darf in der Rechtsanwendung deshalb nur indikative Bedeutung zukommen. ${ }^{1284}$ Nur so kann die Rechtsprechung dem Rechtsuchenden gegenüber einen Anreiz setzen, auch als vermeintlich Unterlegener die Rechtsverfolgung aufzunehmen. Würde sie ähnlich einer Planwirtschaft ohne Wenn und Aber nach dem allmächtigen Maßstab der Effizienz urteilen, so würde sie dem Einzelnen womöglich den Anreiz nehmen, sie überhaupt in Anspruch zu nehmen. ${ }^{1285}$ Deshalb sind die Vorgaben der Effizienz innerhalb der teleologischen Auslegung des § 241 II BGB nicht zwingend. Der Legitimationsdruck auf eine Auslegung des § 241 II BGB, welche effiziente Risikoverteilung durch Aspekte der Einzelfallgerechtigkeit überlagern lässt, sollte indes merklich steigen. ${ }^{1286}$

Die ökonomische Analyse wird zudem bisweilen als praxisfern und abstrakt bemängelt. ${ }^{1287}$ Zieht man sie im Rahmen der teleologischen Auslegung von

Umfeld plädierend Faust, Vorhersehbarkeit, 1996, S. 206f. Aus neuerer Zeit sieht Paßmann, Schutzpflichtverletzungen, 2010, S. 135 die ökonomische Analyse in Bezug auf Nebenpflichten nur als ,rechtspolitische Forderung“, die nicht allein maßgeblich sollte.

1284 So explizit auch Faust, Vorhersehbarkeit, 1996, S. 207 (nicht die ,Rolle einer „,normativen Fliegenklatsche““); Rückert/Seinecke/Rückert, Methodik, 3. Aufl. 2017, Rn. 1456; Schäfer/Ott, Ökonomische Analyse, 5. Aufl. 2012, S. 571 (kein rechtsverbindliches Kriterium); Schwarze, Verständigungspflichten, 2001, S. 67 („Notwendigkeit einer subtileren, rechtsdogmatisch abgesicherten Rechtsfortbildung [...], in der Effizienzerwägungen als wichtiger Aspekt Berücksichtigung finden können"); Schwarze, Leistungsstörungen, 2. Aufl. 2017, S. 8 (,Bedeutung der Effizienzanalyse kann nur eine punktuell-ergänzende sein“).

1285 Murphy/Coleman, Philosophy of Law, 1990, S. 255 (,prevalent [...] intuition is that courts, in part because they are essentially unaccountable, nondemocratic institutions that do not seek out issues or goals to promote or advance, are best left to adjudicate claims brought to them by particular litigants and framed in terms of the interest of the litigants alone").

1286 So überzeugend Ott, FG Kübler, 1997, S. 21, 40; Schäfer/Ott, Ökonomische Analyse, 5. Aufl. 2012, S. 571; Taupitz, AcP 196 (1996), 114, 166.

1287 Faust, Oxford Handbook, 2006, S. 837, 849f.; Fezer, JZ 1986, 817, 820f.; Taupitz, AcP 196 (1996), 114, 165f. Drexl, Selbstbestimmung, 1998, S. 172f. zweifelt gar an, dass indi-viduell nutzenfixiertes Handeln als Arbeitshypothese der ökonomischen Analyse zu gesamtgesellschaftlichem Mehrwert führen solle. Schließlich stütze sich die erste Annahme schon auf deren gesamtgesellschaftlichen Nutzen und lege damit einen logischen Zirkelschluss nahe; vgl. dazu auch Hassemer, Heteronomie, 2007, S. 229. Tröger hält beispielsweise im Kontext der begrifflichen Differenzen von Effizienz und hypothetischem Parteiwillen die Normen des Leistungsstörungsrechts, gerade deshalb [für] konsensfähig, weil sie pareto-effizient sind“", Tröger, Arbeitsteilung, 2012, S. 52. Dass die Normen des Leistungsstörungsrechts (inklusive § 241 II BGB) nach dem Kriterium der Effizienz ausgerich-tet sind, ist aber wiederum Voraussetzung dafür, sie dergestalt in den hypothetischen Par-teiwillen integrieren zu können. Er versucht also die logische Identität beider Begriff mit einer petitio 
$\S 241$ II BGB heran, so treibt man die rechtspraktische Anwendung der Ökonomik im gerichtlichen Alltag voran. ${ }^{1288}$ Zum anderen ist die Rechtspraxis für die Arbeit mit der Ökonomik innerhalb der Subsumtion unter $\S 241$ II BGB auf handhabbare Kriterien angewiesen. Die ökonomische Analyse muss damit alltagstauglich werden. ${ }^{1289}$ Wissenschaft und Praxis können sich die Arbeit insoweit teilen: Die Wissenschaft kann durch theoretische Vorarbeit die Konzepte der ökonomischen Analyse in subsumtionsfähige Kriterien überführen und die Praxis kann diese dann in den Rechtsanwendungsalltag übernehmen. ${ }^{1290}$ Zumindest ein Einwand gegenüber der ökonomischen Analyse lässt sich gerade mit der hier vorgeschlagenen Anwendung derselben im Rechtsalltag entkräften.

(2) Zur Vereinbarkeit der Zielsetzungen von Nebenpflichten und der ökonomischen Analyse

Bei einer Haftung aus Nebenpflichtverletzung geht es weniger um ein spezifisch schuldverhältnisbedingtes Problem als um die Frage, ob die Schadensersatzhaftung des BGB nach $\S \S 249 \mathrm{ff}$. BGB bei einem bestimmten Verhalten generell greifen soll. ${ }^{1291}$ Das Vorgehen bei $\S 241$ II BGB ist also ganz klar rechtsfolgenorientiert. ${ }^{1292}$ In dem zentralen, allgemeinen Haftungsrecht - dem Deliktsrecht -

principii darzulegen. Ebendiese Art von Argumentation - die auch in dieser Arbeit sicher nicht vermieden werden konnte - macht die Gegner der ökonomischen Analyse zu Recht misstrauisch gegenüber deren Grundannahmen. Wie diese Arbeit aber versucht aufzuzei-gen, lösen sich viele der theoretischen Widersprüche in der praktischen Arbeit mit den Prinzipien der Ökonomik.

1288 Ebenfalls für die praktische Anwendung der ökonomischen Analyse im Normalltag plädierend Faust, Oxford Handbook, 2006, S. 837, 849f.; Tröger, Arbeitsteilung, 2012, S. 31; dagegen offenbar Taupitz, AcP 196 (1996), 114, 166 (,,keine wohlfeile und unmittelbar umsetzbare Theorie für den grauen Alltag der Gerichte").

1289 Eindringlich Faust, Oxford Handbook, 2006, S. 837, 850 („,economic analysis must reduce complexity").

1290 Vgl. zu diesem Gedanken auch Tröger, Arbeitsteilung, 2012, S. 64f.

$1291 \mathrm{HKK} /$ Dorn, 2007, § 241 Rn. 77 (Haftung aus Nebenpflichtverletzung ,systembedingter Weg, die als billig anerkannte Haftung bestimmter Personen für bestimmte Schäden aufgrund der durch das Schuldrecht zur Verfügung gestellten Instrumentarien dogmatisch zu begründen").

1292 Diese auch schon als ,heteronom “ bezeichnete Qualität von Nebenpflichten macht den Rückgriff auf allgemeine Haftungsgründe erforderlich. Exemplarisch für dieses moderne Verständnis entstehen Nebenpflichten laut Paßmann, Schutzpflichtverletzungen, 2010, S. 62f. allein „aufgrund allgemeiner Gefahrüberlegungen“ und sind deshalb eben nicht spezifisch „schuld- 
genießt die ökonomische Analyse mehr und mehr Anerkennung. ${ }^{1293}$ Schließlich kann sie hilfreiche Hinweise dafür geben, wie die Verantwortungsbereiche zweier Parteien möglichst kostensparend voneinander abgegrenzt werden können. ${ }^{1294}$ Eine effiziente - folglich zum größtmöglichen Wohle aller erfolgende - Ressourcenallokation sollte stets ein Ziel im Haftungsrecht sein. ${ }^{1295}$ Weil sich integritätsschützende Jedermannspflichten und Nebenpflichten von ihrem Haftungsgrund her ähnlich sind ${ }^{1296}$, wäre es sinnvoll, die im Deliktsrecht mittlerweile weit verbreiteten Grundsätze der ökonomischen Analyse auch auf Nebenpflichten zu erstrecken. Dies gilt umso mehr, als es bei Nebenpflichten weniger um die Konturierung von Rechtsgütern geht, als um die Statuierung von Verhaltenspflichten (Schadensvermeidungspflichten). ${ }^{1297}$ Die verhaltensbezogene Natur von Nebenpflichten und der daraus folgende Vermögensbezug machen umgekehrt deutlich, dass der Integritätsschutz von Rechtsgütern bei Nebenpflichten regelmäßig lediglich Mittel zur Verwirklichung wirtschaftlich schützenswerter Interessen des

rechtlicher“ Natur. Er begründet dies unter anderem damit, dass die „Geschäftlichkeit des Kontakts" den Pflichtinhalt nicht beeinflusst.

1293 MüKo-BGB/Wagner, 7. Aufl. 2017, Vorbem. § 823 Rn. 51ff.; s. bereits Michael Lehmann, Vertragsanbahnung, 1981, S. 316f.; zur Kritik Soergel/Krause, 13. Aufl. 2005, § 823 Anh II Rn. 34; Soergel/Spickhoff, 13. Aufl. 2005, Vor § 823 Rn. 32f.

1294 Lehnt man die ökonomische Analyse im allgemeinen Haftungsrecht wegen der ,Ideologiefreiheit" desselben ab, so gilt es zu bedenken, dass auch moral-philosophische Gerechtigkeit als ein mögliches, anderes Ziel des Schadensersatzrechts mit „Ideologie“ behaftet ist, zutreffend zu diesem inneren Widerspruch vieler Kritiker der ökonomischen Analyse Tröger, Arbeitsteilung, 2012, S. 56.

1295 So auch Tröger, Arbeitsteilung, 2012, S. 55; vgl. auch J. Schmidt, Vertragsfreiheit, 1985, S. 222 (,die Ökonomie [kann] im Rahmen des Marktmodells [...] gewisse richtungsweisende Überlegungen bereitstellen"). Dies gilt allemal, wenn die Teleologie einer Norm wie $\S 241$ II BGB durch den Wortlaut so wenig vorgeprägt ist, vgl. Rückert/Seinecke/Rückert, Methodik, 3. Aufl. 2017, Rn. 1456. Dass dabei die „Glückseligkeit“ der Marktteilnehmer ausgeblendet wird ist bedauernswert, aber hinnehmbar, wenn man die mit einem solchen Wertungsmaßstab verbundene Rechtsunsicherheit bedenkt, präzise Unberath, Vertragsverletzung, 2007, S. 125f.; krit. hingegen Rödl, Gerechtigkeit, 2015, S. 84 („Begriff des Glücks verkümmert“).

1296 Vgl. nur Grünewald, Garantenpflichten, 2001, S. 124; M. Müller/Hempel, AcP 205 (2005), 246, 249; Tröger, Arbeitsteilung, 2012, S. 52 (Fn. 102) m.w.N.

1297 Vgl. Schäfer/Ott, Ökonomische Analyse, 5. Aufl. 2012, S. 191. Ginge es vornehmlich um den Inhalt anerkannter Rechtsgüter, so ließe sich mit mehr Nachdruck vertreten, dass die Definition von Rechtsgütern nicht an ökonomischen Überlegungen hängen sollte, so auch deutlich Larenz/Canaris, Schuldrecht BT 2, 13. Aufl. 1994, S. 417; Schäfer, Travemünder Symposium, 1989, S. 1, 18f. (,Zivilrecht [...] kein reines Effizienzrecht"). 
Gläubigers ist. ${ }^{1298}$ Um die Reichweite (wirtschaftlich) schutzwürdiger Interessen des Gläubigers sinnvoll abzustecken, erscheint die wertende Berücksichtigung ökonomischer Verteilungseffizienz durchaus angebracht. ${ }^{1299}$ Deshalb ist es sinnvoll, die ökonomische Analyse heranzuziehen, wenn Verantwortung mittels Nebenpflichten verteilt wird.

\section{(3) Zumindest indikative Bedeutung der Ökonomie}

Naheliegend erscheint im Ergebnis folgende Überlegung: Im Rahmen der teleologischen Auslegung wird nach dem Sinn und Zweck einer Rechtsnorm gefragt und der Inhalt der Norm entsprechend diesem Zweck ausgelegt. ${ }^{1300}$ Die Berücksichtigung deskriptiver Elemente der ökonomischen Analyse ist dabei schon wegen der damit verbundenen Horizonterweiterung begrüßenswert. Zudem erhöht eine ökonomische Folgenanalyse im Einzelfall die wirtschaftliche Kohärenz und Akzeptanz der rechtswissenschaftlichen Subsumtion. In objektiver Ausfüllung des Zwecks einer Rechtsnorm ist darüber hinaus davon auszugehen, dass der Gesetzgeber eine effiziente Allokation von Ressourcen einer verschwenderi-

1298 Vgl. Michael Lehmann, Vertragsanbahnung, 1981, S. 323f., 329f.; Tröger, Arbeitsteilung, 2012, S. 52f. (,topische Vertragsnähe“).

1299 Ähnlich auch Drexl, Selbstbestimmung, 1998, S. 210 („,Seinsgrund [der Ökonomik] besteht gerade darin, die Optimierung individueller Freiheit im Sinne selbstbestimmter Präferenzen über den Markt zu erreichen“); Faust, Vorhersehbarkeit, 1996, S. 206f.; Grünewald, Garantenpflichten, 2001, S. 124; Faust, Verbraucher-acquis, 2011, S. 201, 220f.; Fleischer, Schuldrechtsreform, 2001, S. 243, 256f.; Kötz, FS Drobnig, 1998, S. 563, 574 („Risikoverteilung, die den Nutzen beider Parteien maximiert“); AK-BGB/Kohl, 1979, vor $\S \S 823$ ff. Rn. 30 (,vernünftige Absicht"); M. Müller/Hempel, AcP 205 (2005), 246, 249; Ott, Travemünder Symposium, 1989, S. 25, 29 („Die aus Treu und Glauben abgeleiteten Rechtsgrundsätze weisen jedenfalls insoweit einen eindeutigen Bezug zum Effizienzprinzip aus, als sie [...] der Risikoverteilung (Begründung von Nebenpflichten und gesetzlichen Schutzpflichtverhältnissen) dienen.“); Ott, FG Kübler, 1997, S. 21, 25; Tröger, Arbeitsteilung, 2012, S. 61 (Teleologie der Informationspflichten hat ökonomischer Analyse „Anwendungsbefehl“ erteilt); etwas verhaltener, aber umso anschaulicher E. Schmidt, JA 1978, 597, 598 (,[S]o liegt es gerade beim Vertrag als dem Standardmechanismus privater Güterversorgung nahe, die aus ihm resultierenden Pflichten vor dem Hintergrund unserer sozialstaatlich determinierten Wirtschaftsordnung zu betrachten, d. h. danach zu fragen, inwieweit die von Gesetzes wegen nicht vorgesehene Verpflichtung des einen Teils, die ja stets mit einer Belastung des Kontrahenten korrespondiert, in dieses System eingepaßt werden kann."); ablehnend Assmann, Travemünder Symposium, 1989, S. 45, 49, der für die „Vertrauenshaftung“ generell einen „Ausgangspunkt jenseits aller Effizienzaspekte“ meint, ausmachen zu können, zumal sie ,auch Ergebnisse abzudecken vermag, die keinesfalls als effizient zu bezeichnen sind“. Das ist im Hinblick auf eindeutige Parallelen zwischen rechtspraktischen Ergebnissen der Rechtsprechung und den rechtstheoretischen Vorgaben der Ökonomik kein überzeugendes Argument.

1300 Staudinger/Honsell, Neubearbeitung 2013, Einl zum BGB Rn. 149. 
schen Verteilung vorzieht ${ }^{1301}$, sofern nicht ausnahmsweise andere Gesichtspunkte überwiegendes Gewicht haben, da dies den gesamtgesellschaftlichen Mehrwert erhöht. ${ }^{1302}$ Auch die Rechtsprechung gibt bisweilen zumindest implizit zu erkennen, dass sie den Geboten der Ökonomie Respekt zollt:

Beispiel 7 In der Sache trifft der BGH im Mietwohnungsfall ${ }^{1303}$ eine Entscheidung mit Blick auf die ökonomischen Aspekte der Vermietung: Vermietung darf auch bei fehlender vertragswidriger Benutzung der Mietsache nicht dazu führen, dass der Vermieter die Kosten für eine wohnliche Selbstverwirklichung des Mieters tragen muss. Ansonsten droht nämlich bei dem Überangebot an Mietern und allgemeiner Wohnraumknappheit die Vermietung gänzlich zu unattraktiv zu werden, d.h Ressourcen werden durch unvermietete Immobilien nicht effizient genutzt. ${ }^{1304}$ Der BGH fällt damit in der Sache eher eine ökonomische Wertung unter dem Deckmantel einer normativen.

1301 So auch Ott, FG Kübler, 1997, S. 21, 39f.; Soergel/Spickhoff, 13. Aufl. 2005, Vor § 823 Rn. 32 (,,kann kaum ernsthaft bestritten werden“").

1302 Vgl. Drexl, Selbstbestimmung, 1998, S. 167 („Einfallstor“), 168 („Ökonomische Argumente im Rahmen der teleologischen Auslegung [...] begegnen solange keinen durchgreifenden Bedenken, wie sie Gegenargumente [...] nicht per se ausschließen."); Faust, Vorhersehbarkeit, 1996, S. 205ff.; Kübler, FS Steindorff, 1990, S. 687, 688 („Integration des Instrumentariums der modernen mikroökononomischen Theorie in die juristischen Begründungszusammenhänge“); Rückert/Seinecke/Laudenklos, Methodik des Zivilrechts, 3. Aufl. 2017, Rn. 1210; Paßmann, Schutzpflichtverletzungen, 2010, S. 135 (Ökonomik als ,rechtspolitische Forderung“); Erman/Schiemann, 14. Aufl. 2014, Vor $§ 823$ Rn. 15 (,ökonomische Analyse [...] kann innerhalb der teleologischen Auslegung herangezogen werden, da von der Prämisse auszugehen ist, dass Gesetzgeber eine wirtschaftlich möglichst effiziente Regelung treffen wollte“); Soergel/Spickhoff, 13. Aufl. 2005, Vor $\S 823$ Rn. 33 (,,dort [...] methodisch legitim [...], wo Wortlaut, Systematik und Entstehungsgeschichte der Norm rechtssichere Antworten ohnehin nicht ermöglichen und der Durchsetzung des Effizienzprinzips nicht entgegenstehen, wenn man also davon ausgehen darf, dass auch der gesetzegeber den Norminhalt am Effizienzprinzip orientiert (oder wenigstens keine gegenteilige Tendenz verfolgt) haben wird"); im Ansatz ähnlich wenn auch mit gewissen Einschränkungen - Eidenmüller, Effizienz, 2. Aufl. 1998, S. $452 \mathrm{ff}$.

1303 S.o., S. 33.

1304 Die Möglichkeiten des Vermieters die Wohnungsvergabe durch exzessive Preissteigerungen ineffizient zu gestalten, sind durch die jeweiligen Mietspiegel $(\S \S 558,558 \mathrm{cf}$. BGB) und die sog. ,Mietpreisbremse“ stark eingeschränkt, näher zu letzterem der durch das Mietrechtsnovellierungsgesetz (MietNovG) vom 1.6.2015 erlassene $\S 556 \mathrm{~d}$ BGB. 
Die ökonomische Analyse muss demnach nicht uneingeschränkten Vorrang genießen, sollte aber zu einer „,behutsamen Modifizierung ${ }^{\text {“1305 }}$ des Normzwecks von $\S 241$ II BGB führen. ${ }^{1306}$

cc) Zwischenergebnis: Anwendbarkeit der ökonomischen Analyse innerhalb $\S 241$ II BGB

Die ökonomische Analyse lässt sich aufgrund teleologischer Überlegungen sinnvoll bei der Ausfüllung der rechtspraktischen Funktion des $\S 241$ II BGB in der Subsumtion heranziehen.

c) Rekonstruktion des vollständigen Schuldverhältnisses zur Bestimmung der Reichweite von Vermögensschutz durch Nebenpflichten

Ein korrekt funktionierender (Ideal-)Markt führt für beide Parteien eines rechtsgeschäftlichen Schuldverhältnisses ein Haftungsausmaß herbei, welches ihren Präferenzen entspricht. ${ }^{1307}$ Das ist aber nur eine wirtschaftspolitische Forderung. ${ }^{1308}$ Realisieren lässt sich diese Forderung nur in Zusammenarbeit mit dem Rechtssystem. Dem Vertragsrecht kommt in den Augen der ökonomischen Analyse die Servicefunktion zu, Transaktionen zu erleichtern, indem durch die parteiwillenkonforme Verteilung von Risiken ein (rechtlicher) Verhaltenskodex aufgestellt wird, über dessen Einhaltung die Gerichte wachen. ${ }^{1309}$ Bestehen Lü-

1305 Begriff von Tröger, Arbeitsteilung, 2012, S. 31 (Fn. 2) m.w.N. zu ähnlich moderaten Ansätzen.

1306 Vgl. Soergel/Spickhoff, 13. Aufl. 2005, Vor $\S 823$ Rn. 32 (,am ehesten in der objektivteleologischen Auslegung zu verorten“); Taupitz, AcP 196 (1996), 114, 127 (,„,Scharnier“ für die Bedeutung der ökonomischen Analyse im Rahmen der Rechtsanwendung können durchaus die herkömmlichen Auslegungsmethoden sein.").

1307 Köndgen/von Randow, Travemünder Symposium, 1989, S. 122, 124; Schäfer/Ott, Ökonomische Analyse, 5. Aufl. 2012, S. 166f.

1308 Unberath/Cziupka, AcP 209 (2009), 37, 45 („Gedankenexperiment“).

1309 Schäfer/Ott, Ökonomische Analyse, 5. Aufl. 2012, S. 428f. („Schmiermittel der Wirtschaft“), 433 allerdings mit dem zutreffenden Hinweis, dass der Gerichtsbarkeit hier eine Gewährleistungsaufgabe zukommt, der sie aufgrund von Informationsdefiziten wohl nicht immer gerecht werden kann. Als absolute Grenze darf die Existenz einer Nebenpflicht dabei nicht dazu führen, dass die Erfüllung des Vertrags für eine Partei betriebswirtschaftlich unsinnig wird, vgl. Unberath, Vertragsverletzung, 2007, S. 157 (Fn. 52). Nur wenn der Parteiwille einmal erkennbar gegenläufig zum eigenen ökonomischen Wohl ist, so erkennt auch die ökonomische 
cken im Vertrag, so soll das Vertragsrecht „eine marktmäßige Lösung [...] simulieren“ ${ }^{1310}$ Hierfür stellt die ökonomische Analyse das Instrument der Rekonstruktion des vollständigen Vertrags - also der Lückenfüllung hinsichtlich von Fragen, welche die Parteien nicht mit wirtschaftlich vertretbarem Aufwand im Vorhinein hätten klären können ${ }^{1311}$, mit dem Maßstab der Effizienz ${ }^{1312}-$ zur Verfügung. ${ }^{1313}$

\section{aa) Modell des vollständigen Vertrags}

Ausgangspunkt des Modells vom vollständigen Vertrag ist, den hypothetischen Parteiwillen für unvorhergesehene Ereignisse in einem Vertrag deskriptiv nach-

Analyse des Rechts eine Vorrangigkeit der Privatautonomie an, R. Posner, Economic Analysis, 9. Aufl. 2014, S. 97.

1310 M.-P. Weller, Vertragstreue, 2009, S. 355; ähnlich bereits Coase, J. Law \& Econ. 3 (1960), 1, 17f.; Eidenmüller, JZ 2005, 216, 222. Tatsächlich werden sich die Parteien über eine Vielzahl von möglicherweise vertragsrelevanten Umständen keine Gedanken machen, Teichmann, JA $1984,545,545$.

1311 Coleman/Maser/Heckathorn, Economic Institutions, 1991, S. 227, 228; Fleischer, Informationsasymmetrie, 2001, S. 182f.; zur Diskussion, ob der Lückenfüllung auch sanktionierende Wirkung zukommen darf, Ayres/Gertner, Yale L.J. 99 (1989), 87, 87ff. Shavell, Economic Analysis, 2004, S. 300 (Fn. 9) weist zutreffend darauf hin, dass die Parteien eine Frage ungeregelt lassen werden, wenn die Kosten für deren Behandlung im Vertrag den (parteiübergreifenden) Schadenserwartungswert übersteigen.

1312 Das ist die Grundannahme des ,ökonomischen Vertragsmodells“, Schäfer/Ott, Ökonomische Analyse, 5. Aufl. 2012, S. 449f.; Unberath/Cziupka, AcP 209 (2009), 37, 47; ähnlich auch Neuner, FS Canaris, Bd. I, 2007, S. 901, 914 („,Vertragsakteuere handeln typischerweise nach egoistischen Motiven"). Nach der „Neuen Institutionenökonomik“ soll sich die ökonomische Analyse nicht am Begriff der Effizienz, sondern am hypothetischen Parteiwillen ausrichten, näher Tröger, Arbeitsteilung, 2012, S. 51 (Fn. 96) m.w.N. Diese Auseinandersetzung ist aber im gegenwärtigen Kontext irrelevant. Beide Parteien streben mit einem rechtsgeschäftlichen Schuldverhältnis schließlich eine Ressourcenallokation an, die aufgrund des beiderseitigen Nutzens eine Effizienzsteigerung zur Folge haben soll. Den Vertrag nun möglichst effizient durchzuführen, also mit minimalen Kosten für beide Beteiligten, entspricht aus einer ex-antePerspektive auch dem hypothetischen Parteiwillen. Damit sind aus der Perspektive des Schuldverhältnisrechts Effizienz und der hypothetische Parteiwille inhaltsgleiche Konzepte, zutreffend Tröger, Arbeitsteilung, 2012, S. 51f. Nichtsdestotrotz ist der Begriff der Effizienz hier mit Blick auf den Untersuchungsgegenstand der Arbeit der überlegene: Schließlich lässt sich das Konzept des hypothetischen Parteiwillens - anders als die Forderung nach Effizienz nicht sinnvoll auf gesetzliche und rechtsgeschäftsähnliche Schuldverhältnisse übertragen.

1313 Eidenmüller, Effizienz, 2. Aufl. 1998, S. 402f.; Kötz, FS Drobnig, 1998, S. 563, 574 (Fn. 19); Mankowski, IPRax 2003, 127, 131f.; Maultzsch, AcP 207 (2007), 530, 547; Tröger, Arbeitsteilung, 2012, S. 57f.; C. Weber, DStR 2014, 213, 217 (Fn. 49); plakativ Faust, Vorhersehbarkeit, 1996, S. 207 (Ökonomik in der Rolle ,eines Lückenbüßers, der auf den Plan tritt, wo andere normative Erwägungen zu keinem Ergebnis geführt haben"). 
zubilden. ${ }^{1314}$ Hypothese ist dabei, dass ein Vertrag durch rationale und allwissende Parteien Regelungen aller denkbaren Fragen beinhaltet und qua dieser Vollständigkeit effizient ist, weil für keine der beiden Parteien ein Anreiz besteht, die getroffenen Regelungen zu unterlaufen. ${ }^{1315}$ Die Hypothese geht davon aus, dass ein vollständiger Vertrag, der unter den vorausgesetzten Bedingungen (keine Verhandlungs- und Transaktionskosten, vollständige Information sowie Rationalität der Partein im Sinne eines homo oeconomicus) zustande gekommen ist, jedes denkbare Risiko derjenigen Partei zuweist, welche es aus ökonomischer Sicht am besten tragen kann. ${ }^{1316}$ Durch die effiziente Risikozuweisung wird so der Transaktionsnutzen und in der Folge der gesamtgesellschaftliche Mehrwert maximiert.

Weil insbesondere Verhandlungskosten eben entgegen der Hypothese in realiter sehr wohl bestehen ${ }^{1317}$, würde das Aushandeln des vollständigen Vertrags jeden Nutzengewinn der Parteien zunichte machen. ${ }^{1318}$ Aus diesem Grund wird im Streitfall der Rechtsanwendung - insbesondere der Rechtsprechung - die Aufgabe zugewiesen, den vollständigen Vertrag hinsichtlich des streitgegenständlichen Risikos nachzubilden. ${ }^{1319}$ Ökonomisch sinnvoll zu vermeidende Risiken werden dabei derjenigen Partei zugewiesen, welche den monierten Schadenseintritt am günstigsten hätte verhindern können. ${ }^{1320}$ Aus ökonomischer Sicht unvermeidbare Schäden werden derjenigen Partei zugewiesen, welche das Risiko am günstigs-

1314 Grundmann/Hoernig, X. Travemünder Symposium, 2007, S. 420, 423f.; Köndgen/von Randow, Travemünder Symposium, 1989, S. 122, 125f.; Kötz, FS Drobnig, 1998, S. 563, 574 (Fn. 19); Tröger, Arbeitsteilung, 2012, S. 227. Warum sich die Parteien die entsprechenden Fragen nicht stellen konnten als das Schuldverhältnis begründet wurde, spielt dabei keine Rolle. So kann es schließlich auch daran gelegen haben, dass das Schuldverhältnis nur rechtsgeschäftsähnlichen oder gesetzlichen Ursprungs ist und die Parteien deshalb gar keine nach $\S \S 133,157$ BGB messbaren Willenserklärungen abgegeben haben.

1315 Coleman/Maser/Heckathorn, Economic Institutions, 1991, S. 227, 227 (,fully specified contract ${ }^{\circ)}$.

1316 Hölzle, Desinformation, 2012, S. 117f. Konzis Murphy/Coleman, Philosophy of Law, 1990, S. 244f. (,In short, if negotiations are in fact costless, there is nothing to lose in specifying the rights and duties of contracting parties under any possible set of feasible conditions.").

1317 Calabresi, Economics, 1975, S. 204, 206; Unberath/Cziupka, AcP 209 (2009), 37, 49; deshalb ein „Realitätsdefizit“" des Ansatzes beklagend Drexl, Selbstbestimmung, 1998, S. 192 (Fn. 124); krit. auch Fezer, JZ 1986, 817, 820f.

1318 Murphy/Coleman, Philosophy of Law, 1990, S. 245 (,,costs of negotiation are too high”).

1319 Murphy/Coleman, Philosophy of Law, 1990, S. 245 (,,court [...] would promote efficiency by reproducing the results of a fully specified contract").

1320 Calabresi, Accidents, 1970, S. 263; s.u., S. $355 \mathrm{ff}$. 
ten hätte versichern oder einpreisen können. ${ }^{1321}$ Beide - alternativen und in einem Rangverhältnis stehenden (Schadensvermeidung vor Schadensversicherung) - Formen der Risikozuweisung bilden den Willen rationaler Marktakteure nach, weil sie die Kosten für beide Parteien zum gemeinsamen Vorteil möglichst gering halten. Würde das Risiko, einen (vermeidbaren) Schaden zu verhindern, schließlich nicht derjenigen Partei zugewiesen, welche den Schadenseintritt am günstigsten hätte verhindern können, so kommt es zu Ineffizienz. Der nunmehr Risikobelastete würde schließlich die (im Vergleich zum Gegenüber) höheren Kosten der Schadensvermeidung der Verhandlung zugrundlegen und damit würden die Kosten auch für diejenige Partei unnötig stark steigen, die augenscheinlich vom Risiko entlastet wurde. ${ }^{1322}$

Diese Nachbildung eines effizienten Parteiwillens durch Risikozuweisung nach Gesichtspunkten der (jeweils günstigsten) Schadensvermeidung oder Schadensversicherung wird in der ökonomischen Analyse als Instrument des vollständigen Vertrags bezeichnet und geschieht im Wege der Konkretisierung des dispositiven Rechts. ${ }^{1323}$ Die Modellierung des Parteiwillens nach dem Gesichtspunkt der Effizienz senkt Transaktionskosten, weil es den Parteien erlaubt, nur die zentralen Fragen (essentalia negotii) durch Willensübereinstimmung zu regeln und bezüglich des Rests auf die Anwendung des dispositiven Rechts zu vertrauen. ${ }^{1324}$ Durch Senkung der Transaktionskosten wird die Entstehung von rechtsgeschäftlichen Schuldverhältnissen befördert. Schließlich werden gleichsam die Barrieren, welche vom Abschluss eines Vertrages abhalten könnten, aufgehoben. Weil jedes rechtsgeschäftliche Schuldverhältnis im Grundsatz einen Nutzengewinn für jeden der Beteiligten darstellt ${ }^{1325}$, steigt der gesamtgesellschaftliche Wohlstand

1321 Hölzle, Desinformation, 2012, S. 122f.; s.u., S. $423 \mathrm{ff}$.

1322 Vgl. Hölzle, Desinformation, 2012, S. 121 (Fn. 373).

1323 Hölzle, Desinformation, 2012, S. 123f.; Tröger, Arbeitsteilung, 2012, S. 232f.

1324 Hölzle, Desinformation, 2012, S. 123 (,Vertrauen in Vertragsbeziehungen ersetzt vollständige Verträge"); Mankowski, IPRax 2003, 127, 131f.; Riha, Sachmängelgewährleistungsrecht, 2007, S. 36f. Schon die Existenz dispositiven Rechts hat Entlastungsfunktion, muss aber nicht immer Effizienz widerspiegeln. Führt die Anwendung einer bestimmten Norm des dispositiven Rechts nicht zu effizienten Ergebnissen, so ist es Aufgabe der ökonomischen Analyse zu überprüfen, ob dieses Ineffizienz intendiert ist oder über die Maßstäbe der Ökonomik korrigiert werden sollte, näher Schäfer/Ott, Ökonomische Analyse, 5. Aufl. 2012, S. $455 \mathrm{f}$.

1325 Sonst würden die Parteien - so die Annahme der Ökonomik auf Basis des Modells vom homo oeconomicus - das Rechtsgeschäft nicht eingehen, Köndgen/von Randow, Travemünder Symposium, 1989, S. 122, 125; Unberath, Vertragsverletzung, 2007, S. 125; vgl. auch J. Schmidt, 
annähernd linear im Verhältnis zur Anzahl der (durchgeführten) Rechtsgeschäfte. ${ }^{1326}$ Damit führt die Rekonstruktion des vollständigen Vertrags auf individueller Ebene auch zu einem gesamtgesellschaftlichen Wohlfahrtsgewinn. ${ }^{1327}$ Gleichzeitig wird das Primat des Parteiwillens im Vertrag durch die nachträgliche Modellierung mittels der ökonomischen Analyse nicht untergraben. ${ }^{1328} \mathrm{Da}$ ein tatsächlicher Wille der Parteien bei Begründung des Schuldverhältnisses zu den hier interessierenden Nebenpflichten eben gerade nicht auszumachen ist sonst kämen eben gerade keine Pflichten nach § 241 II BGB, sondern ausschließlich solche nach $\S 241$ I BGB in Betracht -, kommt es allein auf den hypothetischen Willen an. Es entspricht aber im absoluten Regelfall dem hypothetischen Willen der Parteien, den Nutzen des Schuldverhältnisses für beide Seiten zu maximieren. ${ }^{1329}$ Genau dies bezweckt die Rekonstruktion des vollständigen Vertrags.

(1) Zur Vereinbarkeit des Kriteriums der Effizienz mit dem Parteiwillen in rechtsgeschäftlichen Schuldverhältnissen

Der individuelle Nutzen, welchen jede Partei mit der Durchführung des Schuldverhältnisses anstrebt, soll durch Berücksichtigung des Effizienzkriteriums bei der Auslegung des dispositiven Rechts maximiert werden. Handelt eine Partei hingegen willentlich gegenläufig zu ihrem objektiven, ökonomischen Interesse,

Vertragsfreiheit, 1985, S. 196, der - systemisch grundlegend - der Vertragsfreiheit ,die Funktion zu[weist], die Nutzenvorstellungen der Individuen am Markt zu artikulieren, damit sie durch den Prozeß der Marktpreisbildung mit den Nutzenvorstellungen der anderen Individuen am Markt koordiniert werden können".

1326 Vgl. Faust, Vorhersehbarkeit, 1996, S. 209f.

1327 So auch Tröger, Arbeitsteilung, 2012, S. 232.

1328 S.o., S. 348ff.; vgl. auch Tröger, Arbeitsteilung, 2012, S. 233 (Fn. 86) m.w.N.

1329 So auch Faust, Vorhersehbarkeit, 1996, S. 206f.; Fleischer, Schuldrechtsreform, 2001, S. 243, 256; Kötz, FS Drobnig, 1998, S. 563, 574; Tröger, Arbeitsteilung, 2012, S. 47 ff. (für eine Berücksichtigung der ökonomischen Analyse im Schuldverhältnisrecht aus ,funktionaler Perspektive“), 233 (,Koinzidenz" zwischen dem hypothetischen Parteiwillen und den Ansätzen der ökonomischen Analyse des Rechts); etwas verhaltener Neuner, FS Canaris, Bd. I, 2007, S. 901, 916 (,Vertragsergänzung“ nach $\S 242$ BGB schließt „Effizienzgesichtspunkte“ mit ein); Salje, VII. Travemünder Symposium, 2001, S. 234, 239 (,nicht von vorherein ausgeschlossen“); Unberath, Vertragsverletzung, 2007, S. 143 („eingeschränkte normative Relevanz" der Ökonomik im Vertragsrecht ,vermittelt durch die Interessen der Vertragsparteien“). 
so räumt auch die Ökonomie diesem Willen Vorrang gegenüber der Forderung nach Effizienz ein. Das Primat der Selbstbestimmung gilt schließlich auch bezüglich der Herabstufung des eigenen Nutzens. ${ }^{1330}$

Beispiel 6 Indem der Steuerberater im Haltefristfall ${ }^{1331}$ bei erkennbar hoher wirtschaftlicher Relevanz seines Handelns und einer hohen Inanspruchnahme von Vertrauen auf die Frage des Kunden geantwortet hat, zeigt er nach Ansicht der Rechtsprechung Rechtsbindungswillen für die Begründung eines Auskunftsschuldverhältnisses. ${ }^{1332}$ Die einseitige Haftung des Steuerberaters ist für ihn ökonomisch nachteilig. Er muss die Informationskosten schultern, die er benötigt, um seine Leistungspflicht zu erfüllen. Hierfür erhält er keine Vergütung. Gleichzeitig hat er nach den von der Rechtsprechung konturierten - und hier nicht näher hinterfragten - Kriterien Rechtsbindungswillen gezeigt. Damit ist sein Wille auf die Begründung des Schuldverhältnisses gerichtet. Ein objektiver ökonomischer Nutzen muss dann nicht ermittelt werden. Das Primat der Privatautonomie kommt - ungehindert von der Ökonomie zur Anwendung

Das Vorgehen lässt sich deshalb mit dem Primat des Parteiwillens im Vertragsrecht vereinen. ${ }^{1333}$ Auch ein kursorischer Ergebnisvergleich belegt dies: Wenn die ökonomische Analyse bei einem ex ante ineffizienten ${ }^{1334}$ rechtsgeschäftlichen Schuldverhältnis für einen korrigierenden Eingriff plädiert, entspricht dies grundsätzlich der Handhabung der Privatautonomie durch die herrschende Meinung. ${ }^{1335}$

1330 Objektiv „wenig“ ist dem Einzelnen dann eben „viel“ wert, näher Grundmann/Hoernig, X. Travemünder Symposium, 2007, S. 420, 423f.; Schäfer/Ott, Ökonomische Analyse, 5. Aufl. 2012, S. 451.

1331 S.o., S. 26.

1332 Vgl. zum Maßstab für ein Auskunftsschuldverhältnis BGH, Urt. v. 29.10.1952 - II ZR 283/51, Rn. 7 (BGHZ 7, 371, 374); Bamberger-Roth/Fischer, 3. Aufl. 2012, § 675 Rn. 83 m.w.N.

1333 So auch Schäfer/Ott, Ökonomische Analyse, 5. Aufl. 2012, S. 451; Tröger, Arbeitsteilung, 2012, S. 220f.; mit Blick auf die Leistungspflichten krit. Rödl, Gerechtigkeit, 2015, S. 279ff.

1334 Also einem Schuldverhältnis, was nicht dem „Pareto“-Kriterium genügt.

1335 Tröger, Arbeitsteilung, 2012, S. 219 (Fn. 14) m.w.N. 
In einem Fall zur bürgerlich-rechtlichen Prospekthaftung für außerhalb der Börse gehandelte Aktien bejahte der BGH eine Verhaltenspflichtverletzung des Prospektverantwortlichen und damit im Kern eine Informationspflicht nach dem Abbild des § 241 II $B G B$, weil falsche Angaben über die Anzahl und Bezüge der Vorstandsmitglieder der Gesellschaft gemacht worden waren. ${ }^{1336}$ In der Sache führt der BGH die Informationspflicht hier auf das Recht zur vertraglichen Dispositionsfreiheit, mithin die Vertragsfreiheit, zurück. ${ }^{1337}$ Die ökonomische Analyse führt die Prospekthaftung auf die Informationskostenasymmetrie zwischen Anleger und Emittent und die korrespondierende Zahlungsbereitschaft des Anlegers für eine sorgfältige Prospekterstellung zurück. ${ }^{1338}$

1336 BGH, Urt. v. 5.7. 1993 - II ZR 194/92, Rn. 3, 6, 9 (BGHZ 123, 106, 108ff.). Der Wertverfall der Anleihe beruhte im Ergebnis auf einer verweigerten Zulassung der Aktie zum Handel an der Börse und nicht auf der geltend gemachten Falschinformation. Dennoch bejahte der BGH einen „Rechtswidrigkeitszusammenhang“, weil das „Recht [des Anlegers] zur Selbstbestimmung über die Verwendung [seines] Vermögens“ beeinträchtigt sei, BGH, Urt. v. 5.7. 1993 II ZR 194/92, Rn. 9 (BGHZ 123, 106, 113).

1337 So auch Rehm, Aufklärungspflichten, 2003, S. 119. Nur eine entsprechende Nebenpflicht zur vollumfänglichen Information konnte in den Augen des BGH die Privatautonomie des Gläubigers gewährleisten. Schutzgut einer solchen Nebenpflicht müssen im Übrigen - wie später auch in § 241 II BGB anerkannt - nicht zwingend die Vermögensinteressen des Gläubigers sein, sondern kann - wie hier - auch das Dispositionsinteresse des Gläubigers sein kann. Eine Anknüpfung an ersteres hätte dem Anleger schließlich die Geltendmachung eines Schadens verwehrt, weil die Aufklärungspflichtverletzung nicht kausal für die Wertminderung der Anlage war, so überzeugend Rehm, Aufklärungspflichten, 2003, S. 119. Die Dispositionsfreiheit lässt sich indes auch als Teil aller „,vermögenswerten Interesse“ des Gläubigers deuten, s.o., S. $91 \mathrm{ff}$. Dann wäre eine Haftung dem Grunde nach ohne weiteres zu bejahen gewesen.

1338 Schäfer/Ott, Ökonomische Analyse, 5. Aufl. 2012, S. 709. Ohne konkrete Informationen über die Anlage müsste jedes Anleihegeschäft einzeln ausverhandelt werden. Das erhöht die Transaktionskosten enorm und führt dazu, dass viele Geschäfte entweder gar nicht oder auf völlig unzureichender Informationsbasis geschlossen werden. Deshalb ist der Anleiheprospekt für beide Seiten vorteilhaft. Der Emittent vergrößert damit seinen Absatzmarkt und kann seine Anleihe zu einem angemessenen Preis an den Mann bringen. Er müsste schließlich deutlich Abschläge befürchten, wenn die Anleger keine Anhaltspunkte hätten, das Potential seiner Anlage zu schätzen. Der Anleger kann wiederum eine Entscheidung treffen, die seinen (Risiko-) Präferenzen angemessen ist. Weil die Erstellung des Prospekts für den Emittenten Kosten verursacht, ist dieser daran interessiert, diese an den Anleger weiterzureichen. Weil der Anleger selbst viel höhere Informationsbeschaffungskosten schultern müsste, um an die im Prospekt enthaltenen Informationen zu kommen und eine präferenzadäquate Entscheidung zu fällen, ist er bereit anteilig für die Prospekterstellung zu bezahlen, vgl. Schäfer/Ott, Ökonomische Analyse, 5. Aufl. 2012, S. 709. Diese Hypothese stützt sich auf die zuvor dargelegten Gründe. Die Bezahlung erfolgt, indem der Anleger eine Anleihe erwirbt, deren Preis um die anteilige Um- 
Im Ergebnis kommen beide Ansätze zum gleichen Ergebnis. Das Interessante ist dabei die unterschiedliche Perspektive der Ansätze: Der BGH betrachtet den Fall aus der Perspektive der Vertragsfreiheit. Selbige wäre seiner Ansicht nach im konkreten Fall gefährdet, würde man nicht von einer Informationspflicht ausgehen. Die ökonomische Analyse sieht hingegen die Effizienz des einzelnen Rechtsgeschäfts gefährdet, welche wiederum eine Gefahr für das effiziente Funktionieren des Kapitalmarktes insgesamt darstellt. ${ }^{1339}$ Hieraus lässt sich schließen, dass die Forderung nach Effizienz in rechtsgeschäftlichen Schuldverhältnissen zumindest bei Informationspflichten lediglich die Kehrseite der Vertragsfreiheit darstellt. ${ }^{1340}$

lage der Prospekterstellungskosten erhöht ist. Im Verhältnis zum typisierten Emittenten ist also der typisierte Anleger die „risikoaverse“ Partei, welche lieber die Kosten für die Information schultert, als eine Anleihe ohne nähere Information zu einem diskontierten Preis zu erwerben. Die Frage, ob eine Information für die präferenzadäquate Entscheidung des Anlegers von Bedeutung ist, muss dabei objektiv beantwortet werden. Nur so kann die ökonomische Analyse vorhersehbare Maßstäbe gewährleisten. Die Information über die Bezüge der Unternehmensleitung ist dabei zum einen mit Blick auf die laufenden Kosten des Unternehmens relevant. Zum anderen kann die relative Höhe im Verhältnis zum Umsatz darüber Auskunft geben, ob die Geschäftsleitung angemessen bezahlt ist und das Unternehmen demnach solide wirtschaftet, ähnlich argumentierte der Kläger, vgl. BGH, Urt. v. 5.7. 1993 - II ZR 194/92, Rn. 11 a.E. (BGHZ 123, 106, 115). Die Information ist demnach keineswegs so unerheblich, dass der typische Anleger für ihre Weitergabe nicht implizit in Form eines um anteilige Prospekterstellungskosten erhöhten Ausgabepreises der Anleihe bezahlen würde. Demnach ist auch mit der ökonomischen Analyse eine Informationspflicht zu fordern.

1339 Vgl. Schäfer, AcP 202 (2002), 808, 814; MüKo-BGB/Wagner, 7. Aufl. 2017, § 826 Rn. 15.

1340 Ähnlich auch Tröger, Arbeitsteilung, 2012, S. 220 (Forderung nach Austauscheffizienz „kongeniales Äquivalent" zur Austauschgerechtigkeit); zu den Begriffen der Austausch- und Verteilungsgerechtigkeit grundlegend Aristoteles, Grumach/Flashar (Hrsg.), Bd. 6, Nikomachische Ethik, 10. Aufl. 1999, Buch V, S. 100ff. („Die Gerechtigkeit als Teilerscheinung und das entsprechende Gerechte weist zwei Grundformen auf: die eine (A) ist wirksam bei der Verteilung von öffentlichen Anerkennungen, von Geld und sonstigen Werten, die den Bürgern eines geordneten Gemeinwesens zustehen. [...] Eine zweite (B) Grundform ist die, welche dafür sorgt, daß die vertraglichen Beziehungen von Mensch zu Mensch rechtens sind."). Eine besondere soziale Funktion soll der Vertrag - als Urform des Schuldverhältnisses - hingegen nicht erfüllen, ähnlich auch Faust, Vorhersehbarkeit, 1996, S. 206f.; Ott, FG Kübler, 1997, S. 21, 42. Es wäre auch ineffizient, mittels des mühsamen Umwegs des Schuldverhältnisrechts auf die Verteilungsgerechtigkeit hinzuwirken, wenn dem Gesetzgeber mit staatlicher Intervention ein viel direkteres Mittel zur Verfügung steht, vgl. Schäfer, Travemünder Symposium, 1989, S. 1, 14; Schäfer/Ott, Ökonomische Analyse, 5. Aufl. 2012, S. 490. Damit können zumindest 
Im Ergebnis lässt sich das Kriterium der Effizienz daher auch im Geltungsbereich der Privatautonomie ohne Systembruch anwenden.

\section{(2) Rekonstruktion des vollständigen Schuldverhältnisses}

Mit einigen Modifikationen ${ }^{1341}$ ist die Ermittlung des effizienten Risikoträgers durch die Modellierung des vollständigen Vertrags auch innerhalb gesetzlicher und rechtsgeschäftsähnlicher Schuldverhältnisse sinnvoll (Rekonstruktion des vollständigen Schuldverhältnisses). Unter Berücksichtigung der grundsätzlichen Funktion des Schuldrechts - Ermöglichung und Erleichterung von Gütertransfer $^{1342}$ - spricht nichts dagegen, alle Schuldverhältnisse unter effizienter Zuordnung von Ressourcen abzuwickeln: In gesetzlichen Schuldverhältnissen wird der Akt des Versprechens einer Leistung durch die gesetzliche Anordnung der (Leistungs-)Schuld ersetzt. ${ }^{1343}$ Auch hier gilt es, das geforderte Ergebnis möglichst kosteneffizient zu erreichen. In rechtsgeschäftsähnlichen Schuldverhältnissen gibt es regelmäßig keine Leistungspflichten. Es kommen aber Nebenpflichten als Schuld in Betracht. ${ }^{1344}$ Damit wird klar, dass sich der Zweck eines Schuldverhältnisses auch auf Nebenpflichten beschränken kann. ${ }^{1345}$ Auch dieser Zweck -

solche Bedenken gegen die ökonomische Analyse nicht verfangen, die darauf abstellen, dass Effizienz keinen Spielraum für soziale Gerechtigkeitserwägungen lässt, s. auch zum möglichen Verständnis von Informationspflichten als ökonomisches ,social engineering“ Faust/ Grigoleit, Verbraucher-acquis, 2011, S. 193, 194 („ökonomische Legitimierung von Aufklärungspflichten korrespondiert mit dem sozialpolitischen Desiderat, Ungleichgewichtslagen zu beseitigen").

1341 Insbesondere kann außerhalb rechtsgeschäftlicher Schuldverhältnisse nicht auf den Parteiwillen oder eine „Austauschäquivalenz“ als absolute Grenze abgestellt werden.

1342 Bydlinski, Prinzipien, 1996, S. $172 \mathrm{f}$.

1343 Auch dies geschieht aber mit Blick auf eine verbesserte Ressourcenallokation: Ohne die $\S \S 812 \mathrm{ff}$., $823 \mathrm{ff}$. BGB wäre der Schutz eigener Rechtsgüter vor rechtswidriger Beeinträchtigung oder ungerechtfertigter Bereicherung durch einen Dritten erheblich entwertet. Ressourcen wären dann nicht bestmöglich verteilt, sondern würden sich in den Händen derer ansammeln, die besonders „,dreist“, ,geschäftsfeindlich“ oder gar deliktisch agieren würden, zur Marktbezogenheit des Güterschutzes bereits J. Schmidt, GS Schultz, 1987, S. 341, 344 (Fn. 9).

1344 Vgl. die $\S \S 311$ II, III, 241 II BGB. Dass Nebenpflichten auch rechtstatsächlich geschuldet sein können, wurde bereits dargelegt, s.o., S. 146ff.

1345 Dass der Zweck eines Schuldverhältnisses mit Leistungspflichten dann zumindest die Nebenpflichten mitumfasst, ist die logische Konsequenz. 
der gegenseitige Integritätsschutz in den sachlichen Grenzen des Schuldverhältnisses - ist möglichst kosteneffizient zu erreichen. ${ }^{1346}$

\section{(3) Risiken bei einer Modellierung des Parteiwillens}

Die Anwendung des Modells vom vollständigen Vertrag auf Nebenpflichten bedeutet in concreto, den hypothetischen Parteiwillen für Eventualitäten nachzubilden. Ist das Ergebnis der Modellierung eine schuldverhältnisbedingte Nebenpflicht, so besteht zunächst einmal das Risiko, dass das dies nicht den Parteivorstellungen im Einzelfall entspricht. ${ }^{1347}$ Dann müssten die Parteien das Ergebnis des dispositiven Rechts - die Nebenpflicht - abbedingen. Hierbei entstünden zusätzliche Transaktionskosten, deren Reduktion ausdrücklich erklärtes Ziel der Rekonstruktion des vollständigen Vertrags ist. ${ }^{1348}$ Es ist deshalb von zentraler Bedeutung den individuell erkennbaren Parteiwillen sowie den Kontext des

1346 Aus der Übertragbarkeit des Begriffes auf alle Schuldverhältnisse folgt, dass der hypothetische Parteiwille im hiesigen Kontext letztlich mit der Anwendung des Effizienzkriteriums identisch ist, ähnlich auch Tröger, Arbeitsteilung, 2012, S. 51f. Der hypothetische Parteiwille ist nur ein Konstrukt, um die Forderung nach Effizienz innerhalb rechtsgeschäftlicher Schuldverhältnisse möglichst vereinbar mit dem Primat des Parteiwillens zu halten. Ein Vorteil des hypothetischen Parteiwillens gegenüber dem Effizienzbegriff könnte sein, dass ersterer innerhalb rechtsgeschäftlicher Schuldverhältnisse die Umstände des Einzelfalls besser in die Prüfung integrieren kann. Effizienz lässt sich aber ebenfalls nicht gegen den expliziten oder konkludent ermittelten Willen der Parteien erreichen, vgl. Grundmann/Hoernig, X. Travemünder Symposium, 2007, S. 420, 423f.

1347 Näher Tröger, Arbeitsteilung, 2012, S. 234; Unberath/Cziupka, AcP 209 (2009), 37, 52ff.

1348 Um diesen Widerspruch zu vermeiden, können auch die Abbedingungskosten für das dispositive Recht möglichst gering gehalten werden, hierzu Tröger, Arbeitsteilung, 2012, S. $235 \mathrm{f}$. Dies kann zum einen dadurch geschehen, dass das Ergebnis der Modellierung der Mehrheit der potentiellen Parteien zusagt, Eidenmüller, JZ 2005, 216, 222; Unberath/Cziupka, AcP 209 (2009), 37, 54. Zum anderen kann es genügen, die Modellierung auf die Minderheit potentieller Parteien zuzuschneiden, sofern die Mehrheit eine entsprechende Nebenpflicht besonders günstig abbedingen könnte, Ayres/Gertner, Yale L.J. 99 (1989), 87, 93; Unberath/Cziupka, AcP 209 (2009), 37, 54. Die zweite Alternative wird im hiesigen Kontext nur selten einen Ausweg darstellen, weil sich Nebenpflichten faktisch nur schwer ausschließen lassen, s.o., S. 204ff.; überdies findet E. Posner, Fla. St. U. L. Rev. 33 (2006), 563, 585ff. in einer empirischen Analyse keinen einzigen Fall, in dem (US-amerikanische) Gerichte eine von der ,,majoritarian default rule" abweichende Regelung annehmen wollten. Widersprüche des dispositiven Rechts mit dem individuellen Parteiwillen sollten allerdings bereits auf unterster Stufe und damit bei der Frage zu welchem Ergebnis das dispositive Recht überhaupt kommt - aufgelöst werden. Eine Optimierung auf der Ebene der Abbedingungskosten ist demgegenüber zweitrangig. 
Schuldverhältnisses bereits bei der Modellierung zu berücksichtigen. ${ }^{1349}$ Auch wenn die Rekonstruktion des vollständigen Vertrags als Instrument der Rechtsanwendung ein theoretisches Modell darstellt, darf demnach keine rein abstrakte Modellierung nach risikozuweisenden Kriterien vorgenommen werden. Vielmehr ist bei rechtsgeschäftlichen Schuldverhältnissen der bei Vertragsschluss erkennbare Gestaltungswille zu berücksichtigen. ${ }^{1350}$

Ganz allgemein wird die Heranziehung des hypothetischen Parteiwillens für die nähere Inhaltsbestimmung eines Schuldverhältnisses aus der herkömmlichrechtswissenschaftlichen Perspektive kritisiert, weil aufgrund der Schwammigkeit des Maßstabs stets der Einfall von Billigkeitserwägungen droht. ${ }^{1351}$ Weil die ökonomische Analyse für die Rekonstruktion des vollständigen Vertrags aber gerade handhabbare, konkrete sowie justiziable Maßstäbe für die Bestimmung des hypothetischen Parteiwillens liefert, kann dieser Gefahr hier bedenkenlos begegnet werden.

1349 Überzeugend Tröger, Arbeitsteilung, 2012, S. 236f.

1350 Bei rechtsgeschäftsähnlichen Schuldverhältnissen lässt sich auf den von den Parteien mit der Geschäftsanbahnung verfolgten Zweck abstellen. Das Schuldverhältnis beruht hier zwar nicht auf einem rechtsgeschäftlichen, aber doch zumindest auf einem geschäftlichen Moment, vgl. § 311 II Nr. 3 BGB. Bei gesetzlichen Schuldverhältnissen entsteht das Schuldverhältnis durch Anordnung des Gesetzgebers. Damit fehlt es hier an jeglichem privatautonomen Gestaltungswillen. Für die Ermittlung des konkreten Kontextes des Schuldverhältnisses könnte man zunächst eine vertragliche Übereinkunft zwischen den Parteien fingieren und diesen hypothetischen Parteiwillen als Maßstab nehmen. Bei einem gesetzlichen Schuldverhältnis aus $\S \S 823$ I, 249 I BGB oder $\S \S 812$ I 1 Alt. 2, 818 I BGB schuldet die eine Partei der anderen eine Leistung, die andere schuldet hingegen keine (synallagmatisch verknüpfte) Gegenleistung. Das ist aus vertraglicher Perspektive eine Schenkung, mithin ein unentgeltliches Schuldverhältnis. Der in einer vertraglichen Haftungsmilderung (z.B. § 521 BGB) zum Ausdruck kommende Gedanke, dass der Schuldner dem Gläubiger ,einen Gefallen“ tut und deshalb nicht übermäßig verpflichtet werden sollte, passt jedoch nicht auf diese Restitutionsschuldverhältnisse. Man kann hier also nur auf den gesetzlichen Zweck des Schuldverhältnisses abstellen. All diese Gedanken dienen letztlich dazu, eine mittels einer abstrakten Risikoverteilungserwägung hergeleiteten Nebenpflicht mit Blick auf die konkrete Zielsetzung des Schuldverhältnisses im Einzelfall $\mathrm{zu}$ begrenzen. Im hier vertretenen, doppelfunktionalen Ansatz sind das Fragen der schuldverhältnisspezifischen Funktion einer Nebenpflicht, s.u., S. 529ff.

1351 Vgl Medicus, FS Flume, Bd. I, 1978, S. 629, 638f. 
(4) Zwischenergebnis: Anwendbarkeit des Modells der Rekonstruktion des vollständigen Schuldverhältnisses auf Nebenpflichten

Die Reichweite des Schutzes vermögenswerter Interessen durch Nebenpflichten kann demnach im Folgenden mit den Kriterien der Rekonstruktion des vollständigen Schuldverhältnisses bestimmt werden.

bb) Primäre Haftung des cheapest cost avoider

Grundsätzlich sollte immer diejenige Partei haften, die den Schaden am günstigsten hätte verhindern können. ${ }^{1352}$ Diese wird in der Terminologie der ökonomischen Analyse des Rechts cheapest cost avoider genannt. ${ }^{1353}$ Voraussetzung ist, dass die Schadensvermeidungskosten unterhalb des Erwartungswerts des Schadens bleiben. Die Wahrscheinlichkeit des Schadenseintritts bei unterlassenen Anstrengungen zur Schadensvermeidung multipliziert mit der erwarteten Schadenshöhe ergibt den Schadenserwartungswert. Ist dieser Wert geringer als die Schadensvermeidungskosten, so wäre es für die Gesellschaft als Ganzes günstiger, es auf den Schadenseintritt ankommen zu lassen. Entweder ist dann nämlich

1352 Calabresi, Accidents, 1970, S. 135ff. (,pure market approach to primary accident cost avoidance"); Kötz, Travemünder Symposium, 1989, S. 189, 195; Schäfer/Ott, Ökonomische Analyse, 5. Aufl. 2012, S. 436; anschaulich Kötz, FS Drobnig, 1998, S. 563 , 574 (Fn. 21: „Verschwendung von Ressourcen [...], wenn dem Käufer ein Risiko aufgebürdet würde, das abzuwenden ihn viel und den Händler wenig Geld kostet").

1353 Faust, Vorhersehbarkeit, 1996, S. 214f.; Grundmann/Hoernig, X. Travemünder Symposium, 2007, S. 420, 427; M. Müller/Hempel, AcP 205 (2005), 246, 249. Dabei wird der Begriff nicht nur im Kontext volkswirtschaftlicher Effizienz gebraucht: Coleman, Ariz. L. Rev. 37 (1995), 15, 29 sieht den cheapest cost avoider beispielsweise unter bestimmten Voraussetzungen als haftungszuweisenden Begriff im Dienste kompensatorischer Gerechtigkeit. Auch in der rechtswissenschaftlichen Literatur finden sich ähnliche Ansätze: So befürwortet beispielsweise Tröger, Arbeitsteilung, 2012, S. 226 grundsätzlich eine Risikozuweisung an den ,low-cost risk

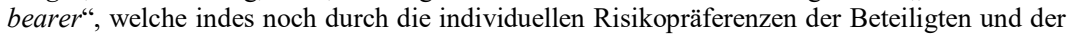
Möglichkeit einer Fremd- oder Eigenversicherung modifiziert werden kann. Er fasst damit alle haftungszuweisenden Kriterien der Rekonstruktion des vollständigen Vertrags in einem Begriff zusammen. Das erhöht zwar die Flexibilität, lässt aber die Aussagekraft der einzelnen Kriterien sinken. Schließlich ist nicht mehr klar, in welchem Hierarchieverhältnis die einzelnen Kriterien zueinander stehen; explizit auf den cheapest cost avoider als sinnvollen Risikoverteilungsmaßstab verweisend Faust, Vorhersehbarkeit, 1996, S. 214f.; Faust, Oxford Handbook, 2006, S. 837, 853; Fleischer, Schuldrechtsreform, 2001, S. 243, 263 (,cheapestcost-avoider-Postulat"); Hopt, AcP 183 (1983), 608, 654; Michael Lehmann, Vertragsanbahnung, 1981, S. 320; Taupitz, AcP 196 (1996), 114, 160f.; Thole, AcP 209 (2009), 498, 532f.; Unberath/Cziupka, AcP 209 (2009), 37, 46, 53. 
der erwartete Schaden sehr gering, oder der Eintritt des Schaden ohnehin sehr unwahrscheinlich oder schließlich die Kosten für die Schadensvermeidung ganz besonders hoch.

Als pragmatischer Weg Risiken zuzuweisen, kann der Ansatz des cheapest cost avoider sinnvolle Ergebnisse präjudizieren, für welche die rechtswissenschaftliche Problemanalyse deutlich mehr Aufwand betreiben muss.

Beispiel 32 Im Krankenbettfall ${ }^{1354}$ hat die Rechtsprechung letztlich den cheapest cost avoider herausgefunden. ${ }^{1355}$ Denn cheapest cost avoider ist der Käufer nur solange, wie er Ursachen aus der eigenen Sphäre als Schadensursache eliminieren kann. ${ }^{1356}$ Zudem sind die Schadensvermeidungskosten geringer als der Schadenserwartungswert. ${ }^{1357}$ Der Schaden liegt in den Kosten, die dem Gläubiger dadurch verursacht werden, dass er eine Nacherfüllung in die We-

1354 S.o., S. 255.

1355 So auch Thole, AcP 209 (2009), 498, 532.

1356 Er muss dabei keineswegs den Mangel ausfindig machen, Thole, AcP 209 (2009), 498, 539f. Geht es um Fehlerursachen außerhalb der Sphäre des Käufers, so wird der Verkäufer cheapest cost avoider hinsichtlich der Ermittlung der Mangelherkunft. Schließlich hat letzterer grundsätzlich höhere Sachkenntnis vom verkauften Gegenstand und der Historie der Herstellung oder des Ankaufs vom Hersteller. Der BGH hat die Nebenpflicht aber explizit von ,die Kaufsache betreffende[n] Fachkenntnisse[n]“ abgekoppelt, BGH, Urt. v. 23.1.2008 - VIII ZR 246/06, Rn. 13

1357 Es handelt sich hier nicht um eine praktisch unvermeidbare Schädigung oder die Realisierung eines völlig unkontrollierbaren Risikos. Wenn der Schuldner die hauseigenen Ursachen für den Fehler vor Benachrichtigung des Gläubigers ausschließt, entstehen keine besonders hohen Kosten. Zudem kann er diese Kosten ausweislich der Regel des § 439 II BGB im Falle eines tatsächlich bestehenden Nacherfüllungsanspruchs vom Verkäufer ersetzt verlangen, vgl. nur Bamberger-Roth/Faust, 3. Aufl. 2012, § 439 Rn. 22. Unterlässt der Käufer diese Evidenzkontrolle, so ist es durchaus wahrscheinlich, dass der Verkäufer umsonst zur Mangelprüfung anreist. Viele vermeintliche Mängel einer Sache sind schließlich auf Fehlbedienungen, Anschlussfehler, etc. zurückzuführen. Die hierbei entstehenden Kosten sind typischerweise höher als die Kosten des Käufers für die Evidenzkontrolle. Schließlich ist der Käufer der Sache meistens näher als der Verkäufer. Zudem muss er nur Ursachen aus der eigenen Sphäre (mit der verkehrserforderlichen Sorgfalt) ausschließen. Das erfordert eine geringere zeitliche Investition als die umfassende Fehlersuche, welche der Verkäufer betreiben wird. Damit ist der Schadenserwartungswert typischerweise unter den Schadensvermeidungskosten. Man merkt aber, dass sich diese Voraussetzung aufgrund des Mangels belastbarer Datensätze bisweilen nur schwammig feststellen lässt. Sie macht einige Annahmen erforderlich, die sich aus Zeitgründen - zumindest in der gerichtlichen Subsumtion - maximal populärwissenschaftlich untermauern lassen. 
ge leitet. ${ }^{1358}$ Interessant ist dabei die unterschiedliche Perspektive der beiden Herangehensweisen mit Blick auf das identische Ergebnis: Während die Rechtsprechung die Nebenpflicht letztlich auf eine komplizierte Abwägung unter Berücksichtigung von Treu und Glauben stützt, käme die ökonomische Analyse hier zur Nebenpflicht über das deutlich simplere Kriterium des cheapest cost avoider.

\section{(1) Vorgang der Risikozuweisung}

Der Begriff des cheapest cost avoider will Schadensrisiken zuweisen. Anders als bei der Verletzung einer Leistungspflicht lässt sich die klare Trennung von Pflichtverletzung und Schaden bei Nebenpflichten aber nicht immer aufrechterhalten. Die Voraussetzungen gehen mitunter ineinander über, weil die Nebenpflicht häufig nur Vorwand dafür ist, einen bestimmten Posten für ersatzfähig zu erklären. Damit ist in Fällen, in denen Nebenpflichten einen Rolle spielen, häufig gar kein klarer Schaden erkennbar, der in der Folge über das Kriterium des cheapest cost avoider zugewiesen werden könnte. Für die Konturierung eines vermögenswerten Interesses, welches durch die Nebenpflicht geschützt werden soll, ist die Rechtswissenschaft mit ihren wertungsoffenen Kriterien im ersten Zugriff besser geeignet.

Beispiel 7 Im Mietwohnungsfall ${ }^{1359}$ lag der Schaden in den Kosten für das Weißeln der bemalten Wände. Diesen Schaden hätte der Mieter am kostengünstigsten verhindern können, wenn er die Wände gar nicht erst bemalt hätte. Dieses Ergebnis stünde aber in Widerspruch zum geltenden Recht. Er hatte schließlich das vertragliche Recht die Wohnung während der Mietdauer nach seinem Belieben zu gestalten, vgl. $\$ 538$ BGB. Alternativ hätte der Mieter die Wandfarbe vor Ablauf der Mietdauer wieder in Weiß verwandeln

1358 Die Wahrscheinlichkeit, dass er diese Kosten umsonst aufwendet, wenn der Käufer noch nicht mögliche Schadensursachen aus der eigenen Sphäre eliminiert hat, ist relativ hoch. Schließlich kann bis dahin noch nicht mit überwiegender Wahrscheinlichkeit davon ausgegangen werden, dass der Mangel aus der Sphäre des Verkäufers stammt.

1359 S.o., S. 33. 
können. Dann würde man zumindest seinem aus $\S 538$ BGB folgenden Nutzungsrecht Respekt zollen. Zu diesem Zeitpunkt ist er aber nicht mehr zwingend cheapest cost avoider. Die Kosten, die Wand wieder weiß streichen zu lassen, sind für ihn schließlich nicht niedriger als für den Vermieter. ${ }^{1360}$ Im Fall galt es deshalb das vermögenswerte Interesse des Vermieters herauszuarbeiten, nicht durch Selbstverwirklichung des Mieters in den Möglichkeiten zur Weitervermietung beeinträchtigt zu werden. Hierbei ist der Begriff des cheapest cost avoider nicht nicht ohne Weiteres ${ }^{1361}$ hilfreich. Schließlich sind beliebig viele Fälle denkbar, in denen der Vermieter die Kosten dafür, eine Veränderung, Umgestaltung oder sonstige, vermeintliche Verschönerung des Mieters wieder rückgängig machen zu lassen, vom Mieter ersetzt verlangen möchte. Wendet man das Kriterium bedenkenlos an, so wäre in jedem Fall - völlig unabhängig von den Umständen des Einzelfalls - eine Haftung des Mieters aus $\$ \$ 280$ I, 241 II BGB zu bejahen. Schließlich wäre stets er es gewesen, der den Schaden mit den geringsten Kosten hätte verhindern können, indem er die Wohnung unverändert belassen hätte. Die Vorschrift des $\S 538$ BGB drohte dann ausgehöhlt zu werden. Im Ergebnis kommt es deshalb auf die Schutzwürdigkeit des Interesses des Vermieters an, das Objekt in einem Zustand zu erhalten, in welchem eine Weitervermietung bereits möglich ist. ${ }^{1362}$ Die Reichweite dieser Schutzwürdigkeit lässt sich vermeintlich besser durch eine rechtswissenschaftliche Abwägung bestimmen. Der Begriff des cheapest cost avoider scheint hierfür zu rigide.

1360 Der Mieter könnte die Wand natürlich kostengünstig selber weißeln. Diese Möglichkeit steht aber theoretisch auch dem Vermieter offen, sodass sich hieraus kein Kostenvorteil des Mieters ergibt.

1361 Sieht man einmal von der Möglichkeit ab, den hier drohenden Ressourcenschaden (näher s.u., S. $369 \mathrm{ff}$. sowie 0, S. $375 \mathrm{ff}$.) als Schaden zu erfassen. Diesen wiederum kann man dann über die Figur des cheapest cost avoider dem Mieter zuweisen. Um die Rekonstruktion des vollständigen Schuldverhältnisses also als universales Subsumtionsinstrument für den Schutz vermögenswerter Interessen durch $\S 241 \mathrm{II}$ BGB zu positionieren, muss der Begriff der ,kostengünstigsten Schadensvermeidung" (cheapest cost avoider) also auch einen möglichen Ressourcenschaden erfassen.

1362 Vgl. MüKo-BGB/Bieber, 7. Aufl. 2016, § 538 Rn. 4. 
Mit dem Ansatz des cheapest cost avoider lässt sich ein Schadensrisiko aber rechtsfolgenorientiert zuweisen. Die Nebenpflicht ist dann schlicht als diejenige Verhaltensanforderung abzuleiten, welche den Schadenseintritt verhindert hätte. Damit wird die Nebenpflicht letztlich erst im zweiten Schritt - nach Zuweisung des Schadensrisikos an den Schuldner - konkretisiert. Das mag zwar kontraintuitiv und dogmatisch fragwürdig wirken, ist aber letztlich dem pragmatischen Einsatz von Nebenpflichten durch die Rechtsprechung geschuldet. ${ }^{1363}$ Es entspricht zudem dem hier vertretenen, funktionalen Verständnis von Nebenpflichten.

Beispiel 38 Das OLG Hamm hat eine Nebenpflicht des Telefonnetzbetreibers angenommen, die Verbindung zu einer teuren 0190-Nummer nach einer Stunde zu unterbrechen (,, Telefongebührenfall“). ${ }^{1364}$ Die eigenen Ansprüche gegenüber Kunden zu maximieren, ist aber Grundlage und Forderung der Marktwirtschaft. ${ }^{1365}$ Der Sachverhalt bietet also zunächst gar keinen Ansatzpunkt dafür, ein Schadens-Risiko über den Ansatz des cheapest cost avoider zuzuwei-

1363 Vgl. BGH, Urt. v. 22.10.2008 - XII ZR 148/06, Rn. 15f.; BGH, Urt. v. 25.3.2009 - XII ZR 117/07, Rn. 13ff. (Hinweispflicht eines Autovermieters gegenüber dem Interessenten auf „mögliche Probleme bei der Abrechnung der Mietwagenkosten mit der Haftpflichtversicherung des Unfallgegners"; der Schaden liegt hier in den nicht von der Versicherung getragenen Mietwagenkosten, welcher wiederum über den Begriff des cheapest cost avoider mittels einer Nebenpflicht dem Autovermieter zugewiesen werden konnte, weil dieser wiederum extra einen deutlich höheren, die Grenzen der Haftpflichtversicherung bewusst austestenden, Unfallersatztarif angeboten hatte und somit minimale Informationsbeschaffungskosten hinsichtlich der möglichen Abrechnungsprobleme hatte); KG Berlin, Urt. v. 2.3.2016 - 26 U 18/15, Rn. $11 \mathrm{ff}$. (Verletzung sowohl einer Obhuts- als auch einer Informationspflicht gegenüber den Kunden durch eine Bank bei letztlich unbefriedigender Absicherung von Schließfächern vor Einbrüchen); Palandt/Grüneberg, 77. Aufl. 2018, § 280 Rn. 37 (,[v]on einer Schädigung kann bei verhaltensbezogenen Pflichten auf eine Pflichtverletzung geschlossen [!] werden, wenn der Gläubiger dartut, dass die Schadensursache allein aus dem Verantwortungsbereich des Schuldners herrühren kann"); ähnlich OLG Hamm, Urt. v. 19.2.2010 - 19 U 106/09, Rn. 14, 18 (Hinweispflicht eines Hörgeräteverkäufer auf mögliche Abrechnungsschwierigkeiten mit der Krankenversicherung); s. auch Werres, Aufklärungspflichten, 1985, S. 145f.

1364 OLG Hamm, Urt. v. 5. 11. 2002 - 19 U 41/02, Rn. 26. Die Pflichtverletzung lag hier darin, dass der Netzbetreiber die Verbindung nicht unterbrochen hatte, der Schaden dann in dem erhöhten Anspruch des Netzbetreibers gegenüber dem Kunden.

1365 Es widerspräche dem Grundsatz der Eigenverantwortlichkeit, den Gläubiger hiergegen grundsätzlich durch eine Nebenpflicht schützen zu wollen, vgl. Klinck, Information, 2013, S. 103, 108 (,vorvertragliche Pflicht zur Vermeidung des Vertragsschlusses“ grenzt ,an das Absur-

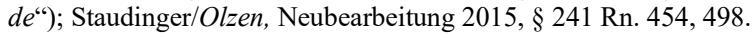


sen. Dennoch ging das OLG hier von einer Nebenpflichtverletzung aus, weil das Ergebnis - knapp 15.000 DM an Telefongebühren für eine über 68 Stunden andauernde Verbindung zu einer 0190Nummer - schon auf den ersten Blick nicht hinnehmbar schien. ${ }^{1366}$ Damit kam das Gericht über den „Umweg “ einer Nebenpflichtverletzung dazu, den Entgeltanspruch des Netzbetreibers aus Billigkeitsgründen zu beschränken.

Wendet man auf den Sachverhalt das Kriterium des cheapest cost avoider an, so kommt man ebenfalls dazu, die Haftung zu bejahen: Nimmt man das Sammelsurium an möglichen ${ }^{1367}$ Ursachen (bewusste und gewollte Herstellung der Verbindung durch den Kunden, fehlerhafte Bedienung des Nutzers ${ }^{1368}$, Fehler des Geräts, Verhalten Dritter sowie fehlerhafte Verbindungsverwaltung des Netzbetreibers), so lässt sich die Eigenschaft des Netzbetreibers als cheapest cost avoider bejahen. Schließlich hat der Kunde keine oder nur extrem kostenintensive Möglichkeiten, den Schaden bei einer der drei Fremdursachen zu verhindern. Der pauschale Abbruch der Verbindung durch den Netzanbieter über ein einmalig einzurichtendes, automatisiertes Verfahren ist dann im Vergleich die günstigere Variante, den Schaden zu verhindern. Ein solches Schutzsystem erfordert nämlich nur eine einmalige Investition, welche auf eine Vielzahl von Kundenverträgen umgelegt werden kann und dadurch im Einzelfall zu keiner übermäßigen Belastung

1366 Mit Blick auf den „Vertragszweck“, den „,redlichen Geschäftsverkehr“ und die dem Netzbetreiber bekannten, besonders hohen Kosten der 0190-Nummern ist es nach Ansicht des Gerichts zumutbar - weil „ohne weiteres technisch möglich“ - die Verbindung nach einer Stunde als ,Schutzvorkehrung[...]“ zugunsten des Kunden zu unterbrechen, OLG Hamm, Urt. v. 5. 11. $2002-19$ U 41/02, Rn. 26.

1367 Das Gericht abstrahierte - in Übereinstimmung mit der schon häufig betonten Heteronomität der Nebenpflichten - von den Umständen des Einzelfalls und stellte zu Recht auf die ,generell denkbaren Ursachen, die zu einer hohen Telefonrechnung und damit zu einem hohen Schaden führen können", ab.

1368 Vgl. hierzu das Vorbringen des Netzbetreibers, OLG Hamm, Urt. v. 5.11.2002 - 19 U 41/02, Rn. 15 a.E. („Insoweit wisse der Kunde, daß eine solche Verbindung teuer sei und daß eine Verbindung bestehen bleibe, falls der Hörer nicht richtig aufgelegt werde."); zur Relevanz der Gebrauchsanleitung im Kontext einer Risikozuweisung über den Begriff des cheapest cost avoider Thole, AcP 209 (2009), 498, 533. 
des Netzbetreibers führt. Dies gilt - unter Inkaufnahme der geringen Kosten des unerwünschten Abbruchs gewollter kostenintensiver Gespräche - auch, wenn nicht sicher festgestellt werden kann, welche der genannten Ursachen dazu geführt hat, dass die Verbindung bestehen bleibt. Schließlich wäre die Unklarheit im Einzelfall leichter vom Netzbetreiber zu beheben gewesen als vom Kunden: Nur der Netzbetreiber kann schließlich die Fehlerhaftigkeit der Verbindungstrennung, die Intervention eines Dritten, die Datenübertragung oder das Abrechnungssystem mit wirtschaftlich vertretbarem Aufwand überprüfen. ${ }^{1369}$

Der Begriff des cheapest cost avoider kann hier also durchaus überzeugend vorgeben, wem das Risiko im Ergebnis zugewiesen werden soll. Die Konkretisierung der Nebenpflicht - Verbindungsabbruch durch den Netzbetreiber - erfolgt dann im Anschluss an die Feststellung, dass der Kunde vom Schadensrisiko befreit werden soll.

Auch in Fällen, in denen es gilt, die Schutzwürdigkeit eines vermögenswerten Interesses herauszuarbeiten, kann der Begriff des cheapest cost avoider also zu vertretbaren Ergebnissen führen.

\section{(2) Relevanz der Erkennbarkeit}

Um verhaltenssteuernde Wirkung leisten zu können, muss der Begriff des cheapest cost avoider zu einer Haftungsverteilung führen, die für den Haftenden aus einer ex ante Perspektive erkennbar ist. ${ }^{1370}$ Basis des Kriteriums ist es ja gerade, dass derjenige ein Risiko tragen soll, der den Schaden mit den geringsten Kosten hätte verhindern können. ${ }^{1371}$ Kann der Schuldner aber gar nicht erkennen, dass

1369 Die Sphäre des Netzbetreibers umfasst insoweit alles, was über die konkrete Benutzung des Telefonapparats hinausgeht, vgl. zu diesem aus der Beweislastverteilung entlehnten Begriff BGH, Urt. v. 3.1.1961 - VI ZR 67/60, Rn. 20.

1370 Vgl. bereits Trimarchi, ZHR 136 (1972), 118, 127. Damit werden schließlich - auch bei rechtsvergleichender Umschau - die zentralen Bedenken gegen einen umfassenden Vermögensschutz ausgeräumt, Wagner, Grundstrukturen, 2003, S. 189, $236 \mathrm{f}$.

1371 Faust, Oxford Handbook, 2006, S. 837, 853. 
ihm eine Handlung abverlangt wird, so wird es faktisch nie zur Schadensvermeidung kommen. ${ }^{1372}$ Das Argument, dass er die Schadensvermeidung mit den geringsten Kosten hätte betreiben können, wird dann ad absurdum geführt. ${ }^{1373} \mathrm{Die}$ Vorhersehbarkeit einer Schädigung wird geprägt durch die Informationskosten, welche bei der Aufdeckung des Risikos entstehen. ${ }^{1374}$ Lässt sich ein (Schadens-) Risiko mit niedrigen Informationskosten erkennen, so ist die Wertung des cheapest cost avoider stimmig.

Beispiel 23 Im Fußballfanfall ${ }^{1375}$ wäre der entstandene Schaden - die Strafe für den Verein - am kostengünstigsten vom Fan verhindert worden. ${ }^{1376}$ Die Opportunitätskosten dafür sind lediglich, die individuelle Präferenz dafür, aus Wut über den Spielverlust einen Böller in die gegnerische Fangemeinde zu werfen, zurückzustellen. Für den einzelnen Fan ist es wegen der medialen Aufarbeitung der Problematik dabei auch durchaus vorhersehbar, dass sein Handeln zu einer Strafe gegen den Verein führen wird. ${ }^{1377}$ Das vermögenswerte Interesse des Vereins, nicht wegen Ausschreitungen der Fans vom DFB in Anspruch genommen zu werden, ist dem einzelnen Fan damit ohne nennenswerte Investition von Informationskosten

1372 Um Schäden überhaupt vermeiden zu können, müsste der Schuldner dann „ins Blaue hinein“ Schadensvermeidungsmaßnahmen treffen, dagegen zu Recht dezidiert BGH, Urt. v. 8.7.1981 IVa ZR 244/80, Rn. 11; deutlich auch E. Schmidt, JA 1978, 597, 604 (Schuldner sollte nur dann mittels einer Nebenpflicht am Schutz des Vermögensinhaber, ,beteiligt werden, falls diesem die Relevanz der betreffenden Position und deren Verflechtung mit den weiteren Interessen des Partners deutlich vor Augen geführt worden ist").

1373 Präzise Faust, Vorhersehbarkeit, 1996, S. 216f.; Faust, Oxford Handbook, 2006, S. 837, 853f.

1374 Köhler, ZHR 144 (1980), 589, 595. Dabei ist eine objektive „Verkehrsperspektive“ angemessen, näher Schäfer/Ott, Ökonomische Analyse, 5. Aufl. 2012, S. 189.

1375 S.o., S. 136.

1376 Der Verein hätte seine Sicherheitsvorkehrungen bei der Einlasskontrolle massiv aufstocken müssen, um das Mitbringen von Feuerwerkskörpern zu verhindern. Dadurch wären ihm sehr hohe Kosten entstanden. Damit ist der einzelne Fan cheapest cost avoider.

1377 Es spricht Bände, dass eine Webseite von (und für) begeisterte(n) Fußballfans eine wissenschaftliche Veranstaltung mit einem Sportrechtler über das Strafensystem des DFB dokumentiert, http://www.faszination-fankurve.de/index.php?head=Wie-funktioniert-das-Strafensystem -des-DFB\&folder $=$ sites\&site $=$ news_detail\&news id $=8653 \&$ gal_id $=543 \&$ bild $n \mathrm{nr}=1, \quad$ zuletzt eingesehen am 24.7.2018; s. auch AG Lingen, Ürt. v 17.2.2010 - 4 C 1222/09, Rn. 7 („,bekannt [...], dass gerade im Rahmen von Fußballspielen jegliches Fehlverhalten - ob tätlicher oder nur verbaler Art - durch Sportverbände geahndet wird"). 
erkennbar. Das Kriterium des cheapest cost avoider kann damit auch wertungsmäßig überzeugen.

Eine Nebenpflicht lässt sich demnach nur dann überzeugend auf das Kriterium des cheapest cost avoider stützen, wenn das von ihr geschützte vermögenswerte Interesse dem Schuldner ex ante erkennbar und die mit seiner Handlung einhergehende Schädigung vorhersehbar war. ${ }^{1378}$

\section{(3) Zur Konvergenz von Pflichtverletzung und Vertretenmüssen}

Eine Nebenpflicht kommt nach dem Begriff des cheapest cost avoider nur infrage, wenn die Grenzkosten der Schadensvermeidung durch den Grenznutzen derselben zumindest aufgewogen werden. ${ }^{1379}$ Nach der sogenannten Learned Hand-Formel ist fahrlässiges Handeln allgemein zu bejahen, wenn der Vorsorgeaufwand geringer als das Produkt aus Schadenshöhe und Schadenseintrittswahrscheinlichkeit ist. ${ }^{1380}$ Individuelle Defizite spielen bei der Bestimmung des

1378 Bei Schadensersatzansprüchen aus schuldverhältnisbedingter Nebenpflichtverletzung sind Pflichtverletzung und Schaden häufig eng miteinander verknüpft. Die Kriterien der Erkennbarkeit sowie der Vorhersehbarkeit greifen damit ineinander. Mit dieser wertenden Einschränkung verliert der Begriff des cheapest cost avoider insgesamt an Präzision. Das lässt sich aber nicht vermeiden, wenn man das Haftungskriterium für alle Arten von Nebenpflichten tauglich gestalten möchte. Hier wäre im Übrigen auch ein möglicher Ansatzpunkt, um den Begriff des cheapest cost avoider auf geldwerte Handlungen zu erstrecken. Ist ein bestimmtes vermögenswertes (Informations-)Interesse dem Schuldner erkennbar und eine Schädigung vorhersehbar, so erscheint die Risikozuweisung über den Begriff des cheapest cost avoider akzeptabel. Es bleibt aber offen, warum der Schuldner eine geldwerte Handlung erbringen soll, ohne hierfür eine Kompensation zu erlangen. Diesen Widerspruch kann auch die Erkennbarkeit eines Risikos nicht auflösen. Dogmatisch würde die Subsumtion zu § 241 II BGB mit dem Grundsatz im deutschen Recht brechen, dass die ,foreseeability rule“ erst auf Rechtsfolgenseite bei $\S 254$ BGB relevant wird, vgl. Faust, Oxford Handbook, 2006, S. 837, 853f.; Trimarchi, ZHR 136 (1972), 118, 127.

1379 Vgl. Tröger, Arbeitsteilung, 2012, S. 521f.

1380 Kötz/Wagner, Deliktsrecht, 15. Aufl. 2018, Rn. 70; Schäfer/Ott, Ökonomische Analyse, 5. Aufl. 2012, S. 183. Das Produkt aus Schadenshöhe und Schadenseintrittswahrscheinlichkeit lässt sich auch als ,Schadenserwartungswert“ bezeichnen, Riha, Sachmängelgewährleistungsrecht, 2007, S. 44 (Fn. 79). Entwickelt wurde diese Formel vom US-amerikanischen Richter Billings Learned Hand im Jahr 1947 im Urteil United States v Carroll Towing Co. (1947), 159 F. 2d 169, 173 (,if the probability be called P; the injury, L; and the burden, B; liability depends upon whether $B$ is less than $L$ multiplied by $P$ : i. e., whether $B>P L^{\prime \prime)}$. Auch in der deutschen Rechtsprechung finden sich Parallelen zur ,Learned-Hand“-Formel, s. dazu Drexl, Selbstbestimmung, 1998, S. 166f.; AK-BGB/Kohl, 1979, vor $\S \S 823$ ff. Rn. 30; Kübler, FS Steindorff, 1990, S. 687, 700f.; Ott, FG Kübler, 1997, S. 21, 29 („tendenzielle Übereinstim- 
Sorgfaltsmaßstabs keine Rolle. ${ }^{1381}$ Dieser Befund lässt sich sowohl bei den Verkehrssicherungspflichten ${ }^{1382}$ als auch bei den Nebenpflichten ${ }^{1383}$ wiederfinden. Die Frage stellt sich also, ob sich der Pflichtinhalt in einem Schuldverhältnis mit diesem rechtsvergleichend für das Vertretenmüssen entwickelten Kriterium bestimmen lässt. ${ }^{1384}$ Zunächst wirkt dies befremdlich: Schließlich ist ein (volkswirtschaftlich) wünschenswerter Fahrlässigkeitsmaßstab normtechnisch auf $\S 276$ II BGB bezogen. Die Prüfung von § 276 II BGB ist indes Gegenstand des Vertretenmüssens. Damit ist sie der Pflichtverletzung - und folglich dem Prüfungsstandort von $\S 241$ II BGB - nachgelagert. Nebenpflichten sind indes von ihrer Zwecksetzung her verhaltensbezogene Pflichten. Die Prüfung des Ver-

mung“); Schäfer/Ott, Ökonomische Analyse, 5. Aufl. 2012, S. 185f.; Taupitz, AcP 196 (1996), $114,155 \mathrm{ff}$. So wird insbesondere bei Verkehrssicherungspflichten - und damit ebenfalls bei entsprechenden Nebenpflichten - stets auf das Ausmaß drohender Gefahr abgestellt, vgl. beispielsweise RG, Urt. v. 11.4.1935 - VI 540/34, RGZ 147, 353, 356; BGH, Urt. v. 20.4.1971 - VI ZR 232/69, Rn. 15; BGH, Urt. v. 31.10.2006 - VI ZR 223/05, Rn. 11 a.E. Das ähnelt dem Schadenserwartungswert in der ökonomischen Analyse. Aufseiten des Schuldners wird stets die „Zumutbarkeit“ der aus den Nebenpflichten folgenden Belastung berücksichtigt, Dezidiert beispielsweise BAG, Urt. v. 14.1.2009 - 3 AZR 71/07, Rn. 32 (Schuldner darf durch Nebenpflicht nicht ,überfordert werden“); BGH, Urt. v. 24.1.2013 - VII ZR 98/12, Rn. 12 (a.A. offenbar die Vorinstanz OLG Köln, Urt. v. 9.3.2012 - 1 U 48/11, Rn. 13, das an die ,allgemeine Pflicht“ des Auftraggebers anknüpfen wollte, sein „Rapsfeld vor den Erntearbeiten von größeren Fremdkörpern freizuhalten" ohne die immense wirtschaftliche Belastung dieser Pflicht explizit zu würdigen); BGH, Urt. v. 29.5.2013 - IV ZR 165/12, Rn. 15ff.; LG Osnabrück, Urt. v. 26.1.2011 - 2 O 2278/08, Rn. 31; vgl. auch Teichmann, JA 1984, 545, 547. Das wiederum ist inhaltlich an den Vorsorgeaufwand angelehnt. Schließlich haben beide Ansätze gemeinsam, dass sie im Grundsatz eine objektive Analyse durchführen.

1381 Brüggemeier, AcP 182 (1982), 385, 436ff.; Brüggemeier, AG 1982, 268, 268f.; Deutsch, Haftungsrecht, 2. Aufl. 1996, Rn. 6; AK-BGB/Kohl, 1979, vor $\S \S 823$ ff. Rn. 48 („Objektivierung der Schuldmaßstäbe"); Tröger, Arbeitsteilung, 2012, S. 59f. (Fn. 142) m.w.N.; Wagner, Grundstrukturen, 2003, S. 189, 269 (,Maßgeblichkeit eines gemäßigt-objektiven Maßstabs").

1382 Die sogenannte ,äußere“ Sorgfalt ist entscheidend für den Anspruchsbestand, die ,innere“ Sorgfalt hat dagegen in diesem Bereich kaum eine eigenständige Bedeutung, vgl. Schäfer/Ott, Ökonomische Analyse, 5. Aufl. 2012, S. 191f. Systematisch lässt sich dieser Befund auf $\S 827$ BGB stützen. Aus der Norm lässt sich der Umkehrschluss ziehen, dass individuelle Defizite außerhalb von Bewusstlosigkeit oder schwerer Geistesbeeinträchtigung keinen Einfluss auf die Fahrlässigkeitshaftung haben.

1383 Oben wurde bereits festgestellt, dass die Haftung aus Nebenpflichtverletzung einen objektiven Sorgfaltsstandard anlegt, der von den individuellen Vorstellungen des Schuldners abstrahiert, s.o., S. 66ff., $139 \mathrm{f}$.

1384 Hierzu bereits Köndgen/von Randow, Travemünder Symposium, 1989, S. 122, 133ff. sowie Koller, Risikozurechnung, 1979, S. 57ff., der allerdings an den praktischen Möglichkeiten des Richters zweifelt, die Schadensvermeidungskosten ausfindig zu machen. 
tretenmüssens - in der Regel die Prüfung der im Verkehr erforderlichen Sorgfalt gem. § 276 II BGB - verliert dadurch entscheidend an Gewicht. ${ }^{1385}$

Der BGH hält ein unbegründetes Nacherfüllungsverlangen dann für ,eine zum Schadensersatz verpflichtende schuldhafte Vertragsverletzung [...], wenn der Käufer erkannt oder fahrlässig nicht erkannt hat, dass ein Mangel nicht vorliegt, sondern die Ursache für die von ihm beanstandete Erscheinung in seinem eigenen Verantwortungsbereich liegt “. ${ }^{1386}$ Der BGH integriert hier mit „,Vertragsverletzung “ und „schuldhaft" die Tatbestandsmerkmale beider Prüfungsvoraussetzungen in eine zusammenhängende Definition und lässt demnach bei präziser Lesart die Grenzen zwischen Pflichtverletzung und Vertretenmüssen verschwimmen. ${ }^{1387}$ Liegt die Mangelursache nämlich im Verantwortungsbereich des Käufers, so wird ein unbegründetes Nacherfüllungsverlangen in aller Regel auch vom Käufer zu vertreten sein. Mit der Verortung der Mangelursache in der Sphäre des Käufers ist schließlich schon ein Verstoß gegen die im Verkehr erforderliche Sorgfalt durch das unbegründete Nacherfüllungsverlangen angelegt. In der Sache verlagert der BGH hier gewisse Bestandteile des Vertretenmüssens in die Pflichtverletzung hinein. Anderenfalls würde die Beweislastumkehr des $\S 280$ I 2 BGB zu intensive Wirkung entfalten. ${ }^{1388}$

Die im Verkehr erforderliche Sorgfalt wird schließlich schon dann relevant, wenn gefragt wird, was der Rechtsverkehr in der risikobehafteten Situation unter Berücksichtigung von Treu und Glauben vom Schuldner für ein Verhalten erwarten konnte - und damit letztlich schon bei der Prüfung der Pflichtverletzung.

1385 Vgl. Tröger, Arbeitsteilung, 2012, S. 519.

1386 BGH, Urt. v. 23.1.2008 - VIII ZR 246/06, Rn. 12.

1387 Für eine - dogmatisch und ökonomisch fragwürdige - strikte Trennung hingegen BGH, Urt. v. 16.1.2009 - V ZR 133/08, Rn. 17ff. (BGHZ 179, 238, 245ff.); AG Bingen, Urt. v. 12.3.2015 - 25 C 21/14, Rn. 26f.; krit. dazu auch Deckenbrock, NJW 2009, 1247, 1248.

1388 Das wird unter anderem als Argument dafür angeführt, die Beweislastumkehr des $\S 280$ I 2 BGB generell bei Nebenpflichten teleologisch zu reduzieren, näher s.o., S. 73ff.; aus einer dogmatischen Perspektive skeptisch gegenüber einer zu offenen Formulierung der Pflichtverletzung in diesem Kontext auch Thole, AcP 209 (2009), 498, 528f., der jedoch - ohne nähere Begründung - der Meinung ist, dass zumindest die Beweislastumkehr den Schuldner „nicht in unzumutbarer Weise belasten" würde. 
Beispiel 39 Der BGH hält einen Anspruch aus vorvertraglicher Nebenpflichtverletzung für angebracht, wenn der Schuldner ,, die Verhandlungen [grundlos ${ }^{1389}$ ] abbricht, obwohl er vorher durch sein Verhalten schuldhaft das Vertrauen geweckt oder genährt hat, der Vertrag werde mit Sicherheit zustandekommen" (,,Verhandlungsabbruchsfall“). ${ }^{1390}$ Auch hier wird die Vermischung von Pflichtverletzung und Vertretenmüssen deutlich: Die zitierte Sentenz des BGH inkorporiert erneut Elemente beider Tatbestandsvoraussetzungen. Die strikte Trennung würde hypothetisch dazu führen, allein den Abbruch der Vertragsverhandlungen als Pflichtverletzung genügen zu lassen. Ob der Schuldner dem Gläubiger gegenüber zurechenbar ein berechtigtes Vertrauen geschaffen hat, dass der Vertrag zustande kommen würde, und dieses dann durch die Grundlosigkeit seines Verhandlungsabbruchs enttäuscht hat, wäre dann erst Gegenstand des Vertretenmüssens. Erst hier kann die zunächst neutrale Pflichtverletzung (das Soll) in den Kontext der im Verkehr üblichen Sorgfalt (das Kann) gesetzt werden. Dort würde aber wegen $\$ 280$ I 2 BGB der Schuldner die Beweislast tragen. Um einem Schadensersatzanspruch wegen eines - durch die Vertragsfreiheit verbürgten - Abbruchs von Vertragsverhandlungen zu entgehen, müsste er dann beweisen, dass sein Verhalten keinerlei berechtigtes Vertrauen erweckt haben konnte. Der Beweis eines Negativums muss - zumindest gegenüber der Alternative - als schwierig bezeichnet werden. Sieht man die Formulierung des BGH als einheitliche Definition der Nebenpflicht in diesem Kontext, trägt der Gläubiger für alle ihre Voraussetzungen die Beweis-

1389 Vgl. BGH, Urt. v. 6.2.1969 - II ZR 86/67, Rn. 29. Über das Erfordernis und die Definition eines ,triftigen Grundes“, welcher eine Haftung aus $\S 280$ I, 311 II, 241 II BGB entfallen ließe, besteht erhebliche Unsicherheit, MüKo-BGB/Emmerich, 7. Aufl. 2016, § 311 Rn. 162.

1390 BGH, Urt. v. 14.7.1967 - V ZR 120/64, Rn. 15. Dogmatisch handelt es sich hierbei um eine Haftung wegen der Enttäuschung berechtigten Vertrauens, explizit BGH, Urt. v. 20.9.1984 III ZR 47/83, Rn. 39 (BGHZ 92, 164, 176). 
last. Das Vertretenmüssen verliert dann entscheidend an Bedeu-
tung.

Die Wertung des $\S 276$ II BGB wird also zum Teil Bestandteil der Nebenpflicht. Das ist auch auch wirtschaftlicher Perspektive stimmig: Wenn ein bestimmtes Verhalten einen objektiven, nach Maßgabe der ökonomischen Analyse ermittelten Verstoß gegen $\S 241$ II BGB darstellt, muss der schadensrechtliche Ausgleich ungeachtet des individuellen Sorgfaltsstandards erfolgen. ${ }^{1392}$ Ansonsten wird die Ermittlung des objektiv effizienten Sorgfaltsniveaus durch unklar definierte Wertungen des Vertretenmüssens untergraben. Deshalb erscheint es ein sinnvolles Unterfangen, die für die Bestimmung des Fahrlässigkeitsmaßstabs maßgeblichen Ansätze auf Nebenpflichten anzuwenden. Zur systemtheoretischen Begründung von Nebenpflichten ist der Ansatz also durchaus in der Lage. ${ }^{1393}$

1391 In der Pflichtverletzung wurde schließlich bereits festgestellt, dass der Schuldner eine berechtigte Erwartung des Gläubigers, dass der Vertrag zustande kommen würde, zurechenbar verursacht hatte. Durch die Objektivierung der Voraussetzungen wird sich das nur in absoluten Ausnahmefällen auf ein Verhalten des Schuldners zurückführen lassen, was der im Verkehr erforderlichen Sorgfalt entspricht. Dieser Gedankengang wird im Ansatz bestätigt, wenn man sich den Streit in der rechtswissenschaftlichen Literatur vor Augen führt, ob die Haftung wegen grundlosen Abbruchs der Vertragsverhandlungen als Ausdruck allgemeiner Vertrauenshaftung nach dem Vorbild von § 122 BGB überhaupt ein Verschulden erfordert, hierzu MüKoBGB/Emmerich, 7. Aufl. 2016, § 311 Rn. 167. Weil die im Verkehr erforderliche Sorgfalt vom BGH bereits zu großen Teilen in die entsprechende Nebenpflicht integriert wurde, wird die Verschuldensprüfung nämlich ohnehin weitgehend entwertet. Deshalb ist letztlich auch der Streit um die Notwendigkeit von Verschulden hinfällig. Schließlich wird durch die Abkopplung der Haftung vom Verschulden nichts erreicht, außer den Anspruch über eine mühsame Analogie zu $\S 122$ BGB aus der allgemeinen Struktur der $\S \S 280$ I, 241 II BGB zu entfernen. Da die Praxis das Verschuldenserfordernis innerhalb der Pflichtverletzung berücksichtigt - und somit die eigentliche Verschuldensprüfung zur Makulatur erklärt -, bietet die abweichende Ansicht keinen rechtspraktischen Vorteil, sondern nur den dogmatischen Nachteil einer strukturell uneinheitlichen Behandlung von Nebenpflichtverletzungen.

1392 Vgl. zum Integritätsschutz Calabresi, Accidents, 1970, S. 263 (,system seeking to burden the cheapest cost avoider would often shift losses even in the absence of fault. Indeed, [...] there are many areas in torts today where the shifting of losses in the absence of fault has clearly resulted in a reduction of the sum of the accidents and their avoidance and therefor in a benefit to society quite apart from possible spreading benefits").

1393 Der Ansatz ist im Kern auf die Beeinträchtigung absolut geschützter Rechtsgüter ausgelegt. Geht es um den Schutz vermögenswerter Interessen, so kann die geforderte Handlung aber auch - anders als das Unterlassen einer ,typischen" Schädigung - einen eigenen Marktwert haben. Ähnlich dem Begriff des cheapest cost avoider - der auch im Übrigen viele Gemeinsamkeiten mit der „Learned-Hand“-Formel hat - kann der Ansatz das (berechtigte) Interesse des Schuldners, die Pflichterfüllungskosten zu amortisieren, nicht berücksichtigen. Der 
Ob sich die Learned-Hand-Formel aber in der (gerichtlichen) Praxis anwenden lässt, ist indes eine andere Frage. Dagegen spricht, dass der Vorsorgeaufwand häufig schwierig zu berechnen ist. ${ }^{1394}$ Insbesondere wenn es um eine innovative oder bislang unbekannte Form der Schadensvermeidung geht, kann vom Richter nicht erwartet werden, an diese nicht nur zu denken, sondern auch noch deren (Entwicklungs-)Kosten zu berechnen. ${ }^{1395}$ Gleichzeitig ließe sich ein Schadensvermeidungsaufwand ja häufig zumindest schätzen. Für die Rechtspraxis wären keine im Detail exakten Zahlen erforderlich, sondern lediglich das Ergebnis, dass die typisierten Schadensvermeidungskosten zumindest unterhalb des typisierten Schadenserwartungswerts liegen. $\mathrm{Zu}$ einer solchen populärwissenschaftlichen Wertung ließe sich wohl auch gelangen, wenn man auf naturwissenschaftlich belegbare Zahlen verzichtet. Das Kriterium verliert dadurch natürlich ein deutliches Stück an Präzision. Dass die rechtswissenschaftliche Interessenabwägung jedoch ein höheres Level an Präzision aufweist, wird auch von Kritikern der Ökonomik nicht behauptet. Insofern sollte man den Ansätzen der Ökonomik zumindest eine Chance geben, bevor man sie wegen fehlender mathematischer Präzision verwirft, welche man nicht auch nur im Entferntesten von der eigenen Dogmatik verlangt. ${ }^{1396}$

Nebenpflichten aus § 241 II BGB mit der Learned Hand-Formel zu begrenzen, kann sich in der Praxis zwar als (zu) schwierig herausstellen, Bemühungen in diese Richtung sind jedoch durchaus sinnvoll.

Gedanke kann deshalb auch aus einer systemtheoretischen Perspektive nicht für alle vermögenswerten Interessen allein maßgeblich sein.

1394 Hier liegt ein Ansatzpunkt derjenigen, welche die ökonomische Analyse als praxisuntauglich kritisieren. Tatsachen lassen sich in diesem Bereich eben schwer ermitteln, vgl. beispielsweise Fezer, JZ 1986, 817, 823 („Gefahr der Scheinpräzision“) sowie selbst Calabresi, Economics, 1975, S. 204, 206 (,largely defined by guesses“).

1395 Grundsätzlich überzeugend Koller, Risikozurechnung, 1979, S. 59.

1396 Vgl. auch Calabresi, Economics, 1975, S. 204, 206 (,,no reason to assume that in the absence of conclusive information no [...] action is better than some action"); Faust, Oxford Handbook, 2006, S. 837, 849f.; AK-BGB/Kohl, 1979, vor $§ \S 823$ ff. Rn. 30 (,vernünftige Absicht“); Kübler, FS Steindorff, 1990, S. 687, 696f.; Kötz/Wagner, Deliktsrecht, 15. Aufl. 2018, Rn. 60 (,Abwägung der Nutzen und Kosten auch dort sinnvoll [...], wo sie mit Schätzungen operieren muss"). Bei einer rein modellhaften Darstellung droht der Ökonomik schließlich wiederum der Vorwurf eines abschreckenden Abstraktionsgrades, zutreffend Faust, Oxford Handbook, 2006, S. $837,849 f$. 


\section{(4) Risikozuweisung im Hinblick auf den ökonomischen Ressourcenschaden}

Das zentrale Argument gegen den breiten Ersatz reiner Vermögensschäden im Deliktsrecht ist die Uferlosigkeit der daraus resultierenden Haftung. ${ }^{1397}$ Im Vordergrund stehen hier aber ökonomische Argumente: Ein Vermögensschaden hat nach der ökonomischen Analyse häufig einen korrespondierenden Vermögenszuwachs bei einer anderen Person zur Folge. ${ }^{1398}$ Um abschreckende Haftungsgefahren auszuschließen, darf ein Vermögensschaden vor allem deshalb nicht pauschal - im Deliktsrecht oder anderswo - ersetzt werden. ${ }^{1399}$ So hat ein reiner Vermögensschaden aus ökonomischer Perspektive zwei Komponenten: den Schaden des Geschädigten (privater Schaden) und einen sogenannten Ressourcenschaden (sozialer Schaden). ${ }^{1400}$ Ersterer wird auch Umverteilungsschaden genannt, weil er mit dem Gewinn einer anderen Person korrespondiert. ${ }^{1401}$ Die vornehmlich in der Ökonomik behandelte Schadenskomponente ist der gesellschaftliche Schaden, den eine pflichtwidrige Handlung endgültig anrichtet. ${ }^{1402}$

1397 Dieses Argument wird auch in der ökonomischen Analyse genannt, Schäfer/Ott, Ökonomische Analyse, 5. Aufl. 2012, S. 324f. (,,,floodgate“-Argument").

1398 MüKo-BGB/Wagner, 7. Aufl. 2017, § 826 Rn. 14 (,[r]eine Vermögensschäden [...] häufig [...] Umverteilungsschäden“); krit. gegenüber dieser Hypothese aus einer spieltheoretischen Perspektive Schweizer, Spieltheorie, 2015, S. 105ff.

1399 Schäfer/Ott, Ökonomische Analyse, 5. Aufl. 2012, S. 325. Die Reaktion der deutschen Rechtsordnung auf diese Bedenken ist es, die Haftung für reine Vermögensschäden zumindest im Deliktsrecht auf vorsatzähnliche Handlungen zu beschränken, Schäfer, AcP 202 (2002), 808, 835ff. Plakatives Beispiel sind hier die $\S \S 826,823$ II BGB i.V.m. $\S \S 263,266$ StGB, näher Schäfer/Ott, Ökonomische Analyse, 5. Aufl. 2012, S. 334. In diesen Fällen wird dem Schädiger (zu Recht) unterstellt, dass er genau wisse, wann er die Grenze zum pflichtwidrigen Verhalten überschritten habe. Deshalb besteht auch keine Gefahr der „Überabschreckung“ mehr, Faust, AcP 210 (2010), 555, 558f.; Kötz/Schäfer, Judex oeconomicus, 2003, S. 132f.; Schäfer, AcP 202 (2002), 808, 836f. Für eine Öffnung der ,schuldrechtliche[n] Grundnorm für reine Vermögensschäden“" aus mathematischer Perspektive plädierend Schweizer, Spieltheorie, 2015, S. 107.

$1400 \mathrm{Kötz/Schäfer,} \mathrm{Judex} \mathrm{oeconomicus,} \mathrm{2003,} \mathrm{S.} 109$ („Differenz zwischen dem Ertrag der Ressource bei richtiger und bei falscher Information"); Schäfer/Ott, Ökonomische Analyse, 5. Aufl. 2012, S. 330; Wagner, Grundstrukturen, 2003, S. 189, $237 f$ f.

1401 Schäfer, AcP 202 (2002), 808, 813. Insofern unterscheiden sich Schäden an absoluten Rechtsgütern und Vermögensschäden. Die sachliche Beeinträchtigung eines Gegenstands durch eine fahrlässige Handlung wird in keinem Fall durch einen Vorteil aufseiten des Schädigers oder eines Dritten aufgewogen.

1402 Schäfer, AcP 202 (2002), 808, 812f. Der Ressourcenschaden wird hierbei ermittelt, indem man von dem Ertrag einer Ressource bei pflichtgemäßem Handeln des Schuldners den Ertrag derselben Ressource bei pflichtwidrigem Handeln des Schuldners abzieht, Kötz/Schäfer, Judex oeconomicus, 2003, S. 109; Schäfer, AcP 202 (2002), 808, 814. 
Beispiel 33 Im Bodengutachtenfall ${ }^{1403}$ entsteht ein Umverteilungsschaden, weil das Grundstück aufgrund des unerwartet hohen Grundwasserstandes nur unter Inkaufnahme zusätzlicher Kosten mit einem unterkellerten Haus bebaut werden kann. Weil diese Information dem Käufer bei den Verhandlungen mit dem Verkäufer nicht bekannt war, wird der Käufer einen über dem eigentlichen Marktwert liegenden Kaufpreis bezahlen. Die Differenz zwischen dem gezahlten Kaufpreis (als Repräsentant des Marktwertes bei unvollständiger Information) und dem tatsächlichen Marktwert des Grundstücks bei vollständiger Information (Kaufpreis abzüglich der Zusatzkosten für die Unterkellerung) ist dann der Umverteilungsschaden des Käufers, der in gleicher Höhe mit einem Gewinn des Verkäufers korrespondiert.

Zusätzlich lässt sich hier aber auch über einen Ressourcenschaden nachdnken: Wenn nämlich ein Käufer nicht mehr davon ausgehen kann, dass er über geschäftsrelevante Risiken im Rahmen eines Hauskaufes aufgeklärt wird, so wird er die Informationen mangels Martkvertrauen vermehrt selber suchen (müssen). ${ }^{1404}$ Wegen der hierdurch für ihn anfallenden Suchkosten wird er bei der Verhandlung einen mit den Informationsbeschaffungskosten korrespondierenden Risikoabschlag verlangen. ${ }^{1405}$ Weil die Informationsbeschaffungskosten hinsichtlich grundsätzlicher Risiken des zu kaufenden Hauses für den Käufer als Außenstehenden aber regelmäßig höher sind als diejenigen des Verkäufers, führt dieser Weg zu Unterbewertungen der zu verkaufenden Häuser. Die gestörte Informationseffizienz des Häusermarktes führt dann zu vermeidbarem Einsatz von Ressourcen (bei der Informationsbeschaffung) und korrespondierend vermeidbarem Fehleinsatz von Ressourcen (bei der Häuserbewertung). ${ }^{1406}$ Zudem werden besonders risikoverse Käufer gänzlich vom Hauskauf absehen, sodass gesamtge-

1403 S.o., S. 260.

1404 Vgl. Kötz/Schäfer, Judex oeconomicus, 2003, S. 109.

1405 Vgl. Schäfer/Ott, Ökonomische Analyse, 5. Aufl. 2012, S. 330.

1406 Zum Wertpapiermarkt Kötz/Schäfer, Judex oeconomicus, 2003, S. $108 \mathrm{f}$. 
sellschaftlich wünschenswerte Transaktionen unterbleiben. All diese Aspekte bilden gemeinsam den Ressourcenschaden ab, der sich quantitativ als der im Vergleich zum informationseffizienten Häusermarkt verloren gegange Ertrag aus den eingesetzten Ressourcen (Geld, geldwerte Zeit) erfassen lässt. ${ }^{1407}$

Die $\S \S 249 f f$. BGB ersetzen - auch in Verbindung mit den $\S \S 280$ I, 241 II BGB - den privaten Schaden (Umverteilungsschaden) ohne Rücksicht auf den gesellschaftlichen Schaden. Im Gegensatz hierzu wird von der Ökonomik vorgeschlagen, den Ressourcenschaden in den Vordergrund zu stellen, um den zu ersetzenden Schaden allein nach dem gesamtgesellschaftlichen Wohlfahrtsverlust - den sozialen Kosten ${ }^{1408}-$ zu bemessen. ${ }^{1409}$

1407 Der von Wagner, Grundstrukturen, 2003, S. 189, 238 vorgeschlagene Weg, um den Unterschied zwischen privatem und gesellschaftlichem Schaden zu berücksichtigen, ,zwischen Verletzungen absoluter Rechtsgüter und reinen Vermögensschäden“" zu differenzieren, ginge hier also ins Leere. Die Informationshaftung aus § 241 II BGB ist schließlich Teil des erweiterten Vermögensschutzes innerhalb eines Schuldverhältnisses.

1408 Die sozialen Kosten bezeichnen den gesellschaftlichen Nettoschaden. Dieser setzt sich zusammen aus den Schadensvermeidungskosten und dem sozialen Schaden (Ressourcenschaden). Die Schadensvermeidungskosten steigen proportional zum Level an Sorgfalt, welches der Schuldner walten lässt. Der soziale Schaden ist als Kurve in einem Modell das Produkt aus der durch das Sorgfaltsniveau des Schuldners determinierten Schadenseintrittswahrscheinlichkeit und dem sozialen Schaden (Ressourcenschaden) bei Schadenseintritt, vgl. zu alldem instruktiv Schäfer/Ott, Ökonomische Analyse, 5. Aufl. 2012, S. 332 (Abb. 9.1).

1409 Der Schädiger muss nach deutschem Recht den vollen privaten Schaden (Umverteilungsschaden) ersetzen, welcher regelmäßig die Nettowohlfahrtseinbuße der Gesellschaft (Ressourcenschaden) übersteigen wird, so Schäfer/Ott, Ökonomische Analyse, 5. Aufl. 2012, S. 332; MüKo-BGB/Wagner, 7. Aufl. 2017, § 826 Rn. 14f. (,gesellschaftliche Schaden nicht identisch mit dem privaten Nachteil, sondern bleibt dahinter zurück"). Übermaßhaftung droht deshalb immer dann, wenn der gesellschaftliche Schaden kleiner als der private Schaden ist. Die Höhe des gesellschaftlichen Schadens ist nämlich Ausdruck des gesamtgesellschaftlichen Wohlfahrtsverlusts, während der private Schaden im Falle der Umverteilung zumindest aus der Vogelperspektive der Volkswirtschaft gar kein echter Schaden ist. Da $§ 249$ I BGB aber nur den Ersatz des privaten Schadens kennt, wird mehr ersetzt als nach diesem Modell gesamtgesellschaftlich zerstört wurde, daher also der Begriff der Übermaßhaftung, hierzu auch Gilead, Int'1 Rev. L. \& Econ. 17 (1997), 589, 597 (,overinternalization“); krit. gegenüber der Hypothese dieses Ansatzes aus mathematischer Perspektive Schweizer, Spieltheorie, 2015, S. 54 (gesamtwirtschaftlicher Schaden womöglich häufig größer als der private Schaden). 
(a) Mögliche Konsequenz für § 241 II BGB: Begrenzung des Schadensersatzes auf den Ressourcenschaden

Eine mögliche Konsequenz hieraus wäre es, einen Schadensersatzanspruch aufgrund Nebenpflichtverletzung aus einer Vermögensbeeinträchtigung auf den entstehenden Ressourcenschaden zu begrenzen. ${ }^{1410}$ Haftung nach $\S \S 280$ I, 241 II BGB muss dann nur derjenige befürchten, der mit seiner Handlung - bei gleichzeitiger (privater) Vermögensschädigung eines anderen ${ }^{1411}$ - einen gesellschaftlichen Schaden verursacht. Es ist allerdings häufig schwierig, das Vorliegen oder gar die genaue Höhe eines Ressourcenschadens präzise zu bestimmen. ${ }^{1412}$

Beispiel 25 Im Insolvenzfall ${ }^{1413}$ ist unklar, ob sich die von der Rechtsprechung angenommene Nebenpflicht des Steuerberaters auch auf einen drohenden Ressourcenschaden wegen einer Vertrauensverringerung in die Berufsbranche stützen lässt: So ist dem Steuerberateranders als dem Rechtsberater - vom Markt nicht die Aufgabe zugewiesen, rechtliche Fragestellungen zu klären. Die Klärung der Insolvenzreife eines Unternehmens basiert zwar auf wirtschaftlichen Feststellungen, ist aber im Ergebnis eine Rechtsfrage ( $\$ \$ 17$, 19 InsO). ${ }^{1414}$ Dass der Markt einem Steuerberater also deshalb besonders skeptisch gegenübertritt, weil er nicht über seinen unmittelbaren Kompetenzbereich hinaus agiert, ist nicht ernsthaft zu befürchten. Der Rechtsverkehr würde im Gegenteil weder eine kostenlose Auskunft noch überhaupt eine Vereinbarung über einen

1410 Vgl. Kötz/Schäfer, Judex oeconomicus, 2003, S. 132; Schäfer, AcP 202 (2002), 808, 835; Schäfer/Ott, Ökonomische Analyse, 5. Aufl. 2012, S. 334. Nur so ließe sich die in der ökonomischen Analyse monierte Gefahr der Übermaßhaftung bannen, näher Gilead, Int'1 Rev. L. \& Econ. 17 (1997), 589, 600ff. (,exclusionary rule“)

1411 Ohne zumindest vermeintliche Schädigung einer konkrete Person wird der Fall rechtstatsächlich gar nicht zur (gerichtlichen) Entscheidung gelangen (Wo kein Kläger, da kein Richter).

1412 So auch Ott, FS Schäfer, 2008, S. 171, 179f.; Schäfer, AcP 202 (2002), 808, 835; Schäfer/Ott, Ökonomische Analyse, 5. Aufl. 2012, S. 334.

1413 S.o., S. 150.

1414 So auch eindringlich OLG Dresden, Teilurt. v. 18.2.2015 - 13 U 1963/13, Rn. 35ff. Nichtsdestotrotz darf der Steuerberater hierzu als Nebenleistung seiner Berufstätigkeit nach §§ 5 I RDG, 57 III Nr. 3 StBerG Stellung nehmen, D. Fischer, DB 2015, 1643, 1644; Kayser, ZIP 2014, $597,597$. 
berufsfremden Beratungsgegenstand erwarten. ${ }^{1415}$ Das Vorliegen oder gar die Höhe eines Ressourcenschadens kann - neben dem hier eindeutig zu bestimmenden privaten Schaden der durch den verspäteten Insolvenzantrag geschädigten Insolvenzgläubiger damit nicht ohne weiteres festgestellt werden.

Schließlich kann ein Ressourcenschaden sich aus vielen unterschiedlichen Faktoren zusammensetzen, die selbst für sich genommen kaum quantifizierbar sind. ${ }^{1416}$ Beispiel 6 Im Haltefristfall ${ }^{1417}$ ist die marktsensitive Komponente des Ressourcenschadens letztlich nur schätzbar. Inwieweit bestimmte schädigende Handlungen das effiziente Funktionieren des Marktes beeinträchtigen, ist schon schwer einzuschätzen. In welcher Höhe durch den unterlassenen Hinweis eines Steuerberaters aber zukünftig unnötige Transaktionskosten entstehen oder unter Inkaufnahme welcher Einbußen Ressourcen zukünftig unter Wert bewirtschaftet werden, weil potentielle Marktteilnehmer von einer Transaktion mit einem Steuerberater insgesamt absehen, lässt sich nicht konkret berechnen.

Selbst wenn klar ist, dass ein Ressourcenschaden entsteht, wird man sich mangels konkreter Berechnungsmöglichkeiten in der Rechtspraxis am privaten Schaden orientieren müssen. ${ }^{1418}$

Beispiel 23 Unmittelbare Folge der Handlung des Fans im Fußballfanfall ${ }^{1419}$ war die körperliche Beeinträchtigung anderer Fans. Das war aber nicht Voraussetzung der Pflichtverletzung. Schließlich konnten die anderen Fans ihr Integritätsinteresse direkt gegenüber dem Schädiger nach $\$ 823$ I BGB liquidieren. Im Mittelpunkt stand vielmehr der private Schaden des Vereins, der vom DFB-Sportgericht eine

1415 So auch Hopt, AcP 183 (1983), 608, 681f.; Picker, FS Medicus, 1999, S. 397, 413; vgl. auch Eschenfelder, BB 2015, 1963, 1965f.

1416 Aus einer mathematischen Perspektive überzeugend Schweizer, Spieltheorie, 2015, S. 108ff.

1417 S.o., S. 26.

1418 Vgl. die überaus vage Aussage von Gilead, Int'1 Rev. L. \& Econ. 17 (1997), 589, 605 („loss of welfare due to negligent misrepresentation or negligent performance of a service is sometimes offset, wholly or partially, by the gains of third parties, and sometimes is not.").

1419 S.o., S. 136. 
Vereinsstrafe erhalten hatte. Für die Frage, ob auch ein Ressourcenschaden entsteht, kann die Vereinsstrafe nicht unmittelbar berücksichtigt werden. Schließlich verschwindet das Geld nicht, sondern fließt an den DFB. ${ }^{1420}$ Wenn man die Vereinsstrafe nicht für ersatzfähig halten würde, würde der Verein den ihm persönlich entstehenden Schaden über den Preis der Eintrittskarte auf alle Fans abwälzen. Dass ihm dies gelingt, erscheint wegen der hohen Nachfrage und des begrenzten Angebots an Karten zumindest mittelfristig durchaus realistisch. Als Beispiel eines externen Effekts ${ }^{1421}$ wäre der widrig handelnde Fan dann in der Lage, die Kosten seines Handelns auf unbeteiligte Dritte abzuwälzen. Die Fans müssten dann einen gehörigen Aufpreis für die Ticketleistung zahlen, nur damit Einzelne sich mittels destruktivem Verhalten selbst verwirklichen könnten (ökonomisch unerwünschte Quersubventionierung). Das führt eine Ineffizienz am Ticketmarkt herbei. Womöglich würden sich langfristig sogar einige Fans vom Stadionbesuch abwenden, weil die erhöhten Kosten sich ja nicht in der erhaltenen Leistung widerspiegeln können. Im Ergebnis droht daher ein vermeidbar suboptimaler Einsatz von Ressourcen - mithin ein Ressourcenschaden.Um einen Ressourcenschaden zu vermeiden, ist es daher erforderlich, dem Fan die gesamte Strafe in Rechnung zu stellen. Ob der drohende Ressourcenschaden aber genau in der Höhe des privaten Schadens des Vereins besteht, ist nicht klar zu beantworten. Die Rechtspraxis würde sich dann aber wohl oder übel daran orientieren müssen.

Zudem würde die Aufgabe, den Ressourcenschaden festzustellen, der Zivilgerichtsbarkeit aufgebürdet, weil sich hierzu keine verallgemeinerungsfähigen

1420 Dieser verwendet das Geld für gemeinnützige Zwecke, s. § 34 der Rechts- und Verfahrensordnung des DFB, abrufbar unter http://www.dfb.de/fileadmin/_dfbdam/50986-08_RechtsVerfahrensordnung.pdf, eingesehen am 4.6.2015. Regelmäßig wird das Geld an die Bundesliga-Stiftung geleitet, die wiederum nach ihrer Satzung über die Verwendung zu gemeinnützigen Zwecken entscheidet, vgl. § $6 \mathrm{~V}$ Anhang I zur Lizenzierungsordnung, abrufbar unter http://www.dfb.de/fileadmin/_dfbdam/15_Ligaverband_Ligastatut-3.pdf, zuletzt eingesehen am 24.7.2018. Dies kann kaum als sozialer Schaden bezeichnet werden.

1421 Zum Begriff Mankiw/Taylor, Volkswirtschaftslehre, 5. Aufl. 2012, S. 245. 
Aussagen treffen lassen. Richter wären mit ihrer begrenzten Zeit und Recherchemöglichkeiten aber selbst bei tiefschürfendem Vortrag der klagenden Partei womöglich - zu Recht - davon überfordert, eindeutige Feststellungen zu dem sozialen Schaden einer Handlung zu treffen. Der Ansatz ist deshalb zwar theoretisch attraktiv, er lässt sich aber in der Rechtspraxis nicht umsetzen. Es ist zudem nicht eindeutig, warum ausgerechnet der Gläubiger einer Nebenpflicht im Falle eines Ressourcenschadens diesen geltend machen können sollte. Schließlich wurde ja unmittelbar vorher festgestellt, dass der Schaden nicht ihm, sondern der Gesellschaft als Ganzes entstanden ist. Im Ergebnis kann deshalb aus dieser ökonomischen ratio, deretwegen Vermögensschäden nicht ungefiltert zu ersetzen sind, kein Schluss für die Reichweite von Nebenpflichten gezogen werden.

(b) Mögliche Konsequenz für § 241 II BGB: Bei Ressourcenschaden zumindest Schadensersatz

Ob der private Schaden über den Ressourcenschaden hinausgeht, ist aus ökonomischer Sicht für den sinnvoll zu ersetzenden Betrag irrelevant, weil diesem im Regelfall der Gewinn eines anderen gegenübersteht. Aus volkswirtschaftlicher Perspektive geht damit kein Geld verloren. Für den gesamtgesellschaftlichen Wohlstand ist nach der Ökonomik damit allein der Ressourcenschaden schädlich. Solche Überlegungen finden sich zwar explizit nicht in der deutschen Rechtsanwendung. Exemplarisch gegenüberzustellen sind aber einige Fälle, in denen eine Nebenpflicht abgelehnt oder angenommen wurde und sich das Ergebnis auch auf die Überlegungen zum Ressourcenschaden übertragen lässt.

Beispiel 7 Im Mietwohnungsfall ${ }^{1422}$ steht nicht der private Schaden des einzelnen Vermieters im Vordergrund, sondern der Ressourcenschaden, der dadurch entsteht, dass Mieter die Kosten ihrer Selbstverwirklichung (auf den ersten Blick) auf den Vermieter abwälzen. Letzterer hat dann zwei Möglichkeiten: Er kann entweder die Kosten, die Wände wieder weiß zu streichen, selbst schultern oder die Wohnung in unverändertem Zustand auf dem Wohnungsmarkt präsentieren. Entscheidet er sich für die erste Alternative, so wird

1422 S.o., S. 33. 
er zukünftig die Miete erhöhen müssen, um potentielles Weißeln der Wände am Ende der Mietzeit zu amortisieren. Dies individuell danach zu bemessen, ob der jeweilige Mieter geneigt ist, seine Wände farbig zu gestalten, würde immense Transaktionskosten nach sich ziehen. Zudem wäre es impraktikabel. Der Mieter darf seine Wände schließlich aus rechtlicher Perspektive während der Dauer der Mietzeit bunt streichen, vgl. § 538 BGB. Im Nachhinein fehlt es dem Vermieter aber an einem Druckmittel, die Kosten für das Weißeln vom Mieter zurückzuverlangen. Den Mieter vor der Anmietung zwischen einer Mieterhöhung oder dem Verzicht auf eine zulässige Nutzung der Mietsache wählen zu lassen, erscheint nicht nur rechtlich bedenklich. Damit wird der Vermieter pauschal die Miete für alle um die Kosten des Weißelns erhöhen. Wegen seiner Marktmacht ist er hierzu auch in der Lage. Der durchschnittliche Mieter wird schließlich eine weiße Wandfarbe in allen Räumen bevorzugen. Selbst ein farbaffiner Mieter wird im Regelfall individuelle Präferenzen bezüglich Farbe und Platzierung haben. Er wird sich kaum mit der Selbstverwirklichung durch einen Fremden zufrieden geben. Damit werden praktisch alle Mieter eine weiße Wandfarbe vorziehen. Gleichzeitig werden aber nicht alle Mieter überhaupt eine bunte Wandgestaltung innerhalb der Mietzeit vornehmen wollen. Sie müssen damit für die farbliche Selbstverwirklichung anderer Mieter mitbezahlen (ökonomisch zu missbilligende Quersubventionierung), was nicht ihrem Interesse entspricht.

Gleiches gilt für die zweite Alternative: Zwischen Mieter und Vermieter besteht - bis auf Aspekte des gesetzlichen Mieterschutzes eine zum Mieter hin geneigte Machtasymmetrie. Die Nachfrage ist im Regelfall größer als das Angebot. Deshalb werden Mieter sich schwer tun, eine Mietpreisreduktion durchzusetzen, weil die Wandfarbe nicht durchgehend weiß ist. Der Nachmieter wird dann notgedrungen aus eigenem Interesse dafür sorgen, dass die Wände wieder weiß gestrichen werden. Da nicht jeder Mieter auch selbst eine farbige Wandgestaltung vornehmen möchte, entspricht es nicht seinem Interesse, diese Kosten der Rückgängigmachung einer fremden Selbstverwirklichung selbst zu tragen. Auch hier 
müssen wieder die anderen Mieter die Kosten für die Handlungen des ersten Mieters schultern, obwohl sie nicht alle das gleiche Interesse an farbiger Wandgestaltung haben.

Wegen der Marktmacht der Vermieter haben also in beiden Alternativen die anderen, zukünftigen Mieter die Kosten dafür zu tragen, die Wände wieder weiß zu streichen. Deren Interessenlage ist aber nicht stets identisch mit der des farbaffinen Mieters. Der Mieter kann damit die Kosten für sein Handeln auf unbeteiligte Dritte abwälzen. Das Handeln des Mieters führt im Fall damit zu einem negativen externen Effekt. Das Entstehen eines negativen externen Effekts ist Zeichen für ein spezifisches Marktversagen, welches einen Markteingriff rechtfertigt. ${ }^{1423}$ Schließlich zahlt nicht derjenige, der von etwas profitiert. Damit entsteht auch ein Ressourcenschaden. Der Vermietungsmarkt ordnet nämlich die Belastungen nicht ausschließlich demjenigen zu, der sie verursacht. Manche Interessenten werden daher vom Abschluss eines Mietvertrages absehen und so dort effizient einzusetzendes Kapital dem Vermietungsmarkt entziehen. Zudem wird dem Vermietungsmarkt insofern zu viel Kapital zugeführt, als der von jedem Mieter zu tragende Aufschlag für das Weißeln einen Aufpreis darstellt, den diejenigen Mieter, welche kein Interesse am farbigen Streichen einer Wand haben, besser gewinnbringend in einem anderen Marktsegment untergebracht hätten. Dadurch werden Ressourcen nicht dort eingesetzt, wo sie den größtmöglichen Ertrag abwerfen - und damit Ineffizienz generiert. Der Markteingriff ist hier mittels einer aus $\S 241$ II $B G B$ abzuleitende Nebenpflicht vorzunehmen.

Droht indes kein nennenswerter Ressourcenschaden, so ist eine Nebenpflicht aus ökonomischer Perspektive mangels gesamtgesellschaftlichen Wohlfahrtsverlusts abzulehnen.

1423 Mankiw/Taylor, Volkswirtschaftslehre, 5. Aufl. 2012, S. 192, 247, 250; vgl. auch Spiecker, Informationsgewinnung, 2003, S. 33 (,[e]ntzieht sich der Staat [...] einer Entscheidung über eine Materie, [...] findet die Weiterentwicklung in diesem Bereich fernab seines Einflusses statt"). 
Der BGH hat entschieden, dass ein Steuerberater nicht auf Regressansprüche gegen den vorherigen Steuerberater sowie eine etwaige drohende Verjährung dieser Ansprüche hinzuweisen hat. ${ }^{1424}$ Das gilt auch dann, wenn der Steuerberater im Einspruchsverfahren gegen den Steuerbescheid tätig ist, welcher inhaltich mit dem Fehlverhalten des vorherigen Steuerberaters in Verbindung steht. ${ }^{1425}$ Zwar ist der Steuerberater cheapest cost avoider hinsichtlich der Schadensvermeidung, weil ihm ein Hinweis ohne größeren Aufwand möglich gewesen wäre. Aus einer volkswirtschaftlichen Perspektive führt der fehlende Hinweis des Steuerberaters auf die drohenden Verjährung eines etwaigen Schadensersatzanspruches gegen den alten Steuerberater indes in erster Linie zu einem Umverteilungsschaden: Der falsch Beratene ist nun nicht mehr in der Lage, den früheren Steuerberater in Anspruch zu nehmen, während jener von der Verbindlichkeit der Schadensersatzzahlung wirtschaftlich befreit wird. Der private Schaden des Beratenen spiegelt damit den Gewinn des früheren Steuerberaters. Ein Ressourcenschaden kommt damit nur noch hinsichtlich des effektiven Funktionierens des Steuerberatermarktes in Betracht. Hier gilt aber das gleiche wie im Insolvenzfall ${ }^{1426}$ : Für die Frage, ob einer Partei Ansprüche gegen eine andere Partei zustehen, ist auf dem Dienstleistungsmarkt der Rechtsanwaltsmarkt zuständig. ${ }^{1427}$ Dass der Steuerberater womöglich im Verhältnis zum Mandanten besser

1424 Hierzu und zum Sachverhalt BGH, Urt. v. 7.5.2015 - IX ZR 186/14, Rn. 1f., 5.m

1425 BGH, Urt. v. 7.5.2015 - IX ZR 186/14, Rn. 9, 11; OLG Schleswig-Holstein, Urt. v. 18.7.2014 - 17 U 21/14, Rn. 34ff.; Meixner/Schröder, Anm. zu OLG Schleswig, Urt. v. 18.7.2014 - 17 U 21/14, DStR 2015, 848; Zwade, Anm. zu BGH, Urt. v. 7.5.2015 - IX ZR 186/14, jurisPRBGHZivilR 12/2015, Anm. 1; insoweit a.A. Esskandari/Schmitt, Anm. zu OLG Schleswig, Urt. v. 18.7.2014 - 17 U 21/14, StBW 2015, 71, 72f.; Röhm/Seichter, Anm. zu BGH, Urt. v. 7.5.2015 - IX ZR 186/14, EWiR 2015, 575, 576 mit Blick auf die „,abstrakte Gefahr“ der Möglichkeit einer Verjährung von Regressansprüchen, auf die der Steuerberater hinweisen solle.

1426 S.o., S. 372.

1427 Dezidiert G. Wolf, Anm. zu BGH, Urt. v. 7.5.2015 - IX ZR 186/14, DStR 2015, 2094, 2095. Weil sich der Aufgabenbereich des Steuerberater gem. $\S \S 3,33$ S. 1 StBerG auf die Hilfeleistung in Steuersachen beschränkt, darf er wegen § 3 RDG gar nicht weitergehend rechtlich beraten, zutreffend Röhm/Seichter, Anm. zu BGH, Urt. v. 7.5.2015 - IX ZR 186/14, EWiR 2015, 575, 576 . 
qualifiziert ist, über dessen Ansprüche wegen fehlerhafter Steuerberatung zu urteilen, ist irrelevant. Entscheidend ist, dass er zumindest im Verhältnis zu einer anderen Berufsgruppe auf dem Dienstleistungsmarkt schlechter qualifiziert ist, über das Bestehen der Ansprüche zu urteilen. ${ }^{1428}$ Da es aber durch die Handlung des Steuerberaters zu keinem nennenswerten Ressourcenschaden kommt, kann von der Annahme einer Nebenpflicht unter diesem Aspekt abgesehen werden. Weil kein Ressourcenschaden droht, wäre eine Risikozuweisung nach dem Prinzip des cheapest cost avoider ökonomisch fehlgeleitet. Schaden im Sinne der cheapest cost avoider ist nämlich grundsätzlich der Umverteilungsschaden. Lässt sich feststellen, dass ein Ressourcenschaden durch das streitige Verhalten nicht droht, so zeigt eine ökonomische Perspektive, dass der Schaden zumindest im Verhältnis dieser beiden Parteien nicht ersatzfähig sein sollte. Anderenfalls würde nämlich dem Mandanten der Anreiz genommen, für die Klärung von Verjährungsfragen einen Anwalt aufzusuchen und der Steuerberater somit in Teilen zum Rechtsanwalt des Mandanten gemacht. Dem besser für die Beantwortung von Rechtsfragen qualifizierten Markt würde in der Folge Kapital entzogen, was zur ineffizienten Verteilung von Ressourcen führt. Die ökonomische Analyse befürwortet hier demnach gleiche Ergebnis, welches die Rechtsprechung erreicht.

1428 Aus diesem Grund kann der Kunde auch nicht auf die Hilfe des Steuerberaters vertrauen, G. Wolf, Anm. zu BGH, Urt. v. 7.5.2015 - IX ZR 186/14, DStR 2015, 2094, 2095. Vgl. auch Picker, FS Medicus, 1999, S. 397, 403, der zutreffend darauf hinweist, dass sich jeder Dienstleister selbst auf freiwilliger Basis davor hüten würde, eine ,professionsfremde Zusatzleistung“ mit ,Assekuranzcharakter" zu versprechen. Wäre hingegen ein Rechtsanwalt mit der Finanzstreitigkeit beauftragt gewesen, so hätte dieser sehr wohl darauf hinweisen müssen, dass bei Verlust im Einspruchsverfahren ein demnächst verjährender Anspruch gegen den vorherigen Steuerberater in Betracht kommen würde, so auch BGH, Urt. v. 7.5.2015 - IX ZR 186/14, Rn. 10. 
(c) Zwischenergebnis: Konvergenz von Ökonomik und Rechtspraxis

Auch wenn die Ökonomik nicht explizit berücksichtigt wird, so zeigen die Beispiele doch, dass die Rechtspraxis die Frage, ob eine Nebenpflicht anzunehmen ist, bereits bisweilen parallel zur Frage beantwortet, ob das Verhalten des Schuldners zu einem Ressourcenschaden führt. Die Forderung der Ökonomik, bei Vorliegen eines Ressourcenschadens daher zumindest Ersatz des privaten Schadens zu gewähren, lässt sich daher gut in die Subsumtion zu § 241 II BGB hinsichtlich der Frage nach der sinnvollen Reichweite von Vermögensschutz integrieren. Da sich der Ressourcenschaden aber einer praktischen Berechnung entzieht, kann auf den Umverteilungsschaden als quantitativen Anhaltspunkt für die Schadenshöhe in der Rechtspraxis indes nicht verzichtet werden.

(5) Besonderheiten bei der Zuweisung von Informationsverantwortlichkeit durch Nebenpflichten

Innerhalb der Kategorie der Nebenpflichten zum Schutz vermögenswerter Interessen machen Informationspflichten den größten Teil der aus § 241 II BGB abgeleiteten Verhaltensanforderungen aus. Weil sie deshalb in der Literatur häufig als isoliertes Diskussionsobjekt ausladend behandelt werden, soll auch im Kontext der Haftung des cheapest cost avoider auf einige Besonderheiten eingegangen werden.

(a) Struktur einer Informationspflicht

(aa) Notwendigkeit der Abgrenzung von Tun und Unterlassen?

Wenn es um die Verletzung von Informationspflichten durch Täuschung geht, wird der Unterscheidung von Tun und Unterlassen von der überwiegenden Ansicht eine zentrale Bedeutung beigemessen. ${ }^{1429}$ Liegt ein Tun vor, so wird mehrheitlich eine Wahrheitspflicht gefordert. ${ }^{1430}$ Unabhängig vom Bestehen einer

1429 Vgl. MüKo-BGB/Bachmann, 7. Aufl. 2016, § 241 Rn. 115 („,Falschinformation ist grundsätzlich immer eine Pflichtverletzung“), 116 (,bei einer unterbliebenen Information [...] Begründungslast für das Bestehen einer positiven Informationspflicht grundsätzlich höher").

1430 BAG, Urt. v. 15.12.2016 - 6 AZR 578/15, Rn. 27; BGH, Urt. v. 27.3.2009 - V ZR 30/08, Rn. 25 (BGHZ 180, 205, 214f.); OLG Köln, Urt. v. 26.2.2016 - 20 U 102/15, Rn. 21 („,verletzt 
Aufklärungspflicht über den konkreten Gegenstand wird in der Äußerung eine Pflichtverletzung gesehen, wenn sie nicht zutreffend ist. ${ }^{1431}$ Liegt der Schwerpunkt der Handlung auf einem Unterlassen, so ist lediglich dann eine wahrheitsgemäße Information gefordert, wenn über den betreffenden Gegenstand auch tatsächlich eine Aufklärungspflicht bestand. ${ }^{1432}$ Eine trennscharfe Abgrenzung ist jedoch in der konkreten Subsumtion nur selten möglich. ${ }^{1433}$

Beispiel 40 Ein Autohändler will einem Interessenten ein Auto verkaufen (,,Tachofall“). Im Rahmen der Verhandlung fragt der Käufer den Verkäufer, nach der Tacholeistung. Der Verkäufer hat an der Authentizität der angezeigten $34.000 \mathrm{~km}$ aufgrund einer gründlicher Inspektion des Tachos „keine Zweifel“ und gibt gegenüber dem Käufer eine „Laufleistung von $34.000 \mathrm{~km}$ auf Basis des von mir gründlich geprüften Tachos" an. In Wahrheit ist das Auto schon über $200.000 \mathrm{~km}$ gelaufen. Zur Verdeckung dieser Tatsache wurde der Tacho vom vorherigen Besitzer zurückgedreht. Dies geschah jedoch auf äußerst geschickte Weise, sodass es auch von einem Fachmann nur bei Ausbau des Tachos hätte bemerkt werden können. Der Verkäufer hatte das Auto von dem ihm vorher unbekannten Vorbesitzer zu einem verdächtig günstigen Preis erworben und

der Makler allerdings dann seine Beratungspflichten, wenn er seinem Auftraggeber falsche Auskünft erteilt"); Faust/Grigoleit, Verbraucher-acquis, 2011, S. 193, 195f.; Lorenz, Schutz, 1997, S. 412ff.; Lorenz, Anm. zu BGH, Urt. v. 27.3.2009 - V ZR 30/08, LMK 2009, 282362; Tröger, Arbeitsteilung, 2012, S. 472 (Fn. 190) m.w.N.; Werres, Aufklärungspflichten, 1985, S. 158. Teichmann, JA 1984, 545, 547 (Fn. 12) weist zutreffend darauf hin, dass der Befragte der Wahrheitspflicht auch genügt, wenn er die Antwort aktiv verweigert. Die überwiegende Ansicht in der Literatur stützt diese Wahrheitspflicht auf eine ,Inanspruchnahme von [normativ geprägtem] Vertrauen“, Tröger, Arbeitsteilung, 2012, S. 483 (Fn. 252f.) m.w.N.

1431 Lorenz, Schutz, 1997, S. 412f.

1432 Ausf. Lorenz, Schutz, 1997, S. 416ff. Die weichenstellende Abgrenzung zwischen Tun (Wahrheitspflicht) und Unterlassen (,nur“ Aufklärungspflicht, sofern vorhanden) wird im Wege einer „Gesamtbetrachtung“ unter Berücksichtigung des (erkennbaren) Parteiwillens und der jeweiligen Informationsasymmetrie vorgenommen, vgl. Lorenz, Schutz, 1997, S. 410f., 414f.; Tröger, Arbeitsteilung, 2012, S. 484

1433 MüKo-BGB/Bachmann, 7. Aufl. 2016, § 241 Rn. 116 („Grenze zwischen unterlassener Information und Falschinformation häufig fließend"); vgl. auch die für den normalen Rechtsverkehr schon beinahe zu diffizil wirkende Analyse von BGH, Urt. v. 13.6.2007 - VIII ZR 236/06, Rn. 18ff. zur Frage, ob es sich bei dem Hinweis, dass die Montage einer Solarheizungsanlage auch „,urch Laien erfolgen könne“, um eine Täuschung handeln könnte. 
hatte dessen Vertrauenswürdigkeit schon damals insgeheim infrage gestellt.

Die Handlungen des Verkäufers lassen sich hier in viele Teilakte unterteilen, denen man mit einer zwingenden Differenzierung zwischen Tun und Unterlassen nicht gerecht wird. So hat er eine aktive Aussage getroffen (,,keine Zweifel"), die im Ergebnis zu einem sachlich falschen Schluss geführt hat. Darin ließe sich ein Tun sehen. Genauso gut ließe sich darin aber ein Unterlassen sehen: So hatte er persönlich zumindest an der Authentizität des Tachos keine Zweifel. Die Aussage war also - auf ihn gemünzt - wahr. Er hätte aber trotzdem einen Irrtum aufseiten des Käufers verschuldet, wenn ihn eine Aufklärungspflicht über den korrekten Kilometerstand getroffen hätte. Genauso ist die Aussage zu werten, dass die Laufleistung ,auf Basis des von mir gründlich geprüften Tachos “ $34.000 \mathrm{~km}$ beträgt. Hier entspricht ein Teil der Aussage der Wahrheit, denn er hatte den Tacho tatsächlich gründlich überprüft und hieraus auf die Laufleistung von $34.000 \mathrm{~km}$ geschlossen. Dass der tatsächliche Kilometerstand aber - wie von ihm explizit angegeben - $34.000 \mathrm{~km}$ beträgt, ist als die entscheidende vom Verkäufer transportierte Information sachlich falsch (Täuschung), er war sich dieser Tatsache aber nicht bewusst (möglicherweise pflichtwidrig unterlassene Aufklärung). Hinzu kommt, dass der Verkäufer hier aus einem anderen Grund Anlass hatte, an dem Auto insgesamt - und damit auch an dessen Tachostand - zu zweifeln. Das ließe sich zum einen als Argument dafür nehmen, dass der Verkäufer hier über die Laufleistung mittels aktiver Aussagen getäuscht hat. ${ }^{1434}$ Zum anderen ließe sich diese Tatsache ebenso dafür ins Feld führen, dass der Verkäufer schwerpunktmäßig unterlassen hat. ${ }^{1435}$ In jedem Fall ist die Abgrenzung hier - wie in vielen Fäl-

1434 Dass die Tacholeistung zutreffend sein müsse, hat er schließlich mehr oder weniger direkt durchblicken lassen.

1435 Schließlich hat er den entscheidenden Grund dafür, dass womöglich Zweifel an der Tacholeistung angebracht gewesen wären, verschwiegen. 
len - kaum überzeugend und vermag auch keinen wirklichen Mehrwert zu leisten.

Eine Unterscheidung zwischen Tun und Unterlassen bei Informationspflichten ist damit wenig sinnvoll. ${ }^{1436}$ Viel wichtiger ist die Frage, ab welchem Punkt einer Partei die Verantwortung für ein bestimmtes Vorstellungsbild der anderen Partei zugewiesen werden kann. ${ }^{1437}$ Für diese Frage muss ein Abgleich der Realität der Informationsverteilung mit einem normativ ermittelten Sollzustand vorgenommen werden. Es müssen also Kriterien abgeleitet werden, welche die Verantwortlichkeit für eine bestimmte Information von der einen Partei zur anderen verlagern. Dieser Ansatz gilt für alle Informationspflichtverletzungen gleichermaßen.

(bb) Verhaltensbezogenheit von Informationspflichten

Das Verhalten eines Vorsatztäters im Kontext von Informationspflichtverletzungen wird von der Rechtsordnung bereits über die - insoweit speziellere - Anfechtung wegen arglistiger Täuschung nach § 123 I Alt. 1 BGB missbilligt. Der originäre Anwendungsbereich informationsbezogener Nebenpflichten findet sich deshalb bei unbewussten Verstößen gegen Informationspflichten. ${ }^{1438}$

Beispiel 40 Im Tachofall ${ }^{1439}$ täuscht der Verkäufer den Käufer in keinem Fall arglistig, denn er hat die Äußerung nicht ins Blaue hinein getä-

1436 So auch Tröger, Arbeitsteilung, 2012, S. 470 (Fn 180) m.w.N., 473f. Bände spricht insofern, dass Lorenz, Schutz, 1997, S. 409ff. zahlreiche Beispiele - nicht nur aus der Rechtsprechung nennt, in denen fälschlicherweise Tun oder Unterlassen angenommen wurde. Eine Abgrenzung, die derart fehleranfällig ist, sollte keinen Bestand haben.

1437 Letztlich auch MüKo-BGB/Bachmann, 7. Aufl. 2016, § 241 Rn. 116 (Unterscheidung zwischen Tun und Unterlassen bei Bestehen einer Aufklärungspflicht ,irrelevant"); i.E. auch BGH, Urt. v. 13.6.2007 - VIII ZR 236/06, Rn. 18ff., 35ff., der zwar eine Täuschung durch den - ohnehin nur schwer in die Dichotomie von Wahrheit und Unwahrheit einzufügenden - Hinweis ablehnte, dass die Montage einer Solarheizungsanlage auch durch ,Laien erfolgen kön$n e^{\text {", }}$ dann aber zumindest eine Hinweispflicht wegen der offenkundig eher schwierigen Montage annahm.

1438 Nur bei der unbewussten Verletzung einer Informationspflicht lassen sich auch ökonomisch fassbare Anreize zur Verbesserung des schuldnereigenen Informationshaushalts ausmachen, Tröger, Arbeitsteilung, 2012, S. 471.

1439 S.o., S. 381. 
tigt $^{1440}$ : Gründlich untersucht hat er den Tacho schließlich. Die vom Verkäufer getätigte Aussage war dennoch in Teilen sachlich falsch. Der korrekte Kilometerstand war dem Verkäufer nicht bekannt. Würde man dem Verkäufer im Rahmen der vorvertraglichen Verhandlungen eine Informationspflicht über den Wahrheitsgehalt des abgebildeten Kilometerstands auferlegen, so hätte er die betreffende Information erst noch beschaffen müssen. Hierfür wäre nicht nur eine kursorische Kontrolle, sondern sogar der Ausbau des Tachos erforderlich gewesen. Die Informationsbeschaffungskosten wären demnach beträchtlich gewesen. Ohne entsprechenden, womöglich gar separat vergüteten Prüfauftrag durch den Kunden muss ein Gebrauchtwagenverkäufer den Tacho daher nicht zur Kontrolle ausbauen. Daran kann aus einer ex-ante-Perspektive auch der Käufer kein Interesse haben, denn ansonsten hätte der Verkäufer den Kaufpreis um die beträchtlichen Informationsbeschaffungskosten erhöht. Da ein solch geschicktes Zurückdrehen des Tachos in der Praxis eher selten ist, wird der Käufer den Aufpreis in den meisten Fällen umsonst zahlen. Eine entsprechende Informationspflicht ist also zu verneinen. Diese - auch die Interessen des Käufers berücksichtigende - Wertung kann nicht berücksichtigen, wer eine unbedingte Wahrheitspflicht fordert. ${ }^{1441}$ Der Verkäufer hat dem Käufer hier schließlich auf dessen Frage eine in der Kernaussage - dem Kilometerstand - sachlich falsche Antwort gegeben. Damit hat er ihn - ohne jede Wertung zum Vertretenmüssen - getäuscht. ${ }^{1442}$

Ausgehend von dem Streit um die Unterscheidung von Tun und Unterlassen lassen sich Informationspflichtverletzungen durch Täuschung auf zwei unterschiedlichen Wegen erfassen: Man kann entweder im Rahmen der Pflichtverletzung eine unbedingte Pflicht zur Information fordern (,generelle[...] Wahrheitspflicht $\left.t^{\circ}\right)$ und die materiell entscheidenden Kriterien erst im Vertretenmüssen

1440 Vgl. zum Subsumtionsstandard HK-BGB/Dörner, 9. Aufl. 2017, § 123 Rn. 5.

1441 So BGH, Urt. v. 27.3.2009 - V ZR 30/08, Rn. 25 (BGHZ 180, 205, 214f.).

1442 Grundsätzlich gegen den Begriff der fahrlässigen Täuschung Honsell, FS Medicus, 2009, S. 181, 183. 
thematisieren. ${ }^{1443}$ Alternativ hierzu könnte man die Informationsverantwortlichkeit direkt im Rahmen der Pflichtverletzung begrenzen. ${ }^{1444}$

Beispiel 40 Im Tachofall ${ }^{1445}$ hat der Verkäufer dem Käufer gegenüber eine „Laufleistung von $34.000 \mathrm{~km}$ auf Basis des von mir gründlich geprüften Tachos" angegeben. Diese Aussage ist, was den wirklichen Kilometerstand anbelangt, nicht übereinstimmend mit der Realität und damit eine ,Lüge“. In der Fortsetzung vom Tachofall wurde - in Übereinstimmung mit der zweiten Ansicht - eine Informationspflicht über den Wahrheitsgehalt der abgebildeten Laufleistung abgelehnt. Weil der Verkäufer sich hierzu aber explizit geäußert hat, würde die erste Ansicht eine Pflichtverletzung wegen Verstoßes gegen die Wahrheitspflicht bejahen. ${ }^{1446}$

Nach der ersten Ansicht würde man im Rahmen der Pflichtverletzung den unbedingten Erfolg der Information über den betreffenden Gegenstand fordern. Das kommt einer erfolgsbezogenen Pflicht gleich und widerspricht der grundsätzlich verhaltensbezogenen Natur von Nebenpflichten. Auch die Bedeutung der Beweislastumkehr steigt hier in deutlichem Maße. Der Schuldner müsste dann bei jeder objektiven Falschaussage wegen $\S 280$ I 2 BGB beweisen, dass die Beschaffung der richtigen Information die im Verkehr erforderliche Sorgfalt überstiegen hätte. Eine Begrenzung der Verantwortlichkeit auf objektiver Ebene ist deshalb sinnvoll, weil es dem Vorgehen bei normalen Aufklärungspflichten entspricht ${ }^{1447}$ sowie einen Bruch mit dem Verständnis von Nebenpflichten insgesamt als verhaltensbezogene Pflichten vermeidet. Demnach sind Informationspflichten verhaltensbezogen zu zu verstehen und die Verantwortungsbereiche der

1443 So die herrschende Meinung, vgl. MüKo-BGB/Emmerich, 7. Aufl. 2016, § 311 Rn. 65; Teichmann, JA 1984, 545, 547 (Fn. 12); Tröger, Arbeitsteilung, 2012, S. 471, 472 (Fn. 190) m.w.N.

1444 Dies befürwortend Grigoleit, Schuldrechtsreform, 2001, S. 269, 275 (Fn. 28); Tröger, Arbeitsteilung, 2012, S. 472.

1445 S.o., S. 381.

1446 Mangels abweichender Regelung kann sich der Verkäufer gem. § 280 I 2 BGB exkulpieren, wenn die Täuschung nicht darauf zurückzuführen ist, dass er die im Verkehr erforderliche Sorgfalt außer Acht gelassen hat, vgl. § 276 II BGB. Die Berücksichtigung der hohen Informationsbeschaffungskosten etc. würde dann erst die verkehrserforderliche Sorgfalt und nicht bereits den Pflichtumfang begrenzen.

1447 Vgl. Tröger, Arbeitsteilung, 2012, S. 472. 
Parteien - unabhängig von der Unterscheidung zwischen Tun und Unterlassen bereits innerhalb der Pflichtverletzung trennscharf abzugrenzen.

(b) Ökonomische Funktion einer Informationspflicht

(aa) Grundsätzliches: Informationsbeschaffungskosten

Eine Informationspflicht hat die Mitteilung einer bestimmten Information ${ }^{1448}$ zum Gegenstand. Ohne Informationspflicht ist der Gläubiger selbst für seine Versorgung mit Informationen das Schuldverhältnis betreffend zuständig. ${ }^{1449}$ Mit einer Informationspflicht wird also die Verantwortlichkeit für einen bestimmten, abgegrenzten Informationsbereich vom Gläubiger auf den Schuldner verlagert. ${ }^{1450}$ Verfügt der Schuldner noch nicht über die Information, muss er sie beschaffen, um keine Pflichtverletzung zu begehen. Dafür muss er (wegen der Opportunitätskosten geldwerte) Zeit und/oder Geld aufwenden. Diese Kosten nennt man Informationsbeschaffungskosten. ${ }^{1451}$ Bei der Rekonstruktion des voll-

1448 Informationen sind nach der ökonomischen Analyse ,zweckorientiertes Wissen“, Schäfer/Ott, Ökonomische Analyse, 5. Aufl. 2012, S. 538. Durch ihre finale Ausrichtung auf einen (kosten)relevanten Vorgang können sie ein Handelsgut darstellen, auch wenn sie nur für ein einzelnes Individuum von Interesse sind.

1449 Roth, Information, 2006, S.104f.

1450 Um die Transaktionskosten möglichst gering zu halten, sollte der Gläubiger in diesem Fall auch auf die etwaige Aufwendung eigener Kosten zur Beschaffung der Information verzichten. Da der Schuldner ja wegen der Informationspflicht ohnehin Kosten zur Beschaffung der Information aufwenden muss, droht sonst ein doppelter Aufwand durch den Gläubiger, der als Teil der parteiübergreifend zur Transaktion aufgewendeten Kosten wiederum die Transaktionskosten erhöhen würde, vgl. Tröger, Arbeitsteilung, 2012, S. 483.

1451 Faust, Verbraucher-acquis, 2011, S. 201, 205. Damit soll nicht nur etwas Schädliches unterlassen werden, vielmehr wird dem Schuldner schon im Vorfeld der Pflichterfüllung ein kostenrelevantes Tun abverlangt. Aus diesem Grund ist eine Informationspflicht über beim Schuldner nicht vorhandenes Wissen nach der Rechtsprechung nur ausnahmsweise anzuerkennen, vgl. BGH, Beschl. v. 28.1.1992 - XI ZR 301/90, Rn. 4 („,Die Bank ist gegenüber dem Kreditinteressenten nicht verpflichtet, sich durch gezielte Auswertung ihr zugänglicher Unterlagen oder gar durch weitere Nachforschungen einen Wissensvorsprung zu verschaffen. Der positiven Kenntnis ist die bloße Erkennbarkeit nur dann gleichzustellen, wenn sich die für den Kreditnehmer bedeutsamen Tatsachen einem zuständigen Bankmitarbeiter nach den Umständen des Einzelfalls aufdrängen mußten [...].“); BGH, Urt. v. 29.4.2008 - XI ZR 221/07, Rn. 17, 20 (,Ausnahmsweise [!] steht die bloße Erkennbarkeit von aufklärungspflichtigen Tatsachen [...] der positiven Kenntnis [...] gleich“); BGH, Urt. v. 10.2.2015 - VI ZR 569/13, Rn. 22 (,Ausnahmsweise steht sogar die bloße Erkennbarkeit von aufklärungspflichtigen Tatsachen [...] der positiven Kenntnis gleich, wenn sich diese dem Vertragspartner [...] aufdrängen mussten und er die Augen davor verschlossen hat [...].“); OLG Bamberg, Urt. v. 18.1.2016 - 4 U 
ständigen Schuldverhältnisses ist deshalb für die Frage, wer von beiden Parteien cheapest cost avoider ist, auf die Informationsbeschaffungskosten abzustellen. ${ }^{1452}$ Sind die Informationsbeschaffungskosten für den Schuldner niedrig, so ist auch die durch eine entsprechende Nebenpflicht drohende Belastung gering.

Beispiel 40 Im Tachofall ${ }^{1453}$ traf den Verkäufer eine Informationspflicht über seine Zweifel an der Ehrbarkeit des Vorbesitzers, weil er aufgrund der Vorgeschichte des Autos konkrete Anhaltspunkte hatte, die Historie des Autos - inklusive der angezeigten Kilometerleistung zu hinterfragen. ${ }^{1454}$ Diese Information hatte auch unmittelbare Relevanz für ein vermögenswertes Interesse des Käufers, weil mit einer unsicheren Vergangenheit des Autos stets die Gefahr von Manipulationen oder versteckten Mängeln verbunden ist. ${ }^{1455}$ Die Information der fragwürdigen Herkunft besaß der Verkäufer bereits. Damit wären keine weiteren Informationsbeschaffungskosten angefallen. Auch bestand keinerlei ökonomisch schutzwürdiges Interesse des Verkäufers, die Information zurückzuhalten.

In einem solchen Fall ist ein mögliches Argument gegen die Belastung des Schuldners mit der Nebenpflicht - die aufoktroyierten Informationsbeschaffungskosten - zwar nicht gänzlich entkräftet, aber doch entscheidend ausgehöhlt. ${ }^{1456}$ Die Ausnahmestellung einer Informationsbeschaffungspflicht wird im

160/14, Rn. 36 (,wesentlicher Punkt, dass sich Aufklärungspflichten grundsätzlich auf präsentes Wissen beschränken“); Juretzek, Anm. zu BGH, Urt. v. 10.2.2015 - VI ZR 569/13, DStR 2015, 1646. Dies sieht auch die überwiegende Ansicht in der Literatur so, statt aller Tröger, Arbeitsteilung, 2012, S. 480f. (Fn. 241) m.w.N.

1452 Kersting, Dritthaftung, 2007, S. 404f.; Ott, Travemünder Symposium, 1989, S. 25, 35.

1453 S.o., S. 381.

1454 Vgl. hierzu BGH, Urt. v. 16.12.2009 - VIII ZR 38/09, Rn. 16.

1455 Vgl. MüKo-BGB/Emmerich, 7. Aufl. 2016, § 311 Rn. 83; zur Aufklärungspflicht über den bloßen „Verdacht“ von „,besonders schwerwiegenden Mängeln“, LG Köln, Urt. v. 17.3.2016 2 O 355/14, Rn. 23.

1456 Eine Nebenpflicht ist dann eher zu bejahen, vgl. BGH, Urt. v. 8.7.1981 - IVa ZR 244/80, Rn. 13 (Hinweispflicht eines Maklers auf eine in Fachkreisen hinlänglich bekannte Rechtsbestimmung im Mietrecht); BGH, Urt. v. 29.4.2008 - XI ZR 221/07, Rn. 20 (Aufklärungspflicht einer Bank gegenüber einem Kreditnehmer über eine offensichtlich erkennbare, sittenwidrige Überteuerung des von einem Dritten zu erwerbenden Kaufobjekts); BGH, Urt. v. 19.3.2013 XI ZR 431/11, Rn. 26f. (Hinweispflicht eines nachgeschalteten Wertpapierdienstleistungsunternehmen auf eine vorherige Falschberatung, sofern sie ,aufgrund massiver Verdachtsmo- 
Rahmen der Behandlung von Aufklärungspflichten durchaus explizit betont. ${ }^{1457}$ Eine Informationsbeschaffungspflicht setzt - anders als eine reine Hinweispflicht ${ }^{1458}$ - schließlich eine vorhergehende Untersuchung und damit deutliche höhere Informationsbeschaffungskosten für den Schuldner voraus. Sie droht damit leichter in Konflikt mit dem (parteiautonom) bestimmten Verhältnis zwischen Leistung und Gegenleistung zu geraten. Die Unterscheidung zwischen reiner Aufklärungspflicht und umfassender Informationspflicht (inklusive einer Recherchepflicht) gelingt aber in der Praxis nicht immer trennscharf. ${ }^{1459}$

Beispiel 6 Im Haltefristfall ${ }^{1460}$ war der Steuerberater aufgrund der Nebenpflicht dazu verpflichtet, auf die drohende, kurz vor Ablauf der

mente objektiv evident ist"); LG Heidelberg, Urt. v. 14.2.2006 - 2 S 46/05, Rn. 15ff. (Hinweispflicht des Maklers auf eine dem Mieter nicht bekannte Sozialproblematik der Wohngegend); LG Rottweil, Urt. v. 23.1.2007 - 6 O 1/06, Rn. 17 (Hinweispflicht einer Autoreparaturwerkstatt auf einen (für Fachkreise) typischen, die ursprüngliche Reparatur begründenden Vorschaden); LG Trier, Urt. v. 19.2.2016 - 1 S 131/15, Rn. 42ff. (keine „Verpflichtung zum Vorhalten einer funktionsfähigen Toilette im Personennahverkehr" mit Blick auf die „Mehrkosten“, aber denkbare „Aufklärungspflicht hinsichtlich nicht funktionsfähiger Toiletten" gegenüber Bahnkunden aufgrund von ,geringerem organisatorischen Aufwand") Menkel, DStR 2010, 2477, 2479f. (Grenze der weiterern „Sachverhaltsermittlung“ für Nebenpflichten des Steuerberaters); M. Müller/Hempel, AcP 205 (2005), 246, 248; Tröger, Arbeitsteilung, 2012, S. 481f.

1457 Laut MüKo-BGB/Bachmann, 7. Aufl. 2016, § 241 Rn. 122 könne die Aufklärungspflicht einer Partei ausnahmsweise ,aber auch so weit [!] gehen, dass sie sich die Kenntnis aus den ihr zugänglichen Quellen verschaffen muss".

1458 Auch wenn von Hinweispflicht gesprochen wird, so ist jedoch präzise zu untersuchen, ob nicht doch eine Informationsbeschaffungspflicht gemeint ist. So wird im Anwaltshaftungs- und sonstigem Beratungsrecht häufig der Gedanke bemüht, dass eine Partei die andere auf ihre Fehler hinweisen muss, weil diese ansonsten nur schwerlich oder unter unzumutbaren Kosten vom Gläubiger aufgedeckt werden könnten, vgl. MüKo-BGB/Heermann, 7. Aufl. 2018, § 675 Rn. 28f.; Staudinger/Olzen, Neubearbeitung 2015, § 241 Rn. 448 sowie nunmehr im Arzthaftungsrecht explizit in § 630c II 2 BGB (,Sind für den Behandelnden Umstände erkennbar, die die Annahme eines Behandlungsfehlers begründen, hat er den Patienten über diese auf Nachfrage oder zur Abwendung gesundheitlicher Gefahren zu informieren.") geregelt; skeptisch hierzu MüKo-BGB/Wagner, 7. Aufl. 2016, §630c Rn. 31 (,praktische Relevanz der Pflicht zur Fehlerinformation dürfte minimal bleiben"). Nur wenn der Dienstleister den begangenen Fehler positiv kennt, handelt es sich aber um eine Hinweispflicht. Hat er seinen eigenen Fehler hingegen fahrlässig (vgl. § 276 II BGB) übersehen - was der praktische Regelfall sein dürfte , so ist einer etwaigen Hinweispflicht eine Informationsbeschaffungspflicht vorgeschaltet.

1459 So wird bei den Informationspflichten von Dienstleistern bisweilen eine Informationsbeschaffungspflicht implizit angenommen, ohne dass die Ausnahmestellung hierbei explizit betont wird.

1460 S.o., S. 26ff. 
Haltefrist maximierte Wirkung des $\$ 23$ III 4 EStG hinzuweisen. Diese Information hatte er im Fall nicht parat. Vielmehr ist er in der kurzen Zeit, die ihm zum Überlegen zur Verfügung stand, nicht darauf gekommen. Damit traf den Schuldner hier nicht nur eine Informationspflicht, sondern auch eine vorgeschaltete Informationsbeschaffungspflicht. Dass der BGH hier aus diesem Grund besonders restriktiv mit der Annahme einer Nebenpflicht umgegangen ist, lässt sich nicht feststellen. Vielmehr hat er eine Nebenpflicht angenommen, obwohl das zugrundeliegende Schuldverhältnis überhaupt keine Vergütung für den Steuerberater vorsah. Dass die Informationspflicht den Steuerberater hier dazu verpflichtete, die - zugegebenermaßen wohl einfach zu beschaffende - Information unter Einsatz seiner geldwerten Arbeitszeit zu beschaffen, wurde vom BGH in der Subsumtion nicht explizit berücksichtigt. $^{1461}$

Anstelle einer qualitativen (kategorialen) Unterscheidung zwischen reinen Hinweis- und umfassenden Informationspflichten sollte eine quantitative (stufenweise) Analyse unter anderem in Bezug auf die Informationsbeschaffungskosten vorgenommen werden.

(bb)Ökonomische Grenzen einer Informationspflicht

Eine natürliche Grenze für eine mit einer Informationsbeschaffungspflicht einhergehende Informationspflicht ist - im Einklang mit dem Prinzip des cheapest cost avoider - ein Kostenvorteil des Gläubigers bei der Informationsbeschaffung. Kann der Gläubiger die Information günstiger als der Schuldner beschaffen, so ist es aus einer volkswirtschaftlichen Perspektive ineffizient, die Informationsbeschaffung dem Schuldner zuzuordnen. ${ }^{1462}$ Auch aus mikroökonomischer Schuldverhältnis-Perspektive ist eine solche Nebenpflicht abzulehnen: Der

1461 M. Müller/Hempel, AcP 205 (2005), 246, 247 (Fn. 4) weisen zutreffend darauf hin, dass die Schadensvermeidungskosten in der ökonomischen Analyse eine größere Rolle spielen als in der rechtswissenschaftlichen Abwägung, vgl. ähnlich zur Herangehensweise der Rechtsprechung Mertens, AcP 178 (1978), 227, 257 (,Kosten-Nutzen-Problem [wird] ignoriert").

1462 Vgl. Ott, Travemünder Symposium, 1989, S. 25, 35; Tröger, Arbeitsteilung, 2012, S. 482 
Schuldner würde versuchen, seine Informationsbeschaffungskosten durch eine Preiserhöhung zu amortisieren. Der Gläubiger würde wiederum nur einen solchen Aufpreis akzeptieren, welche maximal seine eigenen Informationsbeschaffungskosten erreicht. Ansonsten würde er die Information schließlich lieber selber beschaffen und auf die Pflicht des Schuldners verzichten.

Sollte umgekehrt der Schuldner die Information günstiger als der Gläubiger beschaffen können - ist er also cheapest cost avoider - so spricht dies in den Grenzen der Höhe des Nutzens der Information für den Gläubiger (als Repräsentant für dessen Bereitschaft, für die Nebenpflicht zu bezahlen) für die Annahme einer Nebenpflicht. Eine Informationspflicht des Gläubigers kommt dann in Betracht, wenn das angestrebte Geschäft aufgrund einer asymmetrisch verteilten Informationslage - bei individueller Betrachtung - für den Schuldner keinen Nutzen (mehr) abwirft und deshalb - bei überindividueller Betrachtung - Ineffizienzen auf dem jeweiligen Markt drohen (ökonomisch zu missbilligende Gefahr des Opportunismus). ${ }^{1463}$ In der Sache strebt die Ökonomik hier das gleiche Ziel an wie die rechtswissenschaftliche Dogmatik, wenn sie versucht, mittels Nebenpflichten ein funktionales Äquivalenzverhältnis aufrechtzuerhalten ${ }^{1464}$.

(cc) Makroökonomische Folgen einer Informationspflicht

Welchen Einfluss die Folgenbewertung auf Nebenpflichten für Informationen hat, zeigt sich insbesondere dann, wenn die potentiell mit der Nebenpflicht zu belastende Partei bereits über die Information verfügt. Die Informationsbeschaffungskosten belaufen sich auf Schuldnerseite in diesem Fall auf Null, belasten ihn also überhaupt nicht. Eine Nebenpflicht hier abzulehnen, würde bedeuten,

1463 Kübler, FS Steindorff, 1990, S. 687, 701f.; Rehm, Aufklärungspflichten, 2003, S. 118f., 238f., 266f.; Schäfer/Ott, Ökonomische Analyse, 5. Aufl. 2012, S. 451f.; vgl. auch Schweizer, Spieltheorie, 2015, S. 288, der Informationspflichten aus mathematischer Perspektive vor allem bei fremdnützigen (also allein den Nutzen des Schuldverhältnis-Partners betreffend) Informationen in risikoreichen Geschäften für angemessen hält. Das erscheint auch ökonomisch plausibel: Je höher das Risiko eines Geschäfts ex ante ist, umso mehr Einfluss kann eine einzelne Information auf das Äquivalenzverhältnis haben, vgl. auch Kersting, Dritthaftung, 2007, S. 403f.; zu Recht skeptisch gegenüber dem Versuch, für die Annahme von Aufklärungspflichten fremdnützige Schuldverhältnisse ausmachen zu wollen, Klinck, Information, 2013, S. 103, 106.

1464 S.o., S. $244 f f$. 
die Verantwortlichkeit für die betreffende Information beim Gläubiger zu belassen. Dieser müsste sie aber erst beschaffen. Es würden also Informationsbeschaffungskosten anfallen. Weil der Schuldner die Information bereits hat, ist davon auszugehen, dass bereits einmal Informationsbeschaffungskosten aufgewendet wurden. Diese nun doppelt anfallen zu lassen, erscheint wenig sinnvoll. Ähnliches gilt, wenn der Schuldner zumindest niedrigere Informationsbeschaffungskosten als der Gläubiger hat - er also cheapest cost avoider ist. Sollen die gesamtgesellschaftlichen Kosten im Interesse aller möglichst gering gehalten werden, so sprechen die zumindest niedrigeren Informationsbeschaffungskosten des Schuldners zunächst für eine Informationspflicht. Leistet die Beschaffung der Information durch den Gläubiger aber zum Beispiel einen ökonomisch sinnvollen Beitrag zum Funktionieren des Marktes durch die analytische Nutzung offener Quellen, so führt sie zu einem positiven externen Effekt. ${ }^{1465}$

Im Grundsatz ${ }^{1466}$ führt die Beschaffung von Informationen durch den Gläubiger über ein fungibles Handelsgut dazu, dass der Preisbildungsmechanismus gestärkt wird. Schließlich setzt die Vereinbarung eines marktgerechten Preises die Information des Gläubigers über erkennbare Risiken voraus. Nimmt man allzu großzügig Nebenpflichten des Schuldners zur Information des Gläubigers an, so wird dem Gläubiger jeglicher Anreiz genommen, sich selbst an einer Risikoanalyse des Kaufguts zu beteiligen. Dieser Paternalismus kann zum Erlahmen der Preisbildung führen, was wiederum in Unter- oder Überbewertungen die Fehlallokation von Ressourcen auf dem Markt zur Folge haben kann. Abgesehen vom Nutzen des Gläubigers für die konkrete Verhandlung hat die Informationsbeschaffung durch den Gläubiger daher als Beitrag zur Preisbildung auch einen äkonomisch-überindividuellen Nutzen für den

1465 Vgl. Mankiw/Taylor, Volkswirtschaftslehre, 5. Aufl. 2012, S. 246f., 250ff.; Schäfer/Ott, Ökonomische Analyse, 5. Aufl. 2012, S. 538f.

1466 Eine Ausnahme stellt das Umfeld des Kapitalmarktes dar: Hier hat der einzelne Teilnehmer ohnehin kaum Einfluss auf den positiven externen Effekt „Funktionieren des Preisbildungsmechanismus", weshalb eine Informationspflicht mit Blick auf die drohende Dopplung der Informationsbeschaffungskosten hier eher anzunehmen ist, Tröger, Arbeitsteilung, 2012, S. 479 (Fn. 228). 
Markt als Ganzes - und hat damit einen positiven externen Effekt zur Folge.

Eine Nebenpflicht kann demnach trotz der möglicherweise erneut anfallenden Informationsbeschaffungskosten abzulehnen sein, weil dem Gläubiger sonst der Anreiz genommen würde, zum Funktionieren des Marktes beizutragen. ${ }^{1467}$

So muss beispielsweise ein Arbeitgeber seine Mitarbeiter nicht auf die für die Altersversorgung relevante Möglichkeit einer Entgeltumwandlung nach § 1a BetrAVG hinweisen, weil die Mitarbeiter sich hierüber zum einen kostengünstig selbst informieren können und anderenfalls zudem eine völlige Initiativlosigkeit der Arbeitnehmer hinsichtlich ihrer eigenen Altersversorgung droht. ${ }^{1468}$ Will ein Arbeitnehmer zu seinem eigenen Vorteil von einer steuerrechtlichen Grundregel durch Vereinbarung mit dem Arbeitnehmer abweichen, so muss er ebenfalls Eigeninitiative beweisen und kann nicht auf das Tätigwerden des Arbeitgebers vertrauen. ${ }^{1469}$ Entsprechende Nebenpflichten zur Information des Gläubigers werden hier von der Rechtsprechung im Ergebnis zutreffend abgelehnt, weil der Informationsbeschaffung durch den Schuldner in der Sache ein positiver externer Effekt innewohnt. Die Beteiligung des Arbeitnehmers an der Planung seiner Sozialversicherungs- und Steuerplanung führt nämlich dazu, dass er insoweit eine mündigere Rolle einnimmt und in der Folge eine Planung verfolgen kann, die genau seinen individuellen Präferenzen entspricht. Fehleinsatz von Ressourcen bei der Planung der Altersversorgung oder der Steuerangelegenheiten - auch vonseiten der Altersversorger oder der Steuerbehörden - wird so besser vermieden, als wenn der Arbeitnehmer blind auf die zwingend generischen Hinweise des Arbeitgebers vertraut. Nimmt man dem Arbeitnehmer hier über eine Informationspflicht des Arbeitgebers den Anreiz, sich über die Ge-

1467 Tröger, Arbeitsteilung, 2012, S. 477f.

1468 Vgl. BAG, Urt. v. 21.1.2014 - 3 AZR 807/11, Rn. 20 (BAGE 147, 155, 161); Hartmann, Anm. zu BAG, Urt. v. 21.1.2014 - 3 AZR 807/11, EWiR 2014, 569, 570.

1469 BAG, Urt. v. 13.11.2014 - 8 AZR 817/13, Rn. 24f. 
staltungsalternativen zu informieren, so verhindert man das Entstehen dieses positiven externen Effekts.

Das zeigt, dass die jeweilige Höhe der Informationsbeschaffungskosten für den Gläubiger und den Schuldner der Ausgangspunkt für die Entscheidung über eine Nebenpflicht sein muss. Ist aber die Informationsbeschaffung durch den Gläubiger von Vorteil für das Funktionieren des Marktes oder führt sie zu einem anderen positiven externen Effekt, so geben die Informationsbeschaffungskosten nicht mehr den Ausschlag. Vielmehr ist dann zu untersuchen, welche Bedeutung die Informationsbeschaffung für den jeweiligen positiven externen Effekt hat. ${ }^{1470}$

Ist eine Information gesamgesellschaftlich nutzenbringend, so darf dem Schuldner durch eine Nebenpflicht zudem nicht der Anreiz genommen werden, sie zu beschaffen. Die Verwertung einer Information ist dann produktiv, wenn sie zu einem Nettowohlfahrtsgewinn führt. ${ }^{1471}$

Beispiel 41 Ein Verkäufer bietet in einem abgelegenen Teil Schleswig-Holsteins ein großes Grundstück für 100.000€ zum Verkauf an (,,Grünkohlfall“). ${ }^{1472}$ Ein Interessent besichtigt das Grundstück und nimmt im Einvernehmen mit dem Verkäufer eine Bodenprobe. Nach wissenschaftlicher Analyse des Mutterbodens stellt er fest, dass der Untergrund biologisch besonders gut für den Anbau einer seltenen Zuchtform des Grünkohls geeignet ist. Weil diese Form des Grünkohls stark nachgefragt ist, es aber wegen der komplexen Anforderungen an die „Ackerkrume“ (Mutterboden) sehr schwierig ist, ihn anzubauen, beträgt der Marktwert eines Anbauorts in der Größe des Grundstücks vom Verkäufer 200.000€. Die Verwer-

1470 Je mehr Einfluss die Informationsgewinnung durch den Gläubiger auf das Funktionieren des Marktes hat, desto mehr spricht gegen eine Nebenpflicht. Die soeben genannten Kriterien sind letztlich in einer wertenden Abwägung gegenüberzustellen, vgl. Tröger, Arbeitsteilung, 2012, S. $478 \mathrm{f}$.

1471 Kötz, FS Drobnig, 1998, S. 563, 569; Schäfer, AcP 202 (2002), 808, 815; Schäfer/Ott, Ökonomische Analyse, 5. Aufl. 2012, S. 538; Shavell, Economic Analysis, 2004, S. 334. Das ist schon dann der Fall, wenn die Partei, die sie erhalten soll, von ihr einen größeren Nutzen hat, als sie in Form eines (Auf-)Preises dafür hypothetisch zu zahlen bereit gewesen wäre, Faust, Verbraucher-acquis, 2011, S. 201, 206; Kersting, Dritthaftung, 2007, S. 399, 403f.; Kötz, FS Drobnig, 1998, S. 563, 566f.; Schäfer/Ott, Ökonomische Analyse, 5. Aufl. 2012, S. 584.

1472 Fall basierend auf Schäfer/Ott, Ökonomische Analyse, 5. Aufl. 2012, S. 538f.; vgl. auch Shavell, Economic Analysis, 2004, S. 333. 
tung der Information durch den Interessenten führt hier dazu, dass er ein Grundstück deutlich unter Marktwert kauft. Dass der Marktwert so hoch ist, hat er aber durch Investitionen in die Informationsbeschaffung selbst herausgefunden. Ohne ihn oder einen vergleichbar investigativen Interessenten wäre der über dem Kaufpreis liegende Nutzwert des Grundstücks unentdeckt geblieben. Der Käufer hat durch die Informationsverwertung dafür gesorgt, dass eine Ressource (Grundstück des Verkäufers) ihrer gewinnbringendsten Bewirtschaftung zugeführt wird. Damit erhöht die Verwertung dieser Information durch den Käufer den gesamtgesellschaftlichen Wohlstand. Sie ist also produktiv.

Erhöht sie den gesamtgesellschaftlichen Wohlstand nicht, sondern dient lediglich einer einzelnen Privatperson, so ist die Information entsprechend unproduktiv. ${ }^{1473}$

Beispiel 42 Ein Verkäufer bietet ein Grundstück für 100.000€ (aktueller Marktwert) zum Verkauf an (,Erdbeerfall“). ${ }^{1474}$ Das Grundstück bietet als eines der wenigen in Hamburg ausgezeichneten Mutterboden für den Anbau von Erdbeeren. Die landwirtschaftliche Nutzung von Grundstücken innerhalb Hamburgs ist indes derzeit verboten. Ein potentieller Käufer interessiert sich für das Grundstück, ist aber nicht bereit den geforderten Preis zu bezahlen. Während er seine Frau besucht, die im Rathaus arbeitet, hört er ein Gespräch zwischen zwei Stadtangestellten. Aufgrund der gedämpften Lautstärke des Gesprächs kann der Interessent nur verstehen, dass das Verbot der landwirtschaftlichen Nutzung von Grundstücken vonseiten der Legislative ,unter Beschuss “ steht. Angestachelt von der Hoffnung das „, Geschäft seines Lebens“ zu machen, nimmt er sich unbemerkt den Eintrittsausweis seiner Frau für das Rathaus und schleicht sich in eine geschlossene Sitzung des betreffenden Ausschusses. Dort bekommt er mit, wie die Aufhebung des Verbots

1473 Kötz, FS Drobnig, 1998, S. 563, 570; Schäfer, AcP 202 (2002), 808, 815; Shavell, Economic Analysis, 2004, S. 334.

1474 Fall angelehnt an Schäfer/Ott, Ökonomische Analyse, 5. Aufl. 2012, S. $538 f$. 
der landwirtschaftlichen Nutzung von Stadtgrundstücken für das kommende Jahr beschlossen wird. Das Grundstück des Verkäufers ist aufgrund seiner exzellenten Ackerkrume und der Tatsache, dass Hamburger Landwirtschaftsprodukte wegen des geringen Angebots extrem nachgefragt sind, nun 200.000€ wert. Bevor der Beschluss im Newsletter der Bürgerschaft oder im Gesetzesblatt bekanntgegeben wird, eilt der Interessent zum Verkäufer und schließt einen Kaufvertrag über das Grundstück für 100.000€. Der Käufer hat hier Zeit und Mühe (Opportunitätskosten) in die Beschaffung der Information investiert. Durch die Verwertung der Information hat er ein Grundstück letztlich unter Marktwert erworben, weil er sich sicher sein konnte, dass sich der Wert kurz nach dem Kauf verdoppeln würde. Die Verwertung der Information hat ihm daher einen Vorteil verschafft. Dieser Vorteil hat aber keine Steigerung der gesamtgesellschaftlichen Produktivität zur Folge. Schließlich wäre die Information, dass das Grundstück zukünftig für landwirtschaftliche Bewirtung freigegeben ist, auch ohne die "Recherche“ des Käufers öffentlich geworden. Zu diesem Zeitpunkt hätte sich der Marktwert automatisch an die nunmehr verbesserte Nutzbarkeit des Grundstücks angepasst und der Verkäufer hätte das Grundstück für 200.000€ anbieten können. Dass der Käufer die Information vor ihrer Veröffentlichung ausfindig gemacht hat, erhöht auch nicht den Ertrag aus dem Grundstück. Die Nutzung als Anbaufläche ist schließlich auch für den Käufer erst zum gesetzlich geregelten Zeitpunkt möglich. Der Käufer hat also mit der Verwertung der Information keinen Nettowohlfahrtsgewinn erzielt, sondern lediglich einen privaten Gewinn auf Kosten des Verkäufers erzielt. Damit ist die Verwertung dieser Information unproduktiv.

Der Rechtsordnung kommt in den Augen der ökonomischen Analyse die Aufgabe $\mathrm{zu}$, Anreize für die Beschaffung produktiver Informationen $\mathrm{zu}$ setzen und gleichzeitig die Beschaffung unproduktiver Informationen als Fehleinsatz von Ressourcen, welche an anderer Stelle einen Nettwohlfahrtsgewinn generieren 
könnten, zu unterbinden. ${ }^{1475}$ Ein Steuerungsinstrument hierfür sind Nebenpflichten, welche zur (unvergüteten) Weitergabe einer Information verpflichten können. ${ }^{1476}$ Um die richtigen Anreize zu setzen, muss in einem Schuldverhältnis der Inhaber einer unproduktiven Information mit einer Nebenpflicht zur Weitergabe dieser Information an den Schuldverhältnis-Partner verpflichtet werden.

Beispiel 42 Im Erdbeerfall ${ }^{1477}$ hat der Käufer eine unproduktive Information erlangt und verwertet. Will man ihn dazu zwingen die Information vor Abschluss des Vertrages preiszugeben, so muss der Verkäufer Gläubiger einer entsprechenden Nebenpflicht nach \$241 II BGB werden. ${ }^{1478}$ Hat der Verkäufer bereits im Laufe der Verhandlungen Anhaltspunkte, den plötzlichen Sinneswandel des Käufers über die Angemessenheit des Verkaufspreises verdächtig zu finden, so kann er von diesem die Erfüllung einer etwaigen Informationspflicht fordern oder gegebenenfalls gerichtlich durchsetzen. ${ }^{1479}$ Mit einer solchen Nebenpflicht ist der Käufer jedenfalls dazu verpflichtet, die Information kostenlos im Rahmen der Verhandlungen an den Verkäufer weiterzugeben. ${ }^{1480}$ Tut er das nicht, so kann der Verkäu-

1475 Näher Schäfer/Ott, Ökonomische Analyse, 5. Aufl. 2012, S. 538f., 540; Schweizer, Spieltheorie, 2015, S. 265; ähnlich auch Faust, Verbraucher-acquis, 2011, S. 201, 210f.; Matthias Lehmann, ZEuP 2009, 693, 701.

1476 Kötz, FS Drobnig, 1998, S. 563, 568; Schäfer, AcP 202 (2002), 808, 815.

1477 S.o., S. 394.

1478 Er befindet sich im Rahmen der Grundstückskaufverhandlungen in einem Schuldverhältnis mit dem Verkäufer nach $\S 311$ II Nr. 1 BGB.

1479 Nebenpflichten sind nach umstrittener Ansicht sowohl einforder- als auch klagbar, s.o., S. 146f., 152f.

1480 Bei der Begründung einer Nebenpflicht auf diesem Weg wird plastisch deutlich, dass der Gedanke der Kompensation für Nebenpflichten in vorvertraglichen Schuldverhältnissen nur bedingt passt und deshalb Nebenpflichten nicht zur Gänze erfassen kann, s.o., S. 254ff. Der Käufer würde hier eine Information aufgeben müssen, deren Beschaffung ihm (Opportunitäts)Kosten verursacht hat. Das vorvertragliche Schuldverhältnis zwischen Käufer und Verkäufer beinhaltet aber überhaupt keine Leistungspflichten, sodass ein Einpreisen der Nebenpflicht nicht in Betracht kommt. Eine Vergütung allein für die Information kann der Käufer nicht einseitig verlangen. Für eine solche Vergütung müsst er eine separate Vereinbarung mit dem Verkäufer schließen. Da die Informationspflicht ja aber schon aus dem VerhandlungsSchuldverhältnis und § 241 II BGB folgt, hat der Verkäufer keinerlei Anreiz, einem separaten Vergütungs-Schuldverhältnis mit dem Käufer zuzustimmen. Da für den Käufer die Erfüllung der Pflicht aufgrund des ansonsten drohenden Schadensersatzanspruchs nicht optional ist, hat er auch kein probates Mittel, eine solche Vereinbarung durchzusetzen. Gleiches gilt für den womöglich auf die Verhandlung folgenden Kaufvertrag: Da der Käufer bereits aus dem vor- 
fer gem. $\$ \S 280$ I, 241 II, 311 II Nr. 1 BGB Schadensersatz fordern. Da der Käufer für die Information (Opportunitäts-)Kosten aufgewendet hat, stellt die kostenlose Weitergabe an den Verkäufer für ihn ein Verlustgeschäft dar. Dieses Verlustgeschäft kann er nur vermeiden, wenn er bereits die Beschaffung der Information unterlässt. Die Nebenpflicht setzt damit einen Anreiz dafür, unproduktive Informationen gar nicht erst in Erfahrung zu bringen. ${ }^{1481}$ Damit ist eine Nebenpflicht hier die adäquate Reaktion der Rechtsordnung. ${ }^{1482}$

Beispiel 41 Im Grühnkohlfall ${ }^{1483}$ hingegen verwertet der Käufer eine produktive Information. Dieser Vorgang ist von der Rechtsordnung zu schützen. ${ }^{1484}$ Den Käufer hier mit einer Nebenpflicht zur Aufdeckung seiner kostenrelevanten Rechercheergebnisse zu belegen, würde genau das Gegenteil erreichen: Ihm würde ein Anreiz dafür gegeben, die Information gar nicht erst zu beschaffen. Eine Nebenpflicht ist hier daher abzulehnen. ${ }^{1485}$

Die makroökonomischen Folgen der Informationsbeschaffung und -verwertung sind deshalb ein wichtiger Anhaltspunkt dafür, ob die Ökonomik eine informationsbezogene Nebenpflicht befürwortet oder nicht.

vertraglichen Schuldverhältnis dazu verpflichtet ist, die Information an den Verkäufer weiterzuleiten, besteht für ihn kein Anreiz, bei der Vereinbarung des Kaufpreises innerhalb des rechtsgeschäftlichen Schuldverhältnisses die Nebenpflicht des Käufers preismindernd zu berücksichtigen. Der Käufer wiederum hat - bis auf einen ebenfalls keine Vergütung generierenden Verhandlungsabbruch - erneut kein Druckmittel in der Verhandlung darüber, ob seine eigenen Informationskosten als Teil seiner Gegenleistung (Kaufpreis) gelten sollen.

1481 Schäfer, AcP 202 (2002), 808, 815; Schweizer, Spieltheorie, 2015, S. 266 (sog. „Hold-upProblematik").

1482 So zu einem ähnlichen Fall auch Kötz, FS Drobnig, 1998, S. 563, 570.

1483 S.o., S. 393.

1484 In diese Richtung bereits Medicus, Privatautonomie, 1994, S. $21 \mathrm{f}$.

1485 Vgl. Kötz, FS Drobnig, 1998, S. 563, 568; ähnlich Medicus, Privatautonomie, 1994, S. 21f. (,,,Verdiente[s]“" Ungleichgewicht"); R. Posner, Economic Analysis, 9. Aufl. 2014, S. 154 (,incentive to discover information about true values [...] [must not] be blunted"); Shavell, Economic Analysis, 2004, S. 333. 
(dd) Vermeidung von Informationsasymmetrien

In der Diskussion über Informationspflichten ist der Begriff der Informationsasymmetrie als Voraussetzung für eine entsprechende Nebenpflicht allgegenwärtig. Dabei ist gar nicht ganz klar, was mit dem Begriff gemeint ist. ${ }^{1486}$ Der Wortlaut legt nahe, dass bei einer Informationsasymmetrie die Informationen zwischen Gläubiger und Schuldner ungleich - mit anderen Worten: asymmetrisch verteilt sind. Geht es um eine entsprechende Nebenpflicht, so läge eine Informationsasymmetrie also nur vor, wenn der Schuldner über mehr Informationen über den betreffenden Gegenstand als der Gläubiger verfügt. Es ist nun aber eine Selbstverständlichkeit, dass der Schuldner dem Gläubiger nicht jede ihm bekannte Information mitzuteilen hat, über die der Gläubiger nicht verfügt. ${ }^{1487}$ Ein allzu wörtliches Verständnis der Informationsasymmetrie ist demnach nicht angebracht.

Dies rechtfertigt sich auch aus einer Kostenperspektive: Zwar treffen den Schuldner hinsichtlich einer ihm bereits bekannten Information regelmäßig keine Übermittlungskosten. Der Schuldner hat diese Information aber zunächst erlangen müssen und dieser Vorgang wiederum ist regelmäßig nicht kostenneutral. Dieses caveat wird in der Diskussion zu Nebenpflichten selten explizit gewürdigt. ${ }^{1488}$ Allein auf Informationsasymmetrie fußende Nebenpflichten würden damit den Schuldner einseitig finanziell belasten, ohne aus sich selbst heraus eine Rechtfertigung für diese Belastung darstellen zu können.

Knüpft eine Informationspflicht erst an das beim Schuldner vorhandene Wissen an - also an die tatsächliche bestehende Informationsasymmetrie -, so ergibt sich zudem folgendes Paradoxon ${ }^{1489}$ :

1486 Zunächst unklar beispielsweise Mankiw/Taylor, Volkswirtschaftslehre, 5. Aufl. 2012, S. 258 (,,asymmetrische Informationen“).

1487 Ein zufälliger Wissensvorsprung einer Partei kann zwar eine Nebenpflicht auslösen, wenn die Informationsverbreitung sinnvoll erscheint, aber im Regelfall muss der Inhaber der Information für die Weitergabe ein Entgelt verlangen können, Schäfer/Ott, Ökonomische Analyse, 5. Aufl. 2012, S. 585f. Ausfluss der Privatautonomie ist es, dass jedem im Grundsatz nur die Wahrnehmung seiner eigenen Interessen zugewiesen ist, Staudinger/Olzen, Neubearbeitung 2015, Einl zum SchuldR Rn. 50; Staudinger/Olzen, Neubearbeitung 2015, § 241 Rn. 454 (,Prinzip der Eigenverantwortung“); Teichmann, JA 1984, 545, 546f.; spezifisch auf die Beschaffung von Informationen genünzt Klinck, Information, 2013, S. 103, 104.

1488 Positiv hervorzuheben hier MüKo-BGB/Bachmann, 7. Aufl. 2016, § 241 Rn. 123.

1489 Hierzu auch Tröger, Arbeitsteilung, 2012, S. 482. 
Um einer Mitteilungspflicht zu entgehen, könnte der Schuldner dann sogar fahrlässig (\$ 276 II BGB) die Beschaffung der aufklärungspflichtigen Umstände unterlassen. Das würde die praktische Wirksamkeit einer Informationspflicht völlig aushöhlen. Zudem würde es dem Schuldner einen expliziten Anlass dafür geben, seinen Informationshaushalt besonders unsorgfältig zu verwalten. Die Anreizwirkung einer Informationspflicht würde damit ad absurdum geführt. Die ökonomische Analyse bezeichnet dies als mit den Mitteln des dispositiven Rechts zu bekämpfende - Gefahr des Opportunismus. ${ }^{1490}$ Aus diesem Grund muss jede Informationspflicht schon bei der Ermittlung des jeweiligen Sachverhalts ansetzen. Einer reinen Hinweispflicht kann damit eine Informationsbeschaffungspflicht vorzuschalten sein. Kann der Gläubiger den Sachkomplex der betreffenden Information aufgrund seiner Fertigkeiten oder der Struktur der Informationsgewinnung deutlich schlechter als der Schuldner beurteilen, so fehlt ihm nämlich die Möglichkeit, das Ausmaß der notwendigen Sachverhaltsaufklärung durch den Schuldner auszumachen. Dass der Schuldner ihm eine relevante Information aufgrund fehlender Informationsbeschaffung fahrlässig vorenthält, bleibt dem Gläubiger unbekannt. Er kann sich vor dem Leerlaufen der Aufklärungspflicht also auch nicht schützen.

Dreh- und Angelpunkt für die Reichweite der Informationspflichten ist deshalb auch das Ausmaß der Informationsasymmetrie. ${ }^{1491}$ Die Asymmetrie bezieht sich dabei nicht mehr auf die den Parteien des Schuldverhältnisses konkret bekannten Informationen, sondern auf den Vorgang der Informationsbeschaffung. ${ }^{1492}$ Der

1490 Zum Begriff Schäfer/Ott, Ökonomische Analyse, 5. Aufl. 2012, S. 549f.

1491 Tröger, Arbeitsteilung, 2012, S. 482. Im ersten Szenario der fehlenden Fertigkeiten könnte man von einer „,funktionellen“, im zweiten Fall der strukturbedingten Schwierigkeit von einer „strukturellen“ Informationsasymmetrie sprechen.

1492 Verfügt der Schuldner bereits über die Information, so ist auch der Fokus auf die kostenlose Möglichkeit der Informationsweitergabe als Argument für eine entsprechende Informationspflicht bezeichnend: Hier wird deutlich, dass weniger die Verteilung der Informationen an sich als vielmehr der (finanzielle) Aufwand der konkreten Informationsweitergabe für die Bestimmung der Nebenpflicht entscheidend ist. In den Aufwand zur Informationsweitergabe sind aber die Kosten der Informationsbeschaffung mit einzupreisen. 
Begriff der Informationsasymmetrie ist damit zumindest verwirrend. Präzise umschrieben ist vielmehr eine asymmetrische Verteilung der Informationsbeschaffungskosten zwischen Gläubiger und Schuldner gemeint. ${ }^{1493}$ Etwas abgekürzt formuliert, ließe sich folglich auch von Informationskostenasymmetrie sprechen. ${ }^{1494}$ Im Ergebnis basieren informationsbezogene Nebenpflichten aus der Perspektive der Ökonomik auf einer Informationskostenasymmetrie zwischen Gläubiger und Schuldner.

(ee) Verhinderung eines race to the bottom

Eine von der ökonomischen Analyse angemahnte Gefahr ist das in einem sog. Markt für Zitronen ${ }^{1495}$ befürchtete race to the bottom. ${ }^{1496}$ Abstrakt umschrieben ist das ein Markt, in dem sich die Produktqualität bis zum potentiellen Marktzusammenbruch immer weiter verschlechtert, weil sich höhere Qualität für den einzelnen Anbieter nicht lohnt. ${ }^{1497}$ Voraussetzung für diese Gefahr ist zum einen, dass die Qualität des jeweiligen Produkts ex ante nicht erkennbar ist. ${ }^{1498}$ Zum anderen darf keine Möglichkeit für den Nachfragenden bestehen, den einzelnen Anbieter, der seine Qualität verschlechtert, durch Abwanderung zu bestrafen. ${ }^{1499}$

1493 Richtig Kötz, FS Drobnig, 1998, S. 563, 574; Kübler, FS Steindorff, 1990, S. 687, 701; M. Müller/Hempel, AcP 205 (2005), 246, 248. In der Rechtsprechung wird das Kriterium häufig mit der ,überlegenen Sachkunde" des Schuldners umschrieben, vgl. beispielsweise BGH, Urt. v. 15.3.2012 - III ZR 190/11, Rn. 14; BGH, Urt. v. 19.7.2012 - III ZR 71/12, Rn. 22; LG Heidelberg, Urt. v. 27.7.2011 - 1 S 9/10, Rn. 25.

1494 Die „berufliche Professionalisierung“ des Schuldners ist dabei ein Indiz für eine solche Asymmetrie, Schäfer/Ott, Ökonomische Analyse, 5. Aufl. 2012, S. 583f.

$1495 \mathrm{Im}$ Englischen (,The Market for Lemons") ein berühmter Aufsatz von G.A. Akerlof (The Quart. J. of Ec. 84 (1970), 488ff.)

1496 Ausführlich hierzu und zur folgenden Erläuterung Schäfer/Ott, Ökonomische Analyse, 5. Aufl. 2012, S. 370ff.; S. auch Riha, Sachmängelgewährleistungsrecht, 2007, S. $41 \mathrm{f}$.

1497 Vgl. auch generell zu den „costs of dishonesty“ Akerlof, The Quart. J. of Ec. 84 (1970), 488, $490,495$.

1498 Akerlof, The Quart. J. of Ec. 84 (1970), 488, 489. In der Terminologie der ökonomischen Analyse handelt sich dabei entweder um „Erfahrungsgüter" (Qualität ist erst nach dem Erwerb erkennbar) oder „Glaubensgüter" (Qualität ist niemals erkennbar). Einzig bei „Suchgütern“ ist die Qualität durch vorherige Suche feststellbar, näher zu alldem Drexl, Selbstbestimmung, 1998, S. 195; Schäfer/Ott, Ökonomische Analyse, 5. Aufl. 2012, S. 542.

1499 Vgl. Akerlof, The Quart. J. of Ec. 84 (1970), 488, 489f. Ein einzelnes Produkt kann dabei auch nur teilweise die Gefahr einer steten Qualitätsverschlechterung bergen, wenn nur eine von 
Beispiele für Märkte, an denen diese Gefahr droht, sind Restaurants an Touristenorten ${ }^{1500}$ und Makler. Im grundlegenden Aufsatz von Akerlof hierzu ging es um den Verkauf von Gebrauchtwagen. $^{1501}$

Die einem solchen Markt inhärente Gefahr der stetigen Qualitätsverschlechterung kann durch Eingreifen der Rechtsordnung bekämpft werden. Eine Möglichkeit, auf einen Markt für Zitronen zu reagieren, kann die Annahme einer Nebenpflicht über § 241 II BGB sein. Dafür muss das Schuldverhältnis Teil einer Marktdynamik sein, welche die Gefahr eines race to the bottom birgt.

Die Verwendung unwirksamer AGB durch den Schuldner stellt nach ständiger Rechtsprechung der Gerichte eine (vor-)vertragliche Nebenpflichtverletzung dar, die bei Aufwendungen des Gläubigers im Vertrauen auf den Bestand der AGB in einem Schadensersatzanspruch nach den $\$ \S 280$ I, 241 II (, 311 II) BGB resultieren kann. ${ }^{1502}$ Das Produkt wäre hier die Wahrung der Unterlassungspflicht durch den Schuldner, keine unwirksamen $A G B$ zu verwenden. Dies kann vom Gläubiger ex ante entweder gar nicht oder nur unter Inkaufnahme unverhältnismäßiger Informationskosten beurteilt werden. Für einen Rechtsunkundigen ist selbst bei sorgfältiger Lektüre schließlich nicht ohne anwaltliche Beratung erkennbar, ob eine Klausel wirksam ist. Damit stehen die Informationsbeschaffungskosten des Gläubigers - zumindest bei der Ver-

mehreren Qualitäten ex ante nicht erkennbar ist. So ist beispielsweise das Design eines Produkts ex ante überprüfbar, nicht aber dessen Ungefährlichkeit im Gebrauch.

1500 Drexl, Selbstbestimmung, 1998, S. 197. Es muss sich aber um Restaurants handeln, die nicht Mitglieder einer Kette sind. Assoziation mit einer Kette oder einem Markennamen schafft schließlich Transparenz und ,accountability“ für Qualitätsabweichungen auch über den Einzelbesuch hinaus, s. Akerlof, The Quart. J. of Ec. 84 (1970), 488, 499f.

1501 Akerlof, The Quart. J. of Ec. 84 (1970), 488, 489f.

1502 Erstmals - wenn auch ohne gesonderte Herleitung - und plakativ den Wortlaut des $\S 241$ II BGB antizipierend BGH, Urt. v. 28.5.1984 - III ZR 63/83, Rn. 30 (,vorvertragliche Pflicht zur Rücksichtnahme gegenüber dem Kunden"); folgend BGH, Urt. v 12.11.1986 - VIII ZR 280/85, Rn. 15 (BGHZ 99, 101, 106f.); BGH, Urt. v. 11.6.2010 - V ZR 85/09, Rn. 24; OLG Köln, Urt. v. 16.2.1995 - 7 U 100/94, Rn. 16; s. auch Erman/Westermann, 15. Aufl. 2017, $\S 241 \mathrm{Rn} .19$. 
wendung unwirksamer AGB gegenüber Verbrauchern ${ }^{1503}$ - regelmäßig außer Verhältnis zum vermögenswerten Interesse des Gläubigers an Wahrung der Unterlassungspflicht durch den Schuldner, keine unwirksamen $A G B$ zu verwenden. ${ }^{1504}$ Die Qualität des Produkts ist damit für den Gläubiger ex ante nicht erkennbar.

Gleichzeitig ist zweifelhaft, ob der Markt das Verhalten des einzelnen Qualitätsverschlechterers genügend sanktionieren kann. Wegen der regelmäßig prohibitiven Informationskosten hinsichtlich der Frage, ob AGB wirksam sind oder nicht, wird ein Verstoß des Schuldners gegen diese Unterlassungspflicht häufig unentdeckt bleiben. Der Gläubiger wird das Verhalten des Schuldners daher mangels Kenntnis vom Verstoß gar nicht durch Abwanderung sanktionieren können. Damit besteht hier aus ökonomischer Sicht die Gefahr eines race to the bottom.

Insbesondere der Markt für professionelle Dienstleistungen kann dabei die Gefahr eines race to the bottom bergen.

Die Qualität von Dienstleistungen durch Steuerberater ist ex ante nicht erkennbar. Insbesondere ist nicht (sofort) erkennbar, ob der Berater zwar die aus $\$ 241$ I BGB geschuldete Beratung geleistet hat, aber nichtsdestotrotz Schäden an anderen Rechtsgütern des Gläubigers - insbesondere seinen sonstigen, vermögenswerten In-

1503 Bei einer Transaktion zwischen zwei Geschäftsleuten mit großem Handelsvolumen sind die Informationskosten im Verhältnis zum Gesamtvolumen der Transaktion deutlich geringer als bei einer kleineren Transaktion mit einem Verbraucher, Leuschner, ZIP 2015, 1045, 1047. Sofern AGB verwendet werden, erscheint deshalb die Investition von Informationskosten zur Analyse der Wirksamkeit dieser Bedingungen (zum Beispiel durch anwaltlichen Rat) aufgrund der wirtschaftlich gewichtigen Folgen ökonomisch sinnvoll. Bezogen auf die Voraussetzungen des Markts für Zitronen fehlt es deshalb bei wertender Betrachtung an der ex ante fehlenden Erkennbarkeit der Qualität des Produkts, allgemein deshalb auch de lege feren$d a$ für einen „Ausschluss großvolumiger Verträge von der AGB-Kontrolle“ plädierend Leuschner, ZIP 2015, 1045, 1047f.; Leuschner, ZIP 2015, 1326, 1328ff. Damit würde die ökonomische Analyse einen Markteingriff in Form einer Haftung aus $\S \S 280$ I, 241 II BGB in einem solchen Fall ablehnen, näher Schäfer/Ott, Ökonomische Analyse, 5. Aufl. 2012, S. 554.

1504 Vgl. bereits allgemein zur AGB-Kontrolle Leuschner, ZIP 2015, 1326, 1328 (,negative Transaktionskosten-Vertragswert-Relation"). 
teressen - fahrlässig herbeigeführt hat. Damit ist die wichtigste Voraussetzung eines Markts für Zitronen gegeben.

Die zentrale Voraussetzung des Markts für Zitronen ist, dass die Produktqualität für den Nachfragenden ex ante nicht oder nur unter Inkaufnahme unverhältnismäßiger Informationskosten herausgefunden werden kann. Dies deutet auf eine ausgeprägte Informationskostenasymmetrie zwischen Anbieter und Erwerber hin. Diese Asymmetrie bedingt häufig auch die zweite Voraussetzung für die Gefahr eines race to the bottom: Wenn der Nachfragende die Qualität des Produkts ex ante nicht oder nur mit unverhältnismäßigen Informationskosten beurteilen kann, so kann er sich deshalb auch nicht sicher sein, dass die Qualität bei einem Konkurrenten besser ist. Weil aber der Wechsel eines Anbieters regelmäBig mit zumindest geringen Kosten verbunden ist, hat der Nachfragende ohne garantierte Qualitätsverbesserungen keinen Anreiz, das Verhalten des einzelnen Qualitätsverschlechterers durch Abwanderung zu bestrafen. In Fällen, in denen der Nachfragende das Produkt nur ein einziges Mal abnimmt (z.B. der Besuch von Touristenrestaurants), scheidet Abwanderung als Marktkorrektur völlig aus. Um der Gefahr, die ein solcher Markt birgt, entgegenzuwirken, gilt es also die Informationskostenasymmetrie aufzuheben. Eine Nebenpflicht nach $\S 241$ II BGB anzunehmen, mit dem Inhalt, die Gegenseite im Schuldverhältnis über etwas zu informieren, ist ein wichtiger Weg hierzu. Dabei überschneiden sich die Ergebnisse durchaus auch mit denen der Rechtsprechung. Wenn kein Markt für Zitronen vorliegt, so stellt die Möglichkeit des Marktes zur Selbstkorrektur ein Argument gegen die Annahme einer Nebenpflicht dar. Insofern kann der Ansatz auch begrenzend wirken. Auch innerhalb eines Markts für Zitronen gilt es aber, die aus $\S 241$ II BGB folgenden Verhaltensanforderungen $\mathrm{zu}$ begrenzen. Schließlich kann der Schuldner nicht aus § 241 II BGB dazu verpflichtet werden, jede Informationsasymmetrie, ohne Rücksicht auf die ihm entstehenden Kosten, aufzuheben. Damit taugt der Ansatz nur bedingt für die Begrenzung von Vermögensschutz. 
(ff) Marktdynamiken als ausreichendes Korrektiv?

Nach der ökonomischen Analyse gibt es verschiedene - sich nicht zwingend gegenseitig ausschließende - Möglichkeiten bestehende Informationskostenasymmetrien durch intrinsische Marktdynamiken auszugleichen. ${ }^{1505}$ Lässt sich ein solcher Marktmechanismus als Korrektiv feststellen, so ist aus der Sicht der Ökonomik ein Markteingriff in Form einer schuldverhältnisbedingten Nebenpflicht gem. § 241 II BGB unnötig und im Ergebnis abzulehnen. Exemplarisch $^{1506}$ für die Möglichkeiten des Marktes, Informationsasymmetrien auszugleichen, ist die Anwendung des Extrapolationsprinzips ${ }^{1507}$ durch den Nachfragenden. ${ }^{1508}$ Wird ein Schuldverhältnis mit einem Anbieter durchgeführt, ohne dass sich die Informationsasymmetrie negativ für den Nachfragenden auswirkt, so hat letzterer Anlass zur Vermutung, dass dies auch zukünftig nicht der Fall sein wird. Auf den Markt als Ganzes bezogen entwickelt sich so mit der Zeit ein goodwill $^{1509}$ desjenigen Anbieters, der die Informationsasymmetrie erfolgreich

1505 Hierzu Schäfer/Ott, Ökonomische Analyse, 5. Aufl. 2012, S. 544ff.

1506 Zum - letztlich für die Konturierung von $§ 241$ II BGB wenig überzeugenden - „Schutz des Vertrauens" durch Berufsethik, näher Schäfer/Ott, Ökonomische Analyse, 5. Aufl. 2012, S. 544f.; vgl. hierzu auch Akerlof, The Quart. J. of Ec. 84 (1970), 488, 500 (,licensing practices [...] reduce quality uncertainty.“); für eine „,herausragende Rolle“ staatlicher „Aufsichtsämter" im Kontext von Vermögensschutz plädierend Hopt, AcP 183 (1983), 608, 716

1507 Mittels Extrapolation wird von einem Anhaltspunkt in der Vergangenheit auf das Eintreffen eines zukünftigen Ereignisses geschlossen (,Was früher die Qualität X hatte, wird auch zukünftig die Qualität X aufweisen"), vgl. Drexl, Selbstbestimmung, 1998, S. 196.

1508 Ausführlich Schäfer/Ott, Ökonomische Analyse, 5. Aufl. 2012, S. 545ff.

1509 Mit dem englischen Begriff des goodwill bezeichnet man den Geschäftswert eines Unternehmens, MüKo-Bilanzrecht/Hennrichs, 2013, § 246 HGB Rn. 143. Er ergibt sich rechnerisch aus der Differenz zwischen dem Wert aller herkömmlichen Vermögensgegenstände (Aktiva) abzüglich aller Schulden (Passiva) und dem Wert, den das Unternehmen bei Verkauf auf dem freien Markt wert ist. Der Begriff ist mittlerweile in 246 I 4 HGB legal definiert und gilt kraft gesetzlicher Anordnung als bilanzieller Vermögensgegenstand, näher MüKo-Bilanzrecht/ Hennrichs, 2013, § 246 HGB Rn. 142ff. (,Fiktion“). Rein tatsächlich ist der goodwill geprägt von den Gewinnaussichten eines Unternehmens. Diese wiederum werden von einer Vielzahl von ideellen Faktoren beeinflusst, zu denen auch das Qualitätsmanagement, die Kundenzufriedenheit und die Wahrnehmung des Unternehmens auf dem Markt als ehrbarer Kaufmann zählt, vgl. MüKo-Bilanzrecht/Hennrichs, 2013, § 246 HGB Rn. 65, 143. Ob ein Anbieter Nebenpflichten einhält oder nicht, beeinflusst unter anderem die genannten Faktoren und damit unmittelbar den goodwill des Anbieters, vgl. zur empirisch nachweisbaren Korrelation zwischen Unternehmenswert und Unternehmensreputation Klöhn/Schmolke, NZG 2015, 689, 691ff. (,Wert der Reputation [...] entspricht dem Barwert aller zukünftigen Kosteneinsparungen, die auf dem Ruf der Gesellschaft beruhen."). 
und nach außen sichtbar ${ }^{1510}$ auszugleichen versucht. ${ }^{1511}$ Konsequenterweise kann er deshalb auch grundsätzlich höhere Preise als ein Anbieter verlangen, dem es an dieser speziellen Komponente des goodwill fehlt. Er erhält damit einen Anreiz sein Verhalten - konkret: Informationsdefizite der Nachfragenden auszugleichen anstatt sie auszunutzen - aufrechtzuerhalten oder gar zu steigern. ${ }^{1512}$ Konkret auf die Auslegung von § 241 II BGB bezogen müsste man also fragen, ob die Marktdynamik den Schuldner bereits ausreichend mit dem perspektivischen goodwill dazu motiviert, die Informationsasymmetrie auszugleichen. Ist das der Fall, so muss ein Markteingriff in Form einer Nebenpflicht ausscheiden. ${ }^{1513}$

Allein auf diesen Ansatz zu vertrauen bedeutet indes, dem Einzelnen einen möglichen Regress zu verwehren. Nutzt ein Anbieter die bestehende Informationskostenasymmetrie auf Kosten des Nachfragenden aus, so kann der Nachfragende den Anbieter zwar mit Herabstufung des goodwill abstrafen (schlechte Bewertung in Benutzerportalen, Mitteilung an Bekannte und Geschäftspartner, etc.). ${ }^{1514}$

1510 Da Nebenpflichten nicht in Stein geschrieben sind, sondern das Schuldverhältnis nur flexibel schützend begleiten können, kann der Gläubiger nach Abschluss des Schuldverhältnisses nicht die Erfüllung einer bestimmten Nebenpflicht registrieren. Umgekehrt lässt sich aber feststellen, dass mangels Schaden an einem sonstigen Rechtsgut zumindest keine Nebenpflicht verletzt wurde. Insbesondere bei Schäden an vermögenswerten Interessen kann sich die Bewertung zwar etwas verzögern. Regelmäßig wird aber ab einem bestimmten Zeitpunkt feststehen, ob Informationspflichten verletzt wurden oder nicht. Ob ein bestimmter Anbieter Nebenpflichten einhält oder nicht, lässt sich also durchaus erfassen. Dasselbe gilt - da schließlich nur die ökonomische Beschreibung für den rechtlichen Haftungsgrund einer Informationspflicht aus $\S 241$ II BGB - auch für den Ausgleich von Informationskostenasymmetrien.

1511 Drexl, Selbstbestimmung, 1998, S. 195f.

1512 Drexl, Selbstbestimmung, 1998, S. 195f.; Schäfer/Ott, Ökonomische Analyse, 5. Aufl. 2012, S. $545 \mathrm{ff}$.

1513 Bei typisierenden Betrachtung wird sich der Schuldner dann schon aus reinem Gewinnmaximierungsinteresse der opportunisitischen Handlung enthalten, weil sich publiziertes Fehlverhalten eines Unternehmens gegenüber Vertragspartnern - anders als Fehlverhalten gegenüber Dritten - empirisch nachweisbar negativ auf den durch die Unternehmensreputation beeinflussten Unternehmenswert auswirkt, näher Klöhn/Schmolke, NZG 2015, 689, 691f., 693. Die Prämisse, dass der Anbieter über einen goodwill davon profitieren kann, die Informationsasymmetrie auszugleichen, ähnelt vom Gedanken her der Begründung von Nebenpflichten über eine mögliche Kompensation des Schuldners für seine Belastung (S.o., S. 248ff.) sowie über die Vertrauensprämie (S.u., S. 409ff.). Deshalb wird der goodwill in der Ökonomik zum Teil auch als Teil einer möglichen Vertrauensprämie angesehen, zutreffend Schäfer/Ott, Ökonomische Analyse, 5. Aufl. 2012, S. 585.

1514 Hölzle, Desinformation, 2012, S. 131 („Negativprogaganda“). Der zu großen Teilen (einigen Studien nach bis zu 60 Prozent!) durch die Unternehmensreputation repräsentierte Unternehmenswert wird - empirisch nachweisbar - unmittelbar negativ durch publiziertes Fehlverhalten gegenüber Vertragspartnern beeinflusst, Klöhn/Schmolke, NZG 2015, 689, 691, 693. Das 
Abstrakt trägt er damit zwar zur Verdrängung des Anbieters vom Markt bei. Den persönlich erlittenen Schaden kann er aber nicht ersetzt verlangen. Damit fehlt ihm auch der Anreiz, den Sachverhalt überhaupt näher zu erforschen. Insbesondere die (fahrlässige) Schädigung eines Schuldverhältnis-Partners wegen einer Informationskostenasymmetrie kann schwer zu entdecken sein. Kann der Geschädigte nicht nach $\S \S 280$ I, 241 II BGB gegen den Schädiger vorgehen, so trägt er mit der Ausforschung des Sachverhalts zwar zum Funktionieren des Marktes bei, er muss aber die aufgewendeten Informationskosten vollständig selber tragen. Ohne persönlich von der Verbesserung der Marktdynamik profitieren $^{1515}$ zu können, lässt sich die Prämisse des Ansatzes auch unter Zugrundelegung des homo oeconomicus deshalb anzweifeln. ${ }^{1516}$ Der Ansatz vermag § 241 II BGB daher nicht sinnvoll zu begrenzen.

(c) Zwischenergebnis: Informationsverantwortlichkeit von ökonomischer Analyse durchdrungen

In der Rechtspraxis führen die Instrumente der ökonomischen Analyse des Rechts bei der Verlagerung der Informationsverantwortlichkeit häufig zu den gleichen Resultaten wie die herkömmlichen, funktionalen Begründungsansätze, welche die ökonomischen Ansätze entweder explizit ablehnen oder zumindest

gilt zumindest nur in deutlich geringerem Maße für Fehlverhalten gegenüber Dritten, Klöhn/Schmolke, NZG 2015, 689, 693. Wie jemand seine Geschäftspartner behandelt, hat also großen Einfluss auf dessen Reputation. Nebenpflichten setzen ein Schuldverhältnis voraus und spielen damit ohnehin nur innerhalb zumindest geschäftlicher Kontakte (vgl. § 311 II Nr. 3 BGB) eine Rolle. Insoweit kann der Schuldner dem Gläubiger durch Preisgabe dessen „Verfehlung" durchaus schaden. Weil Nebenpflichten aber stark verhaltensbezogen sind, wird dem Verkehr die Einschätzung unter Umständen schwer fallen, ob es sich bei dem Verhalten des Gläubigers um ein „Fehlverhalten“ handelt oder lediglich um angemessenes Geschäftsgebaren.

1515 Der angestrebte Profit läge hier in der rechtlichen Inanspruchnahme des Anbieters nach $\S \S 280,241$ II BGB. Der Anspruch erlaubt aber nur den Ersatz eines erlittenen Schadens und bietet - mangels eines deutschen Äquivalents zu den US-amerikanischen punitive damages keinen Spielraum für tatsächlichen Profit.

1516 Hölzle, Desinformation, 2012, S. 136 („Vertragsbruch des Anbieters, der in einem opportunistischen Ausnutzen von Informatonsasymmetrien besteht, [wird] „öffentlich“ gemacht, indem er klagbar wird“); für eine entsprechende „Gestaltung des Rechts“ deshalb auch Drexl, Selbstbestimmung, 1998, S. $197 \mathrm{f}$. 
namentlich häufig unerwähnt lassen. ${ }^{1517}$ Will man mittels einer Nebenpflicht aus $\S 241$ II BGB die Informationsverantwortlichkeit verteilen, so hat die ökonomische Analyse die Subsumtion wenn auch nicht stets in der Terminologie, so doch zumindest im Ergebnis bis auf weite Teile durchdrungen.

(6) Ergänzung der Haftung des cheapest cost avoider durch den Gedanken des Vertrauensschutzes

Vertrauen kommt auch nach der ökonomischen Analyse eine markterleichternde Funktion zu, ${ }^{1518}$ deren Beziehung zu Nebenpflichten untersucht werden soll.

(a) Folgen einer Risikoverteilung nach dem Prinzip des cheapest cost avoider Verlangt die Wahrung der Nebenpflicht eine Handlung, für die typischerweise eine Vergütung verlangt werden könnte, so entstehen Bedenken, ob das Kriterium des cheapest cost avoider allein maßgeblich sein kann. ${ }^{1519}$

Beispiel $6 \quad$ Wegen der Informationskostenasymmetrie zwischen dem Steuerberater und seinem Kunden ließe sich in Fällen wie dem Haltefristfall $^{1520}$ häufig eine beliebige Anzahl von Nebenpflichten mit dem Kriterium des cheapest cost avoider herleiten. ${ }^{1521}$ Der Steuerbera-

1517 So auch Kersting, Dritthaftung, 2007, S. 407; Ott, Travemünder Symposium, 1989, S. 25, 42; Tröger, Arbeitsteilung, 2012, S. 475.

1518 Näher hierzu Schäfer/Ott, Ökonomische Analyse, 5. Aufl. 2012, S. 537. Ohne Vertrauen in den Schuldverhältnis-Partner muss der eine Schuldverhältnis-Teilnehmer das Verhalten des anderen Schuldverhältnis-Teilnehmers konstant kontrollieren, mit anderen Worten verlässliche Informationen über die Güte dessen Aktionen beschaffen. Das verursacht (Informations)Kosten. Vertrauen erspart diese Kosten. Damit ist Vertrauen in die Gegenseite nach der ökonomischen Analyse ein wichtiges Instrument im Repertoire des rational-egoistisch agierenden homo oeconomicus. Es „vertraut“ also keineswegs nur der schutzbedürftige Privatmann, s. Schäfer/Ott, Ökonomische Analyse, 5. Aufl. 2012, S. 538.

1519 So bereits treffend Trimarchi, ZHR 136 (1972), 118, 136 („Schadensrisiko [sollte] derjenigen Partei auferlegt [werden] [...], die mit geringeren Kosten und [!] gegen eine angemessene Gegenleistung Vorsorge treffen kann“); vgl. auch E. Schmidt, JA 1978, 597, 602 (,gern vernachlässigtes Faktum [im Zivilrecht], daß man das, was man dem einen gibt, notwendig dem anderen nimmt").

1520 S.o., S. 26.

1521 Vgl. Kersting, Dritthaftung, 2007, S. 405; wenn auch nicht eindeutig dafür, so doch diesbezüglich zumindest in Versuchung geratend Hopt, AcP 183 (1983), 608, 654. Voraussetzung dafür, 
ter hat stets überlegene Sachkunde. Deshalb wäre es stets günstiger, einen möglichen Schaden vom Gläubiger durch eine Information vonseiten des Steuerberaters abwenden zu lassen, als dass der Gläubiger ihn eigenhändig abzuwenden versucht. Gleichzeitig ist der Steuerberater für sein Auskommen grundsätzlich darauf angewiesen, für die Informationsweitergabe eine Vergütung verlangen zu können. Das Kriterium des cheapest cost avoider führt deshalb ohne Korrektiv dazu, die Informationsverantwortung sehr zulasten professioneller Ratgeber zu verteilen.

Es kann aber nicht der rechtspraktischen Funktion einer Nebenpflicht entsprechen, eine Informationskostenasymmetrie derart zulasten des Überlegenen auszulegen - und damit in ihr Gegenteil zu verkehren. ${ }^{1522}$

Beispiel 43 Die Folgen einer solchen Risikoverteilung im Haltefristfall wären schließlich die Totalversicherung des Gläubigers durch den Steuerberater. Der Steuerberater würde dann entweder seine Grundberatungsgebühren erheblich anheben müssen, um die Kosten aller zufälligen Hinweispflichten abzudecken, oder aber schlicht jede Aussage ohne Vereinbarung einer zusätzlichen Vergütung verweigern. ${ }^{1523}$ Ersteres wirft das Problem einer unerwünschten Quersubventionierung einiger beratungsintensiver Mandanten

ein Risiko über den Begriff des cheapest cost avoider zuzuweisen, ist, dass die Schadensvermeidungskosten geringer sind als der Schadenserwartungswert. Häufig wird jedoch ein Schaden im Raum stehen, der die Informationsbeschaffungskosten des Steuerberaters (deutlich) übersteigt. Damit würde der Begriff des cheapest cost avoider über die Risikoverteilung entscheiden.

1522 Dezidiert Hopt, AcP 183 (1983), 608, 655 (,praxisüberfordernde Anforderungen kontraproduktiv").

$1523 \mathrm{Ob}$ sich der Steuerberater - als dritte denkbare Handlungsalternative - durch einen bloßen Hinweis auf die Unverbindlichkeit der Auskunft von der Haftung befreien kann (nur dann wäre diese Variante sinnvoll), ist mehr als zweifelhaft. Ein einseitiger Haftungsausschluss ist dem deutschen Recht unbekannt. Selbst wenn man in dem Verweis des Steuerberaters auf die Unverbindlichkeit und die stillschweigende Inkaufnahme dieses caveats durch den Mandanten eine zweiseitige Haftungsbeschränkung sehen würde, so bleibt offen, ob hierdurch die Haftung des Steuerberaters auch tatsächlich entfällt. Nebenpflichten nach § 241 II BGB repräsentieren nämlich im Kern den Gedanken von Treu und Glauben (§ 242 BGB) und sind deshalb einem privatautonomen Haftungsausschluss nur in sehr begrenztem Ausmaß zugänglich, s.o., S. $204 \mathrm{ff}$. 
durch das Gros der normalen Mandanten auf ${ }^{424}$, zweiteres mag vertrauensvolle Mandatsbeziehungen gefährden ${ }^{1525}$ und bedarf zumindest einer genauen Folgenabschätzung.

Wird dem Schuldner mit der Nebenpflicht eine Handlung abverlangt, die isoliert betrachtet einen Marktwert hat ${ }^{1526}$, so ist das Kriterium des cheapest cost avoider damit ohne genaue Berücksichtigung der gesetzten Anreize nicht geeignet, eine überzeugende Risikoverteilung zu gewährleisten. ${ }^{1527}$ Die Risikozuweisung nach dem Begriff des cheapest cost avoider bedarf deshalb einer diese Folgen in den Vordergrund rückenden Ergänzung.

\section{(b) Ansatz der Vertrauensprämie}

Schuldner und Gläubiger haben bei der Frage, ob eine Nebenpflicht bestehen soll oder nicht, im Gerichtsprozess erkennbar gegenläufige Interessen: Die eine Partei verlangt nach Haftung, die andere Partei versucht sie abzuwenden. Die ökonomische Analyse versucht diese kontradiktorische Struktur mit dem Ansatz der Vertrauensprämie ${ }^{1528}$ aufzulösen: Der Gläubiger profitiert von der Existenz der

1524 Alternativ zu einem derart überhöhten Tarif würde womöglich die Mehrzahl der Kunden einen Tarif bevorzugen, der fair im Verhältnis zur Leistungspflicht ist. Tun sich - was nicht immer der Fall sein muss - neue Gefahren oder Fragen auf, so steht es jedem Kunden frei, hierfür mittels separat vergüteten Auftrags Rat einzuholen.

$1525 \mathrm{Vgl}$ zu den praktischen Auswirkungen des Verhaltens eines auf sein Recht bedachten Steuerberaters innerhalb eines bestehenden Mandatsverhältnisses Zwade, Anm. zu BGH, Urt. v. 7.5.2015 - IX ZR 186/14, jurisPR-BGHZivilR 12/2015, Anm. 1 (,Mandant wird [...] entweder Zeter und Mordio rufen und unabhängig von rechtlichen Einstandspflichten eine Kompensation erwarten oder noch auf dem Fuße das Steuerberatungsmandat kündigen")

1526 Damit ist nicht etwa gemeint, dass die Handlung Schadensvermeidungskosten nach sich zieht. Jede Handlung verursacht schließlich zumindest Opportunitätskosten. Gemeint sind Handlungen, die einen eigenen Marktwert haben. Eine gewisse Sorgfalt walten zu lassen, bevor ein vermeintlicher Nacherfüllungsanspruch gegenüber dem Verkäufer geltend gemacht wird, zieht auch Schadensvermeidungskosten nach sich. Die Handlung ließe sich aber nicht eigenständig vermarkten. Professionelle Beratungskapazitäten zum (Integritäts-)Wohle des Gläubigers einzusetzen, verursacht aber nicht nur (Informationsbeschaffungs-)Kosten aufseiten des Schuldners, sondern hat einen eigenständigen Wert auf dem Dienstleistungsmarkt.

1527 Instruktiv auch Hopt, AcP 183 (1983), 608, 654 („Indessen wäre es naiv zu glauben, Berufsrecht und Berufspflichten könnten rechtlich kostenneutral ausgebaut und verschärft werden. Auch die Belastung eines Berufsstands mit vertraglichen oder außervertraglichen Nebenpflichten hat seinen Preis.")

1528 Vgl. Schäfer/Ott, Ökonomische Analyse, 5. Aufl. 2012, S. 559f., 575f.; dazu auch Kersting, Dritthaftung, 2007, S. 400ff. 
Nebenpflicht natürlich ohnehin, weil er die betreffende Information erhält. Darüber hinaus profitiert er von dem um die gesetzliche Festlegung des Pflichtenprogramms reduzierten Kontrahierungsaufwand. Durch eine privatautonome Vereinbarung der betreffenden Informationspflicht hätten sich schließlich die Transaktionskosten erhöht. Der Schuldner wiederum kann für seine Aufklärungsbereitschaft einen Bonus - mit anderen Worten: eine Vertrauensprämie verlangen. ${ }^{1529}$ Selbst ohne konkret zu beziffernden Aufschlag kann er sich durch Aneignung der gesetzlichen Vorgaben als vertrauenwürdig vermarkten. Er kann indirekt von der Information der Gegenseite profitieren, seine Reputation in der Geschäftswelt steigern oder durch seine Handlung zukünftige Geschäftschancen generieren. ${ }^{1530}$ Ein unmittelbarer Handlungsanreiz für den Schuldner wird dann gesetzt, wenn die Vertrauensprämie höher ist als der Nutzen, den das Zurückhalten der Information brächte. ${ }^{1531}$

(c) Die Voraussetzung der Vertrauensprämie in der Subsumtion

Die Annahme einer Nebenpflicht unter Rückgriff auf den cheapest cost avoider ist unter Berücksichtigung des Kriteriums der Vertrauensprämie ökonomisch stimmig, wenn der Schuldner die Kosten für die Wahrung der Nebenpflicht als Teil der von ihm geforderten Gegenleistung amortisieren kann. ${ }^{1532}$ Als Vertrau-

1529 Damit ist die Gesamtheit aller wirtschaftlich messbaren Vorteile gemeint, die der Schuldner durch regelkonformes Verhalten erlangen kann (konkrete Einpreisung des regelkonformen Verhaltens in die geforderte Vergütung, ,goodwill“" als gesteigerter Unternehmenswert, Kundenloyalität wegen vertrauensvoller Schuldverhältnis-Durchführung etc.), vgl. Schäfer/Ott, Ökonomische Analyse, 5. Aufl. 2012, S. 585 sowie zum empirisch eindeutig nachweisbaren Zusammenhang zwischen der Unternehmensreputation und dem (marktbekannten) Umgang mit Vertragspartnern Klöhn/Schmolke, NZG 2015, 689, 691f.

1530 Vgl. Hölzle, Desinformation, 2012, S. 131 (,informationssubstituierende Wirkung des Vertrauens potentieller Abnehmer [greift] auf geronnene Informationen, also vergangenheitsbezogene Informationen zurück, die dadurch für die Geschäftsabschlüsse der Zukunft entscheidend werden").

1531 Die Relevanz der „Vertrauensprämie“ für Informationspflichten spiegelt sich mitunter auch in der herkömmlich argumentierenden Literatur: Dass die Übernahme von Informationsverantwortlichkeit typischerweise vergütet wird, hält Staudinger/Olzen, Neubearbeitung 2015, § 241 Rn. 455 a.E. beispielsweise für eine denkbare Begründung von informationsbezogenen Nebenpflichten.

1532 Vgl. Hopt, AcP 183 (1983), 608, 654 („Belastung eines Berufsstands mit vertraglichen oder außervertraglichen Nebenpflichten hat seinen Preis"); Kersting, Dritthaftung, 2007, S. 401; Kötz, FS Steindorff, 1990, S. 643, 666; Kötz, FS Drobnig, 1998, S. 563, 574 (bei Annahme einer vorvertraglichen Aufklärungspflicht zahlt der Käufer ,einen Kaufpreis, in dem ein Zuschlag für den Aufwand des Händlers enthalten ist"); Schäfer/Ott, Ökonomische Analyse, 
ensprämie kommt ebenso eine Geschäftschance oder eine andere Verbesserung des goodwill des Schuldners in Betracht. ${ }^{1533}$ Die Voraussetzung der Vertrauensprämie spricht aber grundsätzlich gegen eine Haftung aus einem Gefälligkeitsverhältnis. ${ }^{1534}$ Schließlich werden die durch die Nebenpflicht entstehenden Informationskosten bei einer Gefälligkeit nur selten durch messbare Vorteile aufgewogen. ${ }^{1535}$

Beispiel 6 Im Haltefristfall ${ }^{1536}$ konnte der Steuerberater die von ihm gefor-
derten Informationsbeschaffungskosten mangels konkreter Kennt-
nis von der Hinweispflicht im Einzelfall nicht amortisieren. ${ }^{1537} \mathrm{Da}$

5. Aufl. 2012, S. 559; zutreffend daher gegen eine „Verpflichtung zum Vorhalten einer funktionsfähigen Toilette im Personennahverkehr" aufgrund von ,womöglich auch von Bahnkunden aufzufangende[n] Mehrkosten", LG Trier, Urt. v. 19.2.2016 - 1 S 131/15, Rn. 42, 44.

1533 Hölzle, Desinformation, 2012, S. 128f. („Vertrauenswerbung ist [...] geeignet, die Zahl der Geschäftsabschlüsse effektiv zu erhöhen"); dazu - sowie zu den Berechnungs- und Abwägungsschwierigkeiten bei dieser Mischform aus konkreter und nichtexistenter Vertrauensprämie - auch Kersting, Dritthaftung, 2007, S. 401f., 406.

1534 So überzeugend Canaris, FS Larenz, 1983, S. 27, 84; Kersting, Dritthaftung, 2007, S. 402f.; Michaelis, FS Siber, Bd. II, 1945, S. 185, 330f.; Schäfer/Ott, Ökonomische Analyse, 5. Aufl. 2012, S. 56. Mit „Gefälligkeitsverhältnis“"kann zum einen gemeint sein, dass mangels rechtlichen Bindungswillens schon kein Schuldverhältnis zwischen den Parteien besteht, vgl. beispielsweise BGH, Urt. v. 23.7.2015 - III ZR 346/14, Rn. 8. Dann kommt eine Nebenpflicht nach $\S 241$ II BGB schon im Ansatz nicht in Betracht, wenn nicht ausnahmsweise ein Schuldverhältnis nach § 311 II, III BGB vorliegt, zutreffend HKK/Dorn, 2007, § 241 Rn. 64 m.w.N., 73; unklar NK-BGB/Krebs, 3. Aufl. 2016, § 241 Rn. 12f. Dieser Teil der Aussage ist daher für die Arbeit uninteressant. Ist aber ein Schuldverhältnis im sozialen Umfeld gemeint, in dem der Gläubiger der Hauptleistung keine Gegenleistung schuldet (beispielsweise die Fallgruppe der Auskunftshaftung), so kann die Prüfung von § 241 II BGB relevant werden. Da ein Schuldverhältnis mit Gefälligkeitscharakter aber gerade durch seine Unentgeltlichkeit gekennzeichnet ist, kann der Gläubiger hier nicht redlicherweise erwarten, dass dem Schuldner über $\S 241$ II BGB weitere, geldwerte Verpflichtungen auferlegt werden, folgerichtig deshalb auch OLG Hamm, Urt. v. 17.6.2014 - 7 U 77/13, Rn. 41ff. (Keine Nebenpflicht eines Autohändlers zur Versicherung eines zum Verkauf überlassenen Autos oder zur Warnung wegen mangelnder Versicherung, wenn die Vermittlung nur auf einem Auftragsverhältnis beruht). Nichtsdestotrotz kann man mit Kersting, Dritthaftung, 2007, S. 403 auch in solchen Fällen erwarten, „,aß präsentes Wissen subjektiv richtig wiedergegeben“ wird. Verletzt der Schuldner aber diese Pflicht, so ließe sich der Sachverhalt wohl letztlich auch - und mit Blick auf die teleologische Subsidiarität von $\S 241$ II BGB sachnäher - über $\S 826$ BGB regulieren, ähnlich Kersting, Dritthaftung, 2007, S. 403 (,deutliche Annäherung an den deliktischen Pflichtenumfang nach $\left.\S 826 B G B^{\prime \prime}\right)$.

1535 von Bar, JuS 1982, 637, 640.

1536 S.o., S. 26.

1537 Er war sich der drohenden Haftungsgefahr ja gar nicht bewusst. Die Nebenpflicht erwischte ihn - wie für Präzedenzfälle typisch - schließlich auf dem falschen Fuß. Wohl mit Blick auf 
aber aus einer ökonomischen Vogelperspektive nach der rechtspraktischen Sinnhaftigkeit eines Markteingriffs gefragt wird, ist eine objektivierte Betrachtung sinnvoll. Setzt man die Nebenpflicht als gegeben voraus, so muss ein Steuerberater in einer vergleichbaren Situation also die Möglichkeit haben, die Informationskosten als Vertrauensprämie zu erheben. Auch das ist zweifelhaft: Das Schuldverhältnis weist hier keinerlei Gegenleistung des Gläubigers auf. ${ }^{1538}$ Der Schuldner könnte natürlich auf die Frage des Kunden antworten: „Ich kann auf diese beiläufig gestellte Frage erst eine Antwort geben, wenn Sie mir eine Vergütung zusichern". Der Nachfragende kann hierauf aber ebenso gut mit „Nein“ antworten. ${ }^{1539}$ In diesem Fall müsste der Steuerberater eine Auskunft insgesamt verweigern. ${ }^{1540}$

In jedem Fall wirkt ein solches Verhalten äußerst kleinlich. Es verursacht zudem immense Transaktionskosten für beide Seiten, obwohl der Kunde bereit war, sich mit einer beiläufigen Auskunft zufrieden zu geben. ${ }^{1541}$ Dass sich der goodwill des einzelnen Steuer-

die Einzelfallgerechtigkeit mahnt G. Wolf, Anm. zu BGH, Urt. v. 7.5.2015 - IX ZR 186/14, DStR 2015, 2094, 2095 daher auch dazu, die Gefahr einer „,unverhältnismäßigen Vergrößerung der Haftung" nicht zu verkennen.

1538 Eine tatsächliche Prämie für den Schuldner würde damit aus einer reinen Auskunftshaftung einen Dienstvertrag machen. Damit würde sich die Struktur des Schuldverhältnisses grundlegend verändern.

1539 Um dann nicht unnötig Informationskosten aufgewendet zu haben, müsste der Steuerberater bereits unmittelbar nach der Frage des Kunden die Vergütung thematisieren, ohne auch nur einen Gedanken an den Umfang der Fragestellung verschwendet zu haben. Ist der Kunde grundsätzlich zahlungsbereit, so müsste er sogar einen Kostenvoranschlag anbieten, weil erst eine kursorische Analyse der Frage die Höhe der Informationskosten konturiert, welche über die Vertrauensprämie zurückgewonnen werden müssen. In Frage steht hier schließlich nicht das Bestehen der mit dem Auskunftsvertrag verbundener Leistungspflicht, sondern von darüber hinaus gehenden Nebenpflichten zum Schutz sonstiger, vermögenswerter Interessen.

1540 So der Praxishinweis von Eschenfelder, BB 2015, 1963, 1967 für den Bereich der Nebenpflichten bei einer möglichen Insolvenz des betreuten Unternehmens, ähnlich auch Ehlers, BB 2014, 131, 132 (,ausdrücklich jedes einschlägige Gespräch zu insolvenznahen Themen verweigern"). Wie er das Schweigen des Schuldners deutet, ist dann - selbst auf Grundlage der missverständlich formulierten „Wahrheitspflicht“ - Aufgabe des Gläubigers, zutreffend Teichmann, JA 1984, 545, 547 (Fn. 12).

1541 Würde der Kunde diese Haltung auch für sich selbst ernst nehmen, so würde er die Gratisauskunft als das nehmen, was sie ist: Im Zweifel nicht völlig ,wasserdicht“ (,with a grain of 
beraters auf dem Dienstleistungsmarkt durch ein solches Geschäftsgebaren erhöht, ist mehr als fraglich. Man könnte schließlich noch fragen, ob die Vertrauensprämie allein in dem ,goodwill" besteht, den er durch eine umsichtige und kostenlose (Zusatz-)Auskunft für einen Kunden für sich verbuchen kann. Kostenfreie Zusatzhinweise und Warnungen zu erteilen mag zwar bei den Kunden gut ankommen. ${ }^{1542}$ Alle Eventualitäten auch bei beiläufigen Anfragen zu bedenken, erhöht aber die Informationskosten für den Steuerberater ganz erheblich. Steuerberater müssten dann ihre Tarife für (Dauer-)Mandate derart erhöhen, dass alle Informationskosten durch eventuelle Spontananfragen mit großer wirtschaftlicher Relevanz - und damit zusammenhängende Nebenpflichten - abgedeckt sind. ${ }^{1543}$ Dieser Sorglos-Tarif ${ }^{1544}$ entspricht

salt*), vgl. Kersting, Dritthaftung, 2007, S. 404 (Fn. 2091: mögliche, tatbestandliche Berücksichtigung von angesichts des Kontexts einer Aussage unrealistischen Qualitätserwartungen des Gläubigers in der Verneinung einer „Vertrauensinanspruchnahme“). Diese Einstellung würde ihn entsprechend auch davor bewahren, allein im Vertrauen auf eine unvergütete Aussage wirtschaftlich entscheidende Dinge zu regeln, vgl. unter Berufung auf Einstein Zwade, Anm. zu BGH, Urt. v. 7.5.2015 - IX ZR 186/14, jurisPR-BGHZivilR 12/2015, Anm. 1 (,Was nichts kostet, ist nichts wert ${ }^{*}$ ). Das war schließlich auch das Anliegen des (heutigen) $\S 675$ II BGB, der indes mittlerweile von der Rechtsprechung, ,in sein Gegenteil verkehrt" wurde, treffend Honsell, FS Medicus, 1999, S. 211, 223. Anders kann die Lage liegen, wenn der Steuerberater ungefragt eine Auskunft zu neben der Leistungspflicht liegenden Vermögensinteressen gibt. Damit wertet er sein Interesse an einer Vertrauensprämie von eigener Hand ab, plakativ Ehlers, BB 2014, 131, 131 („Wer sich Kompetenz anmaßt, muss auch die Erwartungen der Mandanten erfüllen."); wegweisend bereits Hedley Byrne \& Co Ltd v Heller \& Partners Ltd [1964] AC 465, 486. Ansonsten endet das aus ökonomischer Sicht schutzwürdige Vertrauen des Schuldners aber bei der aus dem unvergüteten Auskunftsvertrag folgenden Leistungspflicht, krit. deshalb zur „,nur eingeschränkt Rechtssicherheit“" vermittelnden Rechtsprechung der Gerichte Ehlers, BB 2014, 131, $131 \mathrm{f}$.

1542 Gerade weil es nicht üblich dem üblichen Geschäftsgebaren entspricht, besteht aber keinesfalls eine „Vermutung“ des Geschäftsverkehrs, dass ein Rat ,schenkweise“ erteilt wird, zutreffend Picker, FS Medicus, 1999, S. 397, 403.

1543 Vgl. Schäfer, AcP 202 (2002), 808, 832 (Fn. 46); deshalb krit. gegenüber der Haftung eines Gutachters gegenüber einem Dritten Faust, AcP 210 (2010), 555, 568 (,zumal eine solche erweiterte Haftung des Gutachters das Gutachten aller Wahrscheinlichkeit nach verteuern würde“); Picker, FS Medicus, 1999, S. 397, 403 (Der Schuldner müsse dann schließlich „auf Dauer" ein ,zusätzliches Entgelt als Ausgleich verlangen“).

1544 Vgl. Eschenfelder, BB 2015, 1963, 1965 („RDG kein Blankoscheck für jedwede rechtliche Beratung“); dezidiert gegen die Umgestaltung eines spezifischen Dienstleistungsverhältnisses in ein Rundum-sorglos-Paket durch Nebenpflichten auch BGH, Urt. v. 23.1.1972 - VII ZR 197/71, Rn. 12 (,,Wollte man dem Berufungsgericht folgen, so würde man den Architekten in 
im Zweifel keinesfalls dem Interesse aller Kunden. ${ }^{1545}$ Eine Vertrauensprämie für den Steuerberater, welche die Annahme einer Nebenpflicht in diesem Fall hätte stützen können, ist demnach nicht ersichtlich.

Geschäftliche Kontaktaufnahme in sozialem Umfeld sollte demnach regelmäßig keine Haftung aus einer Nebenpflichtverletzung nach sich ziehen. Im Regelfall wird es schon an einem Schuldverhältnis fehlen. Besteht wegen der erkennbaren wirtschaftlichen Relevanz der Anfrage ein Auskunfts-Schuldverhältnis oder sind die Parteien bereits durch ein kooperatives Schuldverhältnis verbunden, so kommt eine Nebenpflicht insbesondere dann in Betracht, wenn der Schuldner in der Lage ist, mit dem Gläubiger eine Gegenleistung auszuhandeln. Wegen des sozialen Umfelds des Geschehens wird es dem Schuldner im Regelfall aber an der Möglichkeit fehlen, seine Informationskosten durch eine Vertrauensprämie zu amortisieren. Soziales Umfeld und eine Vertrauensprämie als Förderung von goodwill schließen sich aber insbesondere im Beraterumfeld keineswegs kategorisch aus. ${ }^{1546}$

Beispiel 44 Ein Steuerberater möchte für seine Kunden und potentielle Mandanten ein legeres Get-together organisieren (,,Sommerfestfall “). ${ }^{1547}$ Auf dem Sommerfest trifft er einen Mandanten, mit dem ihn ein Dauermandat verbindet. In einer Runde mit vier potentiellen Mandanten fragt dieser ihn nach einer steuerlichen Optimie-

den steuerlichen Fragen, die mit dem Bau zusammenhängen, praktisch zum Steuerberater des Bauherrn machen.") (BGHZ 60, 1, 3); Krämer, Anm. zu OLG Celle, Urt. v. 10.10.2012 - 4 U 36/12, GmbH-StB 2013, 12; Thole, ZfPW 2015, 31, 42f.

1545 Alternativ zu einem derart überhöhten Tarif würde womöglich die Mehrzahl der Kunden einen Tarif bevorzugen, der fair im Verhältnis zur Leistungspflicht ist. Tun sich - was nicht immer der Fall sein muss - neue Gefahren oder Fragen auf, so steht es jedem Kunden frei, hierfür mittels separat vergüteten Auftrags Rat einzuholen.

1546 So auch Hölzle, Desinformation, 2012, S. 130f.; Hopt, AcP 183 (1983), 608, 680f.; Kersting, Dritthaftung, 2007, S. 401f., 404; anders wohl Canaris, FS Larenz, 1983, S. 27, 84; Schäfer, AcP 202 (2002), 808, 839; Schäfer/Ott, Ökonomische Analyse, 5. Aufl. 2012, S. 585; aus Praktikerperspektive auf die Möglichkeit von wirtschaftlich sinnvollen, unentgeltlichen Auskünften innerhalb eines bestehenden Schuldverhältnisses hinweisend Meixner/Schröder, Anm. zu BGH, Urt. v. 18.12.2009 - IX ZR 12/05, DStR 2009, 819 (,guter Mandant" als Grund); Nassall, Anm. zu BGH, Urt. v. 18.12.2008 - IX ZR 12/05, jurisPR-BGHZivilR 6/2009, Anm. 3 (unentgeltliche Auskunft als mögliche „Beziehungspflege“).

1547 Vgl. zum Ansatz des Falls auch Kersting, Dritthaftung, 2007, S. 404. 
rungsmöglichkeit für ein Projekt, welches er und seine Frau gemeinsam betreiben. Der Steuerberater überlegt kurz. Die Frage ist an sich zu komplex, als dass er sie ohne Hilfsmittel und Ruhe beantworten könnte. Um aber bei den potentiellen Kunden Eindruck mit seiner geistigen Flexibilität zu schinden, überlegt er sich eine ihm vertretbar erscheinende Antwort. Der Mandant vertraut in der Folge auf die Aussage des Steuerberaters und handelt entsprechend. Weil der Steuerberater bei seiner Aussage die Möglichkeit einer steuerlichen Absetzbarkeit nicht ausreichend in Betracht gezogen hat, macht der Mandant mit seiner Investitionsentscheidung einen Verlust. Er will den Steuerberater in der Folge wegen der Verletzung einer Nebenpflicht des Beratungsvertrags in Anspruch nehmen. Die Umstände der Auskunft des Steuerberaters waren hier so gelagert, dass er seinen eigenen Unternehmenswert durch die (richtige) Auskunft gegenüber den anderen (potentiellen) Kunden verbessern konnte. Er erhoffte sich schließlich zusätzliches Geschäft von diesen. ${ }^{1548}$ Im Einzelfall kann daher perspektivischer goodwill auch für relativ hohe Informationskosten entschädigen. ${ }^{1549}$ Die Annahme einer Nebenpflicht lässt sich demnach auf eine Vertrauensprämie für den Steuerberater stützen.

(d) Erkennbarkeit der Nebenpflicht den Schuldner als Prämisse der Vertrauensprämie

Die potentielle Anreizwirkung einer Informationspflicht ist stets an die Erkennbarkeit der Pflicht gekoppelt. ${ }^{1550}$ Auch der Ansatz der Vertrauensprämie setzt

1548 Vgl. zu diesem Aspekt als Haftungsgrund auch BGH, Urt. v. 14.11.1968 - VII ZR 51/67, Rn. 18f.; Kersting, Dritthaftung, 2007, S. 401f.

1549 Zutreffend Hölzle, Desinformation, 2012, S. 131 (,Für die Beurteilung des sich für den Anbieter aus dem konkret gestörten Geschäft ergebenden Vertragswerts ist der diesem voran gegangenen Werbeaufwand daher ohne ökonomischen Belang").

1550 Teichmann, JA 1984, 545, 547; Tröger, Arbeitsteilung, 2012, S. 480. Die Erkennbarkeit ist dabei weder abstrakt noch rein konkret zu ermitteln, vielmehr ist eine typisierte Betrachtung unter Berücksichtigung des jeweiligen Sachverhalts vorzunehmen. All dies verkennt auch die Rechtsprechung nicht, welche die typisierte „Erkennbarkeit“ für den Schuldner im Kontext von Informationspflichten stets zumindest streift, BGH, Urt. v. 28.4.1971 - VIII ZR 258/69, 
daher voraus, dass die Verhaltensanforderung für den Schuldner ex ante erkennbar ist. Ansonsten kann der Schuldner seine in der Nebenpflicht verbriefte Informationsbereitschaft nicht bei der Begründung ${ }^{1551}$ des Schuldverhältnisses verwerten.

Zutreffend geht deshalb auch die Rechtsprechung davon aus, dass es grundsätzlich Aufgabe des Gläubigers ist, die für ihn entscheidenden Umstände einer Geschäftsabwicklung dem Schuldner gegenüber erkennbar zu machen. ${ }^{1552}$ Zudem ist eine Nebenpflicht abzulehnen, wenn der Gläubiger eine für den Schuldner nicht sichtbare Informationsasymmetrie verdeckt. ${ }^{1553}$ Gleiches gilt, wenn der Gläubiger eine im Vergleich zu den Informationskosten des Schuldners günstigere Möglichkeit, selbst das Informationsdefizit auszugleichen, (unbewusst) verdeckt. Das Verhalten des Gläubigers ist dann nicht erst im Rahmen des Mitverschuldens bei der Schadensentstehung über \$ 254 I BGB zu berücksichtigen, sondern lässt die Nebenpflicht an einer ihrer Voraussetzungen - nämlich der Erkennbarkeit der Informationsasymmetrie oder dem Kosten-

Rn. 28 (,offensichtlich von Bedeutung“); BGH, Urt. v. 8.6.1978 - III ZR 136/76, Rn. 34 (Hinweispflicht über ,solche Umstände, die für die Entschließung des anderen Teils erkennbar von Bedeutung sein können“), 37 (Hinweispflicht auf Risiken, die dem Gläubiger ,typischerweise drohten“) (BGHZ 72, 92, 101ff.); BGH, Urt. v. 8.7.1981 - IVa ZR 244/80, Rn. 11 (,keine uferlose Information "ins Blaue hinein" geschuldet"); BGH, Urt. v. 6.7.1993 - XI ZR 12/93, Rn. 16 (expansive „Erkennbarkeitsermittlungspflicht“ für Anlagegeschäfte: Wird der Bank trotz der Verhandlungen nicht erkennbar, was für den Anleger von wesentlicher Bedeutung ist, „muß sie Informationsstand und Anlageziel des Kunden erfragen“) (BGHZ 123, 126, 128f.); BGH, Urt. v. 13.6.2002 - VII ZR 30/01, Rn. 16 (,ohne weiteres erkennbar"); BGH, Urt. v. 29.4.2008 - XI ZR 221/07, Rn. 19f.; BGH, Urt. v. 25.3.2009 - XII ZR 117/07, Rn. 12, 14; BGH, Urt. v. 19.3.2013 - XI ZR 431/11, Rn. 27 (,objektiv evident"); BGH, Urt. v. 10.2.2015 - VI ZR 569/13, Rn. 22 („Augen davor verschlossen“); Staudinger/Olzen, Neubearbeitung 2015, § 241 Rn. 450f. m.w.N.; Ott, Travemünder Symposium, 1989, S. 25, 42.

1551 Bei vorvertraglichen Informationspflichten verliert dieser Gedanke einiges an Überzeugungskraft, s.o., S. 396 (Fn. 1480).

1552 BGH, Urt. v. 8.7.1981 - IVa ZR 244/80, Rn. 11.

1553 Näher Tröger, Arbeitsteilung, 2012, S. 493. 
vorteil des Gläubigers bei der Informationsbeschaffung - scheitern. $^{1554}$

Die Haftung aus $\S \S 280$ I, 241 II BGB käme einer reinen Sanktion gleich, die nicht zu einer effizienten Informationswirtschaft beiträgt. Der Schuldner kann dann nämlich gar nicht cheapest cost avoider sein, weil er keinerlei Schadensvermeidungsmöglichkeit hatte.

Besteht eine Informationspflicht, so sollte der Gläubiger die Aufwendung eigener Informationsbeschaffungskosten sinnvollerweise unterlassen, um unnötige Kostendopplungen zu vermeiden. Grundsätzlich ist es aber die ureigene Aufgabe des Gläubigers, sich mit Informationen zu besorgen. Um den Gegenstand der Informationspflicht zur Minderung der Gesamtkosten bewusst aus seiner Informationssuche auslassen zu können, muss der Informationsbereich, für den der Schuldner zuständig ist, für ihn ex ante abgrenzbar sein. Damit sollte die Übernahme der Informationsverantwortlichkeit durch den Schuldner auch für den Gläubiger erkennbar sein. Ist die Verlagerung des Informationsrisikos vom Gläubiger auf den Schuldner aber gerade wegen der Informationskostenasymmetrie zwischen Schuldner und Gläubiger nicht für den Gläubiger erkennbar, so ist dies unschädlich. Genau diese Informationsasymmetrie soll durch die Annahme einer Nebenpflicht schließlich behoben werden.

Ist für den Schuldner nicht erkennbar, dass er die Informationsverantwortlichkeit übernehmen soll, so scheidet die Realisierung der Vertrauensprämie aus und eine Nebenpflicht ist folglich abzulehnen. Ist die Übernahme der Informationsverantwortlichkeit durch den Schuldner zwar für diesen erkennbar, nicht aber für den Gläubiger, so spricht dies nicht zwingend gegen die Annahme einer Nebenpflicht. Im Ergebnis entscheidet damit die Erkennbarkeit des vom Schuldner zu tragenden Informationsrisikos für den Schuldner darüber, ob die Ökonomik die Annahme einer entsprechenden Nebenpflicht unterstützt oder nicht.

1554 Vgl. Faust, Verbraucher-acquis, 2011, S. 201, 207. 


\section{(e) Ökonomischer Vertrauensschutz in der Subsumtion}

Die bislang erarbeiteten Voraussetzungen der um Vertrauensschutzgesichtspunkte angereicherte Haftungszuweisung mittels des Begriffs des cheapest cost avoider sind beispielhaft auf die Fallgruppe des Abbruchs von Vertragsverhandlungen zu übertragen. ${ }^{1555}$

Beispiel 40 Mit dem Ansatzpunkt des cheapest cost avoider ist-im informatorischen Kontext ${ }^{1556}$ - die erste Voraussetzung für ökonomisch sinnhafte Haftungszuweisung das Bestehen einer Informationskostenasymmetrie. ${ }^{1557}$ Im Verhandlungsabbruchsfall ${ }^{1558}$ geht es darum, kein unbegründetes Vertrauen auf einen künftigen Vertragsschluss zu erwecken. Der Gläubiger hat keine Möglichkeit, die zukünftige Verhandlungsbereitschaft des Schuldners zu beurteilen. Er kann nur das vergangene Verhalten als Anhaltspunkt nehmen und darauf aufbauend extrapolieren. In den Fällen, in denen die Rechtsprechung von einer Nebenpflicht ausgeht, ruft der Schuldner durch sein Verhalten das begründete Vertrauen des Gläubigers herbei, dass die Verhandlungen in einen Vertragsschluss münden. Allein dadurch lässt sich der Gläubiger ja schließlich dazu bringen, für den ungewissen Vertragsschluss Aufwendungen zu machen. ${ }^{1559}$ Will der Schuldner sich auch durch intensive Verhandlungen in keiner Weise binden, so muss er seinen Vorbehalt lediglich dem Gläubiger gegenüber kommunizieren oder durch sein Verhalten klar zu erkennen geben, dass der Vertragsschluss noch ungewiss ist. ${ }^{1560}$ Dieses Verhalten ist dem

1555 Vgl. hierzu bereits S. 83; Beispiel 39, S. 366.

1556 Bei Nebenpflichten mit Vermögensbezug, die keine Information zum Gegenstand haben, ist danach zu fragen, ob der Schuldner einen Kostenvorteil gegenüber dem Gläubiger bei der Schadensvermeidung hat.

1557 Die Information muss also vom Schuldner mit geringeren Kosten zu beschaffen sein als vom Gläubiger.

1558 S.o., S. 366.

1559 Der Gläubiger könnte zur Schadensvermeidung lediglich komplett auf Aufwendungen vor Vertragsschluss verzichten. Bisweilen sind solche aber notwendig. Ein Totalverzicht würde häufig deshalb ebenso feindlich gegenüber den Vertragsverhandlungen wirken wie das Verhalten des Schuldners.

1560 Vgl. OLG Düsseldorf, Urt. v. 8.7.1999 - 10 U 67/98, Rn. 5. 
Schuldner möglich und verursacht ihm auch keine nennenswerten (Opportunitäts-)Kosten. Damit hat der Schuldner hier einen Vorteil gegenüber dem Gläubiger bei der Schadensvermeidung und in der Folge besteht eine Informationskostenasymmetrie.

Im Bereich informatorischen Vermögensschutzes ist Voraussetzung für eine Haftung, dass die geforderte Information produktiv ist. ${ }^{1561}$ Die geforderte Information würde hier dazu führen, dass keine geldwerten Ressourcen wie Zeit und Geld in einen zukünftigen Vertragsabschluss investiert werden, nur um wegen eines grundlosen Abbruchs der Verhandlungen mit einem Schlag unnütz gemacht zu werden. ${ }^{1562}$ Damit wäre die geforderte Information produktiv.

Zudem muss der Schuldner der Nebenpflicht für sein Verhalten eine Vertrauensprämie vom Gläubiger verlangen können. Die Bereitschaft des Schuldners, die Vertragsverhandlungen ohne grundlosen Abbruch fortzusetzen, wird er sich nicht bezahlen lassen können. Vielmehr kommt als Vertrauensprämie nur in Betracht, dass er mit pflichtkonformen Verhalten einer Vertrauensstrafe entgeht. Der grundlose Abbruch fortlaufender Verhandlungen würde schließlich einen schweren Vertrauensverlust aufseiten des Gläubigers nach sich ziehen. Wenn also bereits berechtigtes Vertrauen auf der Seite des Gläubigers geweckt wurde, so kommt dem Schuldner durch pflichtkonformes Verhalten eine indirekte Vertrauensprämie zugute. ${ }^{1563}$

1561 Geht es nicht um eine Information, sondern um eine sonstige vermögensschützende Handlung, muss auf die Produktivität der geforderten Handlung abgestellt werden.

1562 Da die Nebenpflicht auf den grundlosen Abbruch der Verhandlungen beschränkt ist, bleibt auch gewährleistet, dass ein Vertragsschluss nicht entgegen ökonomischen Erwägungen erzwungen wird.

1563 Diese Voraussetzung ist durch die Vertrauenskomponente entscheidend an Wertungen gebunden und damit wenig präzise. Gleichzeitig kann nur mit ihr gegenüber Fällen abgegrenzt werden, in denen der Schuldner in Ausübung seiner Vertragsabschlussfreiheit berechtigterweise die Verhandlungen abbricht. Ressourcen in Form von Aufwendungen und Zeitinvestition werden schließlich durch jeden Verhandlungsabbruch vernichtet. Jedem zwanghaften Fortführen von Verhandlungen würde damit auf den ersten Blick eine gewisse Produktivität innewohnen, vgl. zu diesem aus der Verhaltenswissenschaft als Phänomen der sunk costs umschriebenen 
Damit lassen sich die ersten drei Voraussetzungen vertretbar bejahen. Schließlich muss die Opportunismusprämie größer als die Vertrauensprämie sein. Mit anderen Worten darf sich der Markt nicht schon von allein regulieren. ${ }^{1564}$ Wenn jemand grundlos oder unter Nennung sachfremder Gründe eine Vertragsverhandlung abbricht, so wird der Gläubiger mit dem Schuldner voraussichtlich nie wieder kontrahieren. Der einzelne "Qualitätsverschlechterer " kann damit durch Abwanderung bestraft werden. Indem der Schuldner die Verhandlungen aus sachfremden Erwägungen abbricht, zeigt er ja gerade, dass er rationales Verhalten - das eines homo oeconomicus - geringschätzt ${ }^{1565}$. Damit beeinträchtigt er mutwillig seine eigene Markt- und Wettbewerbsfähigkeit. Im Kontext geschäftlicher Vertragsverhandlungen ist zudem keineswegs pauschal davon auszugehen, dass sich die Parteien „ohnehin nie wieder sehen werden " und deshalb eine Abwanderung faktisch gar nicht möglich sei: Im Einzelfall mag dies so sein, im Modellfall

Problem Drexl, Selbstbestimmung, 1998, S. 196f.; Eidenmüller, JZ 2005, 216, 219; Schäfer/Ott, Ökonomische Analyse, 5. Aufl. 2012, S. 108; Unberath, Vertragsverletzung, 2007, S. 133.

1564 Nur wenn sich das als pflichtwidrig dargestellte Verhalten im Vergleich zum pflichtgemäßen Verhalten aus einer ökonomischen Perspektive lohnt, darf das Rechtssystem überhaupt intervenieren.

1565 Zwar schätzt der Schuldner den Vertragsabbruch hier offensichtlich persönlich höherwertig an als den Gewinn, den er aus der Durchführung des Vertrages ziehen könnte. Sein Affektionsinteresse am Verhandlungsabbruch ist damit als Opportunismusprämie für ihn persönlich höher als die Vertrauensprämie. Auch die ökonomische Analyse erkennt im Vertragsrecht grundsätzlich einen Vorrang der persönlichen Präferenzen (Nutzenmaximierung) vor ökonomischer Rationalität an, Schäfer/Ott, Ökonomische Analyse, 5. Aufl. 2012, S. 449f. An dieser Stelle ist aber eine objektivierte Betrachtung sinnvoll. Es soll schließlich überprüft werden, ob die Marktverhältnisse den Opportunismus aus abstrakter Perspektive rentabel erscheinen lassen oder nicht. Verhält sich der Einzelne mit einem Verhandlungsabbruch irrational, so ist grundsätzlich nicht zu befürchten, dass die Masse dieses Verhalten wiederholt. Aus ökonomischer Vogelperspektive lohnt es sich schließlich nicht. Deshalb ist für das Verhältnis der Opportunismus- zur Vertrauensprämie die Perspektive eines rationalen Marktteilnehmers maßgeblich. Gibt es ökonomisch auch nur im Ansatz vertretbare Gründe für den Verhandlungsabbruch durch den Schuldner, so wird auch von Rechtsprechung und Literatur eine Haftung aus $\S \S 280$ I, 241 II, 311 II BGB abgelehnt, vgl. BGH, Urt. v. 10.1.1996 - VIII ZR 327/94, Rn. 18; Bamberger-Roth/Gehrlein/Sutschet, 3. Aufl. 2012, § 311 Rn. 57, 61. Mit diesem Ansatz würde eine Haftung dann zusätzlich daran scheitern, dass die geforderte Handlung (der Vertragsschluss) dann nicht produktiv wäre. Schließlich gibt es wirtschaftliche Argumente dagegen. 
dürfte jedoch ein erneutes Kontrahieren der Parteien nicht von vornherein auszuschließen sein. Ein Markt für Zitronen besteht bei grundlosem Verhandlungsabbruch deshalb nicht. Damit ist auch die Opportunismusprämie nicht höher als die Vertrauensprämie. Eine Haftung aus $\$ \$ 280$ I, 241 II BGB wegen des Abbruchs von Vertragsverhandlungen ist damit aus einer ökonomischen Perspektive abzulehnen. ${ }^{1566}$

Damit sind die Kriterien ökonomischen Vertrauensschutzes im Kontext der Risikozuweisung an den cheapest cost avoider subsumtionstauglich.

1566 Dies widerspricht zwar im ersten Zugriff der Ansicht der Rechtsprechung, s. hierzu BGH, Urt. v. 4.3.1955 - V ZR 66/54, Rn. 11; BGH, Urt. v. 8.6.1978 - III ZR 48/76, Rn. 16, 18 (BGHZ 71, 386, 395f.) BGH, Urt. v. 7.2.1980 - III ZR 23/78, Rn. 42 (BGHZ 76, 343, 349); BGH, Urt. v. 15.10.2003 - VIII ZR 329/02, Rn. 13. Auch aus rechtswissenschaftlicher Perspektive wird die mit diesen Nebenpflichten einhergehende Beschränkung der Vertragsabschlussfreiheit aber kritisch begutachtet, von Bar, JuS 1982, 637, 639 (,sollte man vom Einsatz der culpa in contrahendo in diesen Fällen besser ganz absehen"); Cziupka, Anm. zu BGH, Urt. v. 9.11.2012 - V ZR 182/11, LMK 2013, 342589; Dauner-Lieb, Schuldrechtsreform, 2001, S. 305, 318 (Tendenz ,ganz grundsätzlich keinen Schadensersatzanspruch aus culpa in contrahendo zu geben"); Kersting, Dritthaftung, 2007, S. 344f.; Medicus, Gutachten, Bd. I, 1981, S. 479, 497ff.; Rieble, Schuldrecht, 2003, S. 137, 151 (,,Mir liegt deshalb der Verzicht auf diese Vertrauenshaftung deutlich näher."). Fehlt es bei einem Grundstückskaufvertrag noch an der Form des $\S 311 \mathrm{~b}$ BGB, so wird das Recht des Schuldners, die Vertragsverhandlungen abzubrechen, auch von der Rechtsprechung besonders hoch eingeschätzt, BGH, Urt. v. 9.11.2012 - V ZR 182/11, Rn. 8; LG Aachen, Urt. v. 15.1.2015 - 10 O 106/14, Rn. 18f. Die Literatur hält die privatautonom begründete Abschlussfreiheit zum Teil ohnehin für so hochrangig, dass sie eine richterliche „Motivanalyse“ beim Abbruch von Vertragsverhandlungen generell ablehnt, Näher von Bar, JuS 1982, 637, 639; Cziupka, Anm. zu BGH, Urt. v. 9.11.2012 - V ZR 182/11, LMK 2013, 342589; Medicus, Gutachten, Bd. I, 1981, S. 479, 498f.; Rieble, Schuldrecht, 2003, S. 137, 150f.; vgl. zur Kritik auch Canaris, FS Larenz, 1983, S. 27, 91; MüKo-BGB/Emmerich, 7. Aufl. 2016, § 311 Rn. 162, 164. Übrig bliebe dann nur noch das vorsätzliche „In-die-Irre-Führen“ des Schuldverhältnis-Partners als Nebenpflichtverletzung, vgl. BGH, Urt. v. 29.3.1996 - V ZR 332/94, Rn. 11, 13; BGH, Urt. v. 9.11.2012 - V ZR 182/11, Rn. 11; etwas großzügiger LG Aachen, Urt. v. 15.1.2015 10 O 106/14, Rn. 20. Das kann indes auch über das Institut der vorsätzlichen, sittenwidrigen Schädigung (§826 BGB) reguliert werden, von Bar, JuS 1982, 637, 639; vgl. auch Erman/Westermann, 15. Aufl. 2017, § 280 Rn. 45. Das wäre zudem sachnäher: Es sollte vorzugwürdig sein, ein Rechtsproblem über ein modifiziertes Verständnis einer speziellen Regelung zu lösen, anstatt den Aussagegehalt der speziellen Regelung mithilfe einer auf eine allgemeine Regelung zurückgehenden Lösung zu entwerten, so bereits treffend Medicus, FS Kern, 1968, S. 313, 326ff. 


\section{(f) Nutzen der Vertrauensprämie}

Auch der ökonomische Vertrauensschutz geht - auf den Schutz vermögenswerter Interessen mittels $\S 241$ II BGB bezogen - als Basis von dem haftungszuweisenden Kriterium des cheapest cost avoider aus. Verfeinert wird das Kriterium aber durch das Element der Vertrauensprämie. Ein Risiko wird nicht nur pauschal demjenigen zugewiesen, der den Schaden am kostengünstigsten hätte verhindern können. Vielmehr wird zusätzlich verlangt, dass dieser für die aus der Nebenpflicht herrührender Weise in irgendeiner Weise entschädigt werden kann. Das Problem an dieser Voraussetzung ist zwar, dass sie sehr wertungsoffen ist. Bei Nebenpflichten lässt sich nämlich häufig keine konkrete Vertrauensprämie berechnen. Stellt man auf den goodwill als Vertrauensprämie ab, ${ }^{1567}$ so müssen Verdienstchancen und Kundenerwartungen analysiert werden. Welche Handlung von potentiellen Kunden mit einer besonders hohen Vertrauensprämie goutiert wird, hängt schließlich auch von deren redlichen Erwartungen ab sowie einer komplexen Marktanalyse ab. Insbesondere die redliche Erwartung des typischen Kunden ist Einfallstor für ebenjene Vagheit, die mehrfach kritisiert wurde. Gleichzeitig ist es genau diese Voraussetzung, die den Ansatz für vermögensschützende Nebenpflichten insgesamt tauglich macht. Trotz gewisser Subsumtionsschwierigkeiten kennzeichnet der Gedanke der Vertrauensprämie präzise die Folgen einer Risikozuweisung nach dem Prinzip des cheapest cost avoider, welche ansonsten allzu leicht in Vergessenheit geraten.

Insbesondere bei Handlungen, die isoliert betrachtet einen Marktwert haben und die pauschale Risikozuweisung mit dem Kriterium des cheapest cost avoider die mit der Nebenpflicht gesetzten ökonomischen Handlungsanreize womöglich aus dem Blick geraten lässt ${ }^{1568}$-, kann der ökonomische Vertrauensschutz die Rekonstruktion des vollständigen Schuldverhältnisses demnach bereichern. Damit ist der Ansatz insgesamt gut in der Subsumtion zu § 241 II BGB zu gebrauchen. $^{1569}$

1567 Hierzu Schäfer/Ott, Ökonomische Analyse, 5. Aufl. 2012, S. 585.

1568 S.o., S. $407 \mathrm{f}$.

1569 Auch Kersting, Dritthaftung, 2007, S. 398ff., 407 hält den Ansatz - beschränkt auf die Informationsverantwortlichkeit in Fällen der Dritthaftung nach § 311 III BGB - für sinnvoll. 
(g) Zwischenergebnis: Symbiose des cheapest cost avoider mit ökonomischem Vertrauensschutz

Das Haftungskriterium des cheapest cost avoider und die Perspektive der ökonomischen Analyse auf Vertrauensschutz ergänzen sich somit sinnvoll.

(7) Zwischenergebnis: Begriff des cheapest cost avoider mit dem Ansatz der Vertrauensprämie zu kombinieren

Das Haftungskriterium des cheapest cost avoider bietet überzeugende Ansatzpunkte, um Risiken mittels der Annahme von Nebenpflichten zu verteilen. Sofern die geforderte Handlung einen Marktwert aufweist, ist über die ergänzende Voraussetzung der Vertrauensprämie sicherzustellen, dass der Schuldner für die mit der Nebenpflicht einhergehende Belastung entschädigt werden kann - und eine solche Entschädigung auch im (ökonomischen) Interesse des Gläubigers ist.

cc) Sekundäre Haftung des cheapest cost insurer

Kann ein Schaden nicht (sinnvoll) verhindert werden, so soll - die Versicherbarkeit des Risikos vorausgesetzt - sekundär derjenige haften, der das Risiko am kostengünstigsten durch Dritte oder selbst hätte versichern können (cheapest cost insurer). ${ }^{1570}$

1570 Grundmann/Hoernig, X. Travemünder Symposium, 2007, S. 420, 427; Kötz, Travemünder Symposium, 1989, S. 189, 195f.; Schäfer/Ott, Ökonomische Analyse, 5. Aufl. 2012, S. 437; zur konkreten Relevanz der Versicherbarkeit eines Risikos für die Fähigkeit zur Risikotragung auch Brüggemeier, AcP 182 (1982), 385, 402ff.; Staudinger/Olzen, Neubearbeitung 2015, Einl zum SchuldR Rn. 90ff.; Schlechtriem, VersR 1973, 581, 593f. Gleiches gilt, wenn der Erwartungswert des Schadens - also die Schadenseintrittswahrscheinlichkeit multipliziert mit der erwarteten Schadenshöhe - unterhalb der Schadensvermeidungskosten liegt, Schäfer/Ott, Ökonomische Analyse, 5. Aufl. 2012, S. 437. In einem solchen Fall wäre es ineffizient, den Schaden durch Aufwendung der dafür notwendigen Kosten zu verhindern. Schließlich muss innerhalb eines Schuldverhältnisses auf das Kriterium des cheapest cost insurer zurückgegriffen werden, wenn der cheapest cost avoider nicht an diesem Schuldverhältnis beteiligt ist. Wer im Zweipersonenverhältnis das Risiko für den Schaden tragen soll, lässt sich dann mit dem Begriff des cheapest cost avoider nicht ermitteln. 
Beispiel 45 Ein Käufer will seinen alten Golf III beim Kauf eines neuen Golf VII bei einem Autohändler in Zahlung geben (,,Inzahlungsgabefall“). ${ }^{1571}$ Der Händler ist aber nicht bereit, den vom Käufer geforderten Preis für den Altwagen zu akzeptieren. Die Verhandlungen kühlen deshalb etwas ab. Zwei Wochen später stößt der Händler auf einen Interessenten, der den vom Käufer geforderten Preis für den Golf III zu zahlen bereit wäre. Dies teilt der Händler dem Käufer mit. Die beiden vereinbaren, dass der Händler die Verkaufsverhandlungen führen soll. Der Händler erhält zu diesem Zweck das Auto, die Schlüssel und die Fahrzeugpapiere. Der Händler und der Interessent einigen sich auf eine Probefahrt. An einer Ampel übersieht der Interessent die klar erkennbare Rotfärbung und fährt mit $50 \mathrm{~km} / \mathrm{h}$ auf das ordnungsgemäß bremsende Fahrzeug vor ihm auf. Der Golf III erleidet schwerste Schäden. Weder der Käufer noch der Händler haben für eine (Voll-)Kaskoversicherung des Autos gesorgt.

Der Käufer möchte nun vom Händler ${ }^{1572}$ Ersatz verlangen. Der BGH bejahte eine Haftung des Autohändlers aus positiver Ver-

1571 Der Fall basiert auf BGH, Urt. v. 8.1.1986 - VIII ZR 8/85.

1572 Gegenüber dem Interessenten besteht ein Anspruch des Käufers aus § 823 I BGB: Zwar geht der BGH davon aus, dass zwischen Verkäufer und Interessent ein stillschweigender Haftungsausschluss für fahrlässige Beschädigungen bei einer Probefahrt zustande kommt, wenn nicht der Verkäufer vor Beginn der Fahrt darauf hingewiesen hat, dass kein Kaskoschutz besteht, BGH, Urt. v. 7.6.1972 - VIII ZR 35/71, Rn. 11. Dieser Haftungsausschluss gilt laut BGH über den - im Bereich der Drittwirkung rechtsgeschäftlicher Vereinbarungen eigentlich deplatzierten - Rechtsgedanken des $\S 278$ BGB sogar gegenüber einem vom Autohändler unterschiedlichen Eigentümer des beschädigten Autos, der den Wagen dem Händler zur Verkaufsvermittlung überlassen hat, BGH, Urt. v. 10.1.1979 - VIII ZR 264/76, Rn. 23, 26 („Die von dem Zeugen M. gewährte Haftungsfreistellung muß der Kläger gegen sich gemäß $\$ 278$ BGB gelten lassen. Die Probefahrt diente der Anbahnung von Verkaufsverhandlungen. Die Haftungsfreistellung erfaßt vertragliche Ersatzansprüche aus Verschulden bei Vertragsschluß und deliktische Ansprüche."). Der Ausschluss umfasst aber keine Beschädigungen aufgrund grob fahrlässigen oder vorsätzlichen Verhaltens, BGH, Urt. v. 7.6.1972 - VIII ZR 35/71, Rn. 11, 13. Bei mindestens grober Fahrlässigkeit endet das schutzwürdige Vertrauen des Kaufinteressenten auf eine finanziell risikolose Probefahrt. Der Interessent hat hier mit der klar erkennbar Rot werdenden Ampel etwas außer Acht gelassen, was jedem vernünftigen Menschen in seiner Situation sofort eingeleuchtet hätte, und in besonders erheblicher Weise gegen die im Verkehr erforderliche Sorgfalt verstoßen. Damit hat der Interessent grob fahrlässig gehandelt. Ihm kommt also kein stillschweigender Haftungsausschluss zugute. Er haftet demnach dem Eigentümer des Autos aus fahrlässiger Eigentumsbeschädigung. Ob zwischen dem Käufer und dem 
tragsverletzung mit dem Argument, dass es ihm möglich und aufgrund des eigenen, wirtschaftlichen Interesses am Verkauf des Autos zumutbar gewesen wäre, das Auto des Kunden zu versichern. ${ }^{1573}$ Ohne konkreten Hinweis des Autohändlers darauf, dass er das zu vermittelnde Auto nicht versichern werde, sei er dazu verpflichtet eine Vollkaskoversicherung abzuschließen. ${ }^{1574} \mathrm{Da}$ der Interessent hier grob fahrlässig gehandelt hatte, bestand aber bereits ein Anspruch gegen ihn. Trotzdem war der Schaden hier laut BGH vom Schutzzweck der (verletzten) Norm gedeckt: Die Neben-

Interessenten ein durch den Händler vermitteltes, vorvertragliches Schuldverhältnis zustande gekommen ist, hat der BGH offen gelassen, vgl. BGH, Urt. v. 10.1.1979 - VIII ZR 264/76, Rn. 12. Bejaht man diese Frage, so haftet der Interessent zudem aus $\S 280$ I, 311 II Nr. 2, 241 II BGB. In einem anderen Fall hat der BGH auf das Verhältnis zwischen Eigentümer des Autos und Interessent den Gedanken des $§ 278$ BGB mit Blick auf das Verhalten des Autohändlers angewandt, BGH, Urt. v. 10.1.1979 - VIII ZR 264/76, Rn. 23, 26. Das lässt sich nur erklären, wenn man ein Schuldverhältnis bejaht.

1573 Näher BGH, Urt. v. 8.1.1986 - VIII ZR 8/85, Rn. 15; zustimmend Erman/Westermann, 15. Aufl. 2017, $\S 241$ Rn. 11. Die Haftung würde heute aus $\S \S 280$ I, 241 II BGB resultieren. Zugrundeliegendes Schuldverhältnis war hier ein Vermittlungsauftrag zwischen dem Händler und dem Käufer zum Verkauf des PKW, vgl. hierzu die Ausführungen des Berufungsgerichts, BGH, Urt. v. 8.1.1986 - VIII ZR 8/85, Rn. 7.

1574 Eigentlich ging es also darum, dem Kunden die bewusste Entscheidung zu ermöglichen, entweder die Vermittlung des Autos an eine Versicherung durch den Händler zu knüpfen oder, ohne Versicherungsschutz ganz auf die Vermittlung zu verzichten, oder, das Risiko von ohne ihn durchgeführten, unversicherten Probefahrten explizit zu akzeptieren. Das Berufungsgericht ging dementsprechend auch von der Verletzung einer Aufklärungspflicht des Händlers aus, dass er keine Versicherung abzuschließen gedenke, BGH, Urt. v. 8.1.1986 - VIII ZR 8/85, Rn. 9. Der BGH formulierte andersherum: Wenn der Händler nicht auf seine Intention hinweise, keine Versicherung abzuschließen, sei er eben dazu aus einer „Fürsorgepflicht" verpflichtet, BGH, Urt. v. 8.1.1986 - VIII ZR 8/85, Rn. 15. Die Nebenpflicht zum Abschluss der Vollkaskoversicherung wäre demnach als erfüllt (oder wirksam abbedungen) anzusehen, wenn der Kunde auf die Warnung des Händlers hin mit dem Vermittlungsgeschäft fortgefahren wäre. Das ist ein überzeugender Blickwinkel: Der Händler wird schließlich eine solche Warnung häufig aus pragmatischen Gesichtspunkten unterlassen wollen, um den Kunden nicht nervös zu machen und das Geschäft womöglich platzen zu lassen. Dann wird er durch das Urteil aber faktisch dazu gezwungen eine Versicherung abzuschließen, um nicht selber zu haften, vgl. Grünewald, Garantenpflichten, 2001, S. 121 (Fn. 563). Es galt also zu überprüfen, ob sich eine solche Versicherungspflicht inhaltlich rechtfertigen lässt - nicht nur, ob eine Hinweispflicht zumutbar ist. Entscheidend war hier also nicht der konkrete Inhalt der Nebenpflicht, sondern die Tatsache, dass sie dem Autohändler das Schadensrisiko für den betreffenden Sachverhalt zuweisen konnte. Das zeigt erneut die haftungsrechtliche Flexibilität der Nebenpflichten im Gebrauch durch die Rechtsprechung sowie die teilweise Befreiung von dem Korsett, die Nebenpflicht im Detail präzise zu formulieren, um eine gewünschte Risikoverteilung zu erreichen. 
pflicht solle schließlich sowohl davor schützen, dass der Interessent nur leicht fahrlässig handele und somit von der Haftung befreit würde, als auch davor, dass er zwar grob fahrlässig handele, aber den gegen ihn bestehenden Anspruch nicht bedienen kön$n$. $^{1575}$

Es gilt zu überprüfen, ob auch die Rekonstruktion des vollständigen Schuldverhältnisses zum gleichen Ergebnis käme. Fraglich ist zunächst, wer cheapest cost avoider ist. Der Käufer hatte hier keinerlei Zugriffsmöglichkeit auf das Auto während des Unfallvorgangs, dementsprechend kommt als cheapest cost avoider nur der Händler in Betracht. Diese war aber nicht Fahrer des Fahrzeugs. Zudem stand ihm keine Möglichkeit der Schadensvermeidung (wie zum Beispiel Einbau einer Fahrschulbremse auf dem Beifahrersitz und entsprechende Kontrolle) zu, welche im Verhältnis zum Schadenserwartungswert (Wahrscheinlichkeit, dass elementare Verkehrsregeln vom Interessenten außer Acht gelassen werden, multipliziert mit dem durchschnittlich zu erwartenden Schaden) gestanden hätte. In der Terminologie der Ökonomik handelt es sich um einen unvermeidbaren Schaden. Das Haftungskriterium des cheapest cost avoider kann bei der Entscheidung, ob eine Nebenpflicht anzunehmen oder abzulehnen ist, demnach nicht helfen. Dementsprechend ist in der Rangfolge der Rekonstruktion des vollständigen Vertrags auf den cheapest cost insurer für die Risikoverteilung abzustellen. Dem Käufer hätte zwar die Möglichkeit einer Kaskoversicherung für sein Auto offen gestanden. Da er diese Versicherungsform aber bislang nicht gewählt hatte, wäre er gezwungen gewesen, nur für die vom Händler angebotene Fahrzeugvermittlung eine solche Versicherung abzuschließen. Das hätte erhebliche Kosten nach sich gezogen. Die Ziffern A.1.2.3 I, A.3.1, A.3.2 sowie A.5.1.1 II der Sonderbedingungen zur Kfz-Haftpflicht- und Kasko-

1575 BGH, Urt. v. 8.1.1986 - VIII ZR 8/85, Rn. 15, 18. Das Berufungsgericht hatte den Anspruch abgelehnt, weil die fehlende, praktische Durchsetzbarkeit eines Anspruchs ein allgemeines Lebensrisiko sei und insofern die Nebenpflicht des Händlers die Realisierung dieses Risikos nicht decke, vgl. BGH, Urt. v. 8.1.1986 - VIII ZR 8/85, Rn. 9. 
versicherung für Kfz-Handel und -Handwerk (KfzSBHH) ${ }^{1576}$ belegen indes, dass dem Autohändler die Möglichkeit zusteht, mit einer Handelsversicherung auch fremde, ihm nur zum Verkauf überlassene Fahrzeuge zu versichern. ${ }^{1577}$ Weil der Händler - anders als der Privatmann - gleich mehrere Fahrzeuge mit einer Kaskoversicherung versehen möchte, besteht regelmäßig ein Preisvorteil sowie der Vorteil niedrigerer Transaktionskosten. Damit konnte der Händler hier das Schadensrisiko am günstigsten versichern. Cheapest cost insurer ist damit der Autoverkäufer. Das Schadensrisiko sollte also aus der Perspektive der ökonomischen Analyse ihm zugewiesen werden. Indem der BGH im hier besprochenen Urteil dasselbe tat, kommen die herkömmlich-rechtswissenschaftliche und die ökonomische Argumentation hier also zum gleichen Ergebnis. $^{1578}$

Der Gedanke, dass ein Risiko dem Schuldner über eine Nebenpflicht zugewiesen werden kann, weil er es am kostengünstigsten versichern kann, findet demnach auch in der Rechtsprechung durchaus Berücksichtigung. ${ }^{1579}$

1576 Unverbindliche Musterbedingungen des Gesamtverbandes der Deutschen Versicherungswirtschaft e.V. (Stand März 2010), abrufbar unter http://www.gdv.de/wp-content/uploads/ 2014/07/KfzSBHH_Maerz2010.pdf, zuletzt eingesehen am 24.7.2018.

1577 Damals bestand dieselbe Möglichkeit nach Nr. 1 oder 4 der Sonderbedingung zur Haftpflichtund Fahrzeugversicherung für Kraftfahrzeug-Handel und -Handwerk (BAnz Nr. 20 vom 28. Oktober 1970), BGH, Urt. v. 8.1.1986 - VIII ZR 8/85, Rn. 15.

1578 So letztlich auch Michael Lehmann, Vertragsanbahnung, 1981, S. $322 \mathrm{f}$.

1579 Vgl. BGH, Urt. v. 25.3.2009 - XII ZR 117/07, Rn. 13ff. (,Aufklärungspflicht des Autovermieters gegenüber dem Mietinteressenten über mögliche Probleme bei der Abrechnung der Mietwagenkosten mit der Haftpflichtversicherung des Unfallgegners“); BGH, Urt. v. 2.6.2016 VII ZR 107/15, Rn. $11 \mathrm{ff}$. (Aufklärungspflicht eines Juweliers über etwaig fehlenden Versicherungsschutz bei der Entgegennahme von Kundenschmuck zur Reparatur aufgrund der „Branchenüblichkeit“ des Versicherungsschutzes); umgekehrt eine Nebenpflicht verneinend, weil der Gläubiger gegenüber dem Schuldner einen Kostenvorteil bei der Versicherung des Schadens hatte BGH, Urt. v. 3.3.1988 - X ZR 54/86, Rn. 36 (BGHZ 103, 316, 326f.); vgl. zur Abhängigkeit eines Haftungsausschlusses für Nebenpflichtverletzungen des Schuldners durch AGB von der Versicherbarkeit des Risikos für den Gläubiger BGH, Urt. v. 7.2.1979 - VIII ZR 305/77, Rn. 19, 23; KG Berlin, Urt. v. 14.11 .1990 - 23 U 5029/89, Rn. 46f. sowie zur Relevanz der Versicherbarkeit eines Risikos für die Annahme von Nebenpflichtverletzungen in einem Vertrag mit Schutzwirkung zugunsten Dritter BHG, Urt. v. 23.1.1985 - IVa ZR 66/83, Rn. 33; OLG Düsseldorf, Urt. v. 30.9.1999 - 6 U 106/98, Rn. 10, 15; OLG Düsseldorf, Urt. v. 8.2.2018 - 6 U 50/17, Rn. 32 (verneinte Haftung einer Ratingagentur gegenüber einem 


\section{(1) Besonderheiten rechtsgeschäftlicher Schuldverhältnisse}

Vorausgesetzt der Schuldner kann das Schadensrisiko kostengünstiger als der Gläubiger versichern, sind in einem rechtsgeschäftlichen Schuldverhältnis zudem besondere Voraussetzungen zu beachten: Um die privatautonome Entscheidung der Parteien, ein Schuldverhältnis zu begründen, nicht zu untergraben, muss der Gläubiger der Nebenpflicht zum Zeitpunkt der SchuldverhältnisEntstehung bei typisierter Interessenlage bereit sein, die Versicherungsprämie welche sich aus dem Schadenserwartungswert sowie der Profitmarge des Versicherers zusammensetzt - als Umlage auf die versprochene Gegenleistung (im Regelfall den vereinbarten Kaufpreis) zu akzeptieren. ${ }^{1580}$ Aufgrund der Signalwirkung der Annahme einer entsprechenden Nebenpflicht ist nämlich davon auszugehen, dass zukünftige Schuldner die durch die Pflichtversicherung über $\S 241$ II BGB entstehenden Kosten einpreisen werden. Dies muss der Interessenlage des typisierten Gläubigers entsprechen. Anderenfalls würde der Gläubiger zukünftig für etwas zahlen müssen, was er nicht haben will (Fehlallokation von Ressourcen). Der gleiche Gedanke wurde bereits im Rahmen der Risikozuweisung nach dem Prinzip des cheapest cost avoider in Form der Vertrauensprämie bemüht. ${ }^{1581}$

Im Einklang mit diesem Gedanken wurde beispielsweise eine Nebenpflicht zur Versicherung eines zum Verkauf übernommenen Autos zutreffend abgelehnt, wenn die Vermittlung des fremden Fahrzeugs vom Autohaus lediglich aus Gefälligkeit (Auftragsverhältnis)

Anleger); OLG Zweibrücken, Urt. v. 30.1.2014 - 4 U 66/13, Rn. 42. Im Arbeitsrecht findet der Gedanke bei der internen Schadensaufteilung zwischen Arbeitnehmer und Arbeitgeber bei einer Nebenpflichtverletzung des Arbeitnehmers Berücksichtigung, vgl. BAG, Urt. v. 18.4.2002 - 8 AZR 348/01, Rn. 15, 22 (BAGE 101, 107, 113, 118); ArbG Köln, Urt. v. 16.5.2002 - 1 Ca 11099/01, Rn. 19f.; s. auch die Einschätzung von Hopt, AcP 183 (1983), 608, 654 (,,notorische, wenn auch selten offen eingestandene Phänomen gerichtlicher Ausrichtung von Schadensersatzansprüchen am Vorhandensein von Haftpflichtversicherungen") sowie von Erman/Westermann, 15. Aufl. 2017, § 241 Rn. 11 (Prüfung, „ob die Kosten, etwa für eine Versicherung einer unbenannten Zahl von Kunden, dem Vertragschließenden billigerweise auferlegt werden können, oder ob es sich nicht im jeweiligen Einzelfall um das allgemeine jedes Verkehrsteilnehmers handelt").

1580 Vgl. hierzu und zum Folgenden Schäfer/Ott, Ökonomische Analyse, 5. Aufl. 2012, S. 438f.

1581 S.o., S. $407 \mathrm{ff}$. 
übernommen wurde. ${ }^{1582}$ Mangels einer über eine Aufwandsentschädigung hinausgehenden „Bezahlung “ des Autohändlers konnte der Kunde „den Abschluss einer Vollkaskoversicherung auf Kosten des Vermittlers gerade nicht erwarten ".

Einen entsprechenden Aufschlag werden nur risikoaverse Gläubiger - also Menschen, die ein bestimmtes Risiko nicht tragen wollen - akzeptieren. ${ }^{1583}$ Denn nur diese werden freiwillig mehr als den Erwartungswert des Schadens - nämlich zusätzlich die Profitmarge des Versicherers - für die Versicherung des Schadensrisikos zahlen. ${ }^{1584}$ Sie sind also bereit für die Absicherung eines bestimmten Risikos eine Prämie zu bezahlen, die - ohne dass eine Umrechnung ohne weiteres möglich wäre - der Intensität ihrer eigenen Risikoaversität entspricht. ${ }^{1585}$

Globales Beispiel ist hier das kaufrechtliche Gewährleistungsrecht
nach § 437 BGB: Der Gedanke des cheapest cost avoider kommt
hier häufig nicht zum Tragen, weil der Schadensvermeidungsauf-
wand des Verkäufers - als bloßer Vertriebsarm einer ihm regel-
mäßig nicht näher zugänglichen Ware - häufig über dem Scha-
denserwartungswert liegen wird und damit die Ökonomik gegen

1582 OLG Hamm, Urt. v. 17.6.2014 - 7 U 77/13, Rn. $41 \mathrm{ff}$.

1583 Wenn das Risikopotential eines Gegenstands nicht typisierbar ist und im Einzelfall ganz erheblich auseinandergehen kann, so kann es auch aus Sicht des Gläubigers unangemessen sein, dem Schuldner das Schadensrisiko über das Kriterium des cheapest cost insurer zuzuweisen. Wenn nämlich des Schuldner die Kosten der Versicherung en bloc auf die Gläubiger abwälzt, kann es sein, dass diese z.T. für das besondere Risikopotential eines einzelnen Gläubigers bezahlen müssen, was nicht ihrer typisierten Interessenlage entspricht, so überzeugend BGH, Urt. v. 3.3.1988 - X ZR 54/86, Rn. 37 (BGHZ 103, 316, 327). Es ist dann für den Durchschnittsgläubiger günstiger, wenn jeder sein eigenes Risiko versichert und eine Nebenpflicht entsprechend abgelehnt wird, vgl. zu den Gefahren von Risikopooling auch Akerlof, The Quart. J. of Ec. 84 (1970), 488, 492f.; Faust, Vorhersehbarkeit, 1996, S. 230ff. (Gefahr der ,Quer-Subventiontierung“); Riha, Sachmängelgewährleistungsrecht, 2007, S. 46.

1584 In dem jeweiligen Risikobereich gewichten sie nämlich „Verluste höher [...] als nominell entsprechende Gewinne“, Falk/Alles, ZIP 2014, 1209, 1215; näher Eidenmüller, JZ 2005, 216, 219; Falk/Alles, ZIP 2014, 1209, 1215 (,loss aversion“); R. Posner, Economic Analysis, 9. Aufl. 2014, S. 13 (,[r]isk aversion [a] corollary of the principle of diminishing marginal utility of money“); Unberath/Cziupka, AcP 209 (2009), 37, 72; Zamir/Ritov, J. Leg. Stud. 41 (2012), 165, 169.

1585 Grundlegend im Kontext der gutachterlichen Dritthaftung hierfür als Voraussetzung für jedweden Vermögensschutz im Schuldverhältnisrecht plädierend Schäfer, AcP 202 (2002), 808, $819 \mathrm{ff}$. (,Werden die Haftungskosten direkt oder indirekt von der geschützten Person oder dem Besteller getragen und hat einer (oder beide) von ihnen trotz dieser Belastung ein Interesse am haftungsrechtlichen Schutz?"). 
eine Schadensvermeidung spricht. Das Gewährleistungsrecht kann den Käufer aber in Bezug auf Sachmängelrisiken durch den Verkäufer versichern. ${ }^{1586}$ Der typische Käufer ist nämlich risikoavers und deshalb bereit den „Aufschlag " auf den Kaufpreis für die Gewährleistungsrisiken des Verkäufers zu tragen. ${ }^{1587}$

Wenn der typische Gläubiger aber nicht bereit ist, die Versicherungsprämie indirekt zu tragen, so ist eine auf die Eigenschaft des Schuldners als billigster Fremdversicherer gestützte Nebenpflicht nicht interessengerecht und demnach abzulehnen. Insbesondere in Schuldverhältnissen eigene Sachen sowie Verbraucher betreffend sind die typisierten Gläubiger möglicher Nebenpflichten jedoch häufig bereit, die Versicherungsprämie zu tragen. ${ }^{1588}$

Beispiel 46 Innerhalb eines Werkvertrags über die Reinigung eines Autos in einer Waschanlage besteht nach der Rechtsprechung die Nebenpflicht, den Waschvorgang so zu gestalten und in Betrieb zu halten, dass das Auto des Kunden nicht beschädigt wird. ${ }^{1589}$ War der Wagen des Kunden nachweisbar vor dem Waschvorgang scha-

1586 Vgl. Riha, Sachmängelgewährleistungsrecht, 2007, S. 45; Schäfer/Ott, Ökonomische Analyse, 5. Aufl. 2012, S. 516; ähnlich zur Wirkung der ,implied warranty for fitness for intended use“ im US-amerikanischen Recht R. Posner, Economic Analysis, 9. Aufl. 2014, S. 111 („,consumers may be willing to pay the higher price in exchange for avoiding the risk").

1587 So zumindest die Hypothese, Schäfer/Ott, Ökonomische Analyse, 5. Aufl. 2012, S. 516f.; skeptisch im Kontext weitreichender Verbraucherschutzgesetze, ob der EU-Gesetzgeber dies bedacht hat, Faust, Oxford Handbook, 2006, S. 837, 860.

1588 So auch Schäfer/Ott, Ökonomische Analyse, 5. Aufl. 2012, S. 440. Davon geht offensichtlich auch der EU-Gesetzgeber aus, präzise Faust, Oxford Handbook, 2006, S. 837, 860; angesichts der eskalierenden Anzahl von Informationspflichten im Verbraucherschutzrecht mach sich aus einer verhaltenswissenschaftlichen Perspektive zunehmend der abnehmende Grenznutzen von Information bemerkbar, vgl. Eidenmüller, JZ 2005, 216, 218, 221 (,Punkt eines information overload [...] bereits erreicht“); Faust, Verbraucher-acquis, 2011, S. 201, 205f.; in der Anlageberatung kann ,information overload“ deshalb auch Anlass für eine Aufklärungspflichtverletzung sein, Brenncke, WM 2014, 1749, 1754f.

1589 OLG Düsseldorf, Urt. v. 16.12.2003 - 21 U 97/03, Rn. 13; LG Krefeld, Urt. v. 30.7.2010 - 1 S 23/10, Rn. 8; AG Braunschweig, Urt. v. 4.2.2014 - 116 C 2943/13, Rn. 25. Ist der Waschprozess an sich fehlerfrei gestaltet, aber erlaubt er keine herausragenden Besonderheiten wie z.B. einen werksmäßig montierten Spoiler, so trifft den Betreiber diesbezüglich eine (vorvertragliche) Hinweispflicht, näher AG Ludwigsburg, Urt. v. 2.11.2007 - 4 C 1536/07, Rn. 17ff. Weil die Schadensvermeidungskosten (Hinweisschild) hier sehr gering sind - und dementsprechend der Schadenserwartungswert in keinem Fall unterhalb der Schadensvermeidungskosten liegt -, lässt sich das mit der Rekonstruktion des vollständigen Schuldverhältnisses schon mit dem Kriterium des cheapest cost avoider begründen. 
densfrei und weist er nach dem Waschvorgang einen Mangel auf, so wird diese Nebenpflicht von der Rechtsprechung als verletzt angesehen. ${ }^{1590}$ Dieser Rückschluss vom Schaden auf die Pflichtverletzung verbietet sich, wenn für die Schädigung innerhalb der Waschstraße auch noch eine andere Ursache, wie z.B. eine Materialschwäche des einzelnen Autos, in Betracht kommt. ${ }^{1591}$

Zwar wirkt es selbstverständlich, dass der Kunde sein Auto nicht waschen lassen möchte, wenn es hinterher beschädigt ist. Aber die Alternative wäre ja keine sichere Beschädigung. Es wäre schließlich denkbar, dass der Waschanlagenbetreiber seine Kontrollmaßnahmen herunterfährt und dafür nur noch einen um die Versicherungsprämie reduzierten Preis fordert. Das Waschen würde dann zwar ,auf eigene Gefahr" erfolgen, dafür müsste der Kunde aber auch weniger bezahlen. Das entspricht indes nicht der typisierten Interessenlage. Seinen eigenen PKW wird der typische Kunde bei einem alltäglichen Vorgang nur äußerst ungern beeinträchtigt sehen. Er ist also bezüglich einer Beschädigung des Autos ein gutes Stück weit risikoavers. Damit entspricht es auch der Wertung der ökonomischen Analyse, das Schadensrisiko dem Unternehmer zuzuweisen, wenn die Beschädigung durch den Waschvorgang feststeht. War der Schadenserwartungswert niedriger als die Schadensvermeidungskosten - greift also nicht bereits der Begriff des cheapest cost avoider -, so folgt dies aus der Eigenschaft des Unternehmenrs als cheapest cost insurer. Dieser kann schließlich über einen Mengenrabbat einer gewerblichen Versicherungspolice

1590 OLG Frankfurt, Urt. v. 14.12.2017 - 11 U 43/17, Rn. 18 (,,von der Schädigung [kann] auf die Pflichtverletzung des Betreibers geschlossen [werden] [...], sofern der Geschädigte darlegt und beweist, dass die Schadensursache aus dem Verantwortungsbereich des Betreibers herrühren kann"). Ist der Waschprozess an sich fehlerfrei gestaltet, aber erlaubt er keine herausragenden Besonderheiten wie z.B. einen werksmäßig montierten Spoiler, so trifft den Betreiber diesbezüglich eine (vorvertragliche) Hinweispflicht, näher AG Ludwigsburg, Urt. v. 2.11.2007 - 4 C 1536/07, Rn. 17ff. Weil die Schadensvermeidungskosten (Hinweisschild) hier sehr gering sind - und dementsprechend der Schadenserwartungswert in keinem Fall unterhalb der Schadensvermeidungskosten liegt -, lässt sich das mit der Rekonstruktion des vollständigen Schuldverhältnisses schon mit dem Kriterium des cheapest cost avoider begründen.

1591 AG Essen, Urt. v. 19.1.2012 - 11 C 110/11, Rn. 5, 12. 
durch den Betrieb seiner Waschanlage hervorgerufene Schäden kostengünstiger als der einzelne Kunde versichern.

Kann die Beschädigung hingegen auch auf einer Materialschwäche des Autos des Gläubigers beruhen, so werden die Schadensvermeidungskosten des Schuldners zwar regelmäßig den Schadenserwartungswert übersteigen - und damit die Risikoverteilung nach dem Kriterium des cheapest cost insurer vorgenommen. Weil es sich hierbei aber um ein nur bei einzelnen Waschanlagenkunden auftretendes Problem handeln wird, ist der typisierte Gläubiger bezüglich dieses Risikos nicht risikoavers, sondern wird eine Eigenversicherung durch Internalisierung des Risikos vorziehen. Durch die Annahme einer Nebenpflicht würde also eine unerwünschte Quersubventionierung einiger Hochrisikokunden durch den Durchschnittskunden drohen. Eine Nebenpflicht ist dann mit der Rechtsprechung auch aus ökonomischen Erwägunge heraus abzulehnen.

Die typische Risikoaversität des Gläubigers einer Nebenpflicht ist damit Voraussetzung dafür, dass das Kriterium des cheapest cost insurer zu einer interessengerechten Risikozuweisung führt. ${ }^{1592}$

(2) Möglichkeit der Eigenversicherung

Die Spezifizierung des cheapest cost insurer für rechtsgeschäftliche Schuldverhältnisse lässt sich indes nicht ohne Probleme auf Nebenpflichten anwenden. Schließlich sind Nebenpflichten kraft ihrer Sachnatur häufig ex-ante nicht präzise zu benennen, wenn nicht bereits Gerichtsentscheidungen in einem vergleichbaren Sachverhalt eine Nebenpflicht angenommen haben. Das von ihnen erfasste Risiko kann damit vor Begründung des rechtsgeschäftlichen Schuldverhältnisses nicht klar benannt werden. Ohne nähere Konkretisierung lässt sich ein

1592 So auch Schäfer/Ott, Ökonomische Analyse, 5. Aufl. 2012, S. 535. 
Risiko aber regelmäßig auch nicht (fremd)versichern. ${ }^{1593}$ Damit kann ein Schuldner die Versicherung nur vor Begründung des Schuldverhältnisses anbieten, wenn sich das von der Nebenpflicht erfasste Risiko ungefähr eingrenzen lässt. ${ }^{1594}$

Der Schuldner kann ein Risiko aber auch intern versichern. ${ }^{1595}$ Zwar resultiert jede Risikozuweisung in einer zwangsweisen Internalisierung des Schadensrisikos durch Eigenversicherung. Ökonomisch sinnvoll ist Eigenversicherung aber vor allem für denjenigen, dessen Informationskosten hinsichtlich der Risikoerkennung nicht unverhältnismäßig hoch sind sind und der durch die Möglichkeit der Internalisierung einer Mehrzahl ähnlicher Risiken einen Kostenvorteil bei der Eigenversicherung hat. ${ }^{1596}$

Beispiel hierfür ist die Bildung von Rücklagen in einem Unterneh-
men für eine Vielzahl potentieller Schadensfälle. Die bewusste Bil-
dung von Rücklagen setzt dabei die Erkennbarkeit des Risikos -
also zu bewältigende Risikoerkennungskosten - für das Unterneh-
men voraus. Die Vielzahl potentieller Schadensfälle garantiert,
dass die Eigenversicherung als Ersatz für einen externen Versi-

1593 So generell zur Versicherbarkeit von Vertragsbrüchen R. Posner, Economic Analysis, 9. Aufl. 2014, S. 111 (,risk and its consequences cannot be calculated with the actuarial precision that insurance companies insist upon").

1594 Grds. skeptisch E. Schmidt, JA 1978, 597, 602 („Risiko einer zusätzlichen Kostenpflichtigkeit qua Aufstellung flankierender Vertragspflichten dürfte einstweilen überhaupt nicht versicherbar sein"). Anderenfalls müsste ex post eine hypothetische Überlegung angestellt werden, ob der Gläubiger bezüglich dieses Risikos ex ante risikoavers eingestellt gewesen wäre oder nicht - mit anderen Worten: Ob er die Versicherungsprämie für das Schadensrisiko hypothetisch als Aufpreis akzeptiert hätte oder nicht. Das erscheint vor allem mit Blick auf die verhaltenssteuernde Wirkung von Nebenpflichten als sinnvolle Anschlussfrage. Da eine (rechtskräftige) Entscheidung zu § 241 II BGB zur Folge hat, dass diese Pflicht in den Kanon der in Kommentaren aufgelisteten Verhaltensanforderungen für vergleichbare Schuldverhältnisse aufgenommen wird, werden zukünftige Parteien sich an der Nebenpflicht orientieren, vgl. Wagner, AcP 206 (2006), 352, 454 („Signal an sämtliche Akteure“). Dementsprechend wird der typisierte Schuldner die Versicherungsprämie in seine Entgeltforderung integrieren. Ob das auch dem Interesse des typisierten Gläubigers entspricht, ist dann zu untersuchen, vgl. Shavell, Economic Analysis, 2004, S. 342 (,risk [...] would be allocated so as to reflect the degrees of risk aversion of the two parties").

1595 R. Posner, Economic Analysis, 9. Aufl. 2014, S. 112 (,self-insurance").

1596 Vgl. Schäfer/Ott, Ökonomische Analyse, 5. Aufl. 2012, S. 442f. 
cherungsmarkt aufgrund der Bündelung von Risiken ökonomisch sinnvoll ist. ${ }^{1597}$

Vorteil der Eigenversicherung ist, dass auch abstrakte Gefahren - für die häufig kein Versicherungsmarkt besteht - versichert werden können. Insbesondere bei Nebenpflichten, die ex ante häufig nebulös bleiben werden, bietet sich die Eigenversicherung daher mehr an als die Fremdversicherung. Versichert ein Schuldner ein Schadensrisiko intern, so hat er - anders als bei der Zahlung einer konkreten Versicherungsprämie - keine für den einzelnen Fall quantifizierbaren Kosten. Nichtsdestotrotz entstehen ihm durch die Internalisierung des Schadensrisikos natürlich Kosten.

Bildet der Schuldner beispielsweise Rücklagen, so entstehen ihmneben administrativen Ausgaben - Kosten in Form von entgangenem Nutzwert, weil er das Geld nicht (anderweitig) investieren kann.

Diese wird er versuchen, in Form einer Risikoumlage auf den Nachfragenden umzuwälzen. ${ }^{1598}$ Wie bei der Fremdversicherung - und bei der Frage nach der Vertrauensprämie im Rahmen des Kriteriums des cheapest cost avoider - stellt sich dann die Frage, ob der typisierte Gläubiger bereit ist, einen Aufschlag in Form der Risikoumlage im Tausch gegen die Risikoabsicherung durch den Schuldner zu akzeptieren.

(3) Konkurrenzverhältnis zwischen cheapest cost avoider und cheapest cost insurer

Ist der Gläubiger cheapest cost avoider und der Schuldner cheapest cost insurer, so stellt sich die Frage, welches Haftungsregime Vorrang haben soll. ${ }^{1599}$ Trägt der Schuldner das Schadensrisiko - geht man also von einer entsprechenden Nebenpflicht aus -, so besteht die Gefahr, dass der Gläubiger sich auf der Versi-

1597 Vgl. zum Gesetz der großen Zahlen Sinn, Ungewißheit, 1980, S. 218; Wandt, Versicherungsrecht, 6. Aufl. 2017, Rn. 23f.

1598 Insoweit beschränkt sich die Möglichkeit auf einen gewerbsmäßig tätigen Schuldner, der hinsichtlich seiner internen Versicherung ,Sozialisierungschancen“ hat, präzise E. Schmidt, JA 1978, 597, 602.

1599 Näher zu dieser Frage Schäfer/Ott, Ökonomische Analyse, 5. Aufl. 2012, S. 441. 
cherung durch den Schuldner ausruht und seinen Schadensvermeidungsaufwand auf ein ineffizientes Maß herabfährt. ${ }^{1600}$ Aufgrund dieser Gefahr ist die Haftung des cheapest cost avoider gegenüber der des cheapest cost insurer grundsätzlich vorrangig. ${ }^{1601}$ Ausnahmen bestehen, wenn die Schadensvermeidungskosten des cheapest cost avoider über den Kosten der Versicherung liegen.

Beispiel 47 Ein Käufer hat vor wenigen Wochen seinen Führerschein erlangt und möchte sich ein erstes Auto kaufen (,,Probefahrtfall“). ${ }^{1602}$ Hierfür kontaktiert er einen Autohändler, der einen Toyota Yaris als Vorführwagen günstig abzugeben hat.Der Käufer und der Händler einigen sich auf eine Probefahrt auf der örtlichen Landstraße. In einer engen Kurve vergisst der unerfahrene Käufer aus Unachtsamkeit die Geschwindigkeit zu reduzieren und gerät beim hektischen Drehen des Lenkrads von der Fahrbahn. Das Auto prallt gegen eine Straßenlaterne. Das Auto war weder voll- noch teilkaskoversichert. Der Händler will den Schaden vom Käufer ersetzt bekommen. Der BGH verneinte den Anspruch des Händlers mit der Begründung, dass es zwischen Käufer und Händler zu einem stillschweigenden Haftungsausschluss gekommen sei. ${ }^{1603}$ Dass

1600 Obwohl er ja qua seiner Eigenschaft als cheapest cost avoider eigentlich dazu prädestiniert wäre, den Schadenseintritt zu verhindern, würde er seine Möglichkeiten diesbezüglich sogar nicht nur unter unterschreiten, sondern womöglich ganz und gar auf Null herabfahren. Als Resultat entstehen durch die unnötigen Schäden gesamtgesellschaftliche Wohlfahrtsverluste, die allein durch die Kostenvorteile des Schuldners bei der Versicherung keinesfalls aufgehoben werden.

1601 Überzeugend Schäfer/Ott, Ökonomische Analyse, 5. Aufl. 2012, S. 441.

1602 Der Fall basiert auf BGH, Urt. v. 7.6.1972 - VIII ZR 35/71.

1603 Der Grund hierfür liegt in den Regressmöglichkeiten der Versicherungsunternehmen: Im Schadensfall gehen nämlich gem. § 86 I VVG etwaige Ersatzansprüche des Geschädigten auf den Versicherer im Wege einer Legalzession über. Entsprechendes war damals in $\S 67 \mathrm{VVG}$ a.F. geregelt, vgl. BGH, Urt. v. 7.6.1972 - VIII ZR 35/71, Rn. 6. Etwaige Ansprüche des Autohändlers gegen den Interessenten aus $\S \S 280 \mathrm{I}, 311 \mathrm{II}$ Nr. 2, 241 II BGB und $\S 823$ I BGB wären im Schadensfall also auf das Versicherungsunternehmen übergegangen. Die Allgemeinen Bedingungen für die KFZ-Versicherung (AKB 2015) geben aber in Ziffer A.2.8 I vor, dass bis einschließlich normaler Fahrlässigkeit kein Regressanspruch gegen den Dritten geltend gemacht werden kann, Unverbindliche Musterbedingungen des Gesamtverbandes der Deutschen Versicherungswirtschaft e.V. (Stand: 19.05.2015), abrufbar unter http://www.gdv. de/wp-content/uploads/2015/05/AKB2015_Stand_Mai_2015.pdf, zuletzt eingesehen am 24.7.2018. Entsprechendes war damals in $\S 15$ II AKB 1971 geregelt, vgl. BGH, Urt. v. 7.6.1972 - VIII ZR 35/71, Rn. 6. Damit hätte der Versicherer hier gegen den Interessenten keinen Regress genommen. Im Falle einer Versicherung des Kraftfahrzeugs hätte der 
der Autohändler damit einen starken rechtlichen Anreiz bekommt, das Schadensrisiko zu versichern, hielt der BGH für zumutbar. ${ }^{1604}$ Anders als für den Interessenten sei es für den Händler leicht möglich und relativ kostengünstig seine angebotenen Wagen mit einer Voll-kaskoversicherung zu versehen. ${ }^{1605}$

Den Schaden verursacht hat hier der Käufer. Der Händler hätte den Schaden während der Probefahrt gar nicht mehr verhindern können. Angesichts der erhöhten Gefahr bei einer Probefahrt ${ }^{1606}$ hätte er seine Vorführwägen womöglich mit den Sicherungssystemen eines Fahrschulautos ausstatten können (Bremspedal auch auf der Beifahrerseite, erleichterter Eingriff in das Steuersystem, eigener Rückspiegel, etc.). Das hätte den Schadenseintritt womöglich verhindert. Es hätte aber ganz erhebliche Kosten für den Händler nach sich gezogen. Diese hätten die Schadensvermeidungskosten des Käufers (Opportunitätskosten erhöhter Sorgfalt) um ein Vielfaches überstiegen. Durch deutlich erhöhte Sorgfalt im Umgang mit einem fremden KFZ hätte er den Unfall womöglich vermeiden können. Cheapest cost avoider kann damit im Verhältnis zum Händler nur der Käufer sein. Gleichzeitig wären auch die Schadensvermeidungskosten des Käufers hier sehr hoch gewesen, denn niemand ist gegen Fahrfehler gefeit und absolute Sorgfalt ist nahezu unmöglich. ${ }^{1607}$ Wie der BGH darlegte, stand demngegen-

Interessent daher im Ergebnis nicht gehaftet. Diese Faktenlage nahm der BGH zum Anlass eine Haftung des Interessenten auch bei fehlender Versicherung zu verneinen.

1604 Näher BGH, Urt. v. 7.6.1972 - VIII ZR 35/71, Rn. 7ff. Anstelle eines stillschweigenden Haftungsausschlusses hätte sich der Fall also auch ebenso gut über die Annahme einer Nebenpflicht lösen lassen, nach welcher der Verkäufer verpflichtet war, im Eigeninteresse für die Versicherung des Fahrzeugs zu sorgen.

1605 Der Interessent hätte eine „Versicherung für das gelegentliche Führen oder Benutzen fremder versicherungspflichtiger Kraftfahrzeuge“" abschließen müssen, welche weder landläufig bekannt noch finanziell zumutbar gewesen wäre, vgl. BGH, Urt. v. 7.6.1972 - VIII ZR 35/71, Rn. 9. Angesichts des wirtschaftlichen Interesses an den Fahrzeugen wäre der Abschluss einer Versicherung dem Händler auch zumutbar.

1606 Hierzu BGH, Urt. v. 7.6.1972 - VIII ZR 35/71, Rn. 8.

1607 Man könnte deshalb durchaus anzweifeln, ob sich das Risiko leichter Fahrlässigkeit wege der unverhältnismäßigen Schadensvermeidungskosten überhaupt mittels des Kriterium des cheapest cost avoider zuweisen lässt. Gibt es gar keinen cheapest cost avoider, so handelt es sich 
über dem Händler eine zumutbare Möglichkeit zu, das Schadensrisiko zu versichern. Cheapest cost insurer ist damit der Autohändler. Damit weisen die Instrumente der ökonomischen Analyse das Schadensrisiko hier innerhalb eines einzigen Schuldverhältnisses unterschiedlichen Parteien zu. Der BGH wies das Schadensrisiko hier dem Autohändler zu. Damit ging er implizit von einem Vorrang des cheapest cost insurer aus. Das überzeugt vom Ergebnis her auch dann, wenn man die Maßstäbe der ökonomischen Analyse anlegt. Schließlich lagen die Schadensvermeidungskosten des cheapest cost avoider hier über den - auf den einzelnen Interessenten heruntergebrochenen - Kosten einer Versicherung des Schadensrisikos durch den Autohändler. Folglich muss das Kriterium des cheapest cost insurer hier - wie auch der BGH im Ergebnis annahm - gegenüber dem des cheapest cost avoider Vorrang haben.

Grundsätzlich hat also die Risikozuweisung nach dem Begriff des cheapest cost avoider Vorrang vor der Risikoverteilung nach dem Gedanken des cheapest cost insurer (Schadensvermeidung vor Schadensversicherung). ${ }^{1608}$ Das gilt aber nur, wenn die Schadensvermeidung nicht im Einzelfall zu höheren Kosten als die Schadensversicherung führt.

dd) Zwischenergebnis: Konzept der Rekonstruktion des vollständigen Schuldverhältnisses für Auslegung von § 241 II BGB sinnvoll

Die Rekonstruktion des vollständigen Schuldverhältnisses ist grundsätzlich dazu geeignet, über § 241 II BGB eine effiziente Risikoverteilung zu erreichen. Die aufeinander abgestimmten Begriffe des cheapest cost avoider und des cheapest cost insurer bieten - gemeinsam mit Gedanken der ökonomischen Sinnhaftigkeit von Vertrauensschutz - ein holistisches Konzept, um die rechtspraktische Funk-

um einen aus ökonomischer Sicht unvemeidbaren Schaden und das Kriterium des cheapest cost insurer hat automatisch Vorrang.

1608 Vgl. treffend Shavell, Economic Analysis, 2004, S. 268 (,if the liability system has a real purpose today, it must lie in the creation of incentives to reduce risk"). 
tion einer Nebenpflicht auszufüllen. Die untersuchten Beispiele haben gezeigt, dass die Rechtsprechung häufig mit den Ergebnissen der Rekonstruktion des vollständigen Schuldverhältnisses übereinstimmt. Ein Vorteil des Instruments ist die Simplizität der haftungszuweisenden Kriterien. Die Kriterien sind aus sich selbst heraus aussagekräftig und helfen somit, die - im Einzelnen nicht immer simple - Subsumtion zu einer Nebenpflicht zumindest ex ante vorhersehbar zu gestalten.

d) Zwischenergebnis: Vermögensschutz wird sinnvoll durch die ökonomische Analyse konturiert

Auch in der ökonomischen Analyse gibt es nicht den einen Ansatz, der Nebenpflichten umfassend zu begründen - und damit zu begrenzen - vermag. Die zugrundeliegenden Wertungen werden aber häufig mit der Terminologie der Ökonomik präziser herausgestellt. Die deskriptive Komponente der ökonomischen Analyse in der Subsumtion zu berücksichtigen, erscheint insoweit nur folgerichtig. Häufig geht es nämlich auch der Rechtsprechung lediglich um die Steuerungswirkung einer Nebenpflicht. Dabei ist im Bereich der vermögensschützenden Nebenpflichten eine eindeutige Konvergenz rechtswissenschaftlicher Ansätze und der ökonomischen Analyse erkennbar. ${ }^{1609}$ Das zeigt, dass sich auch die normative Komponente der Ökonomik mit einer rechtswissenschaftlichen Herangehensweise verträgt. Im Ergebnis bieten das Instrument der Rekonstruktion des vollständigen Schuldverhältnisses in der Kombination mit der ökonomischen Perspektive auf Vertrauensschutz überzeugende Ansatzpunkte, um bei der teleologischen Auslegung des $\S 241$ II BGB die rechtspraktische Funktion einer Nebenpflicht im Kontext vermögenswerter Interessen auszufüllen.

1609 Tröger hält eine rein rechtswissenschaftliche Problemanalyse schon für gar nicht mehr denkbar, weil die ökonomische Analyse mittlerweile bereits die „Denkstrukturen“ beeinflusst habe, Tröger, Arbeitsteilung, 2012, S. 66; vgl. zudem Kersting, Dritthaftung, 2007, S. 407; Kübler, FS Steindorff, 1990, S. 687, 689; Taupitz, AcP 196 (1996), 114, 120f. (,[k]eine Rezeption, aber partieller Begründungsgleichklang“). 
II. Ausgleich haftungsrechtlicher Lücken bei Schädigung des Gläubigers durch dem Schuldner zuzurechnende Dritte

1. Frage nach der Reichweite sinnvoller Haftung für das Verhalten Dritter

Als Ausgangspunkt der Analyse zu $\S 278$ BGB ist die konkrete Subsumtion unter den Wortlaut des $\S 278$ S. 1 Alt. 2 BGB im sachlichen Kontext einer Nebenpflichtverletzung durch den Schuldner zu unternehmen, um die Problemfelder aufzudecken. ${ }^{1610}$

Beispiel 48 Ein Maler schuldet einem Kunden aus $\$ 631$ I Hs. 1 BGB das Streichen einer Wand (,Malerfall“). Am vereinbarten Termin schickt der Maler seinen ordnungsgemäß ausgesuchten und überwachten Angestellten. Dieser nutzt eine sich ihm bietende Gelegenheit und entwendet die wertvolle Uhr des Kunden, die er auf der Kommode im Eingangsbereich entdeckt. Haftet der Maler dem Kunden weder aus $\$ 823$ I BGB noch aus $\$ 831$ BGB - greift die teleologische Subsidiarität des § 241 II BGB also nicht -, so könnte der Kunde gegen den Maler einen Anspruch aus $\$ \$ 280$ I, 241 II $B G B$ wegen Verletzung einer Nebenpflicht haben. Schuldner dieser Nebenpflicht ist aber allein der Maler und nicht der Angestellte. Der Maler ist also nur dann schadensersatzpflichtig, wenn er sich das Verhalten des Angestellten gem. § 278 S. 1 Alt. 2 BGB zurechnen lassen muss. Hierfür müsste er sich des Angestellten „zur Erfüllung seiner Verbindlichkeit bedient" haben. Mit Verbindlichkeit ist dabei die konkret verletzte Pflicht gemeint. Ob sich eine Nebenpflicht aber unter den Wortsinn von Verbindlichkeit subsumieren lässt, ist fraglich. ${ }^{1611}$ Bei Erlass des $\S 278$ S. 1 BGB kannte

1610 Vgl. ebenfalls im Kontext von $\S 278$ und Nebenpflichten Wendelstein, AcP 215 (2015), 70, 78f. (,Beibehaltung der juristischen Methodik [...] kein Selbstzweck $\left.{ }^{6}\right)$.

1611 Vgl. HKK/Schermaier, 2007, §§ 276-278 Rn. 104. Schließlich ist bereits hoch umstritten, ob eine Nebenpflicht aus $\S 241$ II BGB überhaupt einen klagbaren Anspruch (§ 194 I BGB) begründen kann, hierzu - im Ergebnis bejahend - s.o., S. 152. Zudem ist nicht gesichert, ob Nebenpflichten wegen ihrer integritätsschützenden und damit eher präventiven Zielrichtung einer „Erfüllung“ (vgl. § 362 I BGB) zugänglich sind, hierzu - im Ergebnis bejahend - s.o., S. 149. Beides sind aber Charakteristika einer Verbindlichkeit im deutschen Zivilrecht, Medicus/Lorenz, Schuldrecht AT, 21. Aufl. 2015, Rn. 6f., 17ff.; Wendelstein, AcP 215 (2015), 70, 77. 
ein Schuldverhältnis (Vertrag) nach damals herrschender Meinung indes noch keine schuldverhältnisbedingten Nebenpflichten sondern allein Leistungspflichten. Auf diese war denn auch $\S 278$ S. 1 BGB zugeschnitten. ${ }^{1612}$ Mittlerweile ist allerdings anerkannt, dass ein Schuldverhältnis nicht nur Leistungs-, sondern auch Nichtleistungspflichten nach sich ziehen kann kann. ${ }^{1613}$ Um diesem neuen Verständnis Rechnung zu tragen, ist bei systematischer Auslegung des $\$ 278$ S. 1 BGB nicht an dem engen Wortsinn von Verbindlichkeit zu haften. ${ }^{1614}$ Der Begriff ist demnach als schuldverhältnisbedingte Pflicht zu verstehen. ${ }^{1615}$ Damit ist die verletzte Nebenpflicht eine Verbindlichkeit im Sinne von $\$ 278$ S. 1 Alt. 2 $B G B$.

Der Maler müsste sich des Angestellten aber auch zur Erfüllung der Pflicht bedient haben. ${ }^{1616}$ Erneut ist aber der Bezug zur konkreten Verbindlichkeit problematisch. ${ }^{1617}$ So hat der Maler den

1612 Näher Wendelstein, AcP 215 (2015), 70, 71, $73 \mathrm{f}$.

1613 Zwar wurde $§ 278$ S. 1 Alt. 2 BGB seit seinem Erlass nicht in seinem Wortlaut geändert (vgl. Tröger, Arbeitsteilung, 2012, S. 4), dem allgemeinen Schuldrecht liegt aber mittlerweile ein anderes Verständnis von schuldverhältnisbedingten Pflichten zugrunde. Das zeigt schließlich auch die Eingliederung der Nebenpflichten in die Norm des § 241 BGB sowie die Möglichkeit eines Schuldverhältnisses nach § 311 II, III BGB, welches ausschließlich Nebenpflichten enthält.

1614 So auch Kamanabrou, NJW 2001, 1187, 1187f. Angesichts der hier vertretenen These, dass Nebenpflichten sowohl klag- als auch erfüllbar sind (s.o., S. 149ff.), spräche nichts dagegen, Nebenpflichten auch im engeren Sinne mit dem Begriff der „Verbindlichkeit“ für kompatibel zu halten. Da die breite Front in der Literatur hierzu aber nur verhalten und mitunter eher ablehnend Stellung nimmt, wird so verfahren, als wenn Nebenpflichten weder klagbar noch erfüllbar wären. Die exemplifizierte Subsumtion soll schließlich die Ergebnisfindung der h.M. methodisch untermauern.

1615 Vgl. Soergel/Pfeiffer, 13. Aufl. 2014, § 278 Rn. 32; Erman/Westermann, 15. Aufl. 2017, § 278 Rn. 22 (,gesamte Verpflichtung des Schuldners"). Hiervon sind in jedem Fall auch Pflichten im Sinne von $\S 241$ II BGB umfasst.

1616 Hierfür genügt nach herrschender Ansicht eine willentliche Einschaltung des Dritten zum Tätigwerden im eigenen Pflichtenkreis, BGH, Urt. v. 25.3.1982 - VII ZR 60/81, Rn. 15 (BGHZ 83, 293, 295); MüKo-BGB/Grundmann, 7. Aufl. 2016, § 278 Rn. 43; HK-BGB/ Schulze, 9. Aufl. 2017, § 278 Rn. 5; Soergel/Pfeiffer, 13. Aufl. 2014, § 278 Rn. 23; Bamberger-Roth/Unberath, 3. Aufl. 2012, § 278 Rn. 15, 26; Erman/Westermann, 15. Aufl. 2017, $\S 278 \mathrm{Rn} .15$.

1617 Schließlich wird der Wille des Schuldners regelmäßig nur darauf gerichtet sein, den Dritten zur Erfüllung etwaiger Leistungspflichten einzusetzen: Die Existenz von Nebenpflichten wird 
Angestellten zum Streichen der Wand - und damit zur Erfüllung seiner eigenen (Leistungs-)Pflicht aus $\$ 631$ I Hs. 1 BGB - eingesetzt. Eine willentliche Einschaltung spezifisch zur Erfüllung integritätsschützender Nebenpflichten - wie der in Rede stehenden kann ihm letztlich nur mittels einer Fiktion unterstellt werden. ${ }^{1618}$ Zudem ist damit bereits das zweite Problem angesprochen: der Bezug zur ,Erfüllung“. Weil Leistungspflichten unzweifelhaft der Erfüllung zugänglich sind (vgl. § 362 I BGB), lassen sich Dritte auch zur Erfüllung dieser Pflichten einsetzen. ${ }^{1619}$ Es besteht aber erhebliche Unklarheit darüber, ob Nebenpflichten einer Erfüllung zugänglich sind. ${ }^{1620}$

Erschwerend kommt hinzu, dass der Schuldner im Rahmen der Erfüllung von Schutzpflichten aus der Einschaltung Dritter nicht nur Vorteile zieht, sondern aufgrund der personellen Haftungserweiterung isoliert betrachtet sogar einen Nachteil: Bei den Bemühungen des Schuldners, seine Leistungspflichten zu erfüllen lässt sich

dem Schuldner häufig entweder gänzlich unbekannt sein oder aber für die Zwecksetzung der Einschaltung eines Dritten irrelevant gewesen sein.

1618 Zutreffend Wendelstein, AcP 215 (2015), 70, 77. Ob sich eine solche Fiktion rechtfertigen lässt (hiergegen und für eine analoge Anwendung des § 278 BGB Wendelstein, AcP 215 (2015), 70, 78ff.), steht auf einem anderen Blatt. In jedem Fall gerät die Subsumtion hier holprig.

1619 Die h.M. hat ein weites Verständnis vom notwendigen Bezug zur konkreten Erfüllung. So muss der Dritte die Erfüllung keinesfalls selbst herbeiführen, sondern es genügen auch vorbereitende Tätigkeiten. Zudem ist aufseiten des Dritten keine Kenntnis von der zu erfüllenden Pflicht des Schuldners erforderlich, Bamberger-Roth/Unberath, 3. Aufl. 2012, § 278 Rn. 11.

1620 Hierzu - im Ergebnis bejahend - s.o., S. 149. So ist zumindest das Erlöschen einer Pflicht zur Nichtschädigung des Gläubigers im Rahmen der Schuldverhältnis-Ausführung durch Erfüllung (vgl. § 362 I BGB) ungleich schwieriger vorzustellen als die Erfüllung einer Leistungspflicht. Da die konkrete Pflicht eine Unterlassung für die Dauer und den sachlichen Rahmen der Schuldverhältnis-Durchführung fordert, wäre eine „engültige Erfüllung“ - Unterlassungspflichten werden schließlich fortwährend erfüllt - nur insofern denkbar, als der zeitliche und/ oder der sachliche Rahmen des Schuldverhältnisses verlassen wird, ohne dass eine Rechtsgüterbeeinträchtigung durch den Schuldner (Maler) eintritt. Wird allerdings nur der sachliche Rahmen verlassen (z.B. Treffen von Maler und Kunde beim Einkaufen), so darf gleichwohl kein endgültiges Erlöschen der Pflicht angenommen werden, bis nicht auch die zeitlichen Grenzen überschritten sind. Schließlich ist bis zu diesem Zeitpunkt ein Rechtsgüterkontakt von Maler und Kunde innerhalb des sachlichen Schutzbereichs des Schuldverhältnisses denkbar (z.B. Abnahmetermin bei dem Kunden zuhause). 
der Einsatz Dritter leicht als Gewinn (i.e. Zeit ${ }^{1621}$ ) deuten. ${ }^{1622}$ Bei der Bewahrung des Integritätsinteresses führt die Einschaltung von Dritten aber regelmäßig zu einer Haftungserweiterung, da nun sowohl der Schuldner als auch der Erfüllungsgehilfe die Schädigung des geschützten Interesses des Gläubigers zu unterlassen oder - bei einer Bewahrungspflicht - zu verhindern haben. Im Hinblick auf Nebenpflichten erhöht sich also das absolute Risiko einer Nichterfüllung durch die Einschaltung des Angestellten, weil - neben dem Schuldner selbst - eine zusätzliche Person die Haftung aus $\$ \$ 280$ I, 241 II BGB bedingen kann. Das macht den Einsatz eines Dritten zur Erfüllung ebendieser Nebenpflicht sprachlich äußerst unpräzise. ${ }^{1623}$ Ein Vorteil ließe sich nur konstruieren, wenn man die Erfüllung der Nebenpflichten als untrennbar mit der Erfüllung der Leistungspflichten verbunden ansieht. Der Nutzen aus dem Einsatz Dritter bei Leistungspflichten würde dann aufgrund dieses akzessorischen Verständnisses der beiden Pflichtarten auch als Vorteil für die Arbeitsteilung in Bezug auf Nebenpflichten gelten. ${ }^{1624}$ Gegen das Verständnis aller schuldverhältnisbedingten Pflichten als Gemengelage spricht indes schon die klare Trennung der Leistungs- und Nebenpflichten in $\$ 241$ BGB und den $\S \S 280 f f$., 323ff. BGB. Zudem würde dies den telos des $\S 278$

1621 Hier weitergehend auf einen mittelbar aus der Erfüllung der Leistungspflicht resultierenden Vorteil (z.B. Geld als Vergütung) abzustellen vermag die Anwendbarkeit des § 278 S. 1 BGB im Rahmen von unentgeltlichen oder gesetzlichen Schuldverhältnissen (z.B. Leistungspflicht aus $\S \S 823$ I, 249 I BGB) nicht zu erklären.

1622 Zwar wird geltend gemacht, dass die Vorteile der Arbeitsteilung in gleichem Maße auch den Gläubiger treffen, vgl. nur Wendelstein, AcP 215 (2015), 70, 85f. Warum sonst sollte aber der Schuldner sich die Mühe machen ([Opportunitäts-]Kosten: Zeitverlust) Dritte in die Parameter der Verbindlichkeit einzuweisen, wenn es für ihn keinen individuellen Vorteil bergen sollte? Aufgrund dieses der Arbeitsteilung immanenten Vorteils ist es wiederum angemessen, dem Schuldner das Risiko einer vom Dritten zu vertretenden Nicht- oder Schlechtleistung aufzubürden. Damit ist der Normzweck des $\S 278$ BGB bei Leistungspflichten einschlägig.

1623 Skeptisch auch Esser/Schmidt, Schuldrecht AT, Teilbd. 2, 8. Aufl. 2000, S. 103; E. Schmidt, Nachwort zu von Jhering/Staub, 1969, S. 131, 151 (,falscher Zungenschlag“). Die Subsumtion des Verhaltens von Maler und Angestelltem unter die Phrase Bedienen zur Erfüllung einer Nebenpflicht überdehnt somit den Wortsinn von $\S 278$ S. 1 Alt. 2 BGB, krit. auch Kamanabrou, NJW 2001, 1187, 1187.

1624 Vgl. Seok Kim, ZEuP 2013, 263, 277; Tröger, Arbeitsteilung, 2012, S. $147 f$. 
$B G B$ über Gebühr verwässern und ihn damit seiner Aussagekraft berauben.

Erneut ist aber dem Umstand Rechnung zu tragen, dass sich der schuldverhältnisbedingte Pflichtenkanon seit Erlass des § 278 S. 1 BGB nach allgemeiner Ansicht um die Kategorie der Nebenpflichten erweitert hat. So muss eine systematische Auslegung des $§ 278$ S. 1 Alt. 2 BGB hier zu einem extensiven Verständnis des Bedienens zur Erfüllung im Hinblick auf Nebenpflichten führen. ${ }^{1625}$ Der Normzweck des § 278 BGB der herrschenden Meinung für Leistungspflichten ist aber auf Nebenpflichten nicht ohne weiteres übertragbar. ${ }^{1626}$

Wie genau das Problem ${ }^{1627}$ zu lösen ist, dass der Haftungsgrund von $\S 278$ BGB bei Nebenpflichten unklar ist, lässt sich Literatur und Rechtsprechung nur unvollständig entnehmen.

a) Methodisches Zusammenspiel von $\S 278$ S. 1 Alt. 2 BGB und $\S 241$ II BGB Weil der Wortlaut des $§ 278$ S. 1 Alt. 2 BGB auf Leistungspflichten zugeschnitten ist, erfolgt die Anwendung der Norm auf Nebenpflichten in jedem Fall mit einer rechtsfolgenorientierten Perspektive. Die im Wortlaut des $§ 278$ S. 1 Alt. 2 BGB verankerten Voraussetzungen für die Haftung für den Erfüllungsgehilfen verlieren bei einer derart funktionalen Betrachtung aber an Bedeutung. Sie werden dann nämlich alle prädeterminiert durch die Haftungskriterien, welche für die jeweilige Nebenpflicht entscheidend sind. Die Dogmatik der Nebenpflichten wirkt so auf $\S 278$ BGB über. ${ }^{1628}$

1625 Sofern man nicht - wie oben - die Erfüllung einer Nebenpflicht (zugegebenermaßen etwas mühsam) als Nichtschädigung innerhalb des sachlichen und zeitlichen Geltungsbereichs des Schuldverhältnisses definiert, ist sie bei Nebenpflichten obsolet. Es ginge dann bei Nebenpflichten vielmehr um die Wahrung der durch diese geschützten Interessen. Erneut wird die skeptische Stellung der h.M. gegenüber der Erfüllbarkeit von Nebenpflichten als Basis der Subsumtion unterstellt, s.o., S. 440 (Fn. 1614).

1626 So bereits Berger, Grenzen, 1935, S. 39 (Fn. 208).

1627 So auch Staudinger/Caspers, Neubearbeitung 2014, § 278 Rn. 42.

1628 So geht auch Tröger, Arbeitsteilung, 2012, S. 491 davon aus, dass $\S 278$ BGB bei Nebenpflichten keine eigene Wirkung entfalten könne, sondern vielmehr von dem Zweck und Wir- 
In letzter Konsequenz ließe sich daher die Frage nach dem Einstehen des Schuldners für das Verhalten des Dritten bei Nebenpflichtverletzungen vollumfänglich in die Prüfung der Pflichtverletzung integrieren. ${ }^{1629}$ Man könnte dann im Rahmen der Pflichtverletzung erörtern, ob der Schutzzweck der Nebenpflicht (auch) eine Verletzung durch einen Erfüllungsgehilfen des Schuldners abdeckt, sofern dieser in seiner Funktion als Erfüllungsgehilfe mit dem Gläubiger in Kontakt kommt. Maßstab dieser Frage ist, ob dem Schuldner mit Blick auf die Interessen des Gläubigers hier eine (auf das Handeln von Erfüllungsgehilfen beschränkte) Garantiehaftung für Integritätsverletzungen des Gläubigers zuzumuten ist. Ausgangspunkt dieses Gedankens kann dabei der BGB-Gesetzgeber sein, der die Anwendung des $\S 278$ BGB - damals nur für Leistungspflichten angedacht - schließlich aufgrund einer Form der Garantiehaftung des Schuldners für das Verhalten Dritter für gerechtfertigt hielt. ${ }^{1630}$

Liefert ein Schuldner eine mangelhafte Sache, weil sein Angestellter den Kaufgegenstand aus Unachtsamkeit beschädigt hat, so wird das Verhalten des Erfüllungsgehilfen bei einem späteren Schadensersatzanspruch des Gläubigers gegen den Schuldner wegen Verletzung einer Leistungspflicht auch erst im Rahmen des Verschuldens relevant. Die Verletzung der Leistungspflicht zur mangelfreien Lieferung erfolgt durch den Schuldner selbst, eine

kungsgrund der jeweiligen Nebenpflicht konsumiert werde. Ähnlich schlägt Paßmann, Schutzpflichtverletzungen, 2010, S. 168 (Fn. 42) vor, die sinnvolle Begrenzung des $\S 278$ BGB bei Nebenpflichten nicht an dessen Voraussetzungen aufzuhängen, sondern bereits an der Frage, ob man überhaupt eine (drittgerichtete) Nebenpflicht im Sinne von § 241 II BGB annimmt. Ob der Schuldner für das Verhalten eines Dritten schuldverhältnisbedingt einstehen muss, hängt damit inhaltlich allein an den die Pflicht begründenden Haftungskriterien. Die Voraussetzungen des $\S 278$ S. 1 Alt. 2 BGB werden inhaltlich angepasst, sodass sie diese Kriterien repräsentieren.

1629 Ähnlich schlägt Tröger, Arbeitsteilung, 2012, S. 488ff. eine bedachte Anwendung des $\S 278$ BGB auf Nebenpflichten vor, die bereits durch den Pflichtenkreis des Schuldners begrenzt wird. In der Subsumtion ist dann lediglich zu fragen, ob der Schuldner bei einer bestehenden Pflicht auch für das Fehlverhalten Dritter einzustehen hat.

1630 Mugdan, Materialien, Bd. II, 1899, S. 16 („Wenn der Schuldner eine Leistung versprochen hat, so erblickt der heutige Verkehr in diesem Versprechen auch die Übernahme einer Garantie für das ordnungsgemäße Verhalten derjenigen, deren Mitwirkung bei der Leistung sich zu bedienen dem Schuldner ausdrücklich oder stillschweigend gestattet ist"). 
Zurechnung des Verhaltens von Erfüllungsgehilfen wird hier allgemein nicht für erforderlich gehalten.

Führt man den Gedanken der Einstandsgarantie konsequent weiter, so muss dem Schuldner die Verletzung einer Nebenpflicht gar nicht über $\S 278$ S. 1 BGB zugerechnet werden. Aus dem Recht, Dritte in die Erfüllung seiner (Neben)Pflichten einzuspannen, folgt dann eine eigene Pflichtverletzung des Schuldners, wenn der Erfüllungsgehilfe in seiner angestammten Funktion die Integrität des Gläubigers beeinträchtigt. Lässt sich das bejahen, so wird die Anwendung von $\S 278$ S. 1 BGB im Rahmen der Pflichtverletzung gänzlich überflüssig. Eine Zurechnung nach § 278 S. 1 BGB wird dann nur noch im Rahmen des Verschuldens relevant.

Im Bereich der Nebenpflichtverletzung bleiben also $§ 278$ BGB betreffend aus methodischer Perspektive zwei Wege: Entweder man nimmt die wortlautgetreue Anwendung von $\S 278$ S. 1 Alt. 2 BGB auch im Rahmen der Pflichtverletzung Ernst und nimmt dafür massive Subsumtionsschwierigkeiten in Kauf. ${ }^{1631}$ Alternativ hierzu packt man das Problem am Schopfe, integriert die Beteiligung des Dritten bereits in die Prüfung der Nebenpflicht und lässt so § 278 BGB im Rahmen der Pflichtverletzung überflüssig werden. ${ }^{1632}$ Aus einer methodischen Perspektive erscheint es vorzugswürdig, die Subsumtionsschwierigkeitendes hinsichtlich § 278 BGB im Rahmen der Pflichtverletzung zu bewältigen, als sich ihrer durch Annahme einer Art Garantiehaftung für das Verhalten Dritter im Rahmen der Pflichtverletzung zu entledigen. Der Schluss von Leistungspflichten auf Nebenpflichten ist nämlich fragwürdig: Während es bei Leistungspflichten durch das Versprechen der Leistung durchaus angemessen ist, dem Schuldner für jedes Abweichen vom Soll eine Pflichtverletzung vorzuwerfen - und in der Folge eine Exkulpation nach $\S 280$ I 2 BGB zuzumuten -, passt diese Herleitung

1631 S.o., Beispiel 48, S. 439. Hält man diese - anders als viele Vertreter in Rechtsprechung und Literatur - aus einer rechtsmethodischen Perspektive für problematisch, so lassen sie sich letztlich nur dadurch überwinden, dass der ursprüngliche Zweck des $§ 278$ BGB durch den telos der jeweiligen Nebenpflicht überlagert wird. Jede Voraussetzung des Wortlauts muss an die Besonderheiten der Nebenpflichten angepasst werden, s.o., Beispiel 48, S. 439ff. Weil auch der herkömmliche Normzweck des § 278 BGB auf Nebenpflichten nicht ohne Probleme anwendbar ist, muss er durch den Haftungsgrund der Nebenpflicht supplementiert werden.

1632 Es gilt dann zu prüfen, ob der Schuldner mit Blick auf den (spezifischen) Erfüllungsgehilfen eine drittbezogene Nebenpflicht schuldet. 
nicht auf die verhaltensbezogenen Nebenpflichten. Hier ist eben nicht schlechthin Integrität geschuldet, sondern nur in einem bestimmten, einzelfallabhängigen Rahmen. Dem Schuldner die Beeinträchtigung der Integrität des Gläubigers durch ein Verhalten seiner Erfüllungsgehilfen ohne Anwendung von § 278 BGB als eigene Pflichtverletzung zuzurechnen, birgt die Gefahr, der Beweislastumkehr des $\S 280$ I 2 BGB allzu große Wirkung beizumessen. Demnach ist der Wortlaut des $\S 278$ S. 1 Alt. 2 BGB unter Berücksichtigung der Zwecksetzung der jeweiligen Nebenpflicht teleologisch anzupassen.

b) Haftungsgrund?

Es gilt, den Haftungsgrund für die Anwendung von § 278 BGB im Kontext von Nebenpflichtverletzungen ausfindig zu machen.

aa) Historische Differenzierung zwischen $\S 278$ BGB und $\S 831$ BGB

Vorprägend für das Verständnis von Verantwortlichkeit für Drittverhalten ist die historische Differenzierung zwischen $\S 278$ BGB im Schuldverhältnisrecht und $\S 831$ BGB im Jedermannsrecht. So hat der deutsche Gesetzgeber bei Erlass des BGB eine verschuldensunabhängige Haftung des Geschäftsherrn für Gehilfen im Jedermannsrecht aus zwei Gründen abgelehnt: Zum einen sei dieser Gedanke dem ,deutschen Rechtsbewußtsein [...] ganz fern“ und zum anderen würde die verschuldensunabhängige Haftung kleinere Betriebe unverhältnismäßig stark treffen, weil diese sich - anders als Industriebetriebe - nicht ohne weiteres selbst- oder fremdversichern könnten. ${ }^{1633}$ Das erste Argument kann mittlerweile nicht mehr überzeugen. ${ }^{1634}$ Schließlich ist die Anwendung von $\S 278$ BGB durch ein zunehmend großzügiges Verständnis des Schuldverhältnisses und der sich darin befindlichen Pflichten ubiquitär geworden. Der Gedanke für den Gehilfen womöglich unbedingt einstehen zu müssen, ist daher Teil des heutigen Rechtsbewusstseins. Aber auch das zweite, tragende Argument ist angreifbar. Größere Betriebe können wegen des Gesetzes der großen Zahl einzelne Schäden oder

1633 Mugdan, Materialien, Bd. II, 1899, S. 1094.

1634 So auch HKK/Schermaier, 2007, §§ 276-278 Rn. 84 a.E. 
Haftungsrisiken schließlich immer leichter als kleinere Betriebe abfedern. Der Vorteil ist insofern nur relativ. Auch kleinere Betriebe können Risiken durch Eigenversicherung internalisieren, anderenfalls wäre selbst die Haftung für Leistungspflichtverletzungen überfordernd. Zudem werden gerade größere Betriebe durch die Exkulpationsmöglichkeit des $\S 831$ BGB bevorzugt: Ungeachtet der vielfältigen Einschränkungen durch die Rechtsprechung steht einem Großbetrieb nämlich grundsätzlich ein dezentralisierter Entlastungsbeweis offen ${ }^{1635}$ - mithin können Auswahl-, Kontroll- und Überwachungspflichten hinsichtlich der Angestellten bei steigender Unternehmensgröße immer weiter die Hierachieleiter hinab delegiert werden. Mit aufgrund des Gesetzes der großen Zahl wachsendem Nutzen der Arbeitsteilung in Großbetrieben steigt somit gleichzeitig die Möglichkeit des Unternehmens, sich für das Verhalten der diesen komparativen Vorteil generierenden Arbeitskräfte zu exkulpieren. Dieser Widerspruch wurde scharf kritisiert ${ }^{1636}$ und ist stets Ausgangspunkt der - durch die Rechtspraxis mittlerweile zu großen Teilen verwirklichten ${ }^{1637}$ - Forderung, die Haftung für das Verrichtungsgehilfen der Haftung für das Verhalten von Erfüllungsgehilfen anzugleichen. ${ }^{1638}$ Die historischen Gründe für die Einschränkung des $\S 831$ I 2 BGB - und damit raison d'être der Anwendung von § 278 BGB auf Nebenpflichten - sind damit auch ${ }^{1639}$ aus heutiger Perspektive nicht mehr überzeugend. $^{1640}$

1635 S.o., S. $85 \mathrm{ff}$.

1636 Vgl. von Bar, Gutachten, Band II, 1981, S. 1681, 1706 (§ 831 BGB hat „die Phantasie von Generation von Juristen angeregt, über Umgehungsmöglichkeiten nachzusinnen“).

1637 S.o., S. $90 \mathrm{f}$.

1638 Vgl. Schäfer/Ott, Ökonomische Analyse, 5. Aufl. 2012, S. 409 (,aus wohlfahrtsökonomischer Sicht vorteilhaft [...], die Haftung für Verrichtungsgehilfen ebenso auszustatten wie die für Erfüllungsgehilfen“").

1639 Faktisch hatte $\S 831$ BGB auch aus zeitgenössicher Perspektive bereits eher die relative Besserstellung von Großunternehmen zur Folge, was die Argumentation des BGB-Gesetzgebers weiter aushöhlt, instruktiv Berger, Grenzen, 1935, S. 56f.

1640 Vgl. zur Kritik treffend Berger, Grenzen, 1935, S. 56ff.; Tröger, Arbeitsteilung, 2012, S. 162 (Fn. 146) m.w.N. 
bb) Rechtsprinzipien für die Zurechnung von (Neben-)

Pflichtverletzungen eines Erfüllungsgehilfen

Die drei zentralen Zurechnungsprinzipien, die im Rahmen der Auseinandersetzung über $§ 278$ BGB ins Feld geführt werden, sind: das Prinzip der Einheit von Chance und Risiko (Äquivalenz), die Frage der Beherrschbarkeit des Risikos (Prävention) und die Rückführung eines Risikos auf den eigenen Einflussbereich (Sphärengedanke). ${ }^{1641}$

\section{(1) Gedanke der Einheit von Chance und Risiko}

$\S 278$ BGB wird als Durchbrechung des Verschuldensprinzips von der herrschenden Meinung auf den Gedanken der Einheit von Chance und Risiko zurückgeführt. ${ }^{1642}$ Dabei lässt sich generell kritisieren, dass die Betrachtung einseitig nur die Vorteile des Schuldners im Blick hat. Die Vorteile der Arbeitsteilung für den Gläubiger, wie beispielsweise die Einbindung zusätzlicher Expertise, Beschleunigung des Arbeitsprozesses, verbesserte Möglichkeiten der Präferenzbefriedigung, etc., werden dabei außer Acht gelassen. ${ }^{1643}$ Zudem wird kritisiert, dass der Gedanke nicht ohne weiteres auf unentgeltliche Schuldverhältnisse passe. ${ }^{1644}$ Aber auch ohne Gegenleistung kann die Befreiung von einer Pflicht durch Delegation auf einen Gehilfen einen wirtschaftlichen Vorteil generieren. ${ }^{1645}$ Bezieht man nicht die Arbeitserleichterung im Hinblick auf die Erfüllung

1641 Stellvertretend für viele Vertreter in der Literatur Oechsler, Vertragsgerechtigkeit, 1997, S. 176ff. Paßmann meint zudem als Haftungsgrund die rechtspraktische Überlegung ausmachen zu können, dass der Verweis auf den Gehilfen als bereits bestehenden Haftungsadressaten von der herrschenden Meinung als ungenügend angesehen wird, Paßmann, Schutzpflichtverletzungen, 2010, S. 152ff. Tröger kann wegen dieser dogmatisch vielschichtigen Struktur keine eindeutige Funktion der Zuweisung von Betriebsrisiko erkennen und sieht weiteren Klärungsbedarf, Tröger, Arbeitsteilung, 2012, S. 164f.

1642 S.o., S. 253 (Fn. 1023).

1643 Oechsler, Vertragsgerechtigkeit, 1997, S. 180 (unehrliche Bewertung der „Risikoprofitrelation“); E. Schmidt, Nachwort zu von Jhering/Staub, 1969, S. 131, 152 (,Nutznießungsgedanke [...] im Hinblick auf die Schutzpflichtenlage unergiebig").

1644 Vgl. E. Schmidt, AcP 170 (1970), 502, 507 (Fn. 19); Wendelstein, AcP 215 (2015), 70, 86.

1645 Das verkennt zwar auch Wendelstein, AcP 215 (2015), 70, 86 im Ansatz nicht. Er hält den Gedanken aber nicht mehr für tragfähig, wenn der Schuldner seine geldwerte Arbeitsleistung konkret nicht geldwert hätte einsetzen können. Rein wirtschaftlich besehen kommt aber noch eine Vielzahl weiterer Opportunitätskosten in Frage. So könnte sich der Schuldner auch mit seiner Karriereplanung beschäftigen oder seine Lieblingsfernsehserie verfolgen und dieser Zeit durch seine konkludent erklärte Präferenz hierfür wirtschaftliche Relevanz zukommen lassen (volkswirtschaftlich-utilitaristischer Begriff des Nutzens). Faktisch von einer Pflichterbrin- 
der Leistungspflichten mit ein ${ }^{1646}$, so ist im Hinblick auf Nebenpflichten schließlich gar kein Vorteil für den Schuldner durch die Einschaltung des Gehilfen erkennbar. ${ }^{1647}$ Dies zeigt sich insbesondere an der recht großzügigen Zurechnung von Straftaten ${ }^{1648}$ : Hier wird deutlich, dass die Einzelfallumstände sowie insbesondere der Inhalt des konkreten Schuldverhältnisses für die Abgrenzung der Begriffe „,in Ausführung“ und „bei Gelegenheit“ auf Basis des Risiko-ProfitGedankens praktisch keine Rolle spielen. Dieses Prinzip lässt sich daher in der Anwendung der herrschenden Meinung als zumindest zu pauschal und wenig präzise kritisieren. ${ }^{1649}$

\section{(2) Beherrschbarkeit der Gefahr}

$\S 278$ BGB wird zudem in seinem dogmatischen Haftungsgrund darauf zurückgeführt, dass der Schuldner die durch den Erfüllungsgehilfen repräsentierte Gefahr (besser) beherrschen kann. ${ }^{1650}$ Den Begriff plagt auf den ersten Blick eine

gung befreit zu werden, hat somit aus einer volkswirtschaftlichen Perspektive immer einen Wert, vgl. Drexl, Selbstbestimmung, 1998, S. 194; Mankiw/Taylor, Volkswirtschaftslehre, 5. Aufl. 2012, S. 6, 539; Schäfer/Ott, Ökonomische Analyse, 5. Aufl. 2012, S. 53f.; Taupitz, AcP 196 (1996), 114, 117 (Fn. 15f.).

1646 Dagegen s.o., Beispiel 48, S. 439ff.

1647 So auch Esser/Schmidt, Schuldrecht AT, Teilbd. 2, 8. Aufl. 2000, S. 103 sowie i.E. zutreffend Wendelstein, AcP 215 (2015), 70, 98f., der allerdings als - sogleich wegen eines haftungsbegründenden Zirkelschlusses verworfenen - Nutzen die Tatsache nennt, „dass der Gehilfe den Gläubiger nicht schädigt". Dabei erwägt er im Speziellen, ob der Schuldner von der durch den Erfüllungsgehilfen vermittelten ,Nichtschädigung“ profitieren kann, weil er für potentielle Geschäftspartner an Seriosität gewinnt. Anders als bei dem Einsatz von Erfüllungsgehilfen für Leistungspflichten bedeutet die Einschaltung Dritter bei Nebenpflichten aber präzise betrachtet schon im Ansatz keinen Vorteil, sondern einen Nachteil. Schließlich erhöht sich ab dem Moment der Betrauung des Dritten die absolute Wahrscheinlichkeit, dass die Nebenpflicht verletzt wird. Aus diesem Grund kann kein Fernziel der Einschaltung von Erfüllungsgehilfen in die Erfüllung von Nebenpflichten einen Vorteil des Schuldners begründen.

1648 Vgl. MüKo-BGB/Grundmann, 7. Aufl. 2016, § 278 Rn. 48; Jauernig/Stadler, 17. Aufl. 2018, § 278 Rn. 12; Erman/Westermann, 15. Aufl. 2017, § 278 Rn. 39

1649 So zu Recht Oechsler, Vertragsgerechtigkeit, 1997, S. 181f.; gegen den Gedanken von Einheit von Chance und Risiko bei Drittverhalten im Bereich der Nebenpflichten auch Staudinger/Caspers, Neubearbeitung 2014, § 278 Rn. 43; Esser/Schmidt, Schuldrecht AT, Teilbd. 2, 8. Aufl. 2000, S. 103 (,gekünstelt ${ }^{\star}$ ); E. Schmidt, AcP 170 (1970), 502, 507; Tröger, Arbeitsteilung, 2012, S. 162f.; Wendelstein, AcP 215 (2015), 70, 87, 98f.

1650 Vgl. Staudinger/Caspers, Neubearbeitung 2014, § 278 Rn. 54; MüKo-BGB/Grundmann, 7. Aufl. 2016, § 278 Rn. 47; Soergel/Pfeiffer, 13. Aufl. 2014, § 278 Rn. 1; Wendelstein, AcP 
ähnliche Schwäche wie den Vertrauensbegriff ${ }^{1651}$ : Was genau beherrschbar ist, lässt sich nicht ohne normatives Vorverständnis des Begriffs erklären. ${ }^{1652}$ Wann genau der Gläubiger ein Schadensrisiko beherrschen kann, wird nämlich entscheidend davon beeinflusst, welche Vorgänge man aufgrund einer wertenden Entscheidung noch vom ihm als beherrschbar ansieht. Die Frage verschiebt sich damit von „Was ist konkret beherrschbar?“ zu „Was soll abstrakt beherrschbar sein?““ ${ }^{1653}$ Weil das Risiko im Einzelfall eben gerade nicht beherrscht wurde ${ }^{1654}$, kann die Begrenzung der Verantwortlichkeit über dieses Kriterium also nur abstrakt-wertender Natur sein. Welche Gedanken aber wiederum die Beherrschbarkeit konturieren, bleibt regelmäßig im Dunkeln. Allein aus dem Kriterium der Beherrscharkeit ergeben sich die Maßstäbe zur näheren Konturierung - anders als beispielsweise die Risikozuweisung an den cheapest cost avoider, der die Beherrschbarkeit mit dem Maßstab der Effizienz ausfüllt - jedenfalls nicht. Ohne näherere Konkretisierung (beispielsweise durch Ausfüllung des Kriteriums der Beherrscharkeit mit der Forderung effizienter Schadensvermeidung) muss sich dieses Prinzip eine gewisse Beliebigkeit in der Ergebnisfindung vorwerfen lassen. ${ }^{1655}$

(3) Risikoverortung in der Sphäre des Schuldners

Zuletzt kommt die Anwendung des $§ 278$ in Betracht, weil das vom Handeln des Erfüllungsgehilfen repräsentierte Risiko dem Einflussbereich des Schuldners und damit dessen Sphäre - zuzurechnen ist. ${ }^{1656}$ Der Begriff der Sphäre ist aber -

215 (2015), 70, 84; Wiebe, Die elektronische Willenserklärung, 2002, S. 190. Der Begriff der Beherrschbarkeit wird hierbei bisweilen durch den Begriff der Vorhersehbarkeit der Schadensentstehung eingeschränkt, vgl. Oechsler, Vertragsgerechtigkeit, 1997, S. $183 \mathrm{f}$.

1651 Hierzu näher s.o., S. $216 \mathrm{ff}$.

1652 Oechsler, Vertragsgerechtigkeit, 1997, S. $184 f$.

1653 Vgl. beispielsweise Staudinger/Caspers, Neubearbeitung 2014, § 278 Rn. 54, der die Grenze der Beherrschbarkeit - und seiner Ansicht nach deshalb auch diejenige des $\$ 278$ BGB - an der Stelle erreicht sieht, an welcher der Bereich ,der allgemeinen Lebensführung des Gehil-

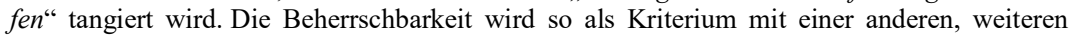
Wertung unterworfen.

1654 Klammert man ein vorsätzlich unterlassenes Eingreifen durch den Geschäftsherrn aus.

1655 Oechsler, Vertragsgerechtigkeit, 1997, S. 186.

1656 S. Paßmann, Schutzpflichtverletzungen, 2010, S. 152f.; Erman/Westermann, 15. Aufl. 2017, $\S 278 \mathrm{Rn} .41$. 
isoliert betrachtet - in hohem Maße unscharf. ${ }^{1657}$ An anderer Stelle wird deshalb danach gefragt, was der Gläubiger vom Schuldner im Einzelfall im Hinblick auf die Verantwortlichkeit für Dritte erwarten kann. ${ }^{1658}$ Allerdings ist Arbeitsteilung in der heutigen Welt eine derartige Selbstverständlichkeit, dass sich hinterfragen lässt, ob der Gläubiger überhaupt noch die Erfüllung durch den Schuldner selbst erwarten darf. ${ }^{1659}$ Kann der Gläubiger aber ohnehin nicht mehr auf die eigenhändige Leistung durch den Schuldner vertrauen, so stellt sich schnell die Frage, inwieweit Handlungen Dritter sich als Nebenpflichtverletzungen des Schuldners darstellen können. Der Versuch einer Risikozuordnung nach Sphären, die ausschließlich die Wahl zwischen Gläubiger oder Schuldner lässt, kann dann durchaus in die Irre führen.

Ist die verletzte Pflicht nämlich - wie im Bereich der Verkehrssicherungspflichten - inhaltlich auf das Jedermannsrecht zurückzuführen, so trifft das Jedermannsrecht in diesen Fällen schließlich die Entscheidung, das Risiko primär dem Schädiger zuzuweisen. Eine sekundäre Risikozuweisung an den Schuldner kommt nur über § 831 I 1 BGB sowie über $\$ 823$ I (Verletzung einer Organisationspflicht) in Betracht. Kommt auch eine sekundäre Risikozu-

1657 Selbst die räumliche Sphäre des Schuldners gehört nicht zwingend zu dessen „Sphäre“, vgl. BGH, Urt. v. 21.12.1965 - VI ZR 161/64, Rn. 16ff.; näher zu diesem augenscheinlichen Widerspruch Oechsler, Vertragsgerechtigkeit, 1997, S. 192f.

1658 Larenz, Schuldrecht AT, 14. Aufl. 1987, S. 302 (,vertragsspezifische Schutzpflicht“); Oechsler, Vertragsgerechtigkeit, 1997, S. 181f. (Fn. 79); Staudinger/Caspers, Neubearbeitung 2014, $\S 278 \mathrm{Rn} .55$ (Frage danach, ,wie weit die [Nebenpflichten] [...] unter Berücksichtigung der Verkehrsanschauung (\$ 157) im konkreten Fall gehen“). Ähnlich überlegt Tröger, Arbeitsteilung, 2012, S. 165 das Betriebsrisiko über die relative Zwecksetzung des Schuldverhältnisses zuzuweisen. Analog zu den Leistungspflichten könnte man in der Subsumtion über $\S \S 133$, 157 BGB überprüfen, ob sich die konkrete Pflicht auch auf eine arbeitsteilige Erbringung erstrecken sollte, vgl. Tröger, Arbeitsteilung, 2012, S. 491. Das Verhalten des Erfüllungsgehilfen wird also zugerechnet, wenn mit einer Pflichterbringung im Wege der Arbeitsteilung nach $\S \S 133,157$ BGB zumindest zu rechnen war. Das passt indes nur auf rechtsgeschäftliche Schuldverhältnisse. Selbst dort müssen Bedenken geäußert werden, ob die §§ 133, 157 BGB zumindest mittelbar auf das mittels - vom Parteiwillen losgelöster - Nebenpflichten verbürgte Haftungsrisiko Einfluss haben dürfen. Was nicht durch Auslegung begründet wurde, sollte eigentlich auch nicht durch Auslegung begrenzt werden dürfen. Tröger, Arbeitsteilung, 2012, S. 488f. will die Grundsätze zu § 278 BGB bei der Handlung eines Dritten bereits in der Pflichtbestimmung berücksichtigen. Damit hat die für § 278 BGB entwickelte Dogmatik nach seiner Ansicht sogar unmittelbare Auswirkung auf den Pflichtbestand nach § 241 II BGB.

1659 So schon vor über vierzig Jahren E. Schmidt, AcP 170 (1970), 502, 513f.; ähnlich Erman/Westermann, 15. Aufl. 2017, § 278 Rn. 1. 
weisung an den Schuldner über die $\$ \S 831,823$ BGB im Einzelfall nicht in Betracht - fällt also eine klare Zuordnung des Risikos in der Dichotomie Schuldner/Gläubiger schwer -, so spricht einiges dafür, von der Anwendung des § 278 BGB gänzlich abzusehen. ${ }^{1660}$ Bezogen auf Nebenpflichten würde das bedeuten, dass gewisse Risiken weder dem Schuldner noch dem Gläubiger sondern vielmehr dem Schädiger zuzuweisen sind - und folglich auch nur dieser für die Integritätsbeeinträchtigung haftet. Insbesondere im Bereich der Verkehrssicherungspflichten wird man aber auch den gesetzgeberischen Willen bei Erlass des § 241 II BGB berücksichtigen müssen. Bleibt die deliktsrechtliche Verantwortlichkeit für Drittverhalten trotz grundsätzlich parallel im Deliktsrecht bestehender Verhaltensanforderung hinter dem Schuldverhältnisrecht zurück, so kommt es in diesem Fall im Ergebnis auf die Anwendung von § 278 S. 1 Alt. 2 BGB an. Sofern aber eine Schutzlücke im Bereich der Drittverantwortlichkeit besteht, widerspräche es der gesetzgeberischen Intention für Nebenpflichten, die Anwendung von $\S 278$ $B G B$ deshalb abzulehnen, weil die Beteiligung von Erfüllungsgehilfen heutzutage ohnehin nahezu selbstverständlich ist.

Vorzugswürdig ist daher an dieser Stelle eine vom konkreten Willen des Schuldners der Nebenpflicht völlig losgelöste Betrachtung.

Tröger schlägt an dieser Stelle als alternative Kriterien einen abstrakten ,Organisationswillen“ sowie - vor allem - eine objektive Risikoanalyse vor. ${ }^{1661}$ Im Rahmen der Risikoanalyse sei zum einen zu fragen, ob der Schuldner das Risiko des Dritten durch überlegene Einwirkungsmöglichkeiten besser hätte beherrschen können (Aspekt der überlegenen Risikobeherrschung). Das ähnelt dem Begriff des cheapest cost avoider. Zum anderen sei zu fragen, ob der Schuldner das Risiko für den Dritten einzustehen, besser tragen kann (Aspekt der überlegenen Risikotragung). Das wiede-

1660 So bereits überzeugend E. Schmidt, AcP 170 (1970), 502, 513f. („Schuldverhältnis [erweist sich] mit seinen überkommenen Gefahrüberwälzungen als immer unsicherer Ordnungsfaktor").

1661 Tröger, Arbeitsteilung, 2012, S. 523f. 
rum ähnelt der Eigenversicherung innerhalb des Begriffs des cheapest cost insurer. Die Risikoanalyse erstreckt sich dann konsequenterweise auch auf die Frage, ob der Dritte zur Erfüllung oder nur bei Gelegenheit der Erfüllung der ihm zur Wahrnehmung übertragenen Verbindlichkeit tätig geworden ist. ${ }^{1662}$ Es sei also zu fragen, ab welchem Punkt dem Schuldner die bessere Risikobeherrschung entgleitet. Eine derart verobjektivierte Erwartung des Gläubigers nähert sich indes wieder dem Gedanken der Beherrschbarkeit - mitsamt der damit verbundenen Ausfüllungsbedürftigkeit des Begriffs - an.

Der Begriff der Sphäre kennzeichnet damit zwar die Notwendigkeit, ein Risiko dem Schuldner zielgerichtet zuordnen zu können. Wie beim Begriff der Beherrschbarkeit bedarf es aber auch hier ergänzender Kriterien, um die Sphäre des Schuldners inhaltlich abzustecken, die sich dem Wortsinn der Sphäre nicht unmittelbar entnehmen lassen.

\section{(4) Prinzipienübergreifende Kritik}

Allen drei Prinzipien ist gemein, dass sie nicht ausschließlich im Schuldverhältnisrecht Anwendung finden: Aspekte der Gefahrbeherrschung, der Gedanke der Einheit von Chance und Risiko sowie Sphären als Zurechnungsgrund spielen allesamt auch im Jedermannsrecht eine Rolle. ${ }^{1663}$ Dass die Prinzipien von der herrschenden Meinung trotzdem zur Bestimmung von Drittverantwortlichkeit herangezogen werden, kann zweierlei bedeuten. Zum einen lässt sich dies kritisieren, weil sich etwaige Unterschiede zwischen Schuldverhältnis- und Jedermannsrecht bei der Verantwortlichkeit für Dritte so nicht überzeugend begründen lassen. Wie können schließlich die Ergebnisse unterschiedlich sein, wenn die zugrundeliegenden Prinzipien identisch sind? Zum anderen könnte man mit dieser subversiven Frage gerade die Prämisse dieser Kritik in Frage stellen. Schließlich konnte bereits oben der Befund getroffen werden, dass sich die Verantwortlichkeit für das Verhalten Dritter trotz grundsätzlicher gesetzlicher

1662 Tröger, Arbeitsteilung, 2012, S. 524f.

1663 Ähnlich auch Paßmann, Schutzpflichtverletzungen, 2010, S. 154. 
Unterschiede zwischen Schuldverhältnis- und Jedermannsrecht faktisch in beiden Bereichen deutlich angenähert hat. ${ }^{1664}$ Das mag man durchaus darauf zurückführen, dass die gleichen Zurechnungsprinzipien herangezogen werden. Insgesamt kann also keines der ins Feld geführten Prinzipien ohne nähere Konkretisierung als alleiniger Haftungsgrund für die Anwendung von $\S 278$ S. 1 Alt. 2 BGB auf Nebenpflichten überzeugen.

\section{cc) Anknüpfung an die Verantwortung des Schuldners für die Verbindlichkeit als Haftungsgrund}

Anknüpfend an ein Urteil des Reichsgerichts ${ }^{1665}$ wird die ratio des $\S 278$ BGB bisweilen auch aus der geschuldeten Verbindlichkeit selbst hergeleitet. ${ }^{1666}$ Das ist indes im Kern eine Argumentation, die auf die Anwendung von § 278 BGB auf Leistungspflichten zugeschnitten ist. ${ }^{1667}$ In einer Variation dieses Ansatzes

1664 S.o., S. 90.

1665 RG, Urt. v. 23.6.1883 - I 249/83, RGZ 10, 164. Dabei war hier vor allem die Sentenz des Reichsgerichts interessant, dass, wer, ,sich unmittelbar zur Herstellung des Endergebnisses im ganzen“ verpflichte, ,alle zur Ausführung etwa erforderlichen Hilfspersonen nur auf seine eigene Gefahr" hin einschalte, RG, Urt. v. 23.6.1883 - I 249/83, RGZ 10, 164, 166f. Das Reichsgericht wies dabei das Risiko aus dem Handeln eines Erfüllungsgehilfen unmissverständlich dem Schuldner zu.

1666 So Paßmann, Schutzpflichtverletzungen, 2010, S. 154ff. Der Begriff der „Verbindlichkeit“ sei dabei desjenigen des „Vertrags“ vorzugswürdig, weil ansonsten gesetzliche Schuldverhältnisse vom Ansatz ausgenommen wären. Entscheidend sei auf die Verpflichtung abzustellen, einen Erfolg im Sinne eines Privatinteresses herbeizuführen, Paßmann, Schutzpflichtverletzungen, 2010, S. 156, 158. Der Begriff des „Privatinteresses“ soll dabei bewusst weiter gefasst sein als der Erfolgsbegriff des $\S 362$ I BGB. Daraus lasse sich dann die Haftung für das Verhalten Dritter ableiten, vgl. zu diesem Gedanken die Aussage des BGB-Gesetzgebers, Mugdan, Materialien, Bd. II, 1899, S. 16 („,Wenn der Schuldner eine Leistung versprochen hat, so erblickt der heutige Verkehr in diesem Versprechen auch die Übernahme einer Garantie für das ordnungsmäßige Verhalten derjenigen, deren Mitwirkung bei der Leistung sich zu bedienen dem Schuldner ausdrücklich oder stillschweigend gestattet ist.").

1667 So müssen denn auch einige Schwierigkeiten zugestanden werden, das Schulden eines Erfolges auf Nebenpflichten zu beziehen: Paßmann, Schutzpflichtverletzungen, 2010, S. 160ff. hält zwar Nebenpflichten nicht für klagbar, die Erfüllung von Nebenpflichten hält er aber dennoch für möglich, wenn sie ausdrücklich oder aufgrund (ergänzender) Auslegung nach den $\S \S 133$, 157 BGB vereinbart wurden. Dieses Verständnis passt allerdings nur auf rechtsgeschäftliche Schuldverhältnisse. Schließlich passt jede Form der Auslegung nicht auf rechtsgeschäftsähnliche oder gesetzliche Schuldverhältnisse. Verallgemeinert werden solche Nebenpflichten mit dem Begriff der Erfolgsschuld im Sinne eines Privatinteresses für vereinbar gehalten, die eine spezifische und unmittelbare Anbindung an die Hauptleistung haben, näher Paßmann, Schutzpflichtverletzungen, 2010, S. 162. Eine Nebenpflichthaftung des Schuldners für das Verhalten 
wird eine Zurechnung deshalb für gerechtfertigt gehalten, weil sich der grundsätzlich persönlich haftende Schuldner überhaupt Dritter zur Erfüllung seiner Leistungspflicht bedienen darf. ${ }^{1668} \mathrm{Im}$ Gegenzug dafür, dass nicht bereits die tatsächliche Betrauung eines Dritten mit Leistungspflichten eine eigene Pflichtverletzung des Schuldners darstelle, müsse der Schuldner für seinen Bewahrungsgehilfen nach Maßgabe des $\S 278$ BGB haften. ${ }^{1669}$

Als Haftungsgrund für die Anwendung von $\S 278$ S. 1 Alt. 2 BGB auf Nebenpflichtverletzungen ist der Gedanke abstrakt durchaus interessant. Als rein theoretischer Ansatz fehlt es ihm aber an Konturen für die Subsumtionspraxis. Zudem lässt sich durchaus hinterfragen, ob sich die (großzügige) Anwendung von $\S 278$ BGB auf eine persönliche Schuld der Nebenpflicht durch der Schuldner stützen lässt. Schließlich wurde bereits herausgearbeitet, dass Nebenpflichten sowohl im methodischen Ansatz als auch in der Begründung fremdbestimmt sind. ${ }^{1670}$ Wenn die Pflicht aber von objektiven (Verteilungs-)Erwägungen geprägt ist, warum sollte der Schuldner sie dann persönlich schulden? Auch der Gedanke einer besonderen Verantwortung des Schuldners, aufgrund derer er sich das Verhalten von Erfüllungsgehilfen zurechnen lassen muss, erweckt den Eindruck, als ob der Schuldner sich zur Nebenpflicht verpflichtet habe. Mit der heteronomen Qualität von Nebenpflichten ist das kaum zu vereinbaren. Schließlich erfolgt auch der Einsatz von Erfüllungsgehilfen im isolierten Hinblick auf die Erfüllung von Nebenpflichten niemals zielgerichtet. ${ }^{1671}$ Ein richtiges Gegen-

ihm zuzurechnender Dritter wird damit über $§ 278$ BGB begründet, wenn sich die Pflicht quasi als notwendige Kehrseite der Hauptleistungspflicht darstellt. Paßmann, Schutzpflichtverletzungen, 2010, S. 162f. benutzt hierbei das Beispiel eines Beförderungsvertrages, der im Verlauf zur Folge hat, dass dem Kunden beide Beine gebrochen werden. Der geschuldete Erfolg in Form eines reibungslosen Transports bleibt damit aus. Dass dieses Ergebnis durch einen vom Schuldner eingeschalteten Dritten befördert wurde, dürfe für die Haftung des Schuldners keine Rolle spielen. Eine Haftung aus Nebenpflichtverletzung - und als notwendiger Bestandteil eine Zurechnung nach $\S 278$ BGB - sei damit zu bejahen.

1668 So Wendelstein, AcP 215 (2015), 70, 87ff. Erneut wird damit der telos des $\S 278$ BGB an die Schuld der Verbindlichkeit geknüpft. Übertragen auf Nebenpflichten wirde der Normzweck des $§ 278$ BGB aber in der Verantwortung des Schuldners für das Schuldverhältnis gesehen, Wendelstein, AcP 215 (2015), 70, 99ff. Damit wird der Begriff der Schuld für Nebenpflichten - und damit auch die oben angesprochenen Abgrenzungsprobleme - vermieden.

1669 Wendelstein, AcP 215 (2015), 70, 100.

1670 S.o., S. 169 (Fn. 688), 142f.

1671 Zutreffend Esser/Schmidt, Schuldrecht AT, Teilbd. 2, 8. Aufl. 2000, S. 103. 
stück hat die Zurechnung über $\S 278$ BGB daher auch nicht in der Möglichkeit des Schuldners, Dritte im Nebenpflichtkreis einzusetzen.

dd) Gefahrerhöhung als Haftungsgrund

Ausgangspunkt der Begründung einer Nebenpflicht muss zumindest dann $§ 278$ BGB selbst sein, wenn es gerade darum geht, diese Norm zur Anwendung zu bringen. ${ }^{1672} \S 278$ BGB ist nach allgemeiner Meinung auf Nebenpflichten aus $\S 241$ II BGB anwendbar. ${ }^{1673}$ Fasst man die Begründungsversuche der herrschenden Meinung zusammen, so ist eine gewisse Zirkularität aber nicht zu verleugnen: Weil § 278 BGB offensichtlich auf Nebenpflichten anwendbar sein muss, wird die Norm trotz ihres Zuschnitts auf Leistungspflichten auch auf Nebenpflichten angewendet. ${ }^{1674}$ Ein überzeugender Ansatzpunkt könnte es deshalb sein, die Lösung weniger in der herkömmlichen Dogmatik des § 278 BGB als vielmehr im Schutzzweck und Haftungsgrund der (jeweiligen) (Neben-) Pflicht(en) zu suchen. ${ }^{1675}$

1672 Sofern Lücken bei der Haftung für Dritte geschlossen werden sollen, ist genau das der Fall. In der Begründung einer Nebenpflicht ist damit auf den Haftungsgrund des $§ 278$ BGB zu rekurrieren. Die dort entwickelten Leitlinien werden bisweilen sogar auf Nebenpflichten insgesamt übertragen, vgl. Lüsing, Schutzpflichten, 2010, S. 112.

1673 MüKo-BGB/Grundmann, 7. Aufl. 2016, § 278 Rn. 21; Jauernig/Stadler, 17. Aufl. 2018, § 278 Rn. 10; Soergel/Pfeiffer, 13. Aufl. 2014, § 278 Rn. 15; Tröger, Arbeitsteilung, 2012, S. 487 (Fn. 277) m.w.N.; Erman/Westermann, Erman, § 278 Rn. 22. Bei Erlass des $§ 241$ II BGB hat auch der Gesetzgeber die tatbestandliche Anwendbarkeit des § 278 BGB auf Nebenpflichten vorausgesetzt, vgl. BT-Drs. 14/6040, SchRModG, Gesetzesbegründung, S. 125 („Verletzung von Schutzpflichten erzeugt daher Ansprüche nach dem Recht der Sonderverbindung, verbunden insbesondere mit der Anwendbarkeit von § 278 [BGB] [...]. [...] Daran soll nichts geändert werden.").

1674 Vgl. jüngst Wendelstein, AcP 215 (2015), 70, 78, der die Vorgehensweise der h.M. als „,begriffsjuristischen Trick" bezeichnet. Schon vor Erlass des § 241 II BGB wurde kritisch hinterfragt, ob sich die ratio hinter der positiven Forderungsverletzung und der culpa in contrahendo überhaupt auch auf die Anwendung des § 278 BGB erstrecke, E. Schmidt, AcP 170 (1970), 502, 507. Auch nach der Schuldrechtsreform wird die uneingeschränkte Geltung des $§ 278$ BGB für Nebenpflichten als ,Rechtsentwicklung „vom Ergebnis her ““ (E. Schmidt, AcP 170 (1970), 502, 507f.) kritisiert, Tröger, Arbeitsteilung, 2012, S. 489.

1675 Vgl. Staudinger/Caspers, Neubearbeitung 2014, § 278 Rn. 43 (Abkehr vom bei Leistungspflichten vorherrschenden „Gefahrtragungsgedanken“ bei Nebenpflichten), 55 (für $§ 278$ BGB entscheidende Frage, ,wie weit" die Nebenpflichten gem. § 157 BGB ,im konkreten Fall gehen"); Tröger, Arbeitsteilung, 2012, S. 491. Genau dieser notwendige Rekurs auf die Dogmatik der Nebenpflichten macht die Lösungsansätze natürlich auch so vielfältig und unüber- 
Beispiel 48 Scheidet im Malerfal ${ }^{1676}$ eine Haftung des Malers gegenüber dem Kunden aus Jedermannsrecht (\$\$ 823, 831 BGB) aus, so besteht im Hinblick auf die Handlung des Gehilfen ${ }^{1677}$ eine Haftungslücke (kein Eingreifen der teleologischen Subsidiarität von $\$ 241$ II BGB), welche mittels eines Anspruchs aus $\$ \$ 280$ I, 241 II, 278 $B G B$ geschlossen werden kann. In Betracht kommt die Verletzung einer Nebenpflicht, welche die sonstigen Rechtsgüter (Eigentum) des Gläubigers im Rahmen der Schuldverhältnis-Durchführung schützen soll. Der Angestellte profitierte beim Diebstahl von der Tatsache, dass er sich im Rahmen seiner Tätigkeit bereits in der Wohnung des Kunden befand und so einfachen, ungeschützten $\mathrm{Zu}$ griff auf die Uhr hatte. Einen Fremden hätte der Kunde schließlich gar nicht in die Wohnung gelassen. Damit nutzte der Angestellte in seiner Position als Malergehilfe beim Diebstahl eine durch den Maler vermittelte, erhöhte Einwirkungsmöglichkeit auf die Rechtsgüter des Kunden.

Dass vom Schuldner (im Malerfall also dem Maler) selbst im Regelfall die gleiche Gefahr für die Integrität des Gläubigers gedroht hätte, ist unbeachtlich. Die Gefahrerhöhung im hier verstandenen Sinne ist vielmehr im Vergleich zu potentiellen Drittschädigern - mithin der Allgemeinheit - festzustellen. Auch die hiernach unterscheidende Literatuansicht legt dem Begriff der Gefahrerhöhung so aus. ${ }^{1678}$ Ähnlich verfährt bisweilen auch die Rechtsprechung, wenn sie den Gedanken ergänzungshalber heranzieht.

Beispiel 49 So rechnete das OLG Nürnberg einem Hotelbetreiber die vorsätzliche Schwarzfahrt mit dem AUDI A8 eines Gastes durch den nicht

sichtlich. Die ausufernde Begründungsvielfalt in der Ursprungsforschung von Nebenpflichten war schließlich unter anderem Anstoß zu dieser Arbeit.

1676 S.o., S. 439.

1677 Hätte der Maler selbst gehandelt, so wäre ein gegen ihn gerichteter Anspruch aus $\S \S 280$ I, 241 II BGB teleologisch subsidiär gegenüber den Ansprüchen aus Jedermannsrecht.

1678 Exemplarisch MüKo-BGB/Grundmann, 7. Aufl. 2016, § 278 Rn. 48 (,maßgeblich, ob die Einschaltung des Gehilfen gefahrerhöhend wirkt, was auch zu bejahen ist, wenn etwa der Installateur in der Wohnung „bei Gelegenheit" eine Goldkette stiehlt"); Soergel/Pfeiffer, 13. Aufl. 2014, § 278 Rn. 41. 
mit einer gültigen Fahrerlaubnis ausgestatteten Nachtportier über $\S 278$ BGB - sowie die hieraus resultierende Beschädigung des Autos - u.a. deshalb zu, weil die schädigende Handlung ,erst dadurch ermöglicht [wurde], dass der [Nachtportier] [...] Zugriff auf den bei ihm in Verwahrung gegebenen Fahrzeugschlüssel hatte“ (,,Portierfall“). ${ }^{1679}$ Ein gegenüber dem Tätigwerden des Schuldners erhöhtes Risiko einer Schwarzfahrt durch den Nachtportier war hier freilich nicht festzustellen, hätte der Hotelbetreiber doch identisch handeln können, wenn man ihm selbst den Schlüssel überlassen hätte.

Die Gefahrerhöhung spiegelt sich damit in den gegenüber Fremden erhöhten Einwirkungsmöglichkeiten des Erfüllungsgehilfen auf die Integritätsinteressen des Gläubigers. Müsste der Einsatz des Erfüllungsgehilfen auch gegenüber dem Tätigwerden des Schuldners eine erhöhte Gefahr für die Integrität des Gläubigers darstellen (z.B. durch besondere kriminelle Energie des Erfüllungsgehilfen oder ausgeprägte Inkompetenz), so würde die Reichweite von $\S 278$ BGB über Gebühr eingeschränkt. In solchen Fällen ist die Zurechnung über § 278 BGB zudem regelmäßig überflüssig - also häufig teleologisch subsidiär -, da schon eine Pflichtverletzung des Schuldners in der Betrauung des Erfüllungsgehilfen liegen dürfte, welche zur Haftung aus $\S \S 823$ I, 831 BGB führt.

Beispiel 48 Dass der Maler bei eigenem Handeln im Ergebnis nicht aus $\$ \S 280$ I, 241 II BGB gehaftet hätte - sondern aus den $\$ \$ 823$ I, 823 II BGB, 242 StGB - liegt allein in der teleologischen Subsidiarität von \$241 II BGB begründet, nicht in einer fehlenden Gefahrerhöhung für die Integrität des Kunden im Vergleich zu Dritten. Die Gefahr für das Eigentum des Kunden hat sich damit durch Einschaltung des Malergehilfen aus einer ex-ante-Perspektive erhöht.

Eine Haftung aus Schuldverhältnis lässt sich folglich im Malerfall auch mit Blick auf die Zielsetzung der Nebenpflicht rechtfertigen. Die schuldverhältnisbedingte Haftung aus $\S \S 280$ I, 241 II BGB setzt aber - rein praktisch besehen - ein 
Überkommen jeglicher Subsumtionsschwierigkeiten im Bereich des $\S 278$ S. 1 Alt. 2 BGB voraus. In Bezug auf Nebenpflichten ist also von einem Überwirken deren Haftungslegitimation auf den telos des $\S 278$ BGB auszugehen. ${ }^{1680}$ Sofern ein Zusammenspiel von schuldverhältnisbedingter Haftung aus Nebenpflichtverletzung und $\S 278$ BGB notwendig ist, wird also das Prinzip der Einheit von Chance und Risiko als Normzweck von $\S 278$ BGB durch die Haftungslegitimation der (jeweiligen) Nebenpflicht(en) ersetzt. Bezugspunkt der teleologischen Auslegung unter anderem des Begriffs des Bedienens ist dann der in dieser Weise modifizierte Normzweck. Da die Haftungslegitimationen der betroffenen Nebenpflicht im Malerfall - wie gezeigt - einschlägig sind ${ }^{1681}$, ist der Begriff des Bedienens innerhalb von $\S 278$ S. 1 Alt. 2 BGB unter systematischer Berücksichtigung der betroffenen Nebenpflicht teleologisch weit auszulegen. Dass sich der Schuldner (Maler) bei Wortsinntreue nicht des Erfüllungsgehilfen (Gehilfen) spezifisch zur Erfüllung einer Nebenpflicht bedient hat, ist damit im Ergebnis unschädlich. ${ }^{1682}$

Bei der wortlautgetreuen Subsumtion gestaltet sich die Anwendung des $\S 278$ BGB auf Nebenpflichten wie gezeigt recht schwierig. ${ }^{1683}$ Dies gilt insbesondere dann, wenn der Erfüllungsgehilfe allein in Bezug auf die Erfüllung von Nebenpflichten eingesetzt wurde und der Anwendungsbereich der Leistungspflichten

1680 In methodischer Hinsicht ähnlich Staudinger/Caspers, Neubearbeitung 2014, § 278 Rn. 43 („Der dem $§ 278$ zugrundeliegende Gefahrtragungsgedanke verschiebt sich hier: Nicht so sehr der mit der Einschaltung der Hilfsperson für den Schuldner verbundene Nutzen, sondern der Umstand, dass der Gläubiger seine Rechtssphäre anlässlich des Schuldverhältnisses dem Schuldner und seinen Hilfspersonen öffnet, rechtfertigt es, dem Gläubiger und den seiner Fürsorge unterfallenden Personen über die Deliktshaftung gem $\S 831$ hinaus den besonderen Vertrauensschutz einer Gehilfenhaftung zukommen zu lassen, die nicht auf das Verschulden des Geschäftsherrn abstellt [...]. Aus dieser Funktion des $§ 278$ folgt, dass der Gehilfe nicht speziell in den Pflichtenkreis des Schuldners gegenüber dem Gläubiger eingebunden sein muss, es vielmehr genügt, dass seine Tätigkeit schädliche Auswirkungen auf den Gläubiger haben kann.“); vgl. bereits Berger, Grenzen, 1935, S. 38f. (Fn. 208).

1681 Das ist die einschränkende Voraussetzung die vorliegen muss, um eine teleologische Extension zu rechtfertigen.

1682 Gegen die Wortlautgrenze bei über $\S 278$ BGB zuzurechnenden Nebenpflichtverletzungen auch Picker, AcP 183 (1983), 369, 488f. (stattdessen „ratio peinlich genau“ zu nehmen). Damit hat sich der Maler des Angestellten „zur Erfüllung seiner Verbindlichkeit“ im Sinne von $\S 278$ S. 1 Alt. 2 BGB bedient. Ob $\S 278$ BGB hier über den Wortlaut hinaus zu begrenzen ist, wird im Kontext der Grenzen von $\S 278$ BGB untersucht, s.u., S. 486ff.

1683 Vgl. auch Kamanabrou, NJW 2001, 1187, $1187 f$. 
somit kein sachliches Korrektiv für die Zurechnung von Nebenpflichtverletzungen mehr bilden kann. ${ }^{1684}$

Beispiel 50 Ein selbständiger Speditionsunternehmer beauftragt einen Lackierer damit, die sechs firmeneigenen LKW's von schwarz auf gelb umzulackieren (,,Lackierfall“). ${ }^{1685}$ Um Zeit zu sparen, würde der Unternehmer den Arbeitsvorgang vom Lackierer gerne auf dem großräumigen Betriebsgelände durchführen lassen. Gemeinsam mit seinem Angestellten lackiert der Lackierer die LKW's mit einer unter Druck stehenden Sprühflasche auf einem sich ganz am Rande des Betriebsgeländes des Unternehmers befindlichen Sandplatz. Durch außergewöhnliche Windverhältnisse und fehlende mobile Abzugshauben sowie Schutzplanen kommt es zu erheblichen Verwehungen des gelben Lacks bis hin zum mehrere hundert Meter entfernt liegenden Firmenparkplatz des Unternehmers. Ein Arbeitnehmer hatte hier wie üblich seinen privaten PKW abgestellt. Durch die gelbe Lackwolke kommt es bei dem Fahrzeug zu Verfärbungen und Korrosionen. Der Arbeitnehmer möchte für den Schaden vom Unternehmer Ersatz verlangen.

In Betracht kommt ein Anspruch des Arbeitnehmers gegen den Unternehmer aus $\$ \$ 280$ I, 241 II $B G B^{1686}$. Der Unternehmer könnte dem Arbeitnehmer gegenüber eine Pflicht nach \$241 II $B G B$ verletzt haben, wenn er sich das Verhalten des Lackierers sowie dessen Angestellten gem. $\$ 278$ S. 1 Alt. 2 BGB bei der Beschädigung des PKW des Arbeitnehmers wie eigenes zurechnen lassen muss. ${ }^{1687}$ Fraglich ist, ob der Unternehmer sich hier konkret

1684 Paradigmatisch hierfür ist der Versuch das „Einschalten“ im Sinne von § 278 S. 1 Alt. 2 BGB in einer Dreipersonenkonstellation zu prüfen: Fallen der Gläubiger der Nebenpflicht und der Gläubiger der im Raume stehenden Hauptleistungspflicht auseinander, so lässt sich ein Einschalten des Dritten durch den Gläubiger der Hauptleistungspflicht in die Erfüllung der Nebenpflicht nur mittels einer Fiktion bejahen, ähnlich Tröger, Arbeitsteilung, 2012, S. 523.

1685 Fall nach BAG, Urt. v. 25.5.2000 - 8 AZR 518/99.

1686 Das BAG hatte den Sachverhalt noch nach alter Rechtslage zu beurteilen und prüfte dementsprechend einen Anspruch aus ,positive[r] Vertragsverletzung“.

1687 Bezüglich des betrieblich eingebrachten Arbeitnehmereigentums trifft den Arbeitgeber schließlich eine „Fürsorgepflicht“, vgl. BAG, Urt. v. 25.5.2000 - 8 AZR 518/99, Rn. 19. 
des Lackierers und dessen Angestellten zur Erfüllung einer $\mathrm{Ne}$ benpflicht als Verbindlichkeit bedient hat. Die herrschende Meinung ist hier sehr großzügig und bejaht ein Bedienen schon dann, wenn der Dritte aufgrund der privatautonomen Einschaltung durch den Schuldner mit den Rechtsgütern des Gläubigers in Berührung kommt. ${ }^{1688}$ Damit lässt diese Ansicht Kausalität zwischen Einschaltung des Dritten und der späteren Schädigung genügen. Sofern der Schuldner bei eigener Handlung selbst aus $\$ \$ 280$ I, 241 II BGB haften würde, dürfe bei der Einschaltung eines Dritten grundsätzlich nichts anderes gelten. Der Lackierer und sein Angestellter kamen hier mit dem Eigentum des Arbeitnehmers nur aufgrund der Beauftragung durch den Unternehmer in Berührung. Damit würde die herrschende Meinung eine Zurechnung des Verhaltens bejahen. Ein Bedienen des Lackierers zur Wahrung der Nebenpflichten im Wortsinne wird dem Unternehmer hier aber mehr unterstellt, als dass es sich rechtstatsächlich belegen ließe.

Die beispielhafte Anwendung von $\S 278$ S. 1 Alt. 2 BGB auf Nebenpflichtverletzungen zeigt, dass die Norm hierbei an ihre Funktionsgrenzen stößt. Die Schwierigkeiten bei der Subsumtion lassen sich nur überwinden, wenn wiederholt auf die Zielsetzung der Nebenpflicht - Integritätsschutz - abgestellt wird. Die häufig bemühten Normzwecke des $§ 278$ BGB im Kontext von Leistungspflichten passen dabei nicht auf Nebenpflichten. Vielmehr wird klar, dass der Erfüllungsgehilfe aus einer ex-ante-Perspektive lediglich eine besondere, gegenüber dem Alltag erhöhte Gefahr für den Gläubiger repräsentieren muss, um die Anwendung von $\S 278$ BGB auf Nebenpflichten - auch über den Wortsinn hinaus - zu rechtfertigen. Das Kriterium der Gefahrerhöhung stellt damit die Verbindung zwischen dem abstrakten Ziel der Nebenpflichten - dem Integritätsschutz - und einer sinnvollen Modifizierung des Normzwecks von $§ 278$ BGB dar.

1688 S.o., S. 440 (Fn. 1616). Begründet wird diese Ansicht häufig damit, dass der Gläubiger sich durch die Einschaltung eines Dritten nicht seiner eigenen Haftung entziehen dürfe, so bereits der BGB-Gesetzgeber, s. Mugdan, Materialien, Bd. II, 1899, S. 16. Jede auf der Arbeitsteilung beruhende Pflichtverletzung müsse - als Ausdruck des Prinzips der Einheit von Chance und Risiko - dem Schuldner zugerechnet werden, s.o., S. 253 (Fn. 1023). 
ee) Zwischenergebnis: Gefahrerhöhung als Haftungsgrund

Haftungsgrund der Anwendung von $\S 278$ BGB im Kontext von Nebenpflichten ist nach hier vertretener Ansicht das Element der Gefahrerhöhung für die Integrität des Gläubigers durch die Einschaltung des Erfüllungsgehilfen.

c) Verlaufen der Haftungsgrenze?

Die in der Rechtspraxis entscheidende Frage ist weniger die Frage nach dem Warum der Anwendung von $\S 278$ BGB auf Nebenpflichten sondern, inwieweit Handlungen von Erfüllungsgehilfen dem Schuldner als Nebenpflichtverletzungen zuzurechnen sind.

aa) Notwendigkeit eines Bezugs der Verletzungshandlung zur Einschaltung des Dritten

Während in $\S 831 \mathrm{I} 1 \mathrm{BGB}$ - sowie ähnlich in $\S 31 \mathrm{BGB}$ und $\S 428 \mathrm{~S} .1$ a.E. HGB - mit der Phrase ,in Ausführung der Verrichtung“ ein sachlicher Bezug des Handelns des Dritten zur Verrichtung der ihm vom Schuldner übertragenen Aufgabe gefordert wird ${ }^{1689}$, fehlt eine solche Tatbestandsvoraussetzung im Wortlaut des $\S 278$ S. 1 Alt. 2 BGB. Dies erklärt sich aus der Tatsache, dass $\S 278$ BGB im Kern für die Verletzung von Leistungspflichten konzipiert ist. Sofern der Schuldner aber einen Dritten auf Basis der vorherigen Tatbestandsmerkmale in die Erfüllung seiner Leistungspflichten eingeschaltet hat und es deswegen zu einer entsprechenden Pflichtverletzung kommt, ist der sachliche Bezug zur übertragenen Aufgabe automatisch gegeben. Bei der Verletzung von Leistungspflichten ist diese ohnehin ungeschriebene Voraussetzung damit auch teleologisch überflüssig. Bei Nebenpflichten ist die Situation jedoch komplexer: Auch wenn ein Dritter auf Basis der vorhergehenden Tatbestandsmerkmale generell mit der Wahrnehmung der durch die Nebenpflichten geschützten Integritätsinteressen des Gläubigers betraut wurde, so kann nicht jede Nebenpflichtverletzung durch einen Erfüllungsgehilfen dem Schuldner zugerechnet werden. Deshalb wird von der ganz überwiegenden Ansicht über den Wortlaut des $\S 278$ S. 1 Alt. 2 BGB

1689 Näher Kupisch, JuS 1984, 250, 254. 
hinaus unter Berufung auf den Normzweck ein irgendwie gearteter Bezug der Verletzungshandlung zur Einschaltung des Dritten gefordert. ${ }^{1690}$ Umstritten ist aber, wie genau dieser Bezug beschaffen sein muss.

\section{bb) Zurechnungsgrenzen der herrschenden Meinung}

Die Ansicht der Rechtsprechung und der (noch) überwiegenden Auffassung in der Literatur fragt danach, ob der Erfüllungsgehilfe auch tatsächlich in Erfüllung der ihm zur Wahrnehmung übertragenen Verbindlichkeit tätig geworden ist, oder nur bei Gelegenheit ebendieser. ${ }^{1691}$

Beispiel 48 Der Diebstahl eines Gehilfen in den Räumlichkeiten des Gläubigers wird als klassischer Fall einer Verletzung nur bei Gelegenheit der Erfüllung angesehen. ${ }^{1692}$ Dem Maler wäre also das Verhalten seines Angestellten im Malerfall ${ }^{1693}$ nicht zuzurechnen.

Die Abgrenzung orientiert sich inhaltlich an der Nähe der Handlung des Erfüllungsgehilfen zum ursprünglichen Einsatzzweck. ${ }^{1694}$

1690 Staudinger/Caspers, Neubearbeitung 2014, § 278 Rn. 52ff.; MüKo-BGB/Grundmann, 7. Aufl. 2016, §278 Rn. 47ff.; Soergel/Pfeiffer, 13. Aufl. 2014, §278 Rn. 37; HKBGB/Schulze, 9. Aufl. 2017, § 278 Rn. 11; Jauernig/Stadler, 17. Aufl. 2018, § 278 Rn. 12; Bamberger-Roth/Unberath, 3. Aufl. 2012, § 278 Rn. 44; Wendelstein, AcP 215 (2015), 70, 75f.; Erman/Westermann, 15. Aufl. 2017, § 278 Rn. 39. Aus methodischer Perspektive stellt dieses Vorgehen eine teleologische Reduktion dar, vgl. MüKo-BGB/Grundmann, 7. Aufl. 2016, § 278 Rn. 47 („Einschränkung findet jedoch im Wortlaut des § 278 keinen Anhaltspunkt und ist daher allenfalls aus dem Normzweck (genauer: dessen Fehlen) herzuleiten"). $^{\text {") }}$

1691 S.o., S. 85 (Fn. 331).

1692 Vgl. Palandt/Grüneberg, 77. Aufl. 2018, § 278 Rn. 22; Körber, JA 2015, 673, 676f.; HKBGB/Schulze, 9. Aufl. 2017, § 278 Rn. 11.

1693 S.o., S. 439.

1694 Letztlich ähnlich bejaht Wendelstein, AcP 215 (2015), 70, 103 eine Zurechnung des Verhaltens des „Bewahrungsgehilfen“ über $\S 278$ BGB, solange der Dritte „,mit dem Willen des Schuldners bei der Bewahrung einer diesem obliegenden Schutzpflicht als seine Hilfsperson tätig wird“. Als Grenze der Zurechnung fragt er danach, ob den Schuldner bei eigenem Verhalten auch eine entsprechende Nebenpflicht getroffen hätte, Wendelstein, AcP 215 (2015), $70,90,103)$. Daran ist zutreffend, dass die Frage, ob das verletzte Interesse schutzwürdig ist, im Verhältnis Schuldner/Gläubiger zu klären ist. Insbesondere bei der Beeinträchtigung vermögenswerter Interessen ist $§ 278$ BGB im hier vertretenen Ansatz ja nur auf sekundärer Ebene betroffen. Zunächst ist schließlich mit eigenständigen Kriterien zu klären, ob die Verantwortung für das Interesse überhaupt dem Schuldner mittels einer Nebenpflicht zuzuweisen 
Beispiel 51 Laut BAG können dem Arbeitgeber aktive „Mobbing“-Handlungen seiner Angestellten nach $\$ 278$ BGB nur zugerechnet werden, wenn sie die Nebenpflichten dem Arbeitnehmer gegenüber als Vorgesetzte konkretisieren (,, Mobbingfall“). ${ }^{1695}$ Bei dem Mobbingopfer gleichrangigen Angestellten fehle es für die Anwendung von $\S 278$ BGB am spezifischen Zusammenhang zur Vertragserfüllung. Damit bemüht das BAG hier sachlich die Abgrenzung danach, ob die Nebenpflichtverletzung in Erfüllung der übertragenen Handlung oder nur bei Gelegenheit derselben begangen wurde.

Beging der Erfüllungsgehilfe die Nebenpflichtverletzung nur bei Gelegenheit seiner Tätigkeit, so ist die Zurechnung nach § 278 S. 1 Alt. 2 BGB zu verneinen.

ist. Erst dann rückt $§ 278$ S. 1 Alt. 2 BGB ins Blickfeld. Die Frage, ob der Schuldner bei eigenem Handeln selbst aus schuldverhältnisbedingter Nebenpflichtverletzung gehaftet hätte, verschiebt den Normzweck des $\S 278$ BGB aber gänzlich auf die Ebene der Nebenpflicht. Irgendeine Grenze muss sich auch aus $\S 278$ BGB selbst ergeben. Sonst ließe sich nicht präzise begründen, warum nicht ein völlig Fremder die Haftung des Schuldners auslösen könnte. So lässt sich in der Definition des „Bewahrungsgehilfen“ erkennen, dass die Zurechnung dort enden soll, wo der Dritte nicht mehr ,mit dem Willen des Schuldners bei der Bewahrung" einer Nebenpflicht tätig war. Wann genau das sein soll, ist nicht erkennbar. Die Phrase „mit Willen des Schuldners bei der Bewahrung tätig sein“ erinnert damit an die - zunächst von Wendelstein verworfene - Abgrenzung der herrschenden Meinung. Etwas ironisch wirkt es daher, wenn Wendelstein, AcP 215 (2015), 70, 103 (Fn. 114) einen Ansatz kritisiert, der ein „Einsetzen“ des Schuldners „mit Richtung“ auf den Gläubiger fordert, weil unklar sei, „wann eine solche Bezogenheit auf den Gläubiger“ vorliege, vgl. zum hier angesprochenen, interessanten Ansatz näher Kamanabrou, NJW 2001, 1187, 1188 sowie s.o., 0, S. 468ff. Die erste Komponente der Definition (,mit dem Willen des Schuldners“) knüpft an den im Nachhinein nur schwerlich auszulotenden Willen des Schuldners an. Der zweite Teil („,bei der Bewahrung") gibt zu erkennen, dass Handlungen des Dritten auch außerhalb der Bewahrung liegen können, was wegen des notwendigen Rückgriffs auf andere Kriterien Einfallstor für eben jene Abgrenzungsprobleme der überwiegenden Auffassung ist. Im Ergebnis sieht Wendelstein, AcP 215 (2015), 70, 105 (Fn. 118) seine Auffassung zwar in Übereinstimmung mit denjenigen, die eine Gefahrerhöhung oder eine erhebliche Erleichterung der Tat durch die Einschaltung des Erfüllungsgehilfen fordern: Ein Schuldverhältnis - welches seinerseits Voraussetzung für die Anwendung von $\S 278$ BGB ist - entstehe schließlich genau wegen eben dieser erhöhten Gefahr, ein geschütztes Interesse des Gläubigers zu beeinträchtigen. Dass beide Ansichten zu gleichen Ergebnissen führen, lässt sich aber durchaus bezweifeln. Zwar mag die faktische Einwirkungsmöglichkeit auf die Rechtsgüter des Anderen Grund dafür sein, ein Schuldverhältnis entstehen zu lassen. Damit ist aber noch nichts darüber gesagt, ob der Dritte auch von diesen Möglichkeiten Gebrauch gemacht hat. Nur wenn die Handlung des Dritten auch tatsächlich durch die Einschaltung als Erfüllungsgehilfe erleichtert wurde, hat sich die ex ante erhöhte Gefahr für die Rechtsgüter des Gläubigers auch realisiert.

1695 Näher BAG, Urt. v. 16.5.2007 - 8 AZR 709/06, Rn. 80f. (BAGE 122, 304, 325) 
Beispiel 52 Eine lokale Fluggesellschaft lädt zwei örtliche Politiker zur Imagepflege auf eine Informationsveranstaltung ein, bei der den beiden auch ein unentgeltlicher Rundflug spendiert werden soll (,,Flugfall“). ${ }^{1696}$ Als Pilot ist ein langjähriger Angestellter der Fluggesellschaft vorgesehen. Weil sich das für den Rundflug vorgesehene Flugzeug zurzeit in Düsseldorf befindet, wird ein Hobbypilot beauftragt, das Flugzeug zu überführen. Dieser hatte das betreffende Flugzeug schon häufig von der Fluggesellschaft gemietet und war daher vertraut mit ihm. Nachdem er das Flugzeng nach Mannheim überführt hat, wird er erneut von der Fluggesellschaft kontaktiert. Die Fluggesellschaft instruiert den Hobbypiloten, den beiden Politikern mitzuteilen, dass sich der Pilot verspäten werde und deshalb der Rundflug um eine Stunde verschoben wurde. Der Hobbypilot ist noch so begeistert vom Fliegen, dass er im Adrenalinrausch beschließt den Rundflug selbst durchzuführen. Er holt daher die Politiker auf dem Rollfeld ab und stellt sich als Pilot vor. Kurz nach dem Abheben kommt der Hobbypilot aus Versehen gegen die Triebwerksregulierung und drosselt die Leistung. Weil das Flugzeug noch nicht die erforderliche Höhe erreicht hatte, gerät es deshalb beim nächsten Lenkeinschlag ins Schleudern und stürzt ab. Alle drei Insassen verunglücken tödlich. Die Hinterbliebenen der beiden Politiker wollen die Fluggesellschaft in Anspruch nehmen. Dabei stützen sie sich darauf, dass der Fluggesellschaft das Verhalten des Hobbypiloten nach § 278 S. 1 Alt. 2 BGB zuzurechnen sei.

Der BGH lehnte eine Zurechnung des Verhaltens ab, weil der Erfüllungsgehilfe hier lediglich bei Gelegenheit der ihm übertragenen Verbindlichkeit gehandelt habe. ${ }^{1697}$ Die Abgrenzung des Handelns in Erfüllung und bei Gelegenheit der Erfüllung im Rahmen von Vorsatztaten des Erfüllungsgehilfen richtete sich laut $B G H$ danach, ob ,dessen Verfehlung sich von dem ihm übertragenen

1696 Fall nach BGH, Urt. v. 14.2.1989 - VI ZR 121/88.

1697 BGH, Urt. v. 14.2.1989 - VI ZR 121/88, Rn. 23. 
Aufgabenbereich so weit entfernt [habe], daß aus der Sicht eines Außenstehenden ein innerer Zusammenhang zwischen dem Handeln der Hilfsperson und dem allgemeinen Rahmen der ihr übertragenen Aufgaben nicht mehr zu erkennen ist " ${ }^{1698}$ Hier sei der „Gehilfe rein zufällig mit den Rechtsgütern des Geschädigten in einer Weise in Berührung gekommen [...], die ihm lediglich die Gelegenheit bot, wie ein deliktisch handelnder Dritter eine von den ihm übertragenen Aufgaben völlig losgelöste unerlaubte Handlung zu begehen " ${ }^{1699}$

Die von der Rechtsprechung vorgenommene Abgrenzung ist damit wertender Natur und bedarf einer angemessenen Berücksichtigung aller Sachverhaltsumstände.

cc) Kritik an der Abgrenzung der herrschenden Meinung

Gegen die Begrenzung des $\S 278$ BGB durch die überwiegende Auffassung spricht, dass sich die hochnormative Wertung, ob eine Tat bei Gelegenheit oder in Erfüllung der übertragenen Aufgabe begangen wurde, nicht transparent herleiten lässt. ${ }^{1700}$ Mit guten Argumenten ließe sich nämlich regelmäßig auch das Gegenteil begründen.

Beispiel 53 So hat das OLG Düsseldorf einmal versucht, sich bewusst von dem Urteil des BGH im Flugfall (Beispiel 52) ${ }^{1701}$ abzugrenzen (,,Prokuristenfall“). ${ }^{1702}$ Es rechnete hier einem Gewerberunternehmen, welches Geschäftsräume vom Gläubiger angemietet hatte, das

1698 BGH, Urt. v. 14.2.1989 - VI ZR 121/88, Rn. 23.

1699 BGH, Urt. v. 14.2.1989 - VI ZR 121/88, Rn. 23.

1700 Krit. auch Soergel/Pfeiffer, 13. Aufl. 2014, § 278 Rn. 41 a.E. (,zum Teil widersprüchliche Rechtsprechung“); Seok Kim, ZEuP 2013, 263, 268f.; Wendelstein, AcP 215 (2015), 70, 76 (Subsumtionsergebnisse ,kaum vorhersehbar"); Erman/Westermann, 15. Aufl. 2017, § 278 Rn. 39 (,Abgrenzung [...] schwierig“); vgl. BGH, Urt. v. 11.10.1994 - XI ZR 238/94, Rn. 25: Dort wurde zunächst pauschal darauf hingewiesen, dass eigenmächtige Handlungen des Erfüllungsgehilfen die Zurechnung nicht zwingend entfallen lassen würden, um in den nächsten beiden Sätzen die Zurechnung abzulehnen, weil der Erfüllungsgehilfe zur konkreten Handlung ,nicht berechtigt" gewesen war.

1701 S.o., S. 465.

1702 Näher hierzu und zum Folgenden OLG Düsseldorf, Urt. v. 20.3.1997 - 24 U 39/96, Rn. 8, 11. 
vorsätzliche Inbrandsetzen der Mieträumlichkeiten durch den Prokuristen des Gewerbeunternehmens zu. Das OLG hielt die - vom Schuldner als Präzedenzfall für nicht über $\$ 278$ BGB zuzurechnende Handlungen von Erfüllungsgehilfen genannte - Aushilfspilotenentscheidung nicht für übertragbar, weil dem Prokuristen tatsächlich konkludent die Aufgabe übertragen worden sei, die Integrität der Geschäftsräume zu schützen. ${ }^{1703}$ In Ausfüllung dieser Tätigkeit habe der Prokurist dann die dem Schuldner zuzurechnende Entscheidung getroffen, die Geschäftsräume anzuzünden. ${ }^{1704} \mathrm{Bei}$ nüchterner Betrachtung erscheint die Differenzierung der Entscheidungen indes recht willkürlich. In beiden Fällen traf der Erfüllungsgehilfe die Entscheidung, vorsätzlich die Rechtsgüter des Gläubigers zu gefährden und in beiden Fällen nutzte er hierfür die ihm vom Schuldner eingeräumten Zugriffsmöglichkeiten. Auch dem Piloten wurden die Schlüssel zum Flugzeug ausgehändigt. Dass der Pilot nach der Überführung des Flugzeugs seinen Aufgabenkreis eigenmächtig erweitern würde, war eben gerade die Gefahr, welche mit der Betrauung der Überführung des Flugzeugs und der Unterrichtung der Passagiere grundsätzlich geschaffen wurde. Die im vorsätzlichen Überschreiten des eigenen Pflichtenkreises liegende Zäsur zwischen erstmaliger Einschaltung des Erfüllungsgehilfen durch den Schuldner und dessen letztendlicher Schädigungshandlung, welche der BGH im Pilotenfall zu begrün-

1703 Schließlich hatte man ihm einen Schlüssel gegeben und ihm damit Zutritt auch außerhalb der Geschäftszeiten ermöglicht.

1704 Anders hatte dies noch die Vorinstanz gesehen, vgl. die beinahe humoristisch trockene Diktion bei OLG Düsseldorf, Urt. v. 20.3.1997 - 24 U 39/96, Rn. 6 (,Das Landgericht verläßt die zuvor zutreffend dargestellte Definitionsgrundlage [der Abgrenzung nach Handeln des Erfüllungsgehilfen in Erfüllung/bei Gelegenheit], wenn es darauf abstellt, zu den Aufgaben eines Prokuristen gehöre es nicht, die von dem Geschäftsherrn zum Betrieb dessen Handelsgewerbes gemieteten Räume anzuzünden."). Ähnlich auch der fast schon absurd anmutende Fall von BGH, Urt. v. 17.10.1990 - VIII ZR 213/89, Rn. 12 (BGHZ 112, 307, 309f.), in welchem einem Pächter das Verhalten seines Unterpächters zugerechnet wurde. Letzterer hatte eine vorsätzliche Brandexplosion in den gepachteten Räumlichkeiten des Geschädigten verursacht. Dass die vorsätzliche Zerstörung nach § 540 II BGB - der wegen $\S 581$ II BGB auch im Pachtrecht anwendbar ist - „, bei dem Gebrauch“ des Pachtobjekts erfolgte, lässt sich indes leichter bejahen, als dass sie auch , in Erfüllung“ der übertragenen Verbindlichkeit nach $§ 278$ S. 1 Alt. 2 BGB erfolgte. 
den versuchte - und welche das OLG im eigenen Fall verneinte -, ließe sich ebenso als außergewöhnliche, aber nicht völlig unvorstellbare Entwicklung aus der Betrauung als Bote und Überführungspilot heraus umschreiben. In jedem Fall zeigt der Vergleich, dass das Abgrenzungspaar in Erfüllung/bei Gelegenheit von einer gewissen Ergebnisbeliebigkeit geprägt ist.

Die Reichweite und Überzeugungskraft der überwiegenden Ansicht ist zudem völlig unklar, wenn Gläubiger der Nebenpflicht und Gläubiger der Hauptleistungspflicht, für deren Erfüllung Dritte eingesetzt werden, nicht personenidentisch sind.

Beispiel 50 Im Lackierfall ${ }^{1705}$ verneinte das BAG ein Bedienen mit der Begründung, dass die „Arbeiten in keiner Weise auf die Arbeitnehmer der Beklagten bezogen " waren. ${ }^{1706}$ Es fordert damit in Mehrpersonenkonstellationen einen konkreten, vom Schuldner privatautonom veranlassten ${ }^{1707}$ „Bezug“ der den Schaden hervorrufenden Tätigkeit des Erfüllungsgehilfen auf den Gläubiger der Nebenpflicht hin. ${ }^{1708}$ Die Problematik einer Nebenpflichtverletzung nur bei Gelegenheit der Erfüllung der Schuldnerverbindlichkeit wurde vom $B A G$ gar nicht in Erwägung gezogen. Schließlich dient dieses Kriterium dazu, Nebenpflichtverletzungen eines Erfüllungsgehilfen auszugrenzen, die in keinerlei sachlichem Zusammenhang mit den dem Gläubiger gegenüber zu erfüllenden (Leistungs-)Pflichten standen. Hier war die Nebenpflichtverletzung zum einen direkter

1705 S.o., S. 460.

1706 BAG, Urt. v. 25.5.2000 - 8 AZR 518/99, Rn. 20.

1707 Das BAG spricht nicht explizit von einer privatautonomen Veranlassung, aber legt diese Auslegung nahe, vgl. BAG, Urt. v. 25.5.2000 - 8 AZR 518/99, Rn. 20 („,Die Beklagte hat eben nicht eine Gefahrenquelle für ihre Arbeitnehmer eröffnet und eine sich daraus für sie ergebende Schutzpflicht zusammen mit den Lackierarbeiten übertragen [!]").

1708 Der Sache nach lehnt das BAG hier eine Zurechnung ab, weil sich die Gefahr für die Rechtsgüter des Arbeitnehmers hier durch die Beauftragung des Lackierers und dessen Angestellten aus einer ex ante Perspektive nicht erhöht hat. Mit der Reichweite von $\S 278$ BGB bei Nebenpflichtverletzungen im Rahmen des „Bedienens“ wirft das BAG hier ein neues und weithin unbeachtetes Problem auf, so treffend Kamanabrou, NJW 2001, 1187, 1187f. Der Entscheidung deshalb auch trotz ihres eindeutig von der herrschenden Meinung abweichenden Inhalts eher gleichgültig begegnend Staudinger/Caspers, Neubearbeitung 2014, § 278 Rn. 43. 
Ausfluss der Erfüllung der (primär übertragenen) Aufgabe aus dem Werkvertrag Unternehmer-Lackierer und geschah quasi uno actu mit derselben. Zum anderen sollten der Lackierer und sein Angestellter dem Arbeitnehmer gegenüber überhaupt keine Leistungspflichten im Verhältnis Unternehmer-Aarbeitnehmer wahrnehmen, sondern die Eigenschaft als Erfüllungsgehilfe beschränkte sich hier auf die Erfüllung der Nebenpflichten aus dem Schuldverhältnis Unternehmer-Arbeitnehmer.

Damit ist belegt, dass die sachliche Verknüpfung von übertragener Aufgabe und Nebenpflichtverletzung der herrschenden Meinung ins Leere laufen muss, wenn der Erfüllungsgehilfe allein auf Nebenpflichten bezogen eingesetzt wurde. Schließlich sind mit übertragener Aufgabe inhaltlich eigentlich die dem Erfüllungsgehilfen übertragenen Leistungspflichten gemeint. Genau diese Kopplung von Leistungs- und Nebenpflichten ist aber nicht sinnvoll, bestehen (oder auch nicht) beide doch ausweislich des $\S 241$ I, II BGB unabhängig voneinander.

Im Ergebnis ist das von der überwiegenden Auffassung zugrundegelegte Begriffspaar des Handelns des Erfüllungsgehilfen in Erfüllung oder bei Gelegenheit im Zusammenhang mit der Verletzung von Nebenpflichten erheblicher Kritik ausgesetzt.

dd) Zurechnungsgrenzen bei der persönlichen Schuld als Haftungsgrund

Ein radikal anderer Ansatz für die Verhaltenszurechnung im Rahmen von $\S 278$ BGB ist es, nur Nebenpflichten zuzulassen, die eine unmittelbare Anbindung an die Hauptleistungspflicht haben. ${ }^{1709}$ Führt das Verhalten eines Erfüllungsgehilfen dazu, einen solchen Nebenpflichtwahrungserfolg zu verhindern, so muss der Schuldner aus dem Schuldverhältnis haften, unabhängig davon, ob er sich selbst etwas vorzuwerfen hat. Umgekehrt zieht der Ansatz eine Grenze dort, wo die Pflicht lediglich eine mittelbare oder zufällige Anbindung an die Leistungspflicht aufweist. $^{1710}$

1709 So Paßmann, Schutzpflichtverletzungen, 2010, S. 162ff.

1710 Paßmann, Schutzpflichtverletzungen, 2010, S. 165. 
Als Beispiel dient der sogar in der Gesetzesbegründung zu $\S 282$ $B G B$ angedeutete ${ }^{1711}$ Fall des Malergehilfen, der in der Wohnung des Kunden aus Versehen eine Vase zerbricht. Weil die Verhaltensanforderung (Keine fahrlässige Beschädigung fremden Eigentums) hier nicht unmittelbar in Verbindung mit der Hauptleistungspflicht (Streichen der Wand) stand ${ }^{1712}$, wäre eine Nebenpflicht - und damit naturgemäß auch eine Zurechnung nach § 278 $B G B$ - nach dieser Ansicht abzulehnen. ${ }^{1713}$

Dieser Ansatz gelangt zu in klarem Widerspruch zur überwiegenden Ansicht stehenden Ergebnissen. ${ }^{1714}$ Augenscheinlich zieht der Ansatz zudem für vor- und nachvertragliche Schuldverhältnisse eine absolute Grenze für Nebenpflichten und damit auch für die Zurechnung nach $\S 278$ BGB. Schließlich bestehen in diesen Schuldverhältnissen gar keine Leistungspflichten. Eine irgendwie geartete Anbindung der Nebenpflicht an die Hauptleistungspflicht ist damit gar nicht möglich, weshalb in diesen Schuldverhältnissen die Anwendung von § 278 BGB bei der Verletzung von Nebenpflichten gänzlich ausscheiden müsste. ${ }^{1715}$ Für die

1711 Vgl. BT-Drs. 14/6040, SchRModG, Gesetzesbegründung, S. 141f. Der Fall - der sich auf den Maler und nicht auf seinen Gehilfen fokussiert - ist hier primär auf $\S 282$ BGB bezogen, $\S 278$ BGB findet deshalb keine Berücksichtigung. Ursprünglich findet der Fall Erwähnung bei Planck/Siber, 4. Aufl. 1914, Vorbm. zu §§ 275-292 S. 186.

1712 Als unmittelbar mit der Hauptleistungspflicht verbunden würde Paßmann wohl die Pflicht des Schuldners ansehen, die zur streichenden Wand gehörenden Stuckverzierungen nicht zu beschädigen, vgl. Paßmann, Schutzpflichtverletzungen, 2010, S. 162. M. Müller/Hempel, AcP 205 (2005), 246, 273 ordnen eine solche Pflicht wegen des unmittelbaren Bezuges zur Leistungsschuld als leistungsbezogene Nebenpflicht ein - und damit nicht als Pflicht nach § 241 II BGB.

1713 Paßmann, Schutzpflichtverletzungen, 2010, S. 165.

1714 Vgl. Wendelstein, AcP 215 (2015), 70, 75 (Fn. 22) m.w.N.

1715 So vom Grundgedanken her denn auch Paßmann, Schutzpflichtverletzungen, 2010, S. 166. Im Rahmen der culpa in contrahendo hält Paßmann, Schutzpflichtverletzungen, 2010, S. 166f. aber dennoch Nebenpflichten für möglich, wenn der (unmittelbare) Leistungsbezug dadurch hergestellt wird, dass es um Informationen über die zu vereinbarende Leistung geht. Die dort angestellte Erwägung bezieht sich nur vom Kontext her auf den Normzweck des $\S 278$ BGB. In der Sache wird hier eine Entscheidung gefällt, welche den Schutz vermögenswerter Interessen durch Nebenpflichten betrifft. Insgesamt scheint Paßmann also eher aus den bei $\S 278$ BGB angestellten Überlegungen Schlüsse für Nebenpflichten insgesamt - und nicht nur für den spezifischen Haftungsvorteil des Schuldverhältnisrechts bei der Verantwortlichkeit für Drittverhalten - zu ziehen. Der Ansatz wird aber trotzdem hier en bloc dargestellt, weil man ihn ansonsten gegen den Willen des Verfassers künstlich trennen müsste. Sachlich passt er in der hier vertretenen Struktur gut zur Begrenzung von Nebenpflichten durch die schuldverhältnisspezifische Funktion. Er wird deshalb unten erneut gewürdigt, s.u., S. 530ff. 
Vielzahl der Kaufhausfälle wird dann auch tatsächlich die Möglichkeit einer Zurechnung von Nebenpflichtverletzungen über § 278 BGB abgelehnt, denn hier fehle der ,spezifische Bezug zur [durch den potentiellen Vertrag angestrebten] Interessenbefriedigung“. ${ }^{1716}$

Im Ergebnis führt dieser Ansatz damit zu einer - grundsätzlich auch hier befürworteten ${ }^{1717}$ - Verringerung der praktischen Relevanz von Nebenpflichten. Gerade im Bereich der Zurechnung nach $\S 278$ BGB dämmt der Ansatz die Haftung aus $\S \S 280$ I, 241 II BGB indes über das sinnvolle Maß hinaus ein. ${ }^{1718}$ Der geforderte, unmittelbare Bezug der Nebenpflicht zur Hauptleistungspflicht lässt sich nämlich nicht überzeugend an der Teleologie der Nebenpflichten festmachen. ${ }^{1719}$ Schließlich wurde bereits im Rahmen der Auseinandersetzung mit der Abgrenzung der herrschenden Meinung festgestellt, dass eine solche Kopplung der Neben- an die Leistungspflicht bei der Frage, inwieweit Handlungen eines Erfüllungsgehilfen dem Schuldner zuzurechnen sind, häufig irreführend und zum Teil gar unmöglich ist. ${ }^{1720}$

ee) Zurechnungsgrenzen unter Rekurs auf die Gefahrerhöhung als Haftungsgrund

Eine sich im Vordringen befindliche Ansicht stellt in Abkehr von der Abgrenzung der Rechtsprechung darauf ab, ob die Einschaltung des Erfüllungsgehilfen für den Gläubiger (erheblich) gefahrerhöhend war. ${ }^{1721}$ Eine Grenze für die $\mathrm{Zu}$ -

1716 So Paßmann, Schutzpflichtverletzungen, 2010, S. 167f.

1717 S.o., S. $275 \mathrm{ff}$.

1718 Vgl. dazu auch Canaris, FS Larenz, 1983, S. 27, 87ff.; U. Huber, AcP 177 (1977), 281, 318 (Fn. 142).

1719 Selbst wenn man den Bezug als Normzweck für § 278 BGB akzeptieren sollte, so bleibt unklar, ob man den Ansatz deshalb - wie Paßmann - auch dafür nutzen sollte, Nebenpflichten zum Schutz vermögenswerter Interessen zu begrenzen.

1720 S.o., S. 466ff.

1721 NK-BGB/Dauner-Lieb, 3. Aufl. 2016, § 278 Rn. 8 a.E.; AK-BGB/Dubischar, 1980, § 278 Rn. 8; MüKo-BGB/Grundmann, 7. Aufl. 2016, § 278 Rn. 47f.; Looschelders, Schuldrecht AT, 15. Aufl. 2017, Rn. 506; Medicus/Lorenz, Schuldrecht AT, 21. Aufl. 2015, Rn. 382; Soergel/Pfeiffer, 13. Aufl. 2014, § 278 Rn. 38; Reischl, JuS 2003, 40, 48; HK-BGB/Schulze, 9. Aufl. 2017, § 278 Rn. 11; Seok Kim, ZEuP 2013, 263, 268f., 276ff.; ähnlich auch Esser/ Schmidt, Schuldrecht AT, Teilbd. 2, 8. Aufl. 2000, S. 104 (,sonst nicht eingeräumte Gelegenheit zur schädlichen Einwirkung auf die Integrität des Gläubigers konstitutives Element des [die Anwendung von $\S 278$ BGB auf Nebenpflichten rechtfertigenden] Vertrauensschutzes"); 
rechnung von Verhalten wird dort gezogen, wo der Einsatz des Erfüllungsgehilfen nicht zu einer gegenüber dem allgemeinen Lebensrisiko erhöhten Rechtsgütergefährdung geführt hat. ${ }^{1722}$

Beispiel 51 Sieht man den Normzweck von $\$ 278$ BGB allein bei einer Gefahrerhöhung für das betroffene Rechtsgut betroffen, so müsste man im Mobbingfall ${ }^{1723}$ eine Zurechnung bejahen. Schließlich hatte der Schädiger hier nur deshalb die Möglichkeit, so nachhaltig auf das Opfer einzuwirken, dass es Mobbing konstituierte, weil er täglich mit dem Opfer am gleichen Arbeitsplatz weilte. Ein täglich nur für fünf Minuten präsenter Postbote hätte beispielsweise gar nicht die gleiche Gelegenheit gehabt, die zeitliche Dauer und Frequenz der systematischen Verletzungshandlungen ${ }^{1724}$ zu gewährleisten. ${ }^{1725}$ Die Gefahr für das - hier betroffene - allgemeine Persönlichkeitsrecht hat sich also durch die Einschaltung jedes Arbeitnehmers am gleichen Arbeitsplatz erhöht. Damit wäre dem Arbeitnehmer jedwedes Mobbingverhalten eines seiner Arbeitnehmer, unabhängig

dagegen Erman/Westermann, 15. Aufl. 2017, § 278 Rn. 39 (,genügt nicht*); zu Ansätzen dieses Gedankens bereits Heinrich Stoll, AcP 136 (1932), 257, 298f. (Fn. 87), 304. Methodisch betrachtet wird hier unter Berufung auf den Normzweck des $\S 278$ BGB eine weitere Voraussetzung für die Verhaltens- und Verschuldenszurechnung nach $\S 278$ S. 1 Alt. 2 BGB aufgestellt. Weil der herkömmliche telos des $\S 278$ BGB (Einheit von Chance und Risiko) bei Nebenpflichten inhaltlich nicht passt, wird er durch den Schutzzweck der jeweiligen Pflicht überlagert. Sofern aus der Einschaltung des Erfüllungsgehilfen keine Gefahrerhöhung für das von der Nebenpflicht geschützte Rechtsgut respektive Pflichtverletzungserleichterung für den Erfüllungsgehilfen resultiert, ist auch der Zweck der Nebenpflicht nicht betroffen. Diese einschränkende Voraussetzung ist damit geronnener telos des §278 BGB bei Nebenpflichten, zumindest i.E. ähnlich Seok Kim, ZEuP 2013, 263, 277f. Scheitert der konkrete Sachverhalt an diesem Prüfungsmaßstab, so ist eine teleologische Reduktion die gebotene methodische Reaktion.

1722 MüKo-BGB/Grundmann, 7. Aufl. 2016, § 278 Rn. 47f.; Soergel/Pfeiffer, 13. Aufl. 2014, $\S 278$ Rn. 39.

1723 S.o., S. 464.

1724 Zur Definition von Mobbing näher BAG, Urt. v. 16.5.2007 - 8 AZR 709/06, Rn. 58 (BAGE 122, 304, 317f.); aus ökonomischer Perspektive zustimmend Sykes, Harv. L. Rev. 101 (1988), $563,606 \mathrm{ff}$.

1725 Insoweit zu kurz gegriffen Sykes, Harv. L. Rev. 101 (1988), 563, 608 („,individuals prone to commit acts of harassment in the absence of any leverage may well do so irrespective of their occupation, position, employment or unemployment"). 
von den hierarchischen Verhältnissen zwischen Täter und Opfer, über $§ 278$ BGB zuzurechnen. ${ }^{1726}$

Auf die Handlung des Erfüllungsgehilfen bezogen ist zu fragen, ob die Schädigung des Gläubigers dem Erfüllungsgehilfen mittels der Einschaltung durch den Schuldner erleichtert wurde. Lässt sich das bejahen, so ist auch eine Zurechnung über $\S 278$ S. 1 Alt. 2 BGB vom Normzweck gedeckt. ${ }^{1727}$

Beispiel 52 Im Flugfall ${ }^{1728}$ gab sich der Erfüllungsgehilfe unentdeckt als Pilot aus. Die Gefahr der hieraus resultierenden Schädigung wurde durch die Einschaltung des Boten erhöht: Schließlich hätte ein völlig Fremder ohne präzise Kenntnisse des Ablaufs sich deutlich schwerer getan, die Passagiere von seiner Eigenschaft als Pilot zu überzeugen. Hätten Passagiere sich trotz bewusster Bedenken freiverantwortlich dafür entschieden, den Boten fliegen zu lassen, so wäre das Handeln des Erfüllungsgehilfen durch den Entschluss der Passagiere überlagert worden. ${ }^{1729}$ Hier konnte er nur mittels der vom Schuldner eingeräumten Befugnisse (Zugang zum Flugzeug, gewohnter Umgang mit dem Flugzeug) sowie des an ihn weitergeleiteten Wissens (Name und Ziel der Passagiere, Flugplan, bisherige Störung im Ablauf, etc.) seine Eigenschaft als Bote so einfach kaschieren. Ein völlig Fremder hätte schließlich schon Schwierigkeiten gehabt, das Flugzeug zu starten und vom Tower eine Starterlaubnis zu bekommen. Der Bote sollte das Flugzeug ja aber auf Anweisung der Airline bereits zum Startflughafen überführen. Er war damit zumindest streckenweise legitimer Pilot. Damit stellt sich die Tat des Erfüllungsgehilfen hier nicht gänzlich als sein Werk dar. Vielmehr wurde dem Erfüllungsgehilfen die Tat durch die Einschaltung erleichtert. Damit ist unter Rückgriff auf

1726 Ähnlich auch NK-BGB/Dauner-Lieb, 3. Aufl. 2016, § 278 Rn. 11.

1727 Vgl. zur Anwendung von § 278 BGB gegenüber einem Hotelbetreiber für das vorsätzliche Fehlverhalten eines Nachtportiers OLG Nürnberg, Urt. v. 19.4.2017 - 4 U 2292/16, Rn. 25 (,Schwarzfahrt erst dadurch ermöglicht, dass der Beklagte zu 1) Zugriff auf den bei ihm in Verwahrung gegebenen Fahrzeugschlüssel hatte").

1728 S.o., S. 465.

1729 Ähnlich MüKo-BGB/Grundmann, 7. Aufl. 2016, § 278 Rn. 48 a.E. (Grenze bei „Willensbetätigung" des Gläubigers). 
den Normzweck des $\S 278$ BGB bei Nebenpflichten - Integritätsschutz - die Zurechnung hier zu bejahen. ${ }^{1730}$

Die Grenze der Anwendung von $\S 278$ BGB auf Nebenpflichten liegt also an der Stelle, an welcher die vorgeworfene Handlung in keiner Weise auf vom Schuldner gewährten Eingriffsmöglichkeiten beruht. ${ }^{1731}$ Hat der Dritte sich die $\mathrm{Zu}$ griffsmöglichkeit auf das betroffene Rechtsgut des Gläubigers selbst erarbeitet, so hebt sich seine Handlung nicht von der eines völlig Fremden ab. Er ist dann in Bezug auf Nebenpflichten kein Erfüllungsgehilfe.

Verletzt der Mitarbeiter eines Supermarkts einen Kunden mit einem Faustschlag, so wäre eine Haftung des Betreibers über $\S 278$ $B G B$ zu verneinen. Schließlich hat sich das Risiko einer Schädigung durch die Einschaltung des einzelnen Mitarbeiters nicht erhöht. ${ }^{1732}$ Der Kunde hätte ebenso gut von einem anderen Kunden geschlagen werden können. Hat der einzelne Mitarbeiter aber eine Sicherheitsvorkehrung außer Kraft gesetzt oder unterlassen, so handelt es sich um ein Risiko gegenüber der körperlichen Integrität des Kunden, welches allein in dem Erfüllungsgehilfen ruht. Ein anderer Kunde hätte den Schuldner nicht in der gleichen Weise schädigen können. Schließlich ist er weder befugt, Sicherheitsmaßnahmen zu treffen oder zu unterlassen, noch hat er typischerweise das Wissen, faktisch auf diese einzuwirken. Damit hätte sich bei einer solchen Schädigung das Risiko für den Schuldner durch die Einschaltung des Erfüllungsgehilfen erhöht. Eine Haftung wäre folglich zu bejahen.

1730 So auch MüKo-BGB/Grundmann, 7. Aufl. 2016, § 278 Rn. 48 a.E. (Fn. 217).

1731 Für einen Gefahrverwirklichungszusammenhang als generelle Grenze für die Haftung aus Nebenpflichtverletzung OLG Saarbrücken, Urt. v. 21.5.1993 - 4 U 79/92, Rn. 67.

1732 Ganz präzise betrachtet hat sich das Risiko einer Schädigung natürlich insofern erhöht, als dass der einzelne Mitarbeiter einen weiteren Menschen im Umfeld des Kunden repräsentiert, der theoretisch in einer Kurzschlussreaktion zuschlagen könnte. Es ist aber nicht entscheidend, ob sich bei gleichbleibendem Risiko einer Schädigung die absolute Wahrscheinlichkeit einer Schädigung des Schuldners erhöht. Vielmehr ist entscheidend, ob der Erfüllungsgehilfe durch erleichterten Zugriff etc. ein gegenüber anderen, potentiellen Schädigern erhöhtes Schadensrisiko für die Rechtsgüter des Schuldners repräsentiert. Das ist hier zu verneinen. 
Voraussetzung für die Eigenschaft als Erfüllungsgehilfe für die Einhaltung von Nebenpflichten ist die privatautonome Veranlassung des Schuldners, dem Dritten erhöhten Zugriff auf die Interessen des Gläubigers zu gewähren. Allein dadurch wird der Dritte in die Erfüllung einer Verbindlichkeit - der Nebenpflicht - eingeschaltet. Diese Ansicht ermöglicht es dem Schuldner das Haftungspotential aus einer ex-ante-Perspektive besser abzuschätzen. Schließlich ist das Kriterium der Gefahrerhöhung als begriffliche Kehrseite einer Erleichterung der Schädigung bereits in sich aussagekräftig und verweist nicht lediglich auf weitere, unvorhersehbare Wertungen im Einzelfall. ${ }^{1733}$ Die so generierte Haftung für das Verhalten Dritter ist zwar weit, aber im Einklang mit dem generell von $\mathrm{Ne}$ benpflichten verfolgten Ziel des Integritätsschutzes ${ }^{1734}$ sowie - wichtig für die Rechtspraxis - wegen der klaren Subsumtionskriterien ex ante erkennbar.

ff) Brauchbarkeit der Ansätze in der Subsumtion

Als engste Ansicht für die Zurechnung von Schutzpflichtverletzungen könnte man - in konsequenter Fortführung des Ansatzes von Paßmann ${ }^{1735}$ - fordern, dass der Erfüllungsgehilfe dem Gläubiger der Schutzpflicht gegenüber auch hinsichtlich der Erfüllung einer Leistungspflicht tätig werden muss. ${ }^{1736}$ Zwischen Gläubiger und Schuldner müssen nach dieser Ansicht also nicht nur Leistungspflichten bestehen, ${ }^{1737}$ sondern die Erfüllung dieser Leistungspflichten mittels des Erfüllungsgehilfen muss der Anlass für die Nebenpflichtverletzung gewesen sein.

Beispiel 50 Nach dieser Ansicht würde im Lackierfall ${ }^{1738}$ eine Anwendung von $\S 278$ S. 1 Alt. 2 BGB an der Voraussetzung des Bedienens scheitern: Zwischen dem Unternehmer und dem Arbeitnehmer bestehen zwar Leistungspflichten aus dem Arbeitsvertrag, die Tätigkeit des

1733 NK-BGB/Dauner-Lieb, 3. Aufl. 2016, § 278 Rn. 8 a.E. („,Vorzug größerer Einfachheit“).

1734 Vgl. anschaulich AK-BGB/Dubischar, 1980, § 278 Rn. 8 („der Kunde [zahlt] (auch) für ordentliches Personal, das er vertrauensvoll ins Haus lassen kann“).

1735 S.o., S. 469f.

1736 Ähnlich, ablehnend Kamanabrou, NJW 2001, 1187, 1188.

1737 Die Ansicht würde daher an ihre Grenzen stoßen, wenn ein Schuldverhältnis lediglich mit Nebenpflichten ausgekleidet ist (z.B. bei Haftung aus culpa in contrahendo).

1738 S.o., S. 460. 
Lackierers und seines Angestellten diente allerdings allein der Erfüllung von Leistungspflichten zwischen dem Unternehmer und dem Lackierer. Gegenüber dem Arbeitnehmer konnten der Lackierer und sein Angestellter daher nur als Erfüllungsgehilfen der $\mathrm{Ne}$ benpflicht auftreten.

Für diese Ansicht könnte sprechen, dass sie den Anwendungsbereich des $§ 278$ BGB bei Nebenpflichtverletzungen auf Situationen potentieller Leistungspflichtverletzungen beschränkt und damit praktisch vorhersehbar gestaltet. Auch der Wortlaut des $\S 278$ BGB S. 1 Alt. 2 BGB mag auf den ersten Blick eine Einschaltung in die Erfüllung tatsächlicher Verbindlichkeiten - sprich: Leistungspflichten - für die Zurechnung im Bereich von Nebenpflichtverletzungen voraussetzen. Mittlerweile hat sich allerdings mit dem Aufstieg der schuldverhältnisbedingten Nebenpflichten die Dogmatik im allgemeinen Schuldrecht vom Wortlaut des $\S 278$ S. 1 Alt. 2 BGB entfernt. Dass ein Schuldverhältnis auch lediglich Nebenpflichten zur Folge haben kann, gilt als gesichert. ${ }^{1739}$ Überhaupt Leistungspflichten für die Anwendung von $\S 278$ BGB in einem Schuldverhältnis vorauszusetzen, setzt sich also in direkten Widerspruch zur herrschenden Meinung im Bereich der Haftung aus culpa in contrahendo und sonstiger Nebenpflichtverletzung. Auch wenn das Schuldverhältnis Leistungspflichten umfasst, überzeugt es nicht, die Anwendung von $\S 278$ BGB bei Nebenpflichten von der Einschaltung des Erfüllungsgehilfen für die Erfüllung der Leistungspflichten abhängig zu machen. Das würde nämlich die Eigenständigkeit der Nebenpflichten als Pflichtkategorie im allgemeinen Schuldrecht missachten. Die Einschaltung eines Dritten muss auch nur hinsichtlich einer Nebenpflicht möglich sein. Anderenfalls könnte der Schuldner sich allein durch den Einsatz Dritter regelmäßig der Gefahr einer Nebenpflichtverletzung entziehen, was den Schutzzweck der Nebenpflichten aushöhlen würde.

Beispiel $50 \quad$ Wäre der Unternehmer im Lackierfall ${ }^{1740}$ selbst tätig geworden, so wäre eine Haftung aus Nebenpflichtverletzung ( $\$ 280$ I, 241 II BGB) gegenüber dem Arbeitnehmer nach herrschen-

1739 Ausgerechnet in diesem Bereich aber gänzlich auf die Anwendung von § 278 BGB zu verzichten, widerspricht dem vom Reichsgericht begründeten Zweck schuldverhältnisbedingter Nebenpflichten: Der Schließung deliktsrechtlicher Haftungslücken.

1740 S.o., S. 460. 
der Meinung zu bejahen gewesen ${ }^{1741}$. Diese Haftung wäre schließlich unabhängig vom Anlass der Tätigkeit des Unternehmers, ${ }^{1742}$ sondern würde allein durch die hier - wie oben bejahte Nebenpflicht begrenzt.

Die besseren Argumente sprechen damit gegen diese Ansicht. Der Erfüllungsgehilfe muss dem Gläubiger der Schutzpflicht gegenüber also nicht auch hinsichtlich der Erfüllung einer Leistungspflicht tätig werden, um eine Zurechnung der Nebenpflichtverletzung über $§ 278$ S. 1 Alt. 2 BGB zum Schuldner zu rechtfertigen. ${ }^{1743}$

Während das BAG einen konkreten Bezug der Tätigkeit des Erfüllungsgehilfen auf den Gläubiger der Schutzpflicht fordert - der im Lackierfall fehlt -, fragt die überwiegende Auffassung danach, ob sich das Geschehen bei Handeln des Schuldners ebenfalls als Nebenpflichtverletzung darstellen würde. ${ }^{1744}$

Beispiel $50 \quad$ Letzteres wäre im Lackierfall ${ }^{1745}$ wohl zu bejahen: Deliktische Verhaltensgebot werden innerhalb eines Schuldverhältnisses nach überwiegender Ansicht zu „Vertragspflichten“. ${ }^{1746}$ Die fahrlässige Beschädigung fremden Eigentums zieht eine Haftung nach \$ 823 I BGB nach sich. Folglich hätte der Unternehmer nach herrschender Ansicht eine schuldverhältnisbedingte Nebenpflicht verletzt, wenn er das Auto des Arbeitnehmers selbst beschädigt hätte.

1741 Wegen der hier vertretenen teleologischen Subsidiarität des § 241 II BGB würde ein Anspruch aus $\S \S 280 \mathrm{I}, 241 \mathrm{II}$ BGB indes verdrängt werden, da der Unternehmer bereits aus $\S 823 \mathrm{I}$ BGB gehaftet hätte, s.o., S. 305.

1742 Auch der Unternehmer hätte schließlich mit der Lackiertätigkeit auf seinem Firmengrund keine Leistungspflicht gegenüber seinem Arbeitnehmer zu erfüllen versucht.

1743 So auch Esser/Schmidt, Schuldrecht AT, Teilbd. 2, 8. Aufl. 2000, S. 104.

1744 Vgl. RG, Urt. v. 29.5.1906 - III 465/05, RGZ 63, 341, 344 („Nur in dem [...] Falle, wo das Versehen zugleich als eine Verletzung der Vertragspflicht sich darstellt, greift der $\S 278$ B.G.B. Platz."); MüKo-BGB/Grundmann, 7. Aufl. 2016, § 278 Rn. 47f.; Picker, AcP 183 (1983), 369, 488f.; E. Schmidt, AcP 170 (1970), 502, 509f.; K. Schmidt, Karlsruher Forum 1993, S. 4, 9; Bamberger-Roth/Unberath, 3. Aufl. 2012, § 278 Rn. 44; Wendelstein, AcP 215 (2015), 70, 90, 103; näher und ablehnend Staudinger/Caspers, Neubearbeitung 2014, § 278 Rn. 53f. (Angleichung der Grenze des $\S 278$ BGB an diejenige des $\S 831$ BGB); dagegen wiederum dezidiert Esser/Schmidt, Schuldrecht AT, Teilbd. 2, 8. Aufl. 2000, S. 104.

1745 S.o., S. 460.

1746 S. BGH, Urt. v. 24.1.2013 - VII ZR 98/12, Rn. 15. 
Die weite Ansicht geht hier davon aus, dass die Haftung des Schuldners bei Handlung eines Erfüllungsgehilfen nicht mit seiner Haftung bei eigenem Handeln auseinanderfallen dürfe. ${ }^{1747}$ Das ist jedoch im Rahmen von $\S 278$ S. 1 Alt. 2 BGB keine zwingende Argumentation. Schließlich schränkt auch die überwiegende Ansicht die Haftung des Schuldners ein, wenn der Erfüllungsgehilfe die Nebenpflichtverletzung nicht in Erfüllung der Verbindlichkeit sondern nur bei Gelegenheit der Erfüllung begeht. ${ }^{1748}$ Sieht man mit der überwiegenden Auffassung aber deliktische Verhaltensgebote innerhalb eines Schuldverhältnisses ohne erkennbare Einschränkung als Vertragspflichten ${ }^{1749}$, so wäre in diesen Fällen aber - vorbehaltlich des hiervon abweichenden Prinzips der teleologischen Subsidiarität des § 241 II BGB - bei eigenem Handeln des Schuldners regelmäßig eine Haftung aus Nebenpflichtverletzung anzunehmen. ${ }^{1750}$ Weil diese Fallgruppe hier aber nicht einschlägig ist, ${ }^{1751}$ fehlt es an einem entsprechenden Korrektiv. ${ }^{1752}$

Überzeugend an der Ansicht des BAG ist, dass sie eine Zurechnung über $\S 278$ BGB sachlich an das Schuldverhältnis zwischen Gläubiger und Schuldner (hier Unternehmer-Arbeitnehmer) koppeln will.

Beispiel $50 \quad$ Wären der Lackierer und sein Angestellter im Lackierfall ${ }^{1753}$ auch mit der Wahrnehmung von Leistungspflichten im Schuldverhältnis Unternehmer-Arbeitnehmer beauftragt gewesen, so hätte schließlich auch die herrschende Meinung die Anwen-

1747 Vgl. krit. Staudinger/Caspers, Neubearbeitung 2014, § 278 Rn. 53f.

1748 S.o., S. 85 (Fn. 331).

1749 So beispielsweise BGH, Urt. v. 24.1.2013 - VII ZR 98/12, Rn. 15.

1750 Dies gilt zumindest dann, wenn man die gängige Praxis fortführt, die deliktischen Verkehrssicherungspflichten großzügig in das Schuldverhältnisrecht zu ,importieren“, krit. im Kontext von $§ 278$ BGB auch MüKo-BGB/Grundmann, 7. Aufl. 2016, § 278 Rn. 48 („Greift nicht nur die allgemeine Pflicht ein, die Integrität fremder Rechtsgüter zu wahren, sondern besteht für das fragliche Gut noch eine weitere [!] Vertragspflicht, so wird ein Gehilfenverstoß nach $\S 278$ zugerechnet (,, vertragsspezifische Schutzpflicht"). Zur Frage, ob die Reichweite der Nebenpflichten bei fehlender Haftungslücke im Deliktsrecht restriktiv auszulegen ist und zu weiteren Begrenzungsmöglichkeiten im Rahmen von § 241 II BGB s.o., S. 194ff, 230ff., 258ff., $275 \mathrm{ff}$.

1751 S.o., S. 468.

1752 Insofern strenggenommen unzutreffend die Zuordnung von Staudinger/Caspers, Neubearbeitung 2014, § 278 Rn. 52 a.E. des hier besprochenen Urteils zur ständigen Rechtsprechung der obersten Zivilgerichte, welche die Grenze des $\S 278$ bei einer Handlung ,bei Gelegenheit“ der Erfüllung der übertragenen Verbindlichkeit sieht.

1753 S.o., S. 460. 
dung des $\$ 278$ BGB bei Nebenpflichtverletzungen über die Abgrenzung „Handeln bei Gelegenheit oder in Erfüllung der Verbindlichkeit" beschränkt.

Es erscheint unbillig, auf jede Beschränkung im Hinblick auf Nebenpflichtverletzungen zu verzichten, nur weil von vorne herein jeder Bezug zu einer Leistungspflicht im entscheidenden Schuldverhältnis (hier Unternehmer-Arbeitnehmer) fehlt. Gerade dadurch wird offenbar, dass die sachliche Begrenzung des Anwendungsbereiches von $\S 278$ BGB bei Nebenpflichtverletzungen nicht über die Feststellung einer (fehlenden) sachlichen Nähe der Verletzungshandlung zu den Leistungspflichten erreicht werden kann. Richtigerweise ist für eine solche Begrenzung - wie, wie oben im Malerfall gezeigt ${ }^{1754}$, bei jeder problematischen Subsumtion im Rahmen des $§ 278$ BGB - ein Rückgriff auf den Schutzzweck der Nebenpflichtverletzung erforderlich. ${ }^{1755}$

Allein entscheidend sind deshalb nicht der Bezug der Nebenpflichtverletzung zu den (womöglich inexistenten) Leistungspflichten, sondern der Schutzzweck sowie die Reichweite der jeweiligen Nebenpflicht.

Beispiel 50 Im Lackierfall ${ }^{1756}$ ist die Reichweite des Schutzzwecks der Nebenpflicht unter Rekurs auf das jeweilige Schuldverhältnis zu ermitteln, vgl. § 241 II BGB (,, nach seinem Inhalt“). Hier besteht - unter dem Vorbehalt der Zumutbarkeit - eine Fürsorgepflicht des Arbeitgebers für das in den betrieblichen Ablauf eingebrachte Ei-

1754 S.o., Beispiel 48, S. 439.

1755 Ähnlich auch Tröger, Arbeitsteilung, 2012, S. 401, 524f., der die Spezifika der jeweiligen Nebenpflicht für das Subsumtionsergebnis bei Beteiligung von Erfüllungsgehilfen maßgeblich hält. Er will allerdings alle problematischen Fragen innerhalb der Reichweite der Pflicht - also der Pflichtverletzung dem Grunde nach - thematisieren und die Subsumtion der eigentlichen Voraussetzungen von $\S 278$ BGB anschließend Makulatur werden lassen. Weil die Voraussetzungen des $\S 278$ BGB für Nebenpflichten nicht wirklich passen, ist dieses Vorgehen verständlich und in jedem Fall dem willkürlichen Ergründen einer Nebenpflicht-spezifischen Dogmatik des $\S 278$ BGB vorzuziehen. Methodisch sauberer erscheint es allerdings den Wortlaut des $\S 278$ S. 1 Alt. 2 BGB bei der Subsumtion zur Verhaltenszurechnung bei Erfüllungsgehilfen auch bei Nebenpflichtverletzungen ernst zu nehmen. Dort, wo er nicht passt, ist die Norm systematisch sowie teleologisch unter Berücksichtigung des Schutzzwecks der jeweiligen Nebenpflicht auszulegen.

1756 S.o., S. 460. 
gentum seiner Arbeitnehmer. ${ }^{1757}$ Rechtspraktischer Zweck jeder Nebenpflicht ist es, Haftungslücken im Deliktsrecht zu schließen. ${ }^{1758}$ Der Arbeitnehmer kann hier vom Unternehmer - anders als vom Lackierer selbst - keinen Schadensersatz aus Delikt verlangen. Damit wäre eine Haftung aus $\$ \S 280$ I, 241 II BGB Voraussetzung, um dem Arbeitnehmer Ersatz gegenüber seinem Schuldverhältnis-Partner zu ermöglichen. Die Begrifflichkeit „,Lücke" impliziert aber, dass es notwendig - oder zumindest normativ geraten - ist sie zu schließen. Die Pflicht müsste also auch konkret von einem aus dem Schuldverhältnis abzuleitenden Zweck getragen werden. Die Fürsorgepflicht hat ihren konkreten Sinn darin, die Zusammenarbeit von Arbeitgeber und Arbeitnehmer zu vereinfachen und abzusichern. Der Arbeitnehmer soll sein im Alltag verwendetes Hab und Gut im betrieblichen Einflussbereich belassen können, ohne zu fürchten, dass es dort vom Arbeitgeber ohne Konsequenz beschädigt wird. Deshalb ist es auch überzeugend, wenn ihm das Verhalten von Personen, die schon von ihrem Einsatzzweck her mit den Rechtsgütern der Arbeitnehmer in Kontakt kommen sollen (z.B. Wachmänner, Parkwächter, etc.), im Rahmen von Nebenpflichtverletzungen über $\S 278$ S. 1 Alt. 2 BGB zugerechnet wird ${ }^{1759}$. Schließlich ist in diesen Fällen zumindest die Gefahr einer Schädigung des Arbeitnehmers für den Arbeitgeber erkennbar und er kann sie entsprechend regulieren. Hier war ein Kontakt zwischen dem Lackierer und seinem Angestellten und den Rechtsgütern des Arbeitnehmers indes in keiner Weise absehbar, sondern das Produkt eines unglücklichen - wenngleich auch durch den Lackierer und seinen Angestellten verschuldeten - Zufalls. Der Lackdunst hätte ebenso gut vom Nachbargrundstück kommen können. Den Arbeitgeber auch für solche Beschädigungen einstehen zu lassen, bedeutet, ihm das Verhalten jeder Person zuzurechnen, mit der ihn ein Schuldverhältnis verbindet. Letzter-

1757 BAG, Urt. v. 25.5.2000 - 8 AZR 518/99, Rn. 14.

1758 S.o., S. $271 \mathrm{ff}$.

1759 Vgl. BAG, Urt. v. 25.5.2000 - 8 AZR 518/99, Rn. 19. 
abwegiger und dennoch logisch konsequenter - Schritt dieser Haftungskaskade wäre das Einstehen für Arbeitnehmereigentum bei Beschädigungen durch Schuldverhältnis-Partner des Arbeitgebers außerhalb seines betrieblichen Einflussbereichs. Das würde ihn unzumutbar belasten. Zudem wäre es auch aus wirtschaftlichen Gesichtspunkten widersinnig, denn der Arbeitgeber hätte keine Möglichkeit ein solches Schadensrisiko effektiv zu regulieren. Das unkalkulierbare Haftungsrisiko käme für ihn damit einer Strafzahlung gleich, die er letztlich als Kosten einer internen Zwangsversicherung an die Arbeitnehmer weitergeben würde (verringerter Lohn, ,Sicherheitsprämie“ als geldwerte Leistung, etc.).

Einen vom Schuldner privatautonom veranlassten Bezug zum zu schützenden Rechtsgut für die Zurechnung über $\S 278 \mathrm{BGB}$ zu verlangen, erscheint damit zumindest gegenüber dem von einigen Willkürlichkeiten geprägten Ansatz der herrschenden Meinung das vorzugswürdige Begrenzungskriterium. ${ }^{1760}$

Beispiel $50 \quad$ Im Lackierfall ${ }^{1761}$ wäre damit bei systematisch-teleologischer Auslegung des §278 S. 1 Alt. 2 BGB unter Berücksichtigung des Schutzzwecks der Nebenpflicht davon auszugehen, dass sich der Unternehmer hier nicht des Lackierers oder des Angestellten zur Erfüllung einer Verbindlichkeit bedient hat. Eine Verhaltenszurechnung über $\S 278$ S. 1 Alt. 2 BGB scheidet damit aus.

Zum gleichen Ergebnis wie das BAG käme diejenige Ansicht, welche eine Gefahrerhöhung als Kehrseite einer Erleichterung der Schädigung des Gläubigers durch die Einschaltung des Gehilfen fordert.

1760 Schließlich steht der Arbeitnehmer in diesen Fällen nicht schutzlos da. Schadensersatz kann er in jedem Fall aus Delikt von den Schädigern verlangen. Zudem ist „die privatautonome Veranlassung“ dieses „Bezugs“ im Wege einer Abwägung zu bestimmen, welche primär die Vorhersehbarkeit einer möglichen Rechtsgütergefährdung in den Blick fasst. Der Arbeitgeber kann sich einer Haftung für seine Erfüllungsgehilfen damit auch nicht konträr zur tatsächlichen Gefahrenlage auf Basis einer Willensentscheidung (,Du hast mit Nebenpflichten nichts zu tun.“) entziehen.

1761 S.o., S. 460. 
Beispiel 50 Im Lackierfall ${ }^{1762}$ standen dem Lackierer und seinem Angestellten nämlich keine Möglichkeiten offen, die Rechtsgüter des Arbeitnehmers zu schädigen, die sie nicht auch von einem Nachbargrundstück aus gehabt hätten, setzt man einen variiert ungünstigen Windverlauf voraus. Damit hat sich die Gefährdungslage des Arbeitnehmers und seiner Rechtsgüter durch die Einschaltung des Lackierer und seines Angestellten nicht erhöht.

Eine Entscheidung zwischen dem Ansatz des BAG und der Voraussetzung der Gefahrerhöhung ist deshalb im Lackierfall nicht erforderlich. Abstrakt bietet aber diejenige Ansicht, welche auf die Gefahrerhöhung abstellt, den Vorteil, dass auf den eher vagen Begriff des vom Schuldner privatautonom gesetzten Bezugs der Tätigkeit des Erfüllungsgehilfen auf den Gläubiger durch den Schuldner verzichtet werden kann. Wann genau ein privatautonom vom Schuldner veranlasster Bezug des Erfüllungsgehilfen auf den Gläubiger hin vorliegt, kann in der Subsumtion nämlich erhebliche Unsicherheit verursachen. Der Ansatz legt den Fokus nämlich - anders als der Gedanke einer Gefahrerhöhung - nicht auf den tatsächlichen Vorgang der Schädigung durch den Erfüllungsgehilfen, welcher sich regelmäßig auch im Nachhinein gut rekonstruieren lässt. Vielmehr wird auf die Handlung des Schuldners beim Einsatz des Erfüllungsgehilfen Bezug genommen, welche einer tatsächlichen Aufarbeitung vor Gericht häufig nicht rechtssicher zugänglich sein wird. Das Kriterium der Gefahrerhöhung ist demgegenüber absolut, aus sich selbst heraus verständlich und bedarf keine Wertungen, die nicht bereits im Kriterium selbst angelegt sind. Im Ergebnis ist daher dem Kriterium der Gefahrerhöhung als Kehrseite von gegenüber Drittschädigern erhöhten Einwirkungsmöglichkeiten des Erfüllungsgehilfen auf die Integritätsinteressen des Gläubigers der Vorzug zu geben.

1762 S.o., S. 460. 
gg) Zwischenergebnis: Bestimmung der Haftungsgrenze durch Gedanken der Gefahrerhöhung

Die Grenzen der Anwendung von $\S 278$ BGB im sachlichen Kontext von Nebenpflichten werden sinnvollerweise durch den - auch als Haftungsgrund hier für vorzugswürdig befundenen - Gedanken der Gefahrerhöhung bestimmt.

d) Zwischenergebnis: Konturierung des $§ 278$ BGB allein über Gedanken der Gefahrerhöhung

Anders als noch beim Vermögensschutz kann der Begriff der Erkennbarkeit der Schädigung die Anwendung des § 278 BGB nicht sinnvoll begrenzen. § 278 BGB bedingt ja gerade eine Haftung auch bei unvorhersehbaren Unfällen. Gleichzeitig muss die Reichweite des $§ 278$ BGB zumindest aus einer Risikoperspektive für den Schuldner erkennbar sein. Hier versagen die Grenzen der herrschenden Meinung. Das Begriffspaar des Handelns in Erfüllung oder bei Gelegenheit der Erfüllung der übertragenen Verbindlichkeit ist in der Subsumtion beliebig und kann keine eindeutigen Ergebnisse liefern. Vorzugswürdig ist deshalb die Ansicht, die danach fragt, ob dem Erfüllungsgehilfen die vorgeworfene Handlung durch seine Tätigkeit für den Schuldner erleichtert wurde. Ist das zu bejahen, so hat sich durch die Einschaltung ${ }^{1763}$ des Gehilfen auch die Gefahr für das von der Nebenpflicht geschützte Interesse aus einer ex-ante-Perspektive erhöht. Eine Verhaltens- und Verschuldenszurechnung über $\S 278$ S. 1 Alt. 2 BGB ist dann zu befürworten. ${ }^{1764}$

1763 Der Schuldner muss lediglich für das Tätigwerden des Erfüllungsgehilfen durch einen generellen Einsatz innerhalb seines Pflichtenkreises kausal geworden sein.

1764 Dieser Ansatz gilt unmittelbar nur für diejenigen Fälle, in denen es primär um den Haftungsvorteil des $\S 278$ BGB geht. Wenn es aber primär um den erweiterten Vermögensschutz im Schuldverhältnisrecht geht, so ist $\S 278$ nur reflexiv betroffen. Schließlich ist das Schutzgut im Jedermannsrecht schon gegenüber Handlungen des Schuldners nicht erfasst - und somit erst Recht nicht gegenüber der Handlungen von Erfüllungsgehilfen desselben. Wird die Verantwortung für das vermögenswerte Interesse über die oben thematisierten Kriterien dem Schuldner zugewiesen, so begeht dieser eine Nebenpflichtverletzung, wenn er das Interesse selbst verletzt. Verletzt einer seiner Erfüllungsgehilfen das Interesse, so ist fraglich, ob sich der oben befürwortete Normzweck des $\S 278$ BGB bei Nebenpflichtverletzungen auch hier anwenden lässt. Dies ist zu bejahen. Sobald dem Erfüllungsgehilfen die (vermögensschützende) Nebenpflichtverletzung erleichtert wurde, weil der Schuldner ihn in irgendeiner Weise in seinen eigenen Pflichtenkreis miteinbezogen hat, so ist eine Verhaltenszurechnung angemessen. Da das 
2. Bestimmung der Reichweite sinnvoller Haftung für das Verhalten Dritter nach Ansätzen der ökonomischen Analyse

a) Rekonstruktion des vollständigen Schuldverhältnisses

aa) Cheapest cost avoider

Als Haftungsgrund von $\S 278$ BGB wird bisweilen auch das Prinzip der Beherrschbarkeit genannt. ${ }^{1765}$ Hinter dem Gedanken der Gefahrenbeherrschung steht letztlich auch der Aspekt der Prävention, also der Verhinderung zukünftiger Schäden. ${ }^{1766}$ Nach der Ökonomik soll derjenige einen Schadenseintritt verhindern, dem es die geringsten Kosten verursacht (cheapest cost avoider). ${ }^{1767}$ Damit folgt die Sinnhaftigkeit der Anwendung von $\S 278$ BGB für die Ökonomik aus der überlegenen Beherrschbarkeit des Risikoherds durch den Schuldner. ${ }^{1768}$ Schädigt ein Erfüllungsgehilfe den Gläubiger, so ergibt bereits der erste Zugriff, dass der Erfüllungsgehilfe selbst den Eintritt des Schadens mit den - absolut besehen - geringsten Kosten hätte verhindern können. Versucht man den cheapest cost avoider ausschließlich im Verhältnis von Gläubiger und Schuldner zu ermitteln, so muss man sich in der Subsumtion näher mit dem Begriff auseinandersetzen.

jeweilige Interesse regelmäßig im Jedermannsrecht nicht in gleicher Intensität geschützt ist, hätte es einem Fremden auch nicht in gleicher Weise zur Beeinträchtigung offen gestanden. Damit wurde dem Erfüllungsgehilfen die Verletzung im Regelfall erst mit der Einschaltung durch den Geschäftsherrn ermöglicht und so - a maiore ad minus - auch erleichtert. Das Kriterium verliert also an dieser Stelle ein gutes Stück an Kontur. Dementsprechend gewinnt die Haftungslegimitation der jeweiligen Nebenpflicht - also beispielsweise die Begründung unter Rückgriff auf ökonomischen Vertrauensschutz - bei der Begrenzung der Verantwortlichkeit auch im Hinblick auf das Handeln von Erfüllungsgehilfen an Bedeutung. Methodisch dehnt sich so der Normzweck des § 241 II BGB noch weiter als üblich auf $\S 278$ BGB aus, s.o., S. $443 \mathrm{f}$.

1765 S.o., S. 449.

1766 Zum - nicht unumstrittenen - Zusammenhang zwischen dem Prinzip der Beherrschbarkeit und der Forderung nach Schadensprävention präzise Koller, Risikozurechnung, 1979, S. 79ff. Weil auch ein Einstehen des Schuldners der Nebenpflicht für den Erfüllungsgehilfen nach $§ 278$ S. 1 Alt. 2 BGB den Schadenseintritt für die (Prozess-)Parteien nicht ungeschehen machen kann, handelt es sich um ein überindividuelles Ziel. Damit werden in der Diskussion zu § 278 BGB also durchaus auch makroökonomische Ziele als Teil der ökonomischen Analyse des Rechts verfolgt, so zu Recht schon Oechsler, Vertragsgerechtigkeit, 1997, S. 186f.

1767 S.o., S. $355 \mathrm{ff}$.

1768 Vgl. Schwarze, Leistungsstörungen, 2. Aufl. 2017, S. 8 (Fn. 36: „wenig überraschend“). 
Beispiel 48 Im Malerfall ${ }^{1769}$ lässt sich die Gefahr eines Diebstahls durch den Angestellten weder durch den Kunden noch durch den Maler besonders gut beherrschen. Versucht man eine Zuordnung zu erzwingen, so stellt man fest, dass der Maler hier die Auswahl und grundsätzliche Überwachung seiner Angestellten kontrollieren kann. Zumindest in den Grenzen der \$\$831 I 2 Alt. 1, 823 I BGB hat er seiner Überwachungspflicht genüge getan. Darüber hinaus könnte man ihm indes die Erhöhung seiner Auswahl- und Kontrollpflichten aufbürden oder ihn über eine Haftung dazu anhalten, zur gegenseitigen Kontrolle stets zwei Gehilfen zum Kunden zu schicken. Je nach Höhe des Schadenserwartungswerts kann es durchaus effizient sein, dem Maler diese Schadensvermeidunskosten aufzubürden. Grundsätzlich ist es hingegen Privileg - aber damit auch Aufgabe - des Eigentümers, Dritte von der Einwirkung auf die eigenen Sachen auszuschließen, $\S 903$ S. 1 a.E. BGB. Dies muss insbesondere in der eigenen Wohnung gelten, wo der Eigentümer die Abläufe regulieren und kontrollieren kann. Damit ließe sich auch dem Kunden die Gefahrenbeherrschung (und die Eigenschaft als cheapest cost avoider) für ein Diebstahlsrisiko zuzuordnen. Führt man sich indes vor Augen, dass die Einschaltung des Angestellten durch den Maler hier zu einer Gefahrerhöhung für die Integrität des Kunden geführt hat (freier und unbeaufsichtigter Zugang zur Wohnung sowie sich darin befindlicher Wertgegenstände), so erscheint allein die Risikozuweisung an den Maler über den Begriff des cheapest cost avoider stimmig.

Angesichts gewisser Schwierigkeiten, einen Schadensvermeider zwischen zwei Parteien zu ermitteln, von denen keine die den Schaden bedingende Handlung begangen hat, könnte man die Frage aufwerfen, ob der cheapest cost avoider aus der Vogelperspektive ermittelt wird oder nur im Zweipersonenverhältnis von Gläubiger und Schuldner der Nebenpflicht. Für ersteres mag auf den ersten Blick sprechen, dass das Kriterium des cheapest cost avoider etwas an Überzeugungskraft verliert, wenn es zu Mehrfachzuweisungen führt. Für letzteres spricht indes

1769 S.o., S. 439. 
entscheidend, dass das Schadensrisiko bei der isolierten Frage, ob eine Nebenpflichtverletzung anzunehmen oder abzulehnen ist, nur entweder dem Gläubiger oder dem Schuldner zugewiesen werden kann. Weist man die Haftung über das Kriterium des cheapest cost avoider nämlich einem Dritten zu - lehnt man also eine Haftung des Schuldners aus $\S 280$ I, 241 II BGB ab -, so trägt im Verhältnis Gläubiger-Schuldner trotzdem der Gläubiger das Schadensrisiko - er bleibt schließlich auf dem Schaden sitzen, obwohl der Schaden aus einem Schuldverhältnis mit dem entlasteten Schuldner herrührt. Logisch folgerichtig ist es daher allein, den Aspekt des cheapest cost avoider stets relativ im Verhältnis der beiden sich gegenüberstehenden Parteien zu verstehen. ${ }^{1770}$

Beispiel 49 Im Portierfall ${ }^{1771}$ hat der Portier die schädigende Handlung vorsätzlich vorgenommen. Ohne Zweifel ist er derjenige, der den Schaden mit den - absolut besehen - geringsten Kosten hätte verhindern können. Ist der Portier indes insolvent, so wird besonders deutlich, warum man die Risikozuweisung nach dem Prinzip des cheapest cost avoider nicht abstrakt vornehmen kann. Im Verhältnis zum eigentlichen Vertragspartner - dem Hotelbetreiber - stünde dem Kunden bei einem derart engen Verständnis nämlich keinerlei Ersatzanspruch zu. Mangels Werthaltigkeit des gegen den Erfüllungsgehilfen gerichteten Anspruchs würde das Schadensrisiko im Ergebnis dem Kunden zugewiesen. Das würde zu Ineffizienzen führen: Im Verhältnis zwischen Kunde und Hotelbetreiber ist nämlich der Hotelbetreiber cheapest cost avoider. Er könnte die Auswahl- und Kontrollbemühungen hinsichtlich seiner Mitarbeiter erhöhen oder ein neues System für die Sicherung der Schlüssel gegen Schwarzfahrten durch die Mitarbeiter einführen. Dem Kunden hingegen standen hier - nach Abgabe des Schlüssels - keinerlei

1770 Vgl. auch Riha, Sachmängelgewährleistungsrecht, 2007, S. 65f., der in der Kette HerstellerVerkäufer-Käufer bei der Frage der Haftung für unzutreffende Werbung durch den Hersteller die Figur des ,relativen“ cheapest cost avoider bemüht. Die Haftung des absoluten cheapest cost avoider (der Hersteller) soll dann im Ergebnis über Regressansprüche durchgesetzt werden. Da zwischen Käufer und Hersteller kein Schuldverhältnis besteht, soll der Käufer zumindest wegen der Eigenschaft des Verkäufers als „,relativer" cheapest cost avoider einen Ersatzanspruch gegen letzteren haben.

1771 S.o., S. 457. 
sinnvolle Möglichkeiten offen, eine Schwarzfahrt zu verhindern. Müsste der Kunde befürchten, sein Auto nur unter Inkaufnahme des Insolvenzrisikos des ihm nicht näher bekannten Nachtportiers abstellen zu können, so würde er entweder zur ständigen Kontrolle der ordnungsgemäßen Verwahrung seines Autos angehalten (was den wirtschaftlichen Nutzen vom Service des Hotels - temporäre Entlastung des Kunden vom Sachbewahrungsaufwand - konterkarieren würde) oder er würde von der Transaktion gänzlich Abstand nehmen (was angesichts der grundsätzlichen Transaktionsbereitschaft des Kunden zur Fehlverwendung von Ressourcen führen würde).

Der Begriff des cheapest cost avoider bringt dabei auch im Rahmen von $\S 278$ BGB zum Ausdruck, dass der Schuldner durch die potentielle Haftung zur Aufsicht über seine Erfüllungsgehilfen angehalten werden soll. ${ }^{1772}$

Bisweilen wird zwar bestritten, ob sich mit dem häufig sehr sachverhaltsspezifischen Schuldverhältnisrecht im Kontext von $\S 278$ BGB überhaupt Prävention betreiben lässt. ${ }^{1773}$ Prävention durch Anwendung des $\S 278$ BGB beruht schließ-

1772 Das gilt indes nur, wenn das Niveau dieser über die Zurechnung aus $\S 278$ BGB geforderten Aufsicht über demjenigen Niveau liegt, welches die $\S \S 823$ I, 831 BGB ohnehin beim Einsatz von Hilfspersonen verlangen. Zum einen würde nach hier vertretener Ansicht dann bereits die teleologische Subsidiarität des $\S 241$ II BGB greifen und eine Haftung aus den $\S \S 280$ I, 241 II BGB mit Blick auf den Haftungsvorteil des § 278 BGB ausscheiden. Zum anderen würde es ansonsten am gerade durch die Anwendung des $\S 278$ BGB dem Schuldner gegenüber gesetzten Impuls zur Verhaltenssteuerung fehlen.

1773 Krit. Oechsler, Vertragsgerechtigkeit, 1997, S. 187. Zumindest vertragliche Sachverhalte lassen sich nämlich nach Ansicht der Kritiker - anders als Konstellationen im Jedermannsrecht nicht ohne weiteres zu präventiven Zwecken verallgemeinern. Zudem beruht jede Form der Generalprävention durch gerichtliche Entscheidung auf einer Rechtsberatung der potentiellen Adressaten, Oechsler, Vertragsgerechtigkeit, 1997, S. 187f. Wer im Vorhinein keine Rechtskunde einholt, dem ist die Haftungsgefahr auch dann unbekannt, wenn sich eine alte Entscheidung auch auf seinen Sachverhalt übertragen lässt. Selbst bei dem rechtlich Beratenen ist die generalpräventive Wirkung laut Oechsler, Vertragsgerechtigkeit, 1997, S. 188 nicht sicher: Schließlich geht Rechtsberatung mit einer gewissen Professionalisierung der Tätigkeit einher. Ein Unternehmer kann sich aber auch stets dazu entschließen, das Haftungsrisiko ohne Anpassung seines Verhaltens in seine Tätigkeit einzupreisen, vgl. im Kontext der Gutachterhaftung Faust, AcP 210 (2010), 555, 575 („Gutachter wird - wenn er rechtlich informiert istdie ihm aufgebürdete Haftung selbstverständlich in den Preis des Gutachtens einkalkulieren") sowie im Kontext von Verkehrspflichten Soergel/Krause, 13. Aufl. 2005, § 823 Anh II Rn. 34 
lich auf dem Gedanken, dass der Geschäftsherr aus dem entschiedenen Fall eine Handlungsanweisung für zukünftige Sachverhalte ableiten kann. Häufig wird sich die Handlung des Erfüllungsgehilfen für den Schuldner der Nebenpflicht aber als Zufall darstellen. ${ }^{1774}$ Haftung über $\S 278$ BGB erfolgt aber auch, wenn der Schadenseintritt für den Schuldner unvermeidbar war, da die Verhaltenszurechnung kein Verschulden des Schuldners voraussetzt. ${ }^{1775}$ Insbesondere die im Kontext von Nebenpflichten zutage tretenden Zufälle lassen sich indes zum Teil nur mit prohibitiv hohen Kosten vermeiden.

Beispiel 52 Um den Schadenseintritt im Flugfall ${ }^{1776}$ zu verhindern, hätte die Fluglinie beispielsweise noch eine weitere Person allein mit dem Zweck beschäftigen können, den Boten kontrollieren zu lassen. Die exorbitanten Kosten hierfür hätten den Schadenserwartungswert wegen der geringen Wahrscheinlichkeit einer derart grotesken Kompetenzüberschreitung bei verständiger Würdigung überstiegen. Ein cheapest cost avoider lässt sich daher hier nicht ermitteln.

Der generalpräventive Aspekt einer Anwendung des Kriteriums des cheapest cost avoider auf $\S 278$ BGB mag daher bei Zufällen bisweilen hinter eine effiziente Form der Risikozuweisung aus ex-post-Perspektive zurücktreten. ${ }^{1777}$ Liegen die Schadensvermeidungskosten über dem Schadenserwartungswert, so muss

(,Preis für eine Aktivität des Schädigers“). Der Schadenseintritt repräsentiert dann die Kosten der Geschäftsstrategie.

1774 Eine unbedingte Verantwortlichkeit, wie sie $§ 278$ BGB zur Folge hat, trifft den Schuldner nämlich auch bei Unvermeidbarkeit des Schadenseintritts, zutreffend Tröger, Arbeitsteilung, 2012, S. 162.

1775 Vgl. BGH, Urt. v. 28.10.2010 - Xa ZR 46/10, Rn. 24 (Zurechnung von durch die Deutsche Bahn AG zu verantwortenden Verspätungen zulasten eines Reiseveranstalter, obwohl dieser ohne Zweifel keinerlei Einflussmöglichkeiten auf die Zugpünklichkeit besaß); Kirsten, Schadensersatzhaftung, 2009, S. 38f.

1776 S.o., S. 465.

1777 Vgl. Schwarze, Leistungsstörungen, 2. Aufl. 2017, S. 8. Oechsler, Vertragsgerechtigkeit, 1997, S. 189 kritisiert die großzügige Handhabung des $\S 278$ BGB bei Nebenpflichten zumindest unter diesem Aspekt als ,Ausübung [...] ausweglosen Zwangs“. 
ohnehin subsidiär auf den Begriff des cheapest cost insurer ${ }^{1778}$ zurückgegriffen werden. ${ }^{1779}$

Auch wenn dem Schuldner ein im Einzelfall überraschendes Risiko zugewiesen wird und der Anwendung des $\S 278$ BGB ihm gegenüber grundsätzlich kein persönlicher Verhaltensvorwurf innewohnt ${ }^{1780}$, so bedeutet dies freilich nicht, dass hiermit keinerlei ökonomisch sinnvolle Verhaltenssteuerung verbunden ist. Der Schuldner wird nämlich dazu angehalten, seine Kontrollbemühungen hinsichtlich des Verhaltens seiner Erfüllungsgehilfen bis zu dem Punkt zu erhöhen, ab welchem der Erwartungswert der Kosten einer späteren Inspruchnahme durch den Gläubiger erreicht ist. Da der Schuldner die aus der Einschaltung seiner Erfüllungsgehilfen resultierenden Risiken für die Integrität des Gläubigers häufig besser als der Gläubiger - und auch besser als die Gerichte - überblicken kann, führt diese Form der Risikozuweisung über die Anwendung des $\S 278$ BGB auch zur effizienten Verwendung von Ressourcen.

Beispiel 54 Ein selbstständiger Handelsvertreter, der für eine Bank regelmäßig Finanzgeschäfte auf Provisionsbasis schließt, nutzt den guten Kontakt zu einem langjährigen Kunden, um ihm ein angeblich besonders gutes Angebot zu machen (,,Handelsvertreterfall“). ${ }^{1781} \mathrm{Er}$ verspricht ihm erstmalig die Gewährung eines Mitarbeiterrabatts bei der Anlage. Wegen der Inansprunahme des Mitarbeiterrabatts müsse der Kunde den Anlagebetrag auf sein Konto und nicht - wie sonst - direkt auf das Konto der Bank überweisen. Nach einer auf dem Briefpapier der Bank gefertigten Bestätigung - in Wahrheit hatte der Vertreter diese unter fremdem Namen abgesandt - über die Möglichkeit zur Geldanlage mit einer gesicherten Verzinsung von $4 \%$ tut der Kunde wie ihm geheißen. Der Handelsvertreter veruntreut das Geld wie von Anfang an geplant. Der Kunde will nun gegen die Bank aus $\S \S 280$ I, 241 II, 278 BGB wegen einer

1778 S.u., S. 492f.

1779 Beide Kriterien vermischend Michael Lehmann, Bürgerliches Recht, 1983, S. 93f. (Geschäfsherr kann ,als „cheapest cost avoider“ [...] diese Risiken kostengünstiger als die potentiell Geschädigten versichern und die Versicherungskosten auf die jeweiligen Abnehmer abwälzen").

1780 Vgl. Kirsten, Schadensersatzhaftung, 2009, S. 38f.

1781 Fall nach OLG Köln, Urt. v. 4.11.2016 - 19 U 2/16. 
der Bank zuzurechnenden Verletzung seiner Integrität durch die Straftaten ( $\$ \S 263,266 \mathrm{StGB})$ des Vertreters vorgehen.

Zwar gab es hier mit der vom Regelfall abweichenden Überweisungsregelung und dem ungewöhnlich guten Zinssatz gekoppelt mit der Erstreckung eines Mitarbeiterrabatts auf einen Kunden gewisse Verdachtsmomente für ein regelwidriges Vorgehen des Vertreters. Das Gericht bejahte aber dennoch einen inneren $\mathrm{Zu}$ sammenhang zwischen der vorgenommenen Handlung Handelsvertreters und demjenigen Aufgabenbereich, welcher ihm als Erfüllungsgehilfe von der Bank übertragen worden war - und damit eine Haftung des Bank für den vom Handelsvertreter verursachten Schaden. ${ }^{1782}$

Das deckt sich auch mit dem Begriff des cheapest cost avoider: Im Grundsatz stehen hier nämlich allein der Bank ökonomisch sinnvolle Schadensvermeidungsmöglichkeiten offen. So kann sie zumindest die Kontrolle der von ihren Handelsvertretern vorgenommenen Geschäfte durch ein neues oder verbessertes Aufsichtssystem erhöhen, sie kann dem Kunden Informationsmaterial zukommen lassen, aus welchem sich ergibt, wann ein angebotenes Geschäft nicht mit der Bank abgestimmt sein kann, oder sie kann die Auswahl der von ihr betrauten Vertreter mit zusätzlicher Sorgfalt vornehmen. Der Gläubiger hingegen könnte nur das einzelne Geschäft mit dem Handelsvertreter einer besonderen Kontrolle unterziehen, um die Kompetenzüberschreitung vor einer Schädigung zu entdecken. Weil ihm aber die internen Geschäftsabläufe unbekannt sind, müsste er sehr hohe Schadensvermeidungskosten aufwenden, um ein derart verheimlichtes Eigengeschäft des Erfüllungsgehilfen erkennen zu können. Das würde die Transaktionskosten im Verhältnis zur Bank über Gebühr erhöhen. Das entspricht letztlich auch nicht dem Interesse der Bank, da hierdurch die Zahlungsbereitschaft des Kunden gehemmt werden würde. Muss der Kunde befürchten, von den in seinen Augen als Angestellte der Bank auf- 
tretenden Vermittlern ohne Haftung der Bank betrogen zu werden, so werden einige ökonomisch sinnvolle Geschäftsabschlüsse gänzlich unterbleiben.

Würde dem Gläubiger hingegen die Aufdeckung von integritätsbezogenem Fehlverhalten eines Erfüllungsgehilfen des Schuldners keine hohen Kosten verursachen, so ist es effizient, die Anwendung von § 278 BGB über das Kriterium des cheapest cost avoider abzulehnen.

Beispiel 54 Muss sich dem Gläubiger aufdrängen, dass der Erfüllungsgehilfe auf eigene Faust handelt, so verliert der Schuldner seine Eigenschaft als cheapest cost avoider. Es wäre dann gesamtgesellschaftlich günstiger, wenn der Schuldner eine Sorgfalt walten lassen würde, mit der er die deutlichen Zeichen eines drohenden Betrugs richtig deuten würde. Im Vergleich zum obigen Fall sinken dann die Schadensvermeidungskosten des Kunden unter diejenigen der Bank. Eine Zurechnung über $\$ 278$ BGB ist dann zu verneinen. In Übereinstimmung hiermit lehnte ein Gericht die Anwendung von $\S 278$ BGB in einem weiteren Handelsvertreterfall ${ }^{1783}$ mangels inneren Zusammenhangs zwischen der konkreten Handlung des Erfüllungsgehilfen und der ihm grundsätzlich übertragenen Aufgaben $a b$, in dem der Vertreter für eine angeblich besonders sichere Anlage völlig unglaubwürdige $12 \%$ Zinsen versprach und überdies dem Kunden erstmalig eine Festgeldanlage vermitteln wollte, was bislang gar nicht zum Geschäftsfeld der Bank gehört hatte. ${ }^{1784}$ Die Verdachtsmomente waren hier derart handgreiflich, dass dem Kunden zuzumuten war, für dieses Schädigung allein den Erfüllungsgehilfen in Anspruch nehmen zu können.

Das Kriterium des cheapest cost avoider kann deshalb bei der Bestimmung der Reichweite sinnvoller Zurechnung über $\S 278$ BGB die auch hier gesetzten Anreize zur Verhaltenssteuerung offenlegen und sicherstellen, dass diese eine effi-

1783 S.o., S. 489.

1784 OLG Köln, Urt. v. 12.5.2017 - 19 U 84/16, Rn. 31 ff. 
ziente Verwendung von Ressourcen befördern und insbesondere Schadensvermeidungsaufwand (nur) in ökonomisch sinnvoller Weise betrieben wird.

\section{bb) Cheapest cost insurer}

Die über $\S 278$ BGB vermittelte Haftung führt zu einer unbedingten Verantwortlichkeit des Geschäftsherrn. Die Vermeidbarkeit des Schadenseintritts durch den Geschäftsherrn ist dabei keine Voraussetzung für die Haftung. ${ }^{1785}$ Aus diesem Grund kann bisweilen kein (effizienter) cheapest cost avoider ermittelt werden. Subsidiär anzuwendendes Kriterium für die Haftungszuweisung ist dann die überlegene Fähigkeit des Schuldners zur Risikotragung ${ }^{1786}$ durch externe oder interne Versicherung, mithin der Begriff des cheapest cost insurer. ${ }^{1787}$ Das Kriterium des cheapest cost insurer kommt dabei vor allem in Konstellationen zur Anwendung, in denen niemand cheapest cost avoider ist, weil das Schadensrisiko unausweichlich war.

Beispiel 55 Im Flugfall war der Schaden aus ökonomischer Sicht unvermeidbar, da das Risiko einer derartigen Kompetenzüberschreitung so klein war, dass der Schadenserwartungswert - trotz der großen Höhe des Schadens - unter den extrem hohen Schadensvermeidungskosten lag. Damit kommt das Kriterium des cheapest cost insurer zur Anwendung. Selbst wenn sich das Risiko einer solchen vorsätzlichen Pflichtverletzung nicht fremdversichern ließe ${ }^{1788}$, stand der Fluglinie die Möglichkeit der Eigenversicherung offen. Da diese alle Risiken aus dem Fehlverhalten von ihr eingeschalteter (Hilfs-)Piloten bündeln kann, profitiert die Fluglinie so durch das Gesetz der großen Zahl ${ }^{1789}$ - anders als die eine einzige

1785 Kirsten, Schadensersatzhaftung, 2009, S. 38f.

1786 So Tröger, Arbeitsteilung, 2012, S. 162.

1787 Insbesondere bei einer Haftung auch für Zufälle gewinnt die Versicherbarkeit des Risikos als Mechanismus ausgleichender Gerechtigkeit an Bedeutung, Rödl, Gerechtigkeit, 2015, S. 174.

1788 Wegen $\S 81$ VVG und der Repräsentantentheorie ist die Möglichkeit des Geschäftsherrn entscheidend eingeschränkt, sich für das Fehlverhalten eines seine Interessen unabhängig repräsentierenden Erfüllungsgehilfen überhaupt zu versichern, näher zu den ein Repräsentantenverhältnis begründenden Umständen MüKo-VVG/Looschelders, 2. Aufl. 2016, § 81 Rn. 120ff.

1789 Näher zu dem aus der mathematischen Analyse des Glückspiels entlehnten Begriff Sinn, Ungewißheit, 1980, S. 218; Wandt, Versicherungsrecht, 6. Aufl. 2017, Rn. $23 \mathrm{f}$. 
Fahrt wahrnehmenden Passagiere - von einem komparativen Kostenvorteil bei der Risikoversicherung.

Die Möglichkeit des Schuldners, sich für eine Nebenpflichtverletzung durch seine Erfüllungsgehilfen zu versichern, ist dabei auch nicht vom Verschuldensgrad des Erfüllungsgehilfen abhängig. ${ }^{1790}$ Das Verhalten von bloßen Erfüllungsgehilfen wird nämlich im Rahmen von § 81 VVG nicht zugerechnet, und zwar insbesondere mit dem Argument, dass sich der Versicherungsnehmer schließlich auch für deren Verhalten absichern will. ${ }^{1791}$

Im anglo-amerikanischen Recht gibt es die Doktrin des respondeat superior, nach welcher ein Arbeitgeber grundsätzlich für jedes Verhalten seiner Angestellten haften soll. ${ }^{1792}$ In der ökonomischen Analyse wird dies überzeugend auf die Tatsache gestützt, dass der Arbeitgeber das vom einzelnen Arbeitnehmer repräsentierte Risiko am kostengünstigsten versichern kann. ${ }^{1793}$ Der Arbeitgeber ist demnach regelmäßig cheapest cost insurer für einen Schaden, den ein Arbeitnehmer anrichtet. ${ }^{1794}$ Aus Sicht der Ökonomik genügt es dabei, wenn der Schaden Ausfluss der Tätigkeit des Arbeitnehmers war (,arising out of and in the

$1790 \S 81$ I VVG befreit den Versicherungsgeber von der Leistungspflicht, wenn der Versicherungsnehmer den Versicherungsfall vorsätzlich herbeiführt. § 81 II VVG ermöglicht dem Versicherungsgeber seine Leistung bei grober Fahrlässigkeit des Versicherungsnehmers zu kürzen. Demnach muss sich der Versicherungsnehmer das Verhalten seiner gesetzlichen Vertreter und Organe sowie seiner Repräsentanten im Hinblick auf die Risikoverwaltung im Rahmen von $\S 81$ VVG zurechnen lassen. Im Bereich der sog. „Repräsentantenhaftung“ ist vieles umstritten, näher zu alldem MüKo-VVG/Looschelders, 2. Aufl. 2016, § 81 Rn. 106, 118ff. Zugrundeliegende Wertung ist, dass sich der Versicherungsnehmer nicht aller Kontrolle über den Versicherungsgegenstand in Richtung des Repräsentanten entledigen darf, ohne sich gleichzeitig dessen Verhalten zurechnen lassen zu müssen, BGH, Urt. v. 26.4.1989 - IVa ZR 242/87, Rn. 14 (BGHZ 107, 229, 232f.).

1791 Näher Staudinger/Caspers, Neubearbeitung 2014, § 278 Rn. 47; MüKo-VVG/Looschelders, 2. Aufl. 2016, § 81 Rn. 116 m.w.N.

1792 Näher Calabresi, Yale L. J. 70 (1961), 499, 543ff.; Wendelstein, AcP 215 (2015), 70, 85 (Fn. 59).

1793 Calabresi, Yale L. J. 70 (1961), 499, 543f.; Michael Lehmann, Bürgerliches Recht, 1983, S. 94; Matusche-Beckmann, Organisationsverschulden, 2001, S. 315 („Argument der deep pocket des Arbeitgebers, der ausgezahlte Schadenssummen durch eine entsprechende Kostenpolitik besser auffangen und verteilen kann").

1794 Calabresi, Yale L. J. 70 (1961), 499, 543 nennt zudem das erhöhte Risikobewusstsein des Arbeitgebers als eine Vorbedingung für seine Eigenschaft als cheapest cost insurer. Das wiederum verweist auf das schon häufig als zentral betonte Kriterium der Erkennbarkeit des Haftungsrisikos. 
course of employment $\left.{ }^{*}\right)^{1795}$, ein besonderer Bezug gerade zur aufgetragenen Aufgabe ist nicht erforderlich. Auch vorsätzliches Handeln des Arbeitnehmers beeinträchtigt nicht die Eigenschaft des Arbeitgebers als cheapest cost insurer. ${ }^{1796}$ Der letztlich nur ein Kausalitätserfordernis aufstellende Gedanke ähnelt demjenigen Ansatz ${ }^{1797}$, der für die Anwendung von $\S 278$ BGB lediglich eine Gefahrerhöhung fordert.

\begin{abstract}
So erachtete beispielsweise ein US-Gericht die Haftung des Arbeitgebers für eine vom Angestellten bei der Lieferung einer Matratze begangene Vergewaltigung unter anderem deshalb für möglich, weil seine Uniform ihm erleichterten Zugang zur Wohnung des Opfers verschafft hatte. ${ }^{1798}$ Grund für die Zurechnung des Verhaltens des Erfüllungsgehilfen war, dass die begangene Tat durch die vom Geschäftsherrn gewährten Einwirkungsmöglichkeiten auf
\end{abstract}

1795 Nach Sykes, Harv. L. Rev. 101 (1988), 563, 571ff. („enterprise causation“) ist eine Haftung des Arbeitgebers zu bejahen, wenn die Auflösung des Unternehmens und darauffolgende Arbeitslosigkeit des Angestellten den Eintritt des jeweiligen Schadens in dieser Weise unmöglich machen würde. Liegt die Schadenseintrittswahrscheinlichkeit trotz der Auflösung des Unternehmens zwischen 1 und 99 Prozent, so ist der Schaden zumindest in Teilen auf die Tätigkeit als Angestellter zurückzuführen und eine Haftung des Arbeitgebers zu bejahen, Sykes, Harv. L. Rev. 101 (1988), 563, 572 (,An enterprise „partially causes" the wrong of an employee if the dissolution of the enterprise and subsequent unemployment of the employee would reduce the probability of the wrong but not eliminate it."). Nur wenn der Schaden ebensogut auch ohne das Beschäftigungsverhältnis hätte eintreten können - die Schadenseintrittswahrscheinlichkeit also unverändert bei 100 Prozent gelegen hätte -, wäre eine Haftung des Geschäftsherrn gänzlich abzulehnen. Für die Anwendung des Ansatzes auch auf Erfüllungsgehilfen, die nicht Arbeitnehmer sind, muss lediglich die zweite Voraussetzung (Arbeitslosigkeit) in Auftragslosigkeit umgedeutet werden - der Erfüllungsgehilfe also nunmehr unabhängig tätig sein. Bleibt die Schadenseintrittswahrscheinlichkeit hiervon unverändert, so ist die Zurechnung abzulehnen, vgl. auch generell im Kontext von Unternehmenshaftung Calabresi, Yale L. J. 70 (1961), 499, 533 (,,,tort“ costs should be borne by the activity which causes them").

1796 Näher Calabresi, Yale L. J. 70 (1961), 499, 544ff. (,all injuries caused by workmen which arise out of and in the course of their employment should result in the master's liability whether or not the injury resulted from some activity which benefited the employer or was authorized by him, and whether it occurred through the servant's willfulness or through his negligence“). Ähnlich auch das englische Deliktsrecht mit der Doktrin der „,vicarious liability“, näher Wagner, Grundstrukturen, 2003, S. 189, $291 \mathrm{f}$.

1797 S..o., S. $463 \mathrm{ff}$.

1798 Lyon v. Carey (D.C. Cir. 1976), 533 F. 2d 649, 651f.; vgl. auch die Behandlung eines ähnlich verstörenden Falls aus der südkoreanischen Rechtsprechung bei Seok Kim, ZEuP 2013, 263, 281. 
die Integrität des Gläubigers erleichtert worden war. ${ }^{1799}$ Das spiegelt den oben vertretenen Ansatz der Gefahrerhöhung als Zurechnungsprinzip wider. ${ }^{1800}$

Damit weist der Begriff des cheapest cost insurer die Verantwortlichkeit für in die Erfüllung eigener Verbindlichkeiten eingespannte Dritte regelmäßig dem Schuldner zu. ${ }^{1801}$ Wichtig ist in diesem Zusammenhang demnach die marktsensitive - und durchaus wertungsoffene - Frage, ob sich das Risiko der Tätigkeit des Erfüllungsgehilfen sinnvollerweise in den Aktivitäts- oder Produktionskosten des Schuldners niederschlagen sollte. ${ }^{1802}$ Dabei geht es letztlich um die Frage, ob der durch den Erfüllungsgehilfen verursachte Schaden eine negative Externalität der Tätigkeit des Geschäftsherrn darstellt, welche es durch eine Zurechnung vom Geschäftsherrn zu internalisieren gilt. ${ }^{1803}$

Beispiel 56 Ein Bauunternehmer mietet - wie ähnlich bereits häufig erfolgtvon einem Gewerbeproduzenten einen Gabelstapler, um diesen an einen Einzelkaufmann unterzuvermieten (,, Gabelstaplerfall“). ${ }^{1804}$ Die Vermietung erfolgt inklusive einer Versicherung durch den Vermieter, welche jedoch - wie üblich - nur den Diebstahl oder die Unterschlagung des Vermietungsgegenstandes durch den Mieter, nicht aber durch dessen Untermieter erfasst. Nach der Lieferung - welche direkt an den Einzelkaufmann erfolgt ist - unterschlägt der Untermieter den Gabelstapler, verkauft ihn auf dem Schwarzmarkt und setzt sich mit dem Erlös ins Ausland ab. Der Vermieter verlangt in der Folge Schadensersatz. Das Gericht sprach den Schadensersatzanspruch zu und rechnete hierbei das Verschulden des Untermieters dem Mieter nach § 278 BGB zu.

1799 Sykes, Harv. L. Rev. 101 (1988), 563, 571, 589 (,probability of a rape was considerably enhanced by the deliveryman's employment status").

1800 AK-BGB/Dubischar, 1980, § 278 Rn. 8 (,der Kunde [zahlt] (auch) für ordentliches Personal, das er vertrauensvoll ins Haus lassen kann").

1801 Auch ein Verhaltens des independent contractor wird über die respondeat superior-Doktrin zunehmend dem Geschäftsherrn zugewiesen, sofern der Geschäftsherr zumindest genauso gut wie der Erfüllungsgehilfe dazu in der Lage ist, das Schadensrisiko in eine (geschäftliche) Tätigkeit einzupreisen, näher Calabresi, Yale L. J. 70 (1961), 499, 545f.

1802 Präzise Wagner, Grundstrukturen, 2003, S. 189, 300.

1803 Vgl. Taupitz, AcP 196 (1996), 114, 147.

1804 Fall nach OLG Düsseldorf, Beschl. v. 31.10.2016 - 24 U 74/16. 
Weil der Einzelkaufmann geschäftlich unauffällig war und vollkommen unabhängig vom Mieter agierte, schied eine Risikozuweisung über den Begriff des cheapest cost avoider hier mangels sinnvoller Schadensvermeidungsmöglichkeiten aus. Der Schaden durch den unvorhersehbaren deliktischen Akt eines unabhängigen Dritten war für beide Parteien ökonomisch unvermeidbar. Die Haftung des Mieters steht aber im Einklang mit dem hier subsidiär anwendbaren Prinzip des cheapest cost insurer: So schied eine Fremdversicherung hier für den Vermieter gänzlich aus, da sich für den Vermieter nach üblicher Marktpraxis der Maschinen- und Kaskoversicherung nur das Risiko einer Unterschlagung durch den unmittelbaren Mieter - nicht aber durch dessen Untermieter fremdversichern ließ. ${ }^{1805}$ Für den Mieter - der als gewerblicher Untervermieter Erfahrung in diesem Bereich besaß - kam eine Fremdversicherung für strafbares Fehlverhalten seiner Untermieter zwar theoretisch in Betracht. Aus dem Fehlen einer solchen Fremdversicherung trotz der als bekannt unterstellten Versicherungslücke aufseiten des Vermieters schloss das Gericht aber letztlich auf Basis des Modells des homo oeconomicus zutreffend darauf, dass der Schadenserwartungswert für den Mieter hier unter den Fremdversicherungskosten lag. ${ }^{1806}$ Das Risiko war also durch Eigenversicherung aufzufangen. Gerade weil die Geschäftstätigkeit des Mieters auf eine Untervermietung gerichtet war, erschien es dem Gericht angemessen, ihm die Haftung unter Entlastung des Vermieters aufzubürden. ${ }^{1807}$ Dahinter steckt der zutreffende ökonomische Gedanke, dass der Mieter hier das Risiko des sich für

1805 Vgl. OLG Düsseldorf, Beschl. v. 31.10.2016 - 24 U 74/16, Rn. 3, 19.

1806 OLG Düsseldorf, Beschl. v. 31.10.2016 - 24 U 74/16, Rn. 31 (,zu unterstellen, dass [der Mieter] [...] bereits eine Versicherung zum Schutz vor Unterschlagung [durch den Untermieter] abgeschlossen hätte, eine solche also existieren würde, wenn [dem Mieter] [...] dies nach einer Abwägung des finanziellen Risikos (Versicherungsprämien in Relation zu den finanziellen Nachteilen aufgrund einer Haftung) sinnvoll erschienen wäre").

1807 OLG Düsseldorf, Beschl. v. 31.10.2016 - 24 U 74/16, Rn. 25 a.E. („kein überzeugender Grund ersichtlich [...], warum der Vermieter für eine Straftat des Untermieters einstehen soll, wo doch der Mieter den Untermieter als Vertragspartner ausgewählt und sich aus der Verbindung einen finanziellen Gewinn versprochen hat"). 
die beiden Parteien als negative Externalität darstellenden Schadens durch Eigenversicherung zu internalisieren hat, weil der erleichterte Zugriff des Untermieters auf den Gabelstapler Teil seines Geschäftsmodells der Untervermietung war. So lässt sich die Anwendung von $\$ 278$ BGB im Einklang mit dem Gedanken der Gefahrerhöhung als auch dem Prinzip des cheapest cost insurer rechtfertigen. ${ }^{1808}$

Weil der Schuldner das Verhalten der von ihm eingespannten Erfüllungsgehilfen regelmäßig kostengrünstiger in seine Risikoverwaltung integrieren kann als der Gläubiger, wird sich so eine ökonomisch sinnvolle Zurechnung häufig auch im Einklang mit dem oben befürworteten Kriterium der Gefahrerhöhung bejahen lassen. ${ }^{1809}$

b) Zwischenergebnis: Gemeinsamkeiten der Ökonomik mit bisheriger Dogmatik zu $§ 278$ BGB

Das Prinzip des cheapest cost avoider kann entgegen erster Annahme auch bei der Subsumtion zu $§ 278$ BGB sinnvoll Schadensrisiken verteilen. Obwohl die erfolgte Schädigung für eine Zurechnung über § 278 BGB nicht vom Geschäftsherrn vermeidbar gewesen sein muss, werden durch die Anwendung von $\S 278$ BGB dennoch regelmäßig Anreize für den Geschäftsherrn zum Risikomanagement gesetzt. Diese Anreize werden durch die ökonomische Analyse offengelegt und mittels der Maßgabe des cheapest cost avoider sichergestellt, dass nur ökonomisch sinnvoller Schadensvermeidungsaufwand betrieben wird. Der Gedanke

1808 Vgl. OLG Düsseldorf, Beschl. v. 31.10.2016 - 24 U 74/16, Rn. 25 (,unumschränkte Einwirkungsmöglichkeit [des Untermieters auf den Vermietungsgegenstand], die nicht nur den Gebrauch, sondern auch den Missbrauch ermöglicht").

1809 Auf diesen Gedanken stützt sich auch die Forderung der Ökonomik, die Regelung des $\S 831$ BGB von ihrer Wirkung her an diejenige des $§ 278$ BGB anzupassen, Schäfer/Ott, Ökonomische Analyse, 5. Aufl. 2012, S. 409. Das zunehmend enge Verständnis der Exkulpationsmöglichkeit aus $\S 831$ I 2 BGB und die Kreation der Organisationspflichten innerhalb § 823 I BGB zeigen, dass dies zum Teil bereits erfolgt ist, s.o., S. 85f. Die ökonomische Forderung die Exkulpationsmöglichkeit aus § 831 I 2, II BGB abzuschaffen, stützt sich dabei auch auf das Argument, dass der Erfüllungsgehilfe den gesamtgesellschaftlichen Schaden mangels ausreichender Mittel häufig selbst gar nicht ausgleichen kann, näher Schweizer, Spieltheorie, 2015, S. 65; Shavell, Economic Analysis, 2004, S. 234. 
des cheapest cost insurer - also die überlegene Fähigkeit des Schuldners zur Risikotragung eines gar nicht oder nur mit unzumutbar hohen Kosten vermeidbaren Schadens - führt ebenfalls bei der Konturierung von $\S 278$ BGB weiter und generiert ähnliche Ergebnisse wie der im rechtswissenschaftlichen Kontext für vorzugswürdig befundene Gedanke der Gefahrerhöhung ${ }^{1810}$. Im Ergebnis kann die Ökonomik hilfreiche Befunde liefern. Wie im Bereich des Schutzes vermögenswerter Interessen fallen auch hier wieder zentrale Gemeinsamkeiten zwischen Ökonomik und rechtswissenschaftlicher Analyse auf.

\section{Ausgleich haftungsrechtlicher Lücken durch eine Beweislastumkehr für das Verschuldenselement}

Der letzte der drei zentralen Vorteile einer schuldverhältnisbedingten Haftung ist die aus $§ 280$ I 2 BGB folgende Beweislastumkehr für das Verschulden. Ist es genau diese rechtspraktische Funktion der Nebenpflichten, welche mangels Pendant im Jedermannsrecht zur Anwendung kommen soll, so ist innerhalb der teleologischen Auslegung des $§ 241$ II BGB die Zwecksetzung und Reichweite von Beweislastumkehren in den Blick zu fassen.

1. Frage nach der Reichweite einer Beweislastumkehr im Rahmen des Verschuldens

a) Suche nach dem Haftungsgrund

Beweisrecht kann die Ausgestaltung des Haftungsrechts entscheidend verändern. ${ }^{1811}$ Grundsätzlich trägt derjenige die Beweislast für eine Voraussetzung, der aus ihrem Vorliegen einen Vorteil zieht. ${ }^{1812}$ Über die Beweiserleichterung des

1810 S.o., S. 483.

1811 Engel, Unsicherheit, 2001, S. 48 (,Konstruktion von Wirklichkeit [im Gerichtsprozess] [...] vor allem durch das Beweisrecht [...] gelenkt"); Konzen, FS Picker, 2010, S. 497, 515f.; Prütting, Karlsruher Forum 1989, S. 3, 9; Schäfer/Ott, Ökonomische Analyse, 5. Aufl. 2012, S. 219. Es kann vor allem gezielt dazu eingesetzt werden, die volkswirtschaftlichen Kosten des (privatrechtlichen) Rechtssystems gering zu halten, näher Hay/Spier, J. Leg. Stud. 26 (1997), 413, 414ff.

1812 BGH, Urt. v. 11.12.1991 - VIII ZR 31/91, Rn. 39 (BGHZ 116, 278, 288); Fuchs/Pauker/ Baumgärtner, Deliktsrecht, 9. Aufl. 2016, S. 118; HK-ZPO/Saenger, 7. Aufl. 2017, § 286 Rn. 58. In Reinform lautet die gewohnheitsrechtlich anerkannte Grundregel gesetzlicher Be- 
Anscheinsbeweises ${ }^{1813}$ hinausgehend ist die Beweislastumkehr eine Möglichkeit, dieses Dogma zu durchbrechen. Mit ihr kann vom Vorliegen einer bestimmten Voraussetzung ausgegangen werden, wenn derjenige, zu dessen Lasten sie geht, sie nicht widerlegen kann. ${ }^{1814}$ Eine Beweislastumkehr für das Verschulden wird dabei insbesondere im Bereich der Produkthaftung angenommen. ${ }^{1815}$ Weil der Geschädigte nur schwerlich Einblick in die für das Verschulden relevante Organisationssphäre des Produzenten bekommen kann, würde die Haftung ohne eine

weislastverteilung: „Der Anspruchsteller trägt die Beweislast für die rechtsbegründenden Tatbestandsmerkmale, der Anspruchsgegner für die rechtshindernden, rechtsvernichtenden und rechtshemmenden Merkmale.", näher Prütting, Karlsruher Forum 1989, S. 3,10f.; MükoZPO/Prütting, 5. Aufl. 2016, § 286 Rn. 110ff. Das in § 286 I 1 ZPO exemplifizierte Regelbeweismaß ist dabei die volle Überzeugung des Richters, dass etwas als erwiesen gilt, MükoZPO/Prütting, 5. Aufl. 2016, § 286 Rn. 40. Anders als im anglo-amerikanischen Rechtsraum (,preponderance of the evidence ${ }^{\text {") }}$ ) wird daher nicht nur die überwiegende Wahrscheinlichkeit gefordert, dass eine Tatsache wahr ist, näher zum Streit Müko-ZPO/Prütting, 5. Aufl. 2016, $\S 286$ Rn. 35ff. Mit Blick auf die omission bias von Menschen - der die irrationale Abneigung zugrunde liegt, lieber im Unterlassen (Klageabweisung) zu irren als im aktiven Tun (Klagestattgebung) - wird aber faktisch auch in Rechtsbereichen, in denen grundsätzlich eine überwiegende Wahrscheinlichkeit $(\mathrm{x}>50 \%)$ als Beweis ausreichen würde, deutlich mehr als nur die mathematisch überwiegende Wahrscheinlichkeit gefordert, instruktiv Zamir/Ritov, J. Leg. Stud. 41 (2012), 165, $192 \mathrm{f}$.

1813 Der Anscheinsbeweis verringert die Anforderungen des Vollbeweises nach $\S 286$ ZPO. Ein Verlauf gilt - bis zum Gegenbeweis - als bewiesen, wenn die Lebenserfahrung eine bestimmte Entwicklung nahelegt und der betroffene Sachverhalt nicht atypisch gelagert ist, vgl. BGH, Urt. v. 16.7.2015 - IX ZR 197/14, Rn. 25f.; Greulich, Anm. zu OLG Koblenz, Urt. v. 15.4.2014 - 3 U 633/13, StBW 2014, 512, 513; Papadelli, Beweislastverteilung, 2011, S. 111; Prütting, Karlsruher Forum 1989, S. 3, 12; Schäfer/Ott, Ökonomische Analyse, 5. Aufl. 2012, S. 220; Zugehör, WM 2010, SBeil. 1, S. 17. Im Bereich der Rechts- und Steuerberatung gesteht der BGH dem Geschädigten - anders als im Bereich der Anlageberatung nur die Beweiserleichterung des Anscheinsbeweises für den Kausalzusammenhang zwischen Pflichtverletzung und Schaden zu, BGH, Urt. v. 16.7.2015 - IX ZR 197/14, Rn. 23, 25; zustimmend D. Fischer, WM 2014, SBeil. 1, S. 17 (,,[n]ur die Grundsätze des Anscheinsbeweises gewährleisten eine angemessene Risikoverteilung"); D. Fischer, DB 2015, 1643, 1647 („Gefahren über die zu belehren sind, stammen nicht regelmäßig aus der Sphäre desjenigen, den die Hinweispflicht trifft"); Geisler, Anm. zu BGH, Urt. v. 16.7.2015 - IX ZR 197/14, jurisPR-BGHZivilR 16/2015, Anm. 2.

1814 Anschaulich Engel, Unsicherheit, 2001, S. 37 („Was vorher grau war, wird für die Zwecke der staatlichen Entscheidung dann eindeutig schwarz").

1815 Weil diese Entwicklung im Jedermannsrecht stattfand, besteht hier ohnehin kein Unterschied mehr zur Regelung des $\S 280$ I 2 BGB, vgl. Michael Lehmann, Vertragsanbahnung, 1981, S. 336f. (Fn. 162); Schäfer/Ott, Ökonomische Analyse, 5. Aufl. 2012, S. 360; Erman/Wilhelmi, 15. Aufl. 2017, § 823 Rn. 121 f. 
Beweislastumkehr faktisch leerlaufen. ${ }^{1816}$ Im Fall von $§ 280$ I 2 BGB betrifft sie das Verschulden der Pflichtverletzung. Kann der Gläubiger eine Pflichtverletzung durch den Schuldner beweisen, so kehrt sich die Beweislast für das Verschulden derselben um. Der Schuldner muss nun beweisen, dass er die Pflichtverletzung nicht verschuldet hat, anderenfalls gilt das Vertretenmüssen derselben als bewiesen. Maßgebliche Gedanken zur Bestimmung der Teleologie von Beweislastumkehren sind in der Rechtspraxis die Begriffe der Sphäre, des Verantwortungsbereichs und des Gefahrenbereichs. ${ }^{1817}$ Aus $\S 309$ Nr. 12 a) BGB lässt sich ableiten, dass auch der Gesetzgeber eine Beweislastverteilung nach Verantwortungsbereichen für die normativ überzeugende Grundregel hält. ${ }^{1818}$ Wenn die Schadensursache nur aus dem Verantwortungsbereich des in Anspruch Genommenen kommen kann, so ist eine Umkehr der Beweislast für die - objektive wie subjektive - Verantwortlichkeit angemessen. ${ }^{1819}$ Ebenso sollte die Kausalität

1816 Vgl. BGH, Urt. v. 28.3.1973 - I ZR 41/72, Rn. 24 (,praktisch oft rechtlos gestellt“). Die Beweislastumkehr greift grundsätzlich erst, wenn die Kausalität der Sphäre des Produzenten für die Rechtsgutsverletzung feststeht. Auch für die Kausalität kann es zu einer Beweislastumkehr kommen, wenn der Kläger eine unzureichende Endkontrolle nachweisen kann, sofern eine solche wegen typischer herstellungsbedingter Risiken erforderlich war, näher zu alldem Schäfer/Ott, Ökonomische Analyse, 5. Aufl. 2012, S. 222f.

1817 BGH, Urt. v. 14.6.1976 - III ZR 81/74, Rn. 29; BGH, Urt. v. 20.6.1990 - VIII ZR 182/89, Rn. 10; BGH, Urt. v. 22.10.2008 - XII ZR 148/06, Rn. 15; BGH, Urt. v. 24.1.2013 - VII ZR 98/12, Rn. 13; Soergel/Benicke/Hellwig, 13. Aufl. 2014, $\$ 280 \quad$ Rn. 249, 255; Palandt/Grüneberg, 77. Aufl. 2018, § 280 Rn. 37; Matusche-Beckmann, Organisationsverschulden, 2001, S. 131f.; Erman/Westermann, 15. Aufl. 2017, § 280 Rn. 27; zur Kritik aus dem Schriftum Sonnenberger, FS Medicus, 1999, S. 621, $623 \mathrm{ff}$.

1818 MüKo-BGB/Wurmnest, 7. Aufl. 2016, § 309 Nr. 12 Rn. 1; vgl. auch BT-Drs. 14/6040, SchRModG, Gesetzesbegründung, S. 136, nach der dem Gläubiger einer Nebenpflicht im Rahmen des Beweises der Pflichtverletzung „,unter dem Gesichtspunkt der Sphärentheorie Beweiserleichterungen zugute" kommen sollen.

1819 BGH, Urt. v. 14.11.1989 - X ZR 116/88, Rn. 25. Anschaulich AG Schwalmstadt, Urt. v. 17.3.2017 - 8 C 429/15, Rn. 17 („Grundsätzlich obliegt es der Klägerin, eine Pflichtverletzung des Beklagten darzulegen und zu beweisen. Davon ist jedoch dann abzuweichen, wenn sich der Schädigungsvorfall im Rahmen einer [...] [Situation] ereignet hat, die in den voll beherrschbaren Gefahrenbereich des [...] [Beklagten] fiel"). Dogmatisch treffend Palandt/Grüneberg, 77. Aufl. 2018, § 280 Rn. 37 (Gefahrenbereichslehre der Rechtsprechung „modifiziert die Regel, dass der Gläubiger die Pflichtverletzung des Schuldners nachweisen muss"); ähnlich auch NK-BGB/Dauner-Lieb, 3. Aufl. 2016, § 280 Rn. 40; AK-BGB/ Dubischar, 1980, § 282 Rn. 8 („Erfolg nach Art der Lückenschließung mit dem Anscheinsbeweis der Fahrlässigkeit als Indiz für Vorsorge-, Überwachungs- oder Organisationsverschulden zu nehmen"); Horst, ZAP Fach 4 (Nr. 23 v. 22.11.2012), 1461, 1464; NK-BGB/Krebs, 3. Aufl. 2016, § 241 Rn. 69; Riehm, FS Canaris, Bd. I, 2007, S. 1079, 1086; Wagner, Schuldrecht, 2003, S. 203, 221; Erman/Westermann, 15. Aufl. 2017, § 280 Rn. 27. 
zwischen Pflichtwidrigkeit und Rechtsgutsverletzung vermutet werden, wenn keine andere, fremde Ursache für die Schädigung in Betracht kommt. ${ }^{1820}$

\section{b) Verlaufen der Haftungsgrenze?}

Der Begriff der Sphäre weist - ebenso wie der des Verantwortungsbereichs und der des Gefahrenbereichs - allerdings eine gewisse inhaltliche Unschärfe auf. ${ }^{1821}$ Nach dem natürlichen Wortsinn liegt zumindest nahe, dass die vom Schuldner beherrschten Räumlichkeiten seiner Sphäre zuzurechnen sind. Aber auch das ist nicht zwingend der Fall:

Beispiel 57 Ein Gast besucht eine Sondervorstellung eines Programmkinos (,,Kinofall“). ${ }^{1822}$ Aufgrund der Fülle von Besuchern muss der Kinogast während der Vorführung in der Nähe des Notausgangs stehen. Wegen der Vielzahl von Besuchern wird die Notausgangstür des Kinos einige Male geöffnet, um zu lüften. In einer der Pausen

1820 BGH, Urt. v. 31.5.1978 - VIII ZR 263/76, Rn. 16; BGH, Urt. v. 17.12.1992 - III ZR 133/91, Rn. 24; BGH, Urt. v. 22.10.2008 - XII ZR 148/06, Rn. 16; Sonnenberger, FS Medicus, 1999, S. 621, 623; zur methodischen Vorgehensweise instruktiv OLG Hamm, Urt. v. 27.1.2014-17 U 35/13, Rn. 8 („Beweislastumkehr analog“ $§ 280$ I 2 BGB); Riehm, FS Canaris, Bd. I, 2007, S. 1079, 1086 (Gefahrenbereichslehre folgt „prozesspraktischen“ und nicht „,dogmatischen Bedürfnissen", daher bezüglich ,aller dogmatischen Kategorien anwendbar"). Ist Schutzzweck der Verhaltensanforderung eine vermögenswerte Disposition des Geschädigten zu verhindern, so wird aber zumindest im Bereich der Rechts- und Steuerberatung nur die Beweiserleichterung des Anscheinsbeweises gewährt, BGH, Beschl. v. 15.5.2014 - IX ZR 267/12, Rn. 2, 4; BGH, Urt. v. 16.7.2015 - IX ZR 197/14, Rn. 23, 25f.; dafür generell bei Informationspflichtverletzungen Faust, Verbraucher-acquis, 2011, S. 201, 216f. Im Bereich der Anlageberatung vermutet der BGH das „aufklärungsrichtige“ Verhalten im Wege einer Beweislastumkehr, BGH, Urt. v. 8.5.2012 - XI ZR 262/10, Rn. 28f. (BGHZ 193, 159, 168); BGH, Urt. v. 15.10.2013 - XI ZR 51/11, Rn. 24f.; BGH, Urt. v. 11.2.2014 - II ZR 273/12, Rn. 10; Buck-Heeb, Anm. zu BGH, Urt. v. 15.10.2013 - XI ZR 51/11, jurisPR-BKR 4/2014, Anm. 2; unentschlossen hingegen BAG, Urt. v. 14.1.2009 - 3 AZR 71/07, Rn. 49; krit. zur Uneinheitlichkeit der Rechtsprechung in dieser Frage und mit einem auf die Regeln zum rechtmäßigen Alternativverhalten aufbauenden Gegenentwurf Canaris, FS Hadding, 2004, S. 3, 12ff.; zum Problem auch Konzen, FS Picker, 2010, S. 497, 515ff.

1821 Vgl. auch Soergel/Benicke/Hellwig, 13. Aufl. 2014, § 280 Rn. 252 (,insoweit noch vieles nicht endgültig geklärt"); Matusche-Beckmann, Organisationsverschulden, 2001, S. 131f. (,schwierig, den unbestimmten Begriff des „Gefahren- und Verantwortungsbereichs“ so konkret zu fassen, daß er als maßgebliches Abgrenzungskriterium für die Verteilung der Beweislast taugt“); E. Schmidt, JuS 2003, 1007, 1010 (Zuordnung „oft genug leichter gesagt als getan“); Erman/Westermann, 15. Aufl. 2017, § 280 Rn. 27.

1822 Fall nach BGH, Urt. v. 21.12.1965 - VI ZR 161/64. 
wird der Kinogast ohnmächtig. Er fällt dabei die hinter der Notausgangstür des Saales hinabführende Treppe hinunter. Als der Kinogast gefunden wird, steht die Notausgangstür offen. Ob sie vor dem Sturz bereits offen stand oder sich durch den Sturz öffnete, kann nicht mehr geklärt werden. Der Kinogast erleidet einen Schädelbasisbruch. Für die durch die Behandlung entstandenen Kosten sowie für entstandene Schmerzen verlangt der Kinogast vom Kinobetreiber Schadensersatz.

Der BGH verneinte eine Haftung des Betreibers mangels Verkehrssicherungspflichtverletzung. Dem Kläger kam dabei keine Beweislastumkehr zugute, obwohl sich das gesamte Geschehen unstrittig in der räumlichen Sphäre der Beklagten - dem Filmvorführungssaal - abgespielt hatte. Laut BGH könne auch die Beweislastumkehr (des heutigen $\S 280$ I 2 BGB) den Kläger nicht von dem Beweis befreien, ,daß bei ihm objektiv durch ein Verhalten des in Anspruch Genommenen eine Rechtsgutverletzung verursacht worden ist ". ${ }^{1823}$ Hier war nicht erwiesen, dass eine sturzbedingte Verletzung des Klägers auch tatsächlich auf einer Verletzung der Verkehrssicherungspflicht beruhte. Weder die organisatorisch bedingte, pflichtwidrige Überfüllung des Saales noch die Öffnung der Saaltür wegen Lüftungsproblemen noch eine womöglich gefährlich steil konzipierte Treppe im Vorführungssaal konnten als Ursache rechtssicher festgestellt werden. ${ }^{1824}$ Zwar stammten alle diese Ursachen aus der Sphäre des Kinobetreibers. Als Möglichkeit verblieb aber bis zum Schluss, dass keine der Pflichtwidrigkeiten vorlag oder dass zumindest keine der Pflichtwidrigkeiten zum Schadeinseintritt führte. ${ }^{1825}$

Ex ante vorhersehbare Subsumtionsergebnisse lassen sich mit dem Begriff der Sphäre daher nur begrenzt erzielen. Weil die Rechtsprechung sich aber zumin-

1823 BGH, Urt. v. 21.12.1965 - VI ZR 161/64, Rn. 29.

1824 Näher BGH, Urt. v. 21.12.1965 - VI ZR 161/64, Rn. $11 \mathrm{ff}$.

1825 Sachlich vergleichbar auch der Fall des AG Bad Segeberg, Urt. v. 14.2.2013 - 17 C 219/12, Rn. 41ff. (Fehlende Beweisbarkeit der Nebenpflichtverletzung eines Busunternehmens bei sturzbedingter Verletzung eines Fahrgastes aufgrund einer Vollbremsung). 
dest an den ähnlichen Begriffen des Gefahren- oder Verantwortungsbereichs orientiert $^{1826}$, ist in der Subsumtion mit ihm vorlieb zu nehmen. Rechtspraktisch gilt dort: Fasst man eine Nebenpflicht begrifflich weit, so entfaltet $\S 280$ I 2 BGB de lege lata besonders intensive Wirkung. Fasst man sie enger, so wird der größte Bestandteil des Vertretenmüssens bereits innerhalb der Pflichtverletzung relevant. Dort fällt die Beweislast gemäß der gesetzlichen Grundregel aber auf den Gläubiger zurück. § 280 I 2 BGB verliert somit seine Wirkung. ${ }^{1827}$ Wird so dem Gläubiger der Beweis auch für einen Umstand aufgebürdet, welcher zumindest in Teilen wiederum in der Sphäre des Schulder liegt, so ist dem Schuldner für diesen in seiner eigenen Sphäre liegenden Teil wiederum eine sekundäre Darlegungslast aufzuerlegen, um dem Gläubiger (substantiierten) Vortrag zu ermöglichen. ${ }^{1828}$ Die Zwecksetzung einer Beweislastumkehr entscheidet dann sinnvollerweise darüber, ob eine Nebenpflicht eng oder weit formuliert werden sollte und inwieweit über die Annahme einer sekundären Darlegungslast nachkorrigiert werden muss. ${ }^{1829}$

\section{Beispiel 32 Würde die Nebenpflicht im Krankenbettfall ${ }^{1830}$ lauten „Äußere kein unberechtigtes Nacherfüllungsverlangen", so würde wegen}

1826 Vgl. zu anderen denkbaren Kriterien E. Schmidt, JuS 2003, 1007, 1010.

1827 Die - bisweilen vorgeschlagene - teleologische Reduktion von $\S 280$ I 2 BGB wird dann überflüssig, skeptisch deshalb Riehm, FS Canaris, Bd. I, 2007, S. 1079, 1091f. Stellschraube der Wirkung des $\S 280$ I 2 BGB ist die Art und Weise, wie man die Pflichtverletzung formuliert, s.o., S. $69 \mathrm{ff}$.

1828 BGH, Urt. v. 10.3.1986 - II ZR 107/85, Rn. 17 („Aus der Verpflichtung zu redlicher Prozeßführung, wie sie nach dem Grundsatz von Treu und Glauben geboten ist, folgt jedoch, daß dem Beklagten eine Darlegungslast im Sinne eines substantiierten Bestreitens obliegt, wenn der Kläger außerhalb des für seinen Anspruch erheblichen Geschehensablaufs steht und keine Möglichkeit hat, den Sachverhalt von sich aus zu ermitteln, der Beklagte aber in der Lage ist, die erforderliche Aufklärung zu geben, und ihm dies nach den Umständen auch zuzumuten ist“); Jaeckel, Beweisrecht, 2. Aufl. 2014, Rn. 36; MüKo-ZPO/Prütting, 5. Aufl. 2016, § 286 Rn. 103. Plakativ LG Heilbronn, Urt. v. 2.5.2018 - Ve 6 O 401/17, Rn. 55 („Sinn der sekundären Darlegungslast besteht [...] darin, der beweisbelasteten Partei weiteren Vortrag zu ermöglichen").

1829 Vgl. Esser/Schmidt, Schuldrecht AT, Teilbd. 2, 8. Aufl. 2000, S. 161 f. (Anwendung der „Gefahrenbereichslehre [der Rechtsprechung] setzt [...] die Abgrenzung solcher - ja keineswegs als natürlich vorgegebenen - „Zuständigkeitszonen“ diverse Risikoverteilungserwägungen voraus, die offener am jeweiligen Pflichtenzuschnitt angestellt werden können.") sowie Sonnenberger, FS Medicus, 1999, S. 621, 635, der schon vor der Schuldrechtsreform die Möglichkeit sieht, ,daß eine Verpflichtung aus einer handlungsbezogenen zu einer erfolgsbezogenen [...] weiterentwickelt wird, und sich damit auch die [...] Beweislast $[\ldots]$ verändert".

1830 S.o., S. 255. 
$\S 280$ I 2 BGB das Vertretenmüssen des Käufers - und damit eine Schadensersatzpflicht - immer dann vermutet, wenn kein Sachmangel vorliegt. ${ }^{1831}$ Der Käufer kann sich dann vor Gericht nur exkulpieren, wenn er zur Überzeugung des Gerichts dokumentiert hat, dass er alle aus seiner eigenen Sphäre stammenden, möglichen Ursachen für den „Mangel“" vor Ausübung des vermeintlichen Nacherfüllungsrechts ausgeschlossen hat. Gekoppelt mit dem Vorrang der Nacherfüllung im Kaufrecht würde eine solche strikte Trennung der Tatbestandsmerkmale womöglich die Mängelrechte des Käufers entwerten. ${ }^{1832}$ Diese Gefahr wird vermieden, wenn die Nebenpflicht lautet „Äußere kein (im Ergebnis unberechtigtes) Nacherfüllungsverlangen, bevor du nicht mit verkehrserforderlicher Sorgfalt Mangelursachen aus deinem eigenen Verantwortungsbereich ausgeschlossen hast “. ${ }^{1833}$ Dass Mangelursachen aus

1831 So im Übrigen explizit BGH, Urt. v. 16.1.2009 - V ZR 133/08, Rn. 17 (Nebenpflichtverletzung einer Partei wenn ,etwas verlangt [wird], was ihr nach dem Vertrag nicht geschuldet ist, oder ein Gestaltungsrecht ausübt, das nicht besteht“) 23 (BGHZ 179, 238, 245ff.); BGH, Urt. v. 14.7.2016 - III ZR 446/15, Rn. 16 (,Vertragspartei, die [...] ein gestaltungsrecht unter Missachtung des vertraglich Vereinbarten [hier: Kündigungsfrist von 6 Monaten] ausübt, verletzt ihre Pflicht zur Rücksichtnahme nach $\$ 241$ Abs. 2 BGB“); AG Bingen, Urt. v. 12.3.2015 - 25 C 21/14, Rn. 26f. (Nebenpflichtverletzung bei Ausübung eines nicht bestehenden Gestaltungsrechts, indes Exkulpation wegen der Tatsache, dass zumindest eine Mindermeinung den intendierten Schenkungswiderruf gewährt hätte). Thole, AcP 209 (2009), 498, 528f. sieht den Schuldner durch die Beweislastumkehr ,zwar nicht in unzumutbarer Weise belaste[t]“, spricht sich aber dennoch - mit Recht - gegen diese erfolgsbezogene Formulierung aus, weil sie „eine unnötige Diskrepanz zwischen Vertragsrecht und Deliktsrecht" darstellt; krit. auch Deckenbrock, NJW 2009, 1247, 1248.

1832 Thole, AcP 209 (2009), 498, 500f., 528f. Auch der BGH sieht diese Gefahr, hält sie aber nicht zuletzt wohl wegen der hier unterstellten Mischung aus Pflichtverletzung und Vertretenmüssen - für unbegründet, BGH, Urt. v. 23.1.2008 - VIII ZR 246/06, Rn. 13; für eine strikte Trennung von Pflichtverletzung und Vertretenmüssen - inklusive der Verlagerung der Beweislast für die unberechtigte Rechtsverfolgung entschuldigenden Umstände auf den Schuldner hingegen BGH, Urt. v. 16.1.2009 - V ZR 133/08, Rn. 17ff. (BGHZ 179, 238, 245ff.). Bei Verbrauchsgüterkäufen erscheint diese Gefahr - auch mit Blick auf die faktische Entwertung von $\S 476$ BGB - besonders akut, krit. auch Wassermann, Anm. zu BGH, Urt. v. 23.1.2008 VIII ZR 246/06, jurisPR-BGHZivilR 5/2008, Anm. 1.

1833 Dafür auch OLG München, Urt. v. 13.12.2017 - 15 U 886/17, Rn. 138 („Geltendmachung unbegründeter Ansprüche noch keine Pflichtverletzung [...] [,wenn] die (im Nachhinein grundlose) Rechtsbehauptung (ex ante) einer Plausibilitätskontrolle standhält"); Deckenbrock, NJW 2009, 1247, 1248; Thole, AcP 209 (2009), 498, 528f.; dagegen möglicherweise BGH, Urt. v. 16.1.2009 - V ZR 133/08, Rn. 23 (BGHZ 179, 238, 247), der indes bei der Vorgehensweise des Berufungsgerichts wohl weniger die - hier vorgeschlagene - dogmatische Ver- 
der Sphäre des Käufers zumindest fahrlässig übersehen wurden, muss dann nämlich der Gläubiger beweisen. ${ }^{1834}$

Dem Käufer muss indes - wie üblich bei der Beweispflicht eines Beweisführers für einen (zumindest zum Teil) in der Sphäre des Beweisgegners liegenden Umstand ${ }^{1835}$ - im Wege einer sekundären Darlegungslast dazu angehalten werden, sich über die Montage des Kaufgutes und eine etwaige Fehlersuche zumindest nachvollziehbar zu erklären. Weil der Verkäufer keinen Einblick in die Handhabung des Kaufgegenstandes durch den Käufer sowie dessen Fehlersuche hat, würde man ansonsten dem Verkäufer die Beweisführung unmöglich machen. Kommt der Käufer dieser Behauptungslast nicht nach, so würde etwaiger Vortrag des Verkäufers zur Pflichtverletzung des Käufers als nach $\S \S 242$ BGB, 138 III ZPO zugestanden gelten. ${ }^{1836}$

Auch von der Wertung, die einer Beweislastumkehr zugrunde liegt, kann das überzeugen: Dass ein Nacherfüllungsverlangen im Ergebnis unberechtigt ist, kann eine Vielzahl von Ursachen haben, die nicht alle ihren Ursprung in der Sphäre des Käufers haben

schmelzung von Pflichtverletzung und Vertretenmüssen kritisierte, als vielmehr die Tatsache, dass es „,besondere Umstände“ für die Annahme einer Pflichtverletzung gefordert hatte.

1834 Dieses Verständnis belegt auch der Verweis auf die Ausführungen des Berufungsgerichts. Dort wurden zahlreiche Mangelursachen aus der Sphäre des Schuldners erwogen. Bei engem Verständnis der Pflichtverletzung hätte es aber wegen § 280 I 2 BGB für den Anspruchserfolg genügt, wenn auf die offenbar fehlende Dokumentation des Schuldners verwiesen worden wäre, eigene Mangelursachen auszuschließen, vgl. BGH, Urt. v. 23.1.2008 - VIII ZR 246/06, Rn. 14.

1835 Exemplarisch BGH, Beschl. v. 16.8.2016 - VI ZR 634/15, Rn. 14 („Zwar muss grundsätzlich der Anspruchsteller alle Tatsachen behaupten, aus denen sich sein Anspruch herleitet. Dieser Grundsatz bedarf aber [durch die Annahme einer sekundären Darlegungslast] einer Einschränkung, wenn die primär darlegungsbelastete Partei außerhalb des von ihr vorzutragenden Geschehensablaufs steht und ihr eine nähere Substantiierung nicht möglich oder nicht zumutbar ist, während der Prozessgegner alle wesentlichen Tatsachen kennt oder unschwer in Erfahrung bringen kann und es ihm zumutbar ist, nähere Angaben zu machen").

1836 Vgl. BGH, Urt. v. 10.3.1986 - II ZR 107/85, Rn. 17 (,einfache[s] Bestreiten ist in solchen Fällen unbeachtlich mit der Folge, daß das Klagevorbringen nach $\S 138$ Abs. 3 ZPO als zugestanden anzusehen ist") ; MüKo-ZPO/Fritsche, 5. Aufl. 2016, § 138 Rn. 21; Jaeckel, Beweisrecht, 2. Aufl. 2014, Rn. 36; MüKo-ZPO/Prütting, 5. Aufl. 2016, § 286 Rn. 103. 
müssen. ${ }^{1837}$ Lediglich wenn der Käufer objektiv fahrlässig Fehlerursachen aus seinem eigenen Gefahrenbereich verkennt oder seiner sekundären Darlegungslast über seinen Umgang mit dem Kaufgegenstand unzureichend nachkommt, ist eine Beweislastumkehr angemessen. ${ }^{1838}$

Damit kann die Teleologie einer Beweislastumkehr unmittelbare Auswirkungen auf die Subsumtion zu § 241 II BGB haben: Lässt sich in einem Sachverhalt die Schadensursache ausschließlich im Verantwortungsbereich des Schuldners verorten, so darf die Nebenpflicht eher weit formuliert werden ${ }^{1839}$, anderenfalls ist

1837 So ist beispielsweise auch in der Anwaltshaftung eine Verhaltenspflichtverletzung erst dann zu bejahen, wenn sich in einer abschlägigen Entscheidung des Gerichts ein Risiko realisiert, dessen Größe vom Anwalt aus der ex ante Perspektive fahrlässig verkannt wurde; keineswegs muss jedes Risiko vermieden werden, instruktiv zu dieser Parallele Deckenbrock, NJW 2009, $1247,1248$.

1838 Vgl. E. Schmidt, JuS 2003, 1007, 1012, der im Kontext der Beweislastverteilung treffend darauf hinweist, dass der Wortlaut des $\S 280$ I BGB nahe legt, dass mit der Pflichtverletzung „,er Haftungsgrund bereits gelegt ist" und dem Schuldner nur noch ein „Entschuldigungsgrund" zusteht, wenn er ,gehörige Sorgfaltsanstrengungen nachweisen kann“. Dies finde seine „Rechtfertigung“ aber ,im vertraglichen Versprechen, bei dessen Nichteinlösung es nahe liegt, der Versprechenden das Aufklärungsrisiko zuzuteilen“. Genau diese Begründung lässt sich nur mit äußerster Vorsicht auf Nebenpflichten anwenden, so auch dezidiert Riehm, FS Canaris, Bd. I, 2007, S. 1079, 1088 (für Nebenpflichten ,lässt sich auf diesen Gedanken dagegen keine Beweislastumkehr stützen"). Diese basieren diese nämlich nicht auf einem vertraglichen Versprechen, s.o., S. 169 (Fn. 688), 196ff.; Schmidlin, FS F. Bydlinski, 2002, S. 415, 425. Auch sonst ist kein Grund erkennbar, den Gläubiger davon zu befreien, die Risikoverteilungserwägungen, welche eine Nebenpflicht begründen, selbst zu beweisen. Die Abgrenzung der Verantwortungsbereiche sollte deshalb - wie gezeigt - zum größten Teil innerhalb der vom Gläubiger darzulegenden Pflichtverletzung erfolgen, vgl. Soergel/Benicke/Hellwig, 13. Aufl. 2014, $§ 280$ Rn. 253 (,[d] ogmatisch zutreffender [...], Eintritt des negativen Erfolgs nicht mit der Pflichtverletzung gleichzusetzen"). Geht also Stritter, Anm. zu AG Bingen, Urt. v. 12.3.2015 - 25 C 21/14, ZErb 2015, 264, 264 davon aus, dass die ,objektive Pflichtverletzung [...] nur in Ausnahmefällen eine Schadensersatzpflicht" bei tatsächlich unberechtigter Rechtsverfolgung begründet, „wenn die Pflichtverletzung zugleich subjektiv zu vertreten ist", so misst er der Beweislastumkehr bedeutend zu geringe Signalwirkung bei. Gem. § 280 I 2 BGB ist schließlich bei bewiesener Pflichtverletzung im Regelfall davon auszugehen, dass eine Haftung eintritt. Genau dieses Regel/Ausnahme-Verhältnis passt nicht auf die unberechtigte Rechtsverfolgung.

1839 Vgl. BGH, Urt. v. 22.10.2008 - XII ZR 148/06, Rn. 15f. Korrekt deshalb AG München, Urt. v. 16.11.2006 - 272 C 24950/06, Rn. 15ff. Dort wurde die Pflichtverletzung eines Tankstellenbetreibers bejaht, dessen Zapfpistole sich mitsamt Gehäuse aus der Zapfsäule löste und gegen das soeben die Zapfsäule passierende Fahrzeug des Klägers fiel. Weil sich auch das Gehäuse löste, schied als Ursache aus, dass ein anderer Kunde die Zapfsäule fahrlässig bedient hatte. Ein möglicher Montagefehler durch das zwei Tage vorher tätige Wartungsunternehmen wäre wegen $\S 278$ BGB dem Betreiber zuzurechnen gewesen. Demnach ließ sich die Schaden- 
sie eher eng zu fassen ${ }^{1840} \cdot{ }^{1841}$ Etwaig verbleibenden Informationsdefiziten einer Partei kann dann über die Annahme einer sekundären Darlegungslast der jeweils anderen Partei im Wege einer Feinsteuerung abgeholfen werden. ${ }^{1842}$

Beispiel 14 Im Parkplatzfall ${ }^{1843}$ stammt die unmittelbare Schadensursache in
beiden Fällen nicht aus dem Verantwortungsbereich des Verkäu-
fers. Knüpft man als Pflichtverletzung nur an den Erfolg der Schä-
digung an, so müsste sich der Verkäufer für Umstände (Raub,
Sachbeschädigung) entlasten, die nicht in seiner Sphäre lie-

sursache ausschließlich im Verantwortungsbereich des Tankstellenbetreibers verorten. Eine großzügige Formulierung der Nebenpflicht (,Zu den vertraglichen, aber auch nachvertraglichen Pflichten der Beklagten gehört es, auf das Eigentum des Vertragspartners Rücksicht zu nehmen und es nicht zu schädigen.") war also angebracht. Die Beweislastumkehr konnte dann hier ihre volle Wirkung entfalten, was in der Folge auch eine Haftung des Beklagten zur Folge hatte.

1840 Vgl. AK-BGB/Dubischar, 1980, § 282 Rn. 7 (,damit nicht über vordergründig „objektive“ Beweisgrundsätze eine gefährdungshaftungsgleiche Risikohaftung eingeführt wird“). Zutreffend daher BGH, Urt. v. 19.11.1996 - X ZR 75/85, Rn. 9ff. Dort wurde eine Nebenpflichtverletzung eines Kfz-Händlers abgelehnt, dem ein vom Kunden zur Verwahrung überlassenes Wohnmobil gestohlen wurde. Als Nebenpflicht wurde hier offenbar nicht die weite Forderung „Verhindere Beeinträchtigungen der Integrität deiner Kunden auf deinem Betriebsgelände“ zugrunde gelegt. Dann hätte man die Pflichtverletzung nämlich bejahen können und wäre über eine Beweislastumkehr womöglich zur Haftung des Händlers gelangt. Das Betriebsgelände des Händlers war hier aber jedermann zugänglich. Damit rührte die Schadensursache nicht zwingend aus dem Verantwortungsbereich des Händlers. Dem Kläger wurde deshalb abverlangt, eine konkrete Verhaltenspflichtverletzung des Händlers darzulegen, was ihm hier misslang. Ähnlich präzise BGH, Beschl. v. 16.8.2016 - VI ZR 634/15, Rn. 6 („Bei ungeklärter Infektionsquelle kommt eine Umkehr der Darlegungs- und Beweislast nach den Grundsätzen über das voll beherrschbare Risiko dagegen nicht in Betracht. Sie tritt vielmehr nur dann ein, wenn feststeht, dass der Gesundheitsschaden aus der von der Behandlungsseite vollbeherrschbaren Sphäre hervorgegangen ist"); OLG Bamberg, Urt. v. 18.1.2016 - 4 U 160/14, Rn. 36 (Kenntnis des Schuldners von der aufklärungspflichtigen Tatsache ist als Voraussetzung der Pflichtverletzung vom Gläubiger zu beweisen und fällt nicht unter § 280 I 2 BGB) sowie beim Sturz einer Heimbewohnerin OLG Hamm, Urt. v. 27.1.2014 - 17 U 35/13, Rn. 11; allgemein Soergel/Benicke/Hellwig, 13. Aufl. 2014, § 280 Rn. 255; HKK/Schermaier, 2007, §§ 280-285 Rn. 97 (,versteht man [...] [unter „Pflichtverletzung“] die bloße Schadenszufügung, weil es allgemeine Nebenpflicht sein soll, den Gläubiger nicht zu schädigen, wird [...] dem Schuldner zu viel auferlegt").

1841 So wohl auch Schlechtriem, VersR 1973, 581, 583; vgl. auch Hans Stoll, AcP 176 (1976), 145, 195 („,Eine Beweislastumkehr kommt nur bezüglich der Umstände in Betracht, welche die Verantwortung des Täters für ein [subsumtiv festzustellendes!] Schadensereignis begründen.").

1842 Vgl. Jaeckel, Beweisrecht, 2. Aufl. 2014, Rn. 36f.

1843 S.o., S. 69. 
gen. Damit ist die Nebenpflicht hier eher eng zu formulieren und der Kunde sollte eine konkrete Verhaltenspflichtverletzung darlegen müssen, die über die reine Schädigung auf dem Gelände des Verkäufers hinausgeht. Gleichzeitig hat der Kunde keinen Einblick in die Vornahme etwaiger Überwachungs- und Sicherungshandlungen durch den Verkäufer, deren Unterlassen haftungsbegründend wirken kann. Dem Verkäufer ist damit hinsichtlich der aus seiner Sphäre stammenden Umstände, die (auch) zu einer Schädigung geführt haben könnten (Unterlassen zumutbarer Schutzvorkehrungen), eine sekundäre Darlegungslast aufzuerlegen. ${ }^{1844}$

In der Subsumtion kann es mitunter schwierig sein festzustellen, was genau die Schadensursache ist. Der Begriff der Sphäre muss hier dann mit Hilfskriterien ergänzt werden.

Beispiel 39 Im Verhandlungsabbruchsfall ${ }^{1845}$ die Nebenpflicht weit zu fassen, könnte auch aus einer beweisrechtlichen Perspektive nicht überzeugen. Ein mögliches Kriterium zur Abgrenzung der Beweissphären, wenn der Begriff der Sphäre allein nicht weiterhilft, ist nämlich das Prinzip von Regel und Ausnahme. ${ }^{1846}$ Der einseitige Abbruch von Vertragsverhandlungen basiert aber in der Regel nicht auf einer völlig grundlosen Entscheidung des Schuldners, die damit berechtigtes Vertrauen des Gläubigers enttäuscht. Ein Verhandlungsabbruch kann - und wird regelmäßig - auf einer Vielzahl von nachvollziehbaren Gründen basieren, zumal auch die Rechtsprechung hier keine hohen Anforderungen an einen ausreichenden Grund stellt. Erst wenn die Grundlosigkeit des Verhandlungsabbruchs sowie die Inanspruchnahme von (objektiv) berechtigtem Vertrauen bewiesen sind, lässt sich über das Regel-/Aus-

1844 Vgl. hierzu Esser/Schmidt, Schuldrecht AT, Teilbd. 2, 8. Aufl. 2000, S. 162; Palandt/Sprau, 77. Aufl. 2018, § 823 Rn. 54, 80, 165. Zur Unterstützung des für eine Aufklärungspflichtverletzung beweisbelasteten Klägers instruktiv OLG Düsseldorf, Urt. v. 4.11 .2014 - 23 U 168/13, Rn. 18f.; D. Fischer, WM 2014, SBeil. 1, S. 16; Hdb. Anwaltshaftung/G. Fischer, 4. Aufl. 2015, § 4 Rn. 13ff.

1845 S.o., S. 366.

1846 Näher Engel, Unsicherheit, 2001, S. 31; Prütting, Karlsruher Forum 1989, S. 3, 9f.; Riehm, FS Canaris, Bd. I, 2007, S. 1079, 1084f.; E. Schmidt, JuS 2003, 1007, 1010. 
nahmeverhältnis vermuten, dass dieser Verlauf auch auf einem subjektiv fahrlässigen Verhalten des Schuldners beruht. ${ }^{1847}$ Weil aber der Gläubiger wiederum keinen Einblick darin hat, warum der Schuldner die Verhandlungen abgebrochen hat, muss der Schuldner über eine sekundäre Darlegungslast und die ansonsten drohende Sanktion des § 138 III ZPO dazu angehalten werden, dem Gläubiger gegenüber die Motivlage beim Verhandlungsabbruch zu schildern.

Strenggenommen sollten die Zwecke der Beweislastverteilung die Subsumtion unter $\S 241$ II BGB aber nur in Fällen beeinflussen, in denen die Nebenpflicht allein mit dem Fokus der Beweislastumkehr angenommen werden soll - mithin Fälle, in denen die tatbestandliche Verhaltensanforderung identisch auch im Jedermannsrecht existiert und sich nur die Beweislastverteilung für die persönliche Verantwortlichkeit unterscheidet. ${ }^{1848}$ Geht es um den Schutz vermögenswerter Interessen, so ist die Wirkung des $\S 280$ I 2 BGB als Haftungsvorteil nur reflexiv betroffen. Unmittelbar über die Annahme einer Nebenpflicht entscheiden dann diejenigen Kriterien, welche man zur Konturierung schützenswerter Vermögensinteressen heranzieht. Der hinter der Annahme der konkreten Nebenpflicht stehende Haftungsgrund ist dann auch im Rahmen der Beweisverteilung zu beachten. ${ }^{1849}$

Beispiel 32 Im Krankenbettfall ${ }^{1850}$ wurde das Risiko der Geltendmachung eines im Ergebnis unberechtigten Nacherfüllungsanspruchs mit dem Kriterium des cheapest cost avoider dem Käufer mittels einer Nebenpflicht zugewiesen. Der Kostenvorteil des Käufers endet aber an derjenigen Stelle, an welcher die Fehlerursache aus dem eigenen Verantwortungsbereich auch unter Beachtung der im Ver-

1847 Ähnlich für die Anwendung des § 280 I 2 BGB erst nach ausschließlicher Verortung der Schadensursache im vom Schuldner beherrschbaren Bereich plädierend $\mathrm{BGH}, \mathrm{Be}-$ schl. v. 16.8.2016 - VI ZR 634/15, Rn. 6.

1848 Das wird indes nur selten der Fall sein. Insbesondere im Bereich der Verkehrssicherungspflichten nimmt der BGH auch im Deliktsrecht eine Beweislastumkehr vor, wenn die Schadensursache aus der Sphäre des Schuldners herrührt, Palandt/Grüneberg, 77. Aufl. 2018, § 280 Rn. 37; Palandt/Sprau, 77. Aufl. 2018, § 823 Rn. 54, 80.

1849 Ähnlich auch Sonnenberger, FS Medicus, 1999, S. 621, $625 f$.

1850 S.o., S. 255. 
kehr erforderlichen Sorgfalt nicht erkennbar gewesen wäre. Ab diesem Punkt wird entweder der Gläubiger cheapest cost avoider oder die Schadensvermeidung wird im Verhältnis zum Schadenserwartungswert zu teuer und das Kriterium des cheapest cost avoider wird unanwendbar ${ }^{1851}$. Würde man eine Beweislastumkehr nun schon für unberechtigte Nacherfüllungsverlangen vornehmen, ohne die objektive Fahrlässigkeit bei der internen Fehlersuche zu berücksichtigen, so würde man die Beweislast entgegen dem Haftungsgrund der Nebenpflicht verteilen. Um das zu vermeiden, gilt es, den Haftungsgrund der Nebenpflicht - hier den Kostenvorteil des Schuldners bei der Schadensvermeidung - zu nutzen, um die beweislastrechtliche Sphäre des Schuldners abzustecken.

Der Haftungsgrund, auf den die jeweilige Nebenpflicht gestützt wird, konturiert damit den sinnvollerweise dem Schuldner zuzuweisenden beweislastrechtlichen Gefahrenbereich. Die Erwägungen ${ }^{1852}$, mit denen der Rechtsanwender eine Nebenpflicht begründet, müssen deshalb bei der Formulierung der Pflicht (eng oder weit) präzise berücksichtigt werden, um einer Nebenpflichtverletzung nicht über die Beweislastumkehr des $\S 280$ I 2 BGB größere haftungsrechtliche Durchschlagskraft zu verleihen, als es nach dem ursprünglichen Haftungsgrund der Nebenpflicht gerechtfertigt ist. Über die Formulierung der Nebenpflicht ist damit sicherzustellen, dass die Nebenpflicht in ihrer praktischen Wirkung über die $\S \S 280$ I, 241 II BGB nicht über ihr Ziel (i.e. der jeweilige Haftungsgrund) hinausschiesst.

1851 In diesem Fall würde subsidiär auf das Kriterium des cheapest cost insurer zurückgegriffen werden. Hiernach wäre der Gläubiger cheapest cost insurer. Zumindest eine Eigenversicherung für im Ergebnis unnötige Problemsuchen wäre für ihn problemlos möglich und wegen der Vielzahl an durchgeführten Transaktionen kostengünstiger als für den einzelnen Schuldner. Zudem ist der typisierte Schuldner in dieser Hinsicht risikoavers. Er möchte schließlich bei einer Fehlfunktion der Sache in der Lage sein, ab einem gewissen Grad an Sorgfalt gefahrlos den Verkäufer kontaktieren zu können. Damit wäre der typisierte Schuldner auch bereit, die Eigenversicherung des Verkäufers über eine in den Kaufpreis integrierte Risikoumlage zu bezahlen.

1852 Nach hier vertretener Ansicht Gedanken der ökonomischen Analyse (primär: Kostenvorteil bei der Schadensvermeidung, sekundär: Fähigkeit zur Risikotragung und -versicherung), ansonsten Integritätsschutz, Vertrauensschutz etc. 
c) Zwischenergebnis: Nullsummenspiel zwischen Pflichtverletzung und Vertretenmüssen

Hinter dem undifferenzierten Wortlaut von $\S 280$ I 2 BGB steht letztlich die Wertung der Rechtspraxis, die Beweislastverteilung bei Pflichtverletzung nach Gefahrenbereichen vorzunehmen. Die Wirkung der Beweislastumkehr wird dabei im Einzelnen entscheidend durch die Formulierung der Pflichtverletzung beurteilt. Zwischen der haftungsrechtlichen Relevanz von Pflichtverletzung und Vertretenmüssen besteht insoweit ein Nullsummenspiel: Wird die Pflicht innerhalb der Pflichtverletzung sehr eng formuliert, so sinkt die haftungsrechtliche Relevanz des Vertretenmüssens, wird die Pflicht sehr weit formuliert, so gewinnt das Vetretenmüssen an Bedeutung. Wenn eine Nebenpflicht spezifisch mit dem Zweck angenommen werden soll, die Beweislastumkehr nach § 280 I 2 BGB zu aktivieren, so muss sich der Gegenstand der Nebenpflicht im Verantwortungsbereich des Schuldners verorten lassen. Ist der schuldverhältnisrechtliche Vorteil in der Beweislastverteilung nur reflexiv betroffen - wie regelmäßig beim Schutz vermögenswerter Interessen -, so wird der Verantwortungsbereich des Schuldners letztlich schon durch den Haftungsgrund der Nebenpflicht konturiert.

2. Bestimmung der Reichweite einer Beweislastumkehr im Rahmen des Verschuldens über Ansätze der ökonomischen Analyse

Bei normaler Beweislastverteilung fällt die Aufgabe, das Verschulden darzulegen, dem Gläubiger der Nebenpflicht zu. Dieser muss nur einen Weg aufzeigen, wie der Schuldner den Schaden hätte verhindern können - und tatsächlich nicht verhindert hat -, sofern dieser Weg der Schadensvermeidung - ebenfalls vom Gläubiger darzulegen - zumindest Teil der im jeweiligen Verkehr erforderlichen Sorgfalt (§ 276 II BGB) gewesen wäre. Bei einer Beweislastumkehr wie § 280 I 2 BGB muss nun der Beklagte nachweisen, dass alle überhaupt denkbaren Schadensvermeidungsprojekte nicht Teil der im Verkehr erforderlichen Sorgfalt waren. ${ }^{1853}$ Eine Beweislastumkehr für das Verschulden vorzunehmen bedeutet aus

1853 Schäfer/Ott, Ökonomische Analyse, 5. Aufl. 2012, S. 224. Ein durchführbares „Schadensvermeidungsprojekt" wird häufig deshalb nicht Teil der verkehrserforderlichen Sorgfalt sein, weil die entstehenden Schadensvermeidungskosten den Schädiger übermäßig belasten würden. Der bei einer Beweislastumkehr vom Schuldner verlangte Beweis stellt dabei höhere Anforderun- 
einer - auch für die ökonomische Analyse typischen - Makro-Perspektive daher, das jeweilige Haftungsgebiet an eine Gefährdungshaftung anzunähern. ${ }^{1854}$ Die Haftung für vermutetes Verschulden - wie sie $§ 280$ I 2 BGB darstellt ${ }^{1855}$ nimmt insoweit eine Stellung zwischen Gefährdungshaftung und Verschuldenshaftung ein. Die Beweislastverteilung wirkt sich damit unmittelbar auf die Qualität des jeweiligen Haftungsrechts aus. Gefährdungshaftungen sind in Deutschland positiv und abschließend vom Gesetzgeber enumeriert. ${ }^{1856}$ Die Beweislastumkehr im Rahmen eines schuldverhältnisbedingten Schadensersatzanspruchs hat in $§ 280$ I 2 BGB indes eine taugliche gesetzliche Grundlage. ${ }^{1857}$

\section{a) Nutzen der Rekonstruktion des vollständigen Schuldverhältnisses?}

Die Rekonstruktion des vollständigen Schuldverhältnisses ist als Instrument dafür gedacht, Schadensrisiken innerhalb eines Schuldverhältnisses mittels einer Modellierung des hypothetischen Parteiwillens zu verteilen. Die prozessuale

gen als an den Gläubiger in einem Fall ohne Beweislastumkehr: Nicht umsonst wird der Beweis von etwas Negativem vom Gesetzgeber tendenziell vermieden, Müko-ZPO/Prütting, 5. Aufl. 2016, § 286 Rn. 122.

1854 Schäfer/Ott, Ökonomische Analyse, 5. Aufl. 2012, S. 224; vgl. auch Deutsch, Haftungsrecht, 2. Aufl. 1996, Rn. 417 (mit einer Beweislastumkehr „Weg zur Kausalhaftung eingeschlagen“); Matusche-Beckmann, Organisationsverschulden, 2001, S. 131 („Umkehrung der Beweislast [...] auf Kosten des Verschuldensprinzips").

1855 HK-BGB/Schulze, 9. Aufl. 2017, § 280 Rn. 2.

1856 Soergel/Spickhoff, 13. Aufl. 2005, Vor $\$ 823$ Rn. 46; MüKo-BGB/Wagner, 7. Aufl. 2017, Vorbem. § 823 Rn. 25f. (,Enumerationsprinzip“); dagegen Deutsch, Haftungsrecht, 2. Aufl. 1996, Rn. 11. Bei einer auf ungesichertem Boden stehenden Beweislastumkehr durch richterliche Rechtsfortbildung besteht damit ein Konflikt zur gesetzgeberischen Einschätzungsprärogative, krit. auch Papadelli, Beweislastverteilung, 2011, S. 109 (,Prozessrisiko [bliebe] damit unkalkulierbar"). Durch mittlerweile zahlreich vorhandene Beweislastumkehren, welche auf richterliche Rechtsfortbildung zurückzuführen sind, wird „,durch die Hintertür“ der Gesetzesvorbehalt für Gefährdungshaftungen untergraben, näher Schäfer/Ott, Ökonomische Analyse, 5. Aufl. 2012, S. 174, 229. Auch mittels erfolgsorientierter Verkehrspflichten kann der gesetzliche Grundfall der Verschuldenshaftung einer Gefährdungshaftung angenähert werden, näher MüKo-BGB/Wagner, 7. Aufl. 2017, Vorbem. § 823 Rn. 27f. Anders ist dies in den USA: Dort ist es stets Sache der Gerichte, festzustellen, wo und inwieweit eine Gefährdungshaftung (,strict liability") angemessen ist, näher Schäfer/Ott, Ökonomische Analyse, 5. Aufl. 2012, S. 228f. (Fn. 144).

1857 Anders war dies noch bei der analogen Anwendung von $\S 282$ BGB a.F. auf Nebenpflichtverletzungen, zur Relevanz der normativen Verankerung von Beweislastveränderungen Prütting, Karlsruher Forum 1989, S. 3, $10 f$. 
Beweislastverteilung für diese Risikoverteilung schließt sich hieran zwar nur akzessorisch an. Zudem sind den Parteien gewisse Grenzen gesetzt, in denen sie Fragen der Beweislastverteilung selber regeln können.

Grundsätzlich können sich zwei Parteien über Fragen der Beweislastverteilung im Vorhinein eines Prozesses ${ }^{1858}$ im Wege eines Beweislastvertrages verständigen, wenn Tatbestandsmerkmale des materiellen Rechts betroffen sind, welche ebenfalls der Disposition der Parteien unterliegen. ${ }^{1859}$ Zwar ist $\S 280$ I BGB grundsätzlich eine dispositive Norm. ${ }^{1860}$ Eine formularmäßige Veränderung der Beweislast zulasten des Vertragspartners, mit welcher sich dieser für Umstände exkulpieren oder solche beweisen muss, welche im Verantwortungsbereich des Verwenders liegen, scheitert dabei gegenüber Verbrauchern hingegen unmittelbar an $\$ \$ 310$ III Nr. 2, 309 Nr. 12 a), 306 II BGB. Auch gegenüber Unternehmern wird regelmäßig eine Unwirksamkeit aufgrund der in $\$ 309 \mathrm{Nr} .12$ a) $B G B$ zum Ausdruck kommenden Grundwertung zugunsten einer Beweislastverteilung nach Sphären gem. $\$ 310$ I 2 Hs. 1, 307 I, II, 306 II BGB anzunehmen sein. ${ }^{1861}$ Darüber hinaus können die $\S \S 308 \mathrm{Nr} .5,6,309 \mathrm{Nr} .7,8$ einer Modifikation des $\S 280$ I 2 BGB in Bezug auf die Haftung des Schuldners wegen Verletzung einer Nebenpflicht entgegenstehen. Im individualvertraglichen Bereich wird eine Modifikation des §280 I 2 BGB zwar eher für möglich

1858 Im laufenden Prozess sind Beweislastmodifikationen aus Gründen der Rechts- und Prozessicherheit unzulässig, zutreffend Papadelli, Beweislastverteilung, 2011, S. 100.

1859 MüKo-ZPO/Prütting, 5. Aufl. 2016, § 286 Rn. 166. Unzulässig sind hingegen Vereinbarungen über die vom Gericht vorzunehmende Beweiswürdigung als solche sowie das hierbei anzulegende Beweismaß, da $\S 286$ ZPO eben gerade nicht dispositiv ist, Papadelli, Beweislastverteilung, 2011, S. 100 (Fn. 248); MüKo-ZPO/Prütting, 5. Aufl. 2016, § 286 Rn. 165.

1860 MüKo-BGB/Ernst, 7. Aufl. 2016, § 280 Rn. 46; Bamberger-Roth/Lorenz, 3. Aufl. 2012, § 280 Rn. 107.

1861 BGH, Urt. v. 28.3.1973 - I ZR 41/72, Rn. 24; BGH, Urt. v. 23.2.1984 - VII ZR 274/82, Rn. 47 (,gerade für den kaufmännischen Verkehr der Grundsatz entwickelt [...], daß es unbillig ist, dem Auftraggeber den Beweis für Umstände aufzuerlegen, die sich im Verantwortungsbereich des Auftragnehmers ergeben haben. Dies gilt insbesondere für den Nachweis des Verschuldens bei objektiver Pflichtverletzung des Auftragnehmers"); BGH, Urt. v. 20.4.1989 - IX ZR 214/88, Rn. 8f.; MüKo-BGB/Ernst, 7. Aufl. 2016, § 280 Rn. 46f.; MüKo-BGB/Wurmnest, 7. Aufl. 2016, § 309 Nr. 12 Rn. 21. 
gehalten. ${ }^{1862}$ Weil die Haftung wegen Verletzung einer Nebenpflicht aber ursprünglich auf dem Grundsatz von Treu und Glauben (\$242 BGB) basiert und damit jeder individualvertraglichen Beschränkung nur sehr eingeschränkt zulässig ist ${ }^{1863}$, wird auch eine Beweislastverteilung zulasten des Gläubigers eines solchen Anspruchs regelmäßig in Konflikt zu § 242 BGB geraten. ${ }^{1864}$

Weil die Rekonstruktion des vollständigen Schuldverhältnisses aber gerade aus hypothetischer Perspektive Risiken verteilt, ist die tatsächliche Abdingbarkeit gesetzlicher Beweislastverteilung für die Anwendbarkeit des Modells irrelevant. Wie oben dargestellt, strahlt aber der Haftungsgrund von Nebenpflichten auf die Formulierung der Nebenpflicht und damit auf die Wirkung der Beweislastumkehr aus. ${ }^{1865}$ Weil nach hier vertretener Ansicht die rechtspraktische Funktion von Nebenpflichten sinnvoll durch die Rekonstruktion des vollständigen Schuldverhältisses konturiert werden kann, wird damit für das Abstecken der beweislastrechtlichen Sphäre des Schuldners der ökonmische Haftungsgrund der Nebenpflicht (cheapest cost avoider oder cheapest cost insurer) relevant. Ist der Haftungsgrund einer Nebenpflicht zum Schutz vermögenswerter Interessen beispielsweise das Kriterium des cheapest cost avoider, so bestimmt der Kostenvorteil des Schuldners bei der Schadensvermeidung - und damit ein ökonomisches Kriterium - die sinnvolle Wirkung der Beweislastumkehr des §280 I 2 BGB. Die Beweislastumkehr darf dann nicht über zu eine weite Formulierung der Nebenpflicht - welche die Wirkung einer Beweislastumkehr für das Vertretenmüssen einer Pflichtverletzung steigert - dazu führen, dass der Schuldner haftet, obwohl er nicht (mehr) cheapest cost avoider ist.

Beispiel 58 Zutreffend hat daher der BGH eine auf die Wirkung der Beweislastumkehr des $\$ 282$ BGB a.F. gestützte Haftung in einem Fall abgelehnt, in welchem der Gläubiger durch ein auf die Betriebshalle des Schuldners übergegriffenes Feuer geschädigt wurde

1862 Bamberger-Roth/Lorenz, 3. Aufl. 2012, § 280 Rn. 107.

1863 S.o., S. $204 f f$.

1864 MüKo-BGB/Ernst, 7. Aufl. 2016, § 280 Rn. 47 nennt noch § 138 BGB als ein mögliches Hindernis für Individualvereinbarungen über die Beweislast.

1865S.o., S. 509. Zur Berücksichtigung des Kriteriums für die Verteilung der Beweislast auch Gottwald, FS Fasching, 1988, S. 181, 185. 
(Feuerfall). ${ }^{1866}$ Die Brandursache entstammte einem benachbarten Gebäude. Dem Schuldner wurde zwar zunächst eine dortige (fahrlässige oder vorsätzliche) Brandlegung vorgeworfen, von diesem Vorwurf wurde er aber strafrechtlich freigesprochen und auch zivilrechtlich sah das Gericht hierfür keine zureichenden Anhaltspunkte. Weil die Brandursache nicht aus der vom Schuldner beherrschbaren Sphäre stammte und auch eine Sorgfaltspflichtverletzung des Schuldners nicht nachweisbar war, hob der BGH das Berufungsurteil auf, welches dem Schuldner die Exkulpation verwehrt hatte.

Das vom BGH gefundene Ergebnis wird auch durch die ökonomische Analyse gestützt: Cheapest cost avoider konnte der Schuldner für die Vermeidung der konkreten Schädigung nicht sein, da ihm auf Basis der Feststellungen des Gerichts gerade keine Schadensvermeidung möglich war. Den Schuldner nur bei einer genauen Rekonstruktion des offensichtlich unaufklärlichen Brandverlaufs aus der Haftung zu entlassen, hätte ihn für ein Risiko haften lassen, welches er - auf Basis der gerichtlichen Feststellungen - gar nicht beherrschen konnte. ${ }^{1867}$ Die Nebenpflicht war hier also nicht - wie vom Berufungsgericht offenbar angenommen - rein erfolgsbezogen (Schädigungserfolg innerhalb der Sphäre des Schuldners) $z u$ verstehen. Dann würde der Beweislastumkehr eine Wirkung zukommen, welche sie mit Blick auf den vom Berufungsgericht bemühten Haftungsgrund - dem Schuldner (wirtschaftlich) zumutbare Schadensvermeidung - nicht verdient hätte. Vielmehr hätte der

1866 Fall nach BGH, Urt. v. 14.11.1989 - X ZR 116/88, Rn. $23 \mathrm{ff}$.

1867 Vgl. BGH, Urt. v. 14.11.1989 - X ZR 116/88, Rn. 23 (,Überspannung der [...] an den Beklagten zu stellenden Anforderungen [...], wenn man von ihm den Nachweis dafür verlangt, daß er die Brandlegung [...] nicht seinerseits in irgendeiner Weise veranlaßt oder beeinflußt hat"); a.A. noch BGH, Urt. v. 17.4.1952 - IV ZR 168/51, NJW 1952, 1170, 1170 (,[Haftung zu bejahen, sofern] eine Wahrscheinlichkeit offenbleibt, daß [...] ein Verschulden des Schuldners in Betracht kommt"). Da aber auch der Gläubiger das Risiko nicht hätte beherrschen können, handelte es sich um einen für die Parteien (ökonomisch) unvermeidbaren Schaden. $\mathrm{Ob}$ das Kriterium des cheapest cost insurer hier das Risiko dem Gläubiger oder dem Schulder zugewiesen hätte, war im Fall unklar, da eine konkrete Abrede über die Schadensversicherung im Raum stand, s. BGH, Urt. v. 14.11.1989 - X ZR 116/88, Rn. 27. 
Gläubiger eine konkrete Sorgfaltspflichtverletzung des Schuldners darlegen müssen, weil die Schadensursache erweislich nicht der Sphäre des Schuldners entstammte. ${ }^{1868}$

Insoweit hat die Rekonstruktion des vollständigen Schuldverhältnisses im Kontext von Nebenpflichten über die Formulierung der jeweiligen Pflicht (eng oder weit) unmittelbare Auswirkungen auf die Wirkung der Beweislastumkehr.

aa) Genereller Kostenvorteil des Schuldners bei der Bestimmung der eigenen Verantwortlichkeit?

Man könnte argumentieren, dass das Vertretenmüssen der Pflichtverletzung stets von Umständen geprägt ist, die der Schuldner einfacher und mit weniger Kosten als der Gläubiger aufdecken kann. ${ }^{1869}$ Nur weil sich die Information vom Beklagten leichter als vom Kläger beschaffen lässt, kann aber nicht stets eine Beweislastumkehr für die jeweilige Frage vorgenommen werden. ${ }^{1870}$ Schließlich verändert sich die Qualität des Haftungsrechts mit einer Beweislastumkehr von Verschuldenshaftung in Richtung Gefährdungshaftung. Diese tektonische Verschiebung bedarf einer besonderen Begründung. Bei einer Gefährdungshaftung muss der Schädiger alle Kosten schultern, welche nötig sind, um den optimalen Vorsorgeaufwand ausfindig zu machen und die entsprechende Vorsorge zu treffen. ${ }^{1871}$ Schließlich muss er bei einer Schädigung eines anderen durch die Ge-

1868 Hierin liegt der entscheidende Unterschied zum ansonsten ähnlichen Fall in BGH, Urt. v. 16.6.1992 - X ZR 90/90, Rn. 9ff. Hier lehnte der BGH eine Exkulpation ab, weil überzeugende Indizien für eine Brandlegung durch den Schuldner sprachen. Dass die Brandlegung durch einen Fremden aber - so die Feststellungen des Berufungsgerichts - auch nicht völlig ausgeschlossen werden konnte, genügt richtigerweise nicht für eine Exkulpation, weil das Prinzip von Regel und Ausnahme wegen der Indizien für eine Brandlegung durch den Schuldner hier ja gerade dafür sprach, eine verbleibende Restunsicherheit zulasten des Schuldners gehen zu lassen.

1869 Die Umstände der persönlichen Verantwortlichkeit werden dem Schuldner immer zumindest näher als dem Gläubiger liegen, vgl. Michael Lehmann, Bürgerliches Recht, 1983, S. 97 (,Überlegung, daß billigerweise demjenigen eine genauere Sachverhaltsaufklärung zugemutet werden kann, der ,näher dran "ist"). Der Schuldner hat insoweit ganz regelmäßig einen Kostenvorteil bei der Informationsbeschaffung.

1870 So auch Schäfer/Ott, Ökonomische Analyse, 5. Aufl. 2012, S. 224. Zumindest als Indiz sollten sich die relativen Informationsbeschaffungskosten von Schuldner und Gläubiger indes nutzbar machen lassen, Hay/Spier, J. Leg. Stud. 26 (1997), 413, 419.

1871 Schäfer/Ott, Ökonomische Analyse, 5. Aufl. 2012, S. 236. 
fährdungsquelle ohne eine Möglichkeit der Exkulpation haften. ${ }^{1872}$ Soweit allein der Pflichtige das Risiko beeinflussen kann - und damit einen Kostenvorteil bei der Schadensvermeidung hat -, ist die Gefährdunghaftung somit aus einer ökonomischen Perspektive gegenüber einer Verschuldenshaftung vorzugswürdig. ${ }^{1873}$ Weil bei Nebenpflichten aber gerade die Abgrenzung der eng miteinander verwobenenen Verantwortungsbereiche von Schuldner und Gläubiger im Zentrum der Subsumtion steht - und somit ein Kostenvorteil des Schuldners im Hinblick auf ein erst durch die Nebenpflicht konturiertes Schadensrisiko keineswegs generell bejaht werden kann -, lässt sich eine generelle Gefährdungshaftung bei $\mathrm{Ne}$ benpflichten nicht auf diesen Gedanken stützen. Aus diesem Grund ist eine Beweislastumkehr aus der Perspektive der ökonomischen Analyse auch nur für Schadensrisiken angemessen, deren Realisierung der Schuldner tatsächlich günstiger vermeiden oder zumindest günstiger versichern kann - mithin die gesamtgesellschaftlichen Kosten durch eine (möglichst effektive) Haftung des Schuldners auf effiziente Weise gering gehalten werden. ${ }^{1874}$ Allein aus einem abstrakten Kostenvorteil des Schuldners bei der Informationsgewinnung über die eigene Verantwortlichkeit lässt sich damit keine Beweislastumkehr rechtfertigen. Vielmehr muss der konkrete Kostenvorteil, auf den sich die Annahme der Nebenpflicht stützt, die Annahme der Beweislastumkehr tragen.

1872 Voraussetzung ist allerdings die ex ante Erkennbarkeit des von der Gefährdungshaftung erfassten Risikos für den Schuldner, näher Schäfer/Ott, Ökonomische Analyse, 5. Aufl. 2012, S. 240.

1873 Näher Grundmann/Hoernig, X. Travemünder Symposium, 2007, S. 420, 461f.; AK-BGB/ Kohl, 1979, vor $\S \S 823$ ff. Rn. 16; verhaltene Zustimmung bei HKK/Schiemann, 2013, $\S \S 823-830,840,842-853$ Rn. 155 a.E. (,auch Haftungen ohne Verschulden durchaus positive verhaltenssteuernde Wirkungen").

1874 Eine Beweislastumkehr kann nicht stets vorgenommen werden, nur weil der Beklagte die im Vertretenmüssen betroffenen Informationen leichter als der Kläger beschaffen kann, so zu Recht Schäfer/Ott, Ökonomische Analyse, 5. Aufl. 2012, S. 224. Das könnte im Übrigen dazu führen, dass viele Klagen ohne Rücksicht auf Erfolgsaussichten erhoben werden, um den beweisbelasteten Beklagten zu einem (außergerichtlichen) Vergleich zu zwingen. Sofern die Kosten des Vergleichs für den Beklagten unter den Informationsbeschaffungskosten für den Gegenbeweis bleiben, wäre die Zustimmung zum Vergleich schließlich die wirtschaftlich vernünftige Entscheidung, zutreffend Hay/Spier, J. Leg. Stud. 26 (1997), 413, 422; skeptisch zu den Steuerungsmöglichkeiten der Gerichte diesbezüglich Zamir/Ritov, J. Leg. Stud. 41 (2012), $165,188$. 
bb) Anreizsetzung im Hinblick auf die Informationsgewinnung

Gefährungshaftung hat eine ,stärkere Dezentralisierung der Entscheidungen über Sorgfaltsaufwendungen" zur Folge. ${ }^{1875}$ Jeder achtet dann auf die Gefahrenherde, die er selbst eröffnet, weil er sicher von der Haftung für verursachte Schäden ausgehen kann. ${ }^{1876}$ Vor Gericht wird dann nicht näher auf mögliche Schadensvermeidungsprojekte eingegangen, da sie nicht entscheidungsrelevant sind.

Bei einer Verschuldenshaftung ohne Beweislastumkehr muss der Geschädigte auf eine einzige (ungenutzt gebliebene) Möglichkeit des Schuldners, den Schaden zu verhindern, hinweisen, sofern er schlüssig vorträgt, dass diese Möglichkeit Teil der im Verkehr erforderlichen Sorgfalt war. Der Schädiger muss dann will er den Rechtsstreit nicht verlieren - nachweisen, dass diese Möglichkeit gar nicht bestand oder aber das Gericht davon überzeugen, dass die vom Gläubiger vorgeschlagene Schadensvermeidung die verkehrserforderliche Sorgfalt überstiegen hätte.

Kommt hingegen eine Beweislastumkehr für das Verschulden zum Tragen, so muss der Geschädigte nur zur Pflichtverletzung des Schädigers vortragen. Der Schädiger muss dann zur Abwendung seiner Haftung darlegen, dass es entweder keine Möglichkeiten zur Schadensvermeidung gab, oder sämtliche Möglichkeiten zur Schadensvermeidung nicht mehr Teil der im Verkehr erforderlichen Sorgfalt waren. Der Schädiger erhält durch die drohende Haftung so einen starken Anreiz, zu allen denkbaren Schadensvermeidungsprojekten vorzutragen, der Geschädigte wird hingegen entlastet. Auf dem Umweg des gerichtlichen Rechtsstreits Gerichte können damit - aus einer gesellschaftlichen Perspektive grundsätzlich wünschenswert - Informationen über mögliche Vorsorgevorkehrungen ans Licht gebracht werden. ${ }^{1877}$ Schließlich muss sich das Gericht bei entsprechendem Vortrag des Schädigers zur Exkulpation nun mit der Frage auseinandersetzen, welche Schadensvermeidungsprojekte es gibt, und inwieweit sie noch Teil der im Verkehr erforderlichen Sorgfalt sind. Dabei sind nach der ökonomi-

1875 Schäfer/Ott, Ökonomische Analyse, 5. Aufl. 2012, S. 237.

1876 Michael Lehmann, Bürgerliches Recht, 1983, S. 97.

1877 Vgl. Schäfer/Ott, Ökonomische Analyse, 5. Aufl. 2012, S. 237 (Verbreitung von Wissen über „Sicherheitstechnologien"). Zur Relevanz der richtigen Anreizsetzung für Informationsgewinnung im Hinblick auf Gefahrenstoffe beispielsweise Spiecker, Informationsgewinnung, 2003, S. $17 \mathrm{ff}$. (drohende „Anreize zur Verschleierung vorhandenen Wissens"). 
schen Analyse nicht die Verkehrserwartungen, sondern die Kosten der Schadensvermeidung für den Schädiger entscheidend. Bei Leistungspflichten ist dieser Aspekt gesamtgesellschaftlich uninteressant.

Für den Verkehr ist es schließlich nicht von allgemeinem Interesse, wie der Schuldner einer Leistungspflicht seine Abläufe in der Weise organisiert, dass er die Erfüllung der Leistungspflicht gewährleisten kann. Trägt er nichts zur Entlastung vor, so haftet er, ohne dass vor Gericht Möglichkeiten zur Schadensvermeidung erörtert worden wären. Leistungspflichten und der dahinter stehende Ablauf oder Betrieb divergieren zu stark von Fall zu Fall, als dass sich im Prozess gewonnene Informationen über Schadensvermeidungsprojekte sinnvoll weiterverwenden ließen.

Nebenpflichten sollen hingegen eine fremdbestimmte Risikoverteilung innerhalb eines Schuldverhältnisses gewährleisten und können somit in vergleichbaren Fällen immer wieder relevant werden. Damit besteht ein größeres Verkehrsinteresse daran, Informationen über mögliche Schadensvermeidungsprojekte freizulegen.

Wer bei einer Beweislastumkehr für das Verschulden jedoch Informationsgewinnung betreiben muss und wer sie lediglich betreiben kann, hängt indes entscheidend von der Formulierung der Pflichtverletzung ab. Wird diese nämlich verhaltensbezogen (eng) gefasst, so muss der Gläubiger bereits für einen schlüssigen Vortrag zur Pflichtverletzung Informationsgewinnung über einen sorgfaltsgemäßen Weg zur Schadensvermeidung betreiben.

Beispiel 58 Im Feuerfall ${ }^{1878}$ muss der Gläubiger dann schon für die Darlegung der Pflichtverletzung eine (wirtschaftlich zumutbare) Möglichkeit des Gläubigers, den Feuerschaden zu verhindern (z.B. die Installation automatischer Feuerlöscher oder das Unterlassen der Brandlegung), schlüssig aufzeigen. Gelingt ihm das, so muss der Schuldner darlegen, dass diese Form der Schadensvermeidung entweder gar nicht bestand (Feuerlöscher hätten beim Löschvorgang einen identischen Sachschaden hervorgerufen oder Indizien für Brand-

1878 S.o., S. 514. 
legung durch den Schuldner widerlegt) oder zumindest nicht Teil der im Verkehr erforderlichen Sorgfalt war (Installationskosten der Feuerlöscher hätten Schadenserwartungswert überstiegen).

Wird sie hingegen erfolgsbezogen (weit) formuliert, so kann sich der Gläubiger mit einem Verweis auf den Schadenseintritt begnügen und die Informationsgewinnung zu allen denkbaren Formen zur Schadensvermeidung erfolgt nur, sofern der Schuldner die ihm gewährte Möglichkeit zur Exkulpation ernsthaft wahrnimmt.

Beispiel 58 In der Vorinstanz zum Feuerfall ${ }^{1879}$ musste der Gläubiger als Basis der erfolgsbezogen verstandenen Pflichtverletzung nur den auf dem Feuer beruhenden Schadenseintritt darlegen. Wegen der extensiv verstandenen Beweislastumkehr wurde der Schuldner hier über eine ansonsten drohende Haftung dazu angehalten, zum Schadenshergang und etwaigen Schadensvermeidungsprojekten Stellung zu nehmen. Er sollte dann darlegen, dass ihm überhaupt kein Schadensvermeidungsprojekt offenstand ${ }^{1880}$ oder zumindest alle denkbaren Schadensvermeidungsprojekte die im Verkehr erforderliche Sorgfalt überstiegen hätten, was ihm - wie zu erwarten - nicht zur Überzeugung des Gerichts gelang. Damit blieb offen, was genau das Gericht von ihm erwartet hätte.

Weil Nebenpflichten verhaltensbezogene Pflichten sind, besteht ein besonderes Verkehrsinteresse daran, zu erfahren, was der gerichtlich geforderte Verhaltensstandard ist. Die Abgrenzung der Verantwortungsbereiche von Gläubiger und Schuldner - welche beispielsweise bei einer Gefährdungshaftung wie § 7 I StVG im Falle einer Schädigung im Grundsatz keine Probleme bereitet - ist vor allem bei Pflichten nach $\S 241$ II BGB zum Schutz vermögenswerter Interessen häufig völlig unklar. Werden Nebenpflichten in diesem Bereich weit formuliert - die Beweislastumkehr also aus praktischer Perspektive aktiviert -, so kann der Kläger obsiegen, ohne dass für den Verkehr der vom Gericht geforderte Verhaltensstandard im Nachhinein ersichtlich ist. Ein schädigendes Verhalten kann dann

1879 S.o., S. 514.

1880 Vgl. BGH, Urt. v. 14.11.1989 - X ZR 116/88, Rn. 23 („Nachweis dafür [...], daß er die Brandlegung $[\ldots]$ nicht seinerseits in irgendeiner Weise veranlaßt oder beeinflußt hat"); 
dem Verantwortungsbereich des Schuldners zugeordnet werden ohne, dass die Grenze seines Verantwortungsbereichs (weiter) konturiert wird

So besteht beispielsweise im Verhandlungsabbruchsfall ${ }^{1881}$ ein großes Verkehrsinteresse daran herauszufinden, wie verhindert werden kann, dass aufseiten des Gläubigers ein objektiv berechtigtes Vertrauen dahingehend hervorgerufen wird, dass der Vertrag auch tatsächlich zustande kommt. Genügt als Pflichtverletzung der abrupte Abbruch einer Verhandlung, so erhält zwar der Schuldner einen Anreiz, dazu vorzutragen, dass ihn für den Abbruch der Verhandlungen kein Verschulden trifft. Wenn das Gericht aber seinen Vortrag nicht für ausreichend hält, wird es der Klage gegen ihn allein aufgrund der Beweislastumkehr für das Verschulden stattgeben. Eine Festlegung hinsichtlich des im Rahmen des Verschuldens exakt geforderten Verhaltensstandards erfolgt dann nicht. Der Verkehr bleibt weiterhin darüber im Dunkeln, welches Verhalten die Hervorrufung berechtigten Vertrauens in die Fortführung von Vertragsverhandlungen vermeidet. Er kann sich nun lediglich sicher sein, welches Verhalten - sofern der Schuldner überhaupt von der Möglichkeit zur Exkulpation Gebrauch gemacht hat nicht der verkehrserforderlichen Sorgfalt genügt. Sinnvollerweise ist deshalb auch die Erregung von objektiv berechtigtem Vertrauen - und korrespondierende Grundlosigkeit des Verhandlungsabbruchs - als Teil der Pflichtverletzung zu sehen. Wird einer Klage dann stattgegeben, so kann der Verkehr der dort vorgeworfenen Pflichtverletzung den geforderten Verhaltensstandard genau entnehmen.

Ist aber der geforderte Verhaltensstandard für den Verkehr nicht ersichtlich, so droht Ressourcenverschwendung beim Vorsorgeaufwand aufseiten des Schuldners. Weil regelmäßig der vom Schuldner zu ersetzende private Schaden über dem verursachten Ressourcenschaden liegt, droht ihm im Zweifel eine aus ökonomischer Sicht übermäßige Haftung. ${ }^{1822}$ Ist nun der von ihm erwartete Verhal-

1881 S.o., S. 366.

1882 S.o., S. 371 (Fn. 1409). 
tensstandard unklar, so wird er - um die Übermaßhaftung zu vermeiden - korrespondierend übermäßige Sorgfaltsanstrengungen betreiben. ${ }^{1883} \mathrm{Um}$ ökonomisch zu missbilligende Rechtsunsicherheit $\mathrm{zu}$ vermeiden, sollte daher dem Gericht die Aufgabe, im Bereich vermögensschützender Nebenpflichten unter Rückgriff auf den Parteivortrag konkrete Verhaltensstandards aufzustellen, nicht durch die (zu weitgehende) Wirkung einer Beweislastumkehr abgenommen werden.

Je nach typisiertem Informationsinteresse der Gesellschaft kann also im Einzelfall auch die durch eine Beweislastumkehr beförderte Informationsgewinnung über Schadensvermeidungsprojekte ein sinnvolles Ziel sein. ${ }^{1884}$ Bei Nebenpflichten ist dennoch die Erforschung einer Vielzahl möglicher Schadensvermeidungsprojekte gesamtgesellschaftlich weniger interessant als die gerichtliche Festlegung auf einen konkreten - nach hier vertretener Ansicht, möglichst effizienten - Verhaltensstandard. Dies gilt insbesondere im Bereich des Schutzes vermögenswerter Interessen. Hierauf sollte sich die Informationsgewinnung konzentrieren. Die im Mittelpunkt des Verschuldensbegriffs stehende im Verkehr erforderliche Sorgfalt sollte daher weitmöglichst in die vom Gläubiger darzulegende Pflichtverletzung integriert werden. Die systemtheoretische Funktion von Beweisrecht als „Instrument[...] zur autoritativen Konstruktion von Nichtwissen “1885 kann hier nämlich nicht überzeugen, vielmehr ist möglichst genaues Wissen über den geforderten Verhaltensstandard anzustreben, und nicht der Beweislastverteilung zu überlassen. ${ }^{1886}$ Das kann nur geschehen, wenn dem Verschulden - und damit auch der Vermutung des $§ 280$ I 2 BGB hierfür - vor einer vollständigen Abgrenzung der Verantwortungsbereiche von Gläubiger und

1883 Zur „Überabschreckung“ s.o., S. 369 (Fn. 1399).

1884 Insbesondere wenn Risiken betroffen sind, in deren Kontrolle und Auswirkungen nur der Schuldner Einblick hat, kann die wegen der Beweislastumkehr drohende Haftung ein sinnvoller Anreiz sein, um den Schuldner zu öffentlicher Informationsgewinnung anzuhalten, die er anderenfalls unterlassen hätte, vgl. beispielsweise zu einem Ansatz im Gefahrstoffbereich, den Hersteller für Informationsgewinnung durch staatliche Institution (teilweise) bezahlen zu lassen, weil das Haftungssystem mangels vorhandener oder aufgrund verschleierter Informationen (noch) nicht genügend Schlagkraft aufweist Spiecker, Informationsgewinnung, 2003, S. 22.

1885 Treffend Engel, Unsicherheit, 2001, S. 37. Ähnlich auch Spiecker, Informationsgewinnung, 2003, S. 32 (,Konstruktion von Sicherheit mittels prozessualer Regelungen“).

1886 Vgl. Spiecker, Informationsgewinnung, 2003, S. 31f. („Beseitigung von Unsicherheit [durch] [...] das Mittel der Informationsgewinnung"). 
Schuldner möglichst wenig eigenständige Bedeutung zukommt und die Gerichte so zur durch den Vortrag der Parteien beförderten Informationsgewinnung über den genauen Inhalt der Nebenpflicht angehalten werden. ${ }^{1887}$ Etwaigen Informationsdefiziten des Gläubigers ist dann über eine sekundäre Darlegungslast des Schuldners Rechnung zu tragen. Anderenfalls bleibt der für den Verkehr perspektivisch interessante Verhaltensstandard womöglich im Dunkeln.

b) Zwischenergebnis: Informationsinteresse des Verkehrs an präzisem Pflichtstandard

Der Haftungsgrund der Nebenpflicht bestimmt über die Formulierung der konkreten Verhaltensanforderung (eher allgemein oder eher spezifisch) die haftungsrechtliche Wirkung der Beweislastumkehr. Weil sich Nebenpflichten nach hier vertretenem Ansatz regelmäßig auf einen Kostenvorteil des Schuldners bei der Schadensvermeidung oder der Schadensversicherung als Haftungsgrund stützen, findet die ökonomische Analyse mit der Rekonstruktion damit auch Eingang in die Bestimmung der Reichweite sinnvoller Haftung durch eine Beweislastumkehr im Rahmen des Verschuldens. Die Beweislastumkehr darf schließlich keine Umstände erfassen, für welche die Eigenschaft des Schuldners als cheapest cost avoider oder cheapest cost insurer nicht mehr greift. Anderenfalls wird die Verschuldenshaftung über § 280 I 2 BGB entgegen ökonomischer Sinnhaftigkeit in Richtung einer Gefährdungshaftung transformiert. Die ökonomische Analyse liefert dann ein Argument dazu, der Beweislastumkehr bei Nebenpflichten durch eine präzise Definition der Pflichtverletzung etwas den Wind aus den Segeln zu nehmen. Hierfür spricht auch das Informationsinteresse des Verkehrs an einer möglichst präzisen Festlegung des geforderten Verhaltensstandards, um Fehlverwendung von Ressourcen bei der Haftungsabwehr zu vermeiden.

1887 Das deckt sich letztlich mit der Erwägung, § 280 I 2 BGB bei Nebenpflichten teleologisch zu reduzieren, s.o., S. 73. 


\section{Ausfüllung der schuldverhältnisspezifischen Funktion von Nebenpflichten}

Die für eine Nebenpflicht notwendige Beziehung zwischen einem eingetretenen Schaden und dem Wirkungskreis des Schuldverhältnisses bleibt trotz der Fülle an Veröffentlichungen vage und im Kern ungeklärt. ${ }^{1888}$ Es soll hier ein Versuch unternommen werden, ein zumindest subsumtionsfähiges Merkmal zu entwickeln.

\section{Suche nach dem Haftungsgrund}

Es wird vertreten, dass die entscheidende Voraussetzung für die Annahme einer Nebenpflicht sei, ob sie die Zweckerreichung des jeweiligen Schuldverhältnisses erleichtere oder nicht. ${ }^{1889}$ Da das BGB in $\S 311$ II, III BGB mittlerweile explizit Schuldverhältnisse ohne Leistungspflichten vorsieht, wird deutlich, dass es für die Ergründung des Zwecks eines Schuldverhältnisses nicht allein auf die Leistungspflichten ankommen kann. Es erscheint aber zweifelhaft, ob der Gedanke einer Zweckbezogenheit zur Begründung einer Nebenpflicht in der konkreten Subsumtion taugt. Wann im Einzelfall die notwendige Wandlung des „Nebeneinander des Deliktsrechts in ein Miteinander ${ }^{\text {“1890 }}$ vollzogen ist, um eine Nebenpflicht dem Schuldverhältnis gegenüber dienlich zu machen, ist aus sich heraus nicht präzise zu begründen. Aus genau diesem Grund ist es auch die rechtspraktische Funktion ${ }^{1891}$ der Nebenpflicht, welche die Argumentationstopoi für die Begründung einer Nebenpflicht liefern muss. ${ }^{1892}$

1888 So auch Lüsing, Schutzpflichten, 2010, S. 173. Forderungen nach einem „qualifizierten Zusammenhang" (so z.B. Lüsing, Schutzpflichten, 2010, S. 337f.) zwischen dem eingetretenen Schaden und dem Schuldverhältnis umschreiben das Problem eher, als dass sie es lösen. Schließlich bleibt immer offen, worin die Qualifizierung genau liegen soll.

1889 Krebs, Sonderverbindungen, 2000, S. 217 ff., 237f.; Papadimitropoulos, Schutzwirkung, 2007, S. 230ff. Diese „Zweckförderung“ lässt sich plastisch mit einem „Dienst“ der Nebenpflicht dem Schuldverhältnis gegenüber umschreiben. Mit Blick auf die „unmittelbare“ Förderung des Schuldverhältnisses durch die Leistungspflichten wird bei Nebenpflichten lediglich eine ,mittelbare" Förderung vorausgesetzt.

1890 Paßmann, Schutzpflichtverletzungen, 2010, S. 127; ähnlich bereits Thiele, JZ 1967, 649, 651.

1891 S.o., S. 318, 323ff.

1892 Vgl. auch Picker, FS Medicus, 1999, S. 397, 425ff., der treffend darauf hinweist, dass die bereits häufig als gescheitert konstatierte - Unterscheidung zwischen allgemeinen und besonderen Pflichten deshalb so schwer fällt, weil auch innerhalb von Schuldverhältnissen nur ,ein 
Aus einer rechtssystemischen Perspektive kann eine Nebenpflicht einem (rechtsgeschäftlichen) Schuldverhältnis indes einen wichtigen Dienst erweisen: Sie kann es von unnötigen Fiktionen freihalten, indem mittels Annahme einer Nebenpflicht offen zugegeben wird, dass aufgrund von objektiv-teleologischen Erwägungen Risiken verteilt werden.

Beispiel 34 Im Märklinfall ${ }^{1893}$ könnte sich der Anspruch des Geschäftsführers gegen den Steuerberater aus verschiedenen dogmatischen Quellen ergeben ${ }^{1894}$ : Zum einen könnte es sich um einen Anspruch aus einem eigenständigen Auskunftsvertrag handeln (Auskunftshaftung). ${ }^{1895}$ Zum anderen könnte es sich um eine konkludente Erweiterung der (Leistungs-)Pflichten aus dem Steuerberatervertrag ${ }^{1896}$ handeln. ${ }^{1897}$ Schließlich kommt ein Anspruch aus $\$ \S 280$ I, 241 II $B G B$ wegen einer Nebenpflichtverletzung des Steuerberatervertrags in Betracht. ${ }^{1898}$ Die beiden ersten Varianten haben gemein-

gewöhnliches Fehlverhalten“ vorliege. Ein „besonderes soziales Unwerturteil“ sei damit nicht verbunden. Vielmehr liege „wie sonst“ im Jedermannsrecht nur ein ,sozial unerwünschtes Verhalten“ vor. Was ,sozial unerwünscht" ist und was nicht, muss sich folglich nach allgemeingültigen Maßstäben feststellen lassen, denen wiederum die ökonomische Analyse eine sinnvolle Kontur geben kann.

1893 S.o., S. 264.

1894 Instruktiv Thole, ZfPW 2015, 31, 37ff.; vgl. auch Kayser, ZIP 2014, 597, 602f.

1895 Ehlers, BB 2014, 131, 132; Kayser, ZIP 2014, 597, 603. Sofern sich die Parteien einvernehmlich auf eine vergüteten Insolvenzprüfung durch den Steuerberater geeinigt hätten, hätte es sich um einen Werkvertrag gehandelt, D. Fischer, DB 2015, 1643, 1644.

1896 Ein Vertrag mit einem Steuerberater ist - ähnlich dem Vertrag mit einem Rechtsanwalt regelmäßig ein Dienstvertrag mit Geschäftsbesorgungscharakter gem. $\S 675$ I, 611 BGB, MüKo-BGB/Heermann, 7. Aufl. 2018, §675 Rn. 41. In Einzelfällen mag auch ein Werkvertrag mit Geschäftsbesorgungscharakter nach $\S \S 675 \mathrm{I}, 631$ BGB in Betracht kommen. Für ein - hier vorliegendes - steuerliches Dauermandat ist aber das dienstvertragliche Element kennzeichnend. Der Mandant erwartet schließlich keinen konkreten Erfolg, sondern ein umfassendes Bemühen des Steuerberaters um seine (steuerlichen) Interessen. Dass auch im Rahmen des Dauermandats einzelne Aspekte Erfolgsschuldcharakter haben (wie z.B. die Anfertigung der Steuererklärung oder die korrekte Aufstellung einer Bilanz), ist hierfür ohne Belang. Eine Aufspaltung des Vertragstypus in werk- und dienstvertragliche Element wird weder dem Willen der Parteien noch der Forderung nach Rechtssicherheit gerecht, vgl. zu alldem anschaulich BGH, Urt. v. 4.6.1970 - VII ZR 187/68, Rn. 10, 12 (BGHZ 54, 106, 107f.)

1897 Dafür Thole, ZfPW 2015, 31, 40f.; wohl auch D. Fischer, WM 2014, SBeil. 1, S. 14; D. Fischer, DB 2015, 1643, 1646; Kayser, ZIP 2014, 597, $602 \mathrm{f}$.

1898 Dagegen Thole, ZfPW 2015, 31, 43f. (,Sonst würde eine Leistungspflicht, für die ein Mandant zu bezahlen hätte, in eine schon kraft Gesetzes beachtliche schuldrechtliche Rücksichtnahme- 
sam, dass sie als Leistungspflichten nach $\$ 241$ I BGB aufseiten des Steuerberaters einen Rechtsbindungswillen erfordern. Ein Rechtsbindungswillen lässt sich hier indes nicht im Wege der Auslegung, sondern nur mittels Fiktion feststellen. ${ }^{1899}$ Eine konkludente Erweiterung der Vertragspflichten einer Partei ist ohne Zweifel möglich. Hiermit sollte jedoch restriktiv umgegangen werden. Schließlich wird dem Schuldner unterstellt, seine Vertragslast erhöhen zu wollen, ohne dass sich dies in einer erhöhten Gegenleistung widerspiegelt. Gerade in Fällen wie hier, in denen der Schuldner der Frage eher ausweicht, als eine definitive, Vertrauen der Gegenseite rechtfertigende Aussage zu treffen, wird der Grundsatz der Privatautonomie entschieden aufgeweicht, wenn dem Schuldner eine konkludente Vertragserweiterung untergeschoben wird. Gleiches gilt für die Auskunftshaftung: Innerhalb eines bestehenden Vertragsverhältnisses erscheint es wenig sinnvoll für einen Berater, ein zusätzliches Haftungsrisiko unentgeltlich zu übernehmen. ${ }^{1900}$ Das fragwürdige ${ }^{1901}$ - und auch von der Rechtsprechung mit immer größer werdender Zurückhaltung herangezogene $^{1902}$ - Instrument der Auskunftshaftung erscheint zudem

pflicht umfunktioniert."). Der Mandant hat in einem solchen Fall aber auch in keiner der anderen dogmatischen Konstruktionen (Erweiterung des Vertragsgegenstandes, eigenständiger (Auskunfts-)Vertrag) für die ihm geschuldete Information „,bezahlt“. Mangels Vergütung erscheint die Rückführung der Risikoübernahme auf ein privatautonomes Moment des Steuerberaters (noch) widersinniger, vgl. auch Hörnig/Matz, Anm. zu OLG Koblenz, Urt. v. 15.4.2014 - 3 U 633/13, DStR 2015, 966, 966f. Der Hinweis von Thole, ZfPW 2015, 31, 43, dass es sich hier „nicht ausschließlich um eine gesetzlich, heteronom determinierte Pflichtenbindung“ handele, kann daher nicht - oder zumindest weniger als die Alternative - überzeugen.

1899 Das muss auch Thole, ZfPW 2015, 31, 40f. zugeben.

1900 Wegen des ,hohen Abstraktionsgrades der Konstruktion des selbstständigen Beratungsvertrags neben einem anderen Vertrag“" krit. auch Schaub, AcP 202 (2002), 757, 788f.

1901 von Bar, Gutachten, Band II, 1981, S. 1681, 1724; von Bar, JuS 1982, 637, 642; Canaris, FS Larenz, 1983, S. 27, 93f.; Faust, Gutachten DJT, 2016, S. 40 (,Fiktion des Rechtsbindungswillens in Fällen [...], in denen das Vorliegen eines Schuldverhältnisses der Billigkeit entspricht ${ }^{*}$ ); Heese, Beratungspflichten, 2015, S. 105f. (Fn. 78) m.w.N.; Hopt, AcP 183 (1983), 608, 617f.; U. Krüger, NJW 2013, 1845, 1849 (,gekünstelt“); Schaub, AcP 202 (2002), 757, 787; vgl. auch Heinrichs, FS Canaris, Bd. I, 2007, S. 421, 441f.(„Probleme [können] jetzt mit [§ $311 \mathrm{II}]$ Nr. 3 [BGB] gelöst werden").

1902 Vgl. Doobe, Vermögensschäden, 2014, S. 63; Hopt, AcP 183 (1983), 608, 619; Paschke, AcP 187 (1987), 60, 68; Seibt/Wollenschläger, DB 2011, 1378, 1380; richtigerweise gegen eine 
subsidiär gegenüber der Erweiterung des Pflichtenkreises in einem bestehenden Vertragsverhältnis. ${ }^{1903}$ Weil es sich - wie für Nebenpflichten typisch - um eine plötzlich auftretende und von beiden Teilen unvorhergesehene Gefahr für die Integrität des Gläubigers handelt, ist es daher vorzugswürdig, hier von einer Nebenpflicht auszugehen. ${ }^{1904}$ Damit wird die heteronome Natur der Pflicht offen eingestanden und ein frontaler ${ }^{1905}$ Konflikt mit der Privatautonomie vermieden. ${ }^{1906}$

So ließe sich im Einzelfall mit diesem Gedanken zumindest eine bestimmte Wahl des Mittels der Risikoverteilung - namentlich: eine Nebenpflicht - vorgeben. ${ }^{1907}$

(weitere) „Verrechtlichung“ im Sozialleben auch BGH, Urt. v. 23.7.2015 - III ZR 346/14, Rn. 11 (Keine Ansprüche aus den $\S \S 677 f f$. BGB im Verhältnis eines Sportvereins und einer Großmutter, die ihre Enkelin zu den auswärtigen Mannschaftsspielen fuhr); OLG Hamm, Urt. v. 17.6.2014 - 7 U 77/13, Rn. 41 ff. (Keine Nebenpflicht eines Autohändlers zur Versicherung eines zum Verkauf überlassenen Fahrzeugs, wenn die Vermittlung nur aus Gefälligkeit erfolgt).

1903 Zutreffend Schaub, AcP 202 (2002), 757, 790f.; Thole, ZfPW 2015, 31, 38.

1904 So i.E. auch BGH, Urt. v. 6.2.2014 - IX ZR 53/13, Rn. 2, 4; Geuß, BB 2013, 599, 601; Menkel, DStR 2010, 2477, 2479; s. auch Thole, ZfPW 2015, 31, 44 (,,[p]rima facie liegt die Annahme einer Rücksichtnahmepflicht allerdings nahe“); ähnlich Schaub, AcP 202 (2002), 757, 792f., 801f.; vgl. im Kontext des Vertrags mit Schutzwirkung zugunsten Dritter auch Honsell, FS Medicus, 1999, S. 211, 233, der generell eine „Rückbesinnung auf das liberale Modell der Privatautonomie“ fordert und in Ausnahmefällen die Annahme ,richterrechtliche[r] Schutzpflichten" für ,methodisch ehrlicher" hält.

1905 Es bleibt natürlich noch ein tangentialer Konflikt mit der Privatautonomie insofern, als dass das ursprünglich festgesetzte Verhältnis von Leistung und Gegenleistung durch die darüber hinausgehende Pflicht aus $\S 241$ II BGB aus Sicht des Steuerberaters negativ beeinflusst wird, s.o., S. 258.

1906 Ähnlich im Kontext der Kapitalanlageberatung U. Krüger, NJW 2013, 1845, 1849f. (Plädoyer für eine „Umorientierung der Rechtsprechung weg von der Fiktion des Beratungsvertrags hin zur gesetzlichen Nebenpflicht" aus $\S 241$ II BGB).

1907 Besteht zwischen beiden Parteien überhaupt kein Schuldverhältnis, ist aber eine Haftung aus rechtspraktischer Perspektive angemessen, so ist zu überlegen, ob hierauf mit einem Schuldverhältnis gem. § 311 II Nr. 3 BGB reagiert werden kann, um Willensfiktionen zu vermeiden, hierzu instruktiv Reischl, FS Musielak, 2004, S. 411, 419ff., 434 (,,Vorteil dieses Lösungswegs [...], dass man sich bei der Frage des Schadensersatzanspruchs nicht mehr mit der Primärbindung auseinander setzen muss"); ähnlich Faust, Gutachten DJT, 2016, S. 41, 44; vgl. zur möglichen Rolle des $\S 311$ II Nr. 3 BGB als Auffangbecken für Fälle, in denen unüberwindbare Mängel im Deliktsrecht kompensiert werden müssen, auch Heinrichs, FS Canaris, Bd. I, 2007, S. 421, $437 f f$. 
Beispiel 47 In der Sache nahm der BGH im Probefahrtfall ${ }^{1908}$ einen stillschweigenden Haftungsausschluss für leicht fahrlässige Beschädigungen des Probefahrzeugs durch den Interessenten an, wenn sich ein Probefahrt-typisches Risiko realisiert hat. Er deutete aber an, dass der Haftungsausschluss abzulehnen gewesen wäre, wenn der Verkäufer vor Beginn der Probefahrt darauf hingewiesen hätte, dass der Wagen nicht versichert sei. ${ }^{1909}$ Entscheidend ist also gar nicht die Kaskoversicherung des Autos, sondern die Freiheit des Kunden, selbst darüber zu entscheiden, ob er das Risiko einer unversicherten Fahrt tragen möchte oder nicht. Das ähnelt der Begründung einer vermögensschützenden Nebenpflicht. Das vom BGH erwünschte Ergebnis ließe sich nämlich auf ähnlichem Weg mit einer Nebenpflicht erreichen: Durch die Fiktion eines Haftungsausschlusses wird der Autohändler schließlich faktisch dazu gezwungen, dem Interessenten die gleiche, haftungsrechtliche Ausgangslage zu bieten, wie wenn er für das zu verkaufende Auto eine Kaskoversicherung abgeschlossen hätte. Der Autohändler hätte das Auto also entweder versichern müssen oder den Interessenten auf das besondere Risiko, mit einem unversicherten Auto eine Probefahrt zu machen, hinweisen müssen. In die Termini einer Nebenpflicht umgemünzt muss der Autohändler hier also das vermögenswerte Interesse des Interessenten wahren, nicht unerkannt für Risiken einer Probefahrt haften zu müssen. Zwar hat ein Anspruch aus $\$ \$ 280$ I, 241 II BGB die zusätzliche Voraussetzung eines Verschuldens des Schuldners. Weil die Nebenpflicht zum Schutz vermögenswerter Interessen aber verhaltensbezogen zu definieren ist, wäre die im Verkehr erforderliche Sorgfalt (\$276 II BGB) im Großteil bereits Bestandteil der Pflichtverletzung.

Die stillschweigende Vereinbarung hat mit einer Nebenpflicht gemein, dass sie Risiken nach allgemeingültigen Grundsätzen verteilt. ${ }^{1910}$ Nebenpflichten sind

1908 S.o., S. 435.

1909 BGH, Urt. v. 7.6.1972 - VIII ZR 35/71, Rn. 11.

1910 Auch der BGH sprach im Urteil davon, dass es aus den abstrakt erörterten Gründen dem Autohändler ,zuzumuten“ sei, den Kunden durch Einladung zu einer Probefahrt von den Fol- 
aber zumindest offensichtlich fremdbestimmt. Ihre Begründung muss daher die Interessen beider Parteien angemessen berücksichtigen und genauer Überprüfung standhalten. Dinge, die dem Parteiwillen zu entnehmen sind, dürfen als Ausfluss der Privatautonomie gar nicht mehr auf ebendiese Interessengerechtigkeit überprüft werden. Der Parteiwille ist insofern ein praktisches Vehikel für den Transport von Risikoverteilungserwägungen. Derart großzügig mit konkludenten Abmachungen zu verfahren, bedeutet aber, den Aussagegehalt rechtsgeschäftlichen Willens als solchen zu entwerten. Dementsprechend ist mit stillschweigenden Vereinbarungen vorsichtig zu verfahren. ${ }^{1911}$

Beispiel 47 Eine Nebenpflicht wäre im Probefahrtfall ${ }^{1912}$ daher aus einer methodischen Perspektive das vorzugswürdige Werkzeug gewesen, das Schadensrisiko zuzuweisen. ${ }^{1913}$

Die schuldverhältnisspezifische Funktion von Nebenpflichten kann - anders als deren rechtspraktische Funktion - nicht die Argumentationstopoi für die Begründung einer Nebenpflicht liefern. Sie kann aber - nachdem die Notwendigkeit einer Haftung des Schuldners aufgrund anderer Kriterien begründet wurde eine Nebenpflicht als Instrument zur Durchsetzung dieser als sinnvoll vorausgesetzten Haftung vorgeben, um den Parteiwillen von rechtsgeschäftlichen Fiktionen freizuhalten.

\section{Verlaufen der Haftungsgrenze?}

Ungeachtet der Tatsache, dass sich Nebenpflichten mit dem Aspekt der Dienlichkeit für das Schuldverhältnis nicht überzeugend begründen lassen, bleibt aber

gen einer fahrlässigen Beschädigung des Fahrzeugs freizustellen, BGH, Urt. v. 7.6.1972 - VIII ZR 35/71, Rn. 11. Die Wortwahl macht deutlich, dass es hier weniger um die konkrete Auslegung des rechtsgeschäftlichen Verhaltens nach $\S \S 133,157$ BGB ging, sondern um das Unterschieben einer Pflicht, welches aus abstrakten Risikoerwägungen heraus vom Gericht für sinnvoll erachtet wurde.

1911 Dezidiert gegen die „Hypostasierung eines Vertragsschlusses“ auch Canaris, Vertrauenshaftung, 1971, S. 539.

1912 S.o., S. 435.

1913 Vgl. Honsell, FS Medicus, 1999, S. 211, 233 (Annahme einer Nebenpflicht „methodisch ehrlicher" als die Ausweitung der ,stillschweigende[n]“" Risikoverteilung); U. Krüger, NJW 2013, 1845, 1849f. 
zu untersuchen, ob das Merkmal unverändert oder in einer begrifflichen Variante als Grenze für die aus $\S 241$ II BGB folgenden Verhaltensanforderungen taugt.

\section{Dienlichkeit der Nebenpflicht im konkreten Schuldverhältnis}

Eine Nebenpflicht erfüllt dann keine schuldverhältnisspezifische Funktion mehr, wenn sie dem Schuldverhältnis nicht konkret dienlich ist. Weist ein Schuldverhältnis Leistungspflichten auf, so stehen diese im Zentrum eines etwaigen Zwecks des Schuldverhältnisses. Leistungspflichten tragen daher unmittelbar zur Erreichung des im Schuldverhältnis verbürgten Ziels bei. Nebenpflichten müssen diesen Zweck dann konsequenterweise nur auf mittelbare Weise fördern. ${ }^{1914}$ Gibt es keine Leistungspflichten in einem Schuldverhältnis, so muss ein davon unabhängiger Zweck ausgemacht werden. Anderenfalls lässt sich die Begrenzung von Nebenpflichten über das Kriterium der mittelbaren Zweckförderung nicht aufrechterhalten. Schließlich impliziert der Begriff der Mittelbarkeit eine gegenüber etwas Anderem zweitrangige, zurückgestufte Nähebeziehung. Die Existenz eines Schuldverhältnisses auch ohne Leistungspflichten ist in §311 II BGB sogar gesetzlich verankert. Der Begriff des Dienstes einer Nebenpflicht für das Schuldverhältnis soll begrifflich modifiziert werden, um die Realität widerzuspiegeln, dass ein Leistungsbezug in vielen Schuldverhältnissen bereits von vornherein ausgeschlossen ist. Es wird deshalb der Begriff des Transaktionsbezugs vorgeschlagen. ${ }^{1915}$

\section{Transaktionsbezug}

Ausgangspunkt der Begrenzung durch den Transaktionsbezug ist der Begriff der Transaktion. Im klassischen Sprachgebrauch bedeutet Transaktion den Austausch von Wirtschaftsgütern. Damit passt der Begriff auf den ersten Blick nur

$1914 \mathrm{Zu}$ dieser Unterscheidung aus definitorischer Sicht Lüsing, Schutzpflichten, 2010, S. 78, 87; a.A. Paßmann, Schutzpflichtverletzungen, 2010, S. 162, der eine unmittelbare Anbindung der Nebenpflicht an die Hauptleistungspflicht fordert. Das führt aber zu z.T. problematischen Ergebnissen, s.o., S. 469f.

1915 Vgl. Mankowski, IPRax 2003，127，131 („Schutz transaktionsspezifischer Investitionen“); Michael Lehmann, Vertragsanbahnung, 1981, S. 337 („Schutz des transaktionsnahen Integritätsinteresses“). 
auf rechtsgeschäftliche Schuldverhältnisse. ${ }^{1916}$ Das hier zugrunde gelegte Verständnis von Transaktion legt den Fokus auf die Übersetzung ${ }^{1917}$ als durchführen. Der notwendige Bezug soll also nicht nur etwaige Leistungspflichten in den Blick nehmen. Vielmehr geht es um einen Bezug der Nebenpflicht zur Durchführung des Schuldverhältnisses in concreto. Dabei muss überlegt werden, ob auch außerhalb klassisch vertraglicher Schuldverhältnisse ein Austausch von Gütern, Interessen oder sonstigen Elementen der Zielsetzung nach stattfinden soll.

Beispiel 31 Im Kaufhausfall ${ }^{1918}$ existieren zwischen Kaufhausbesucher und Kaufhausbetreiber keine Leistungspflichten. Zudem dienen die dort geltenden Nebenpflichten nicht dem Gegenstand eines späteren Vertrags. Sofern man Nebenpflichten über einen etwaigen Leistungsbezug begrenzen will, muss § 241 II BGB in diesem Bereich entgegen der herrschenden Meinung völlig leerlaufen. ${ }^{1919}$ Untersucht man den Zweck des Schuldverhältnisses näher, so lässt sich eine Transaktion im weitesten Sinne durchaus feststellen: Der Betreiber tauscht auf einer faktischen Ebene den Zugang zu einer attraktiven Verkaufsfläche und die Gelegenheit, Produkte auszuprobieren, gegen die Aufmerksamkeit des Kunden, der sich im Idealfall von der Werbung des Verkaufsraumes zu einem Kauf hingerissen fühlen soll. ${ }^{1920}$ Der Zweck des Schuldverhältnisses (hier: Begründung eines rechtsgeschäftlichen Schuldverhältnisses in Form eines Kaufvertrags) lässt sich also auf einer faktischen Ebene durchaus häufig in einen Austausch von Interessen und Angeboten herunterbrechen. In concreto bedeutet das bei Kundenverletzungen im Rahmen von Kaufhausbesuchen, dass zumindest die Schuldverhältnis-spezifische Funktion von Nebenpflichten häufig

1916 Auch dort müsste man beispielsweise bei der Schenkung dann den einseitigen „Austausch“ eines Wirtschaftsgutes genügen lassen.

$1917 \mathrm{http} / / /$ de.pons.com/\%C3\%BCbersetzung/latein-deutsch/transigere, zuletzt eingesehen am 24.7.2018.

1918 S.o., S. 249.

1919 Insofern konsequent, wenn auch im Ansatz problematisch Paßmann, Schutzpflichtverletzungen, 2010, S. 167f.

1920 Vgl. s.o., Beispiel 31, S. 249; Michael Lehmann, Vertragsanbahnung, 1981, S. $317 f$. 
erfüllt sein wird. Schließlich basiert die faktische Transaktion unter anderem darauf, dass der Betreiber den Besucher keinen körperlichen Risiken aussetzt. Ansonsten hätte der Kunde kein Interesse dem Betreiber seine Aufmerksamkeit zu offerieren. Der Bezug einer integritätsschützenden Nebenpflicht zur Transaktion lässt sich also durchaus herstellen. ${ }^{1921}$

Der Begriff des Transaktionsbezugs lässt sich damit nach hier vertretenem Verständnis - anders als der des Leistungsbezugs - auch auf rechtsgeschäftsähnliche, gesetzliche und rechtsgeschäftliche Schuldverhältnisse ohne Gegenleistung anwenden. Es bedarf hierfür nur eines weiten Verständnisses von dem das Schuldverhältnis begründenden Interessenaustausch. Weder ist am juristischen Begriff des Tausches festzuhalten, noch muss der Tauschgegenstand eine rechtsgeschäft(sähn)liche Handlung sein. Der Transaktionsbezug soll deutlich machen, dass eine schuldverhältnisbedingte Haftung aus Nebenpflichtverletzung nur dann in Frage kommt, wenn die Nebenpflicht eine enge Anbindung an die Durchführung des Schuldverhältnisses aufweisen kann. ${ }^{1922}$ Der Transaktionsbezug repräsentiert damit das juristische Bauchgefühl, dass eine bestimmte Nebenpflicht in dem jeweiligen Schuldverhältnis fehl am Platze ist. ${ }^{1923}$

1921 Scheitern wird ein Anspruch des Kunden aus $\S 280$ I, 241 II BGB nach dem hier vertretenen Ansatz aber häufig an der fehlenden rechtspraktischen Funktion einer Nebenpflicht im Einzelfall. Schließlich sind die meisten Szenarien der Kaufhausfälle in Gänze durch das Jedermannsrecht abgedeckt. Ausnahmen sind bei Relevanz von § 278 BGB denkbar, s.o., S. $475 \mathrm{ff}$.

1922 Wenn eine Verhaltensanforderung nicht förderlich ist, um einem Schuldverhältnis zu seinem Ziel zu verhelfen, so fehlt es am Transaktionsbezug und eine entsprechende Nebenpflicht ist abzulehnen. So lehnt beispielsweise das AG Hoyerswerda, Urt. v. 27.4.2004 - 1 C 66/04, Rn. 15ff. zutreffend eine Nebenpflicht des Gebrauchtwagenverkäufers ab, den Käufer ungefragt über Änderungen der Servicebestimmungen zu informieren, weil ,die geforderten Angaben“ für die Erfüllung der gegenseitigen Hauptleistungspflichten „nicht erforderlich“ waren. Einer entsprechenden Pflicht fehlte es somit am Transaktionsbezug, vgl. zu diesem Gedanken bereits Michael Lehmann, Vertragsanbahnung, 1981, S. 325.

1923 Treffend OLG Saarbrücken, Urt. v. 21.5.1993 - 4 U 79/92, Rn. 67 (Kein Ersatz von „Zufallsschäden" durch die Haftung aus Nebenpflichtverletzung); ähnlich Soergel/Benicke/Hellwig, 13. Aufl. 2014, § 280 Rn. 133 (keine Pflichtverletzung des Malermeisters gegenüber einem Auftraggeber, wenn ersterer letzteren im Straßenverkehr anfährt, während der Malermeister „,neue Farbe für den Auftrag besorgte"). Dabei lässt sich über den Transaktionsbezug auch eine Pflicht ausscheiden, die in zeitlicher Hinsicht „fehl am Platze“ ist, vgl. zur Integration der zeitlichen Dauer eines Schuldverhältnisses in den (Neben-)Pflichtinhalt Hoffmans, Nebenpflichten, 1986, S. 181ff. 
Beispiel 2 Im Seniorenfall ${ }^{1924}$ ist eine Nebenpflicht deshalb mit Rücksicht auf die schuldverhältnisspezifische Funktion einer Nebenpflicht abzulehnen. Die Transaktion (Austausch von Wohnungsüberlassung und Geld) wird durch diese Verhaltensanforderung weder gefördert, noch wird sie durch das Fehlen einer entsprechenden Pflicht beeinträchtigt. Die Nebenpflicht, Schädigungen des Gläubigers auch im Alten Land zu unterlassen, hat damit keinerlei Transaktionsbezug.

Beispiel 4 Gleiches gilt im Diebstahlsfall ${ }^{1925}$ : Die Transaktion besteht dort aus dem Austausch eines Buches gegen Geld. Auch über den Austausch der gegenseitigen Leistungspflichten hinaus besteht ein Transaktionsbezug bezüglich solcher Handlungen, die sich auf die Abwicklung des Geschäfts beziehen. So hätte der Käufer das Geschäft des Verkäufers aufsuchen können, um Gewährleistungsrechte geltend zu machen. Dann bestünde zwischen dem ursprünglichen Kaufvertrag und einer Pflicht des Händlers, den Kunden während des erneuten Aufenthalts nicht in seiner Integrität zu verletzen, ein Transaktionsbezug. Hier betrat der Kunde aber den Laden nicht wegen des vorherigen Einkaufs und dies war - wegen der Vermummung und des regelwidrigen Eintritts - auch nach außen hin erkennbar. Damit fehlt es auch hier am Transaktionsbezug. $^{1926}$

Beispiel 3 Anders liegt die Lage indes im Herzinfarktfall ${ }^{1927}$ : Hier wird auf einer vorvertraglichen Ebene die Aufmerksamkeit des Kunden gegen die Möglichkeit des Kunden getauscht, die betreffenden Produkte gefahrlos in Augenschein nehmen zu können. Die Gefahr ging hier zwar nicht vom Ladenbetreiber aus, sondern hatte ihren Ursprung in der Person des Schuldners selbst. Anders als auf der offenen Straße konnte der Kunde hier aber wegen des sich anbahnenden Geschäfts davon ausgehen, dass ein im Laden anwesender

1924 S.o., S. 5. 1925 S.o., S. 7.

1926 Vgl. bereits von Caemmerer, FS DJT, Bd. II, 1960, S. 49, 58.

1927 S.o., S. 6. 
Verkäufer ihm eine besondere Aufmerksamkeit zukommen lassen würde. ${ }^{1928}$ Mit der Ausnahme von völlig externen Gefahren möchte der Kunde sich bei der Begutachtung der Ware sicher fühlen. Das kann auch die Notfallhilfe des Verkäufers bei einer plötzlichen Erkrankung erfassen. Damit lässt sich ein Transaktionsbezug vertretbar bejahen. Die schuldverhältnisspezifische Funktion einer Nebenpflicht ist demnach erfüllt. ${ }^{1929}$

Mit dem Begriff des Transaktionsbezugs lassen sich Nebenpflichten auch mit Blick auf den Zweck oder die Zielsetzung eines konkreten Schuldverhältnisses begrenzen. ${ }^{1930}$ Die abstrakten Risikoverteilungserwägungen der ökonomischen Analyse - die hier innerhalb der rechtspraktischen Funktion der Nebenpflicht thematisiert wurden - werden damit durch den Transaktionsbezug als schuldverhältnisspezifische Funktion der Nebenpflicht sinnvoll ergänzt.

1928 Vgl. auch Bodewig, Jura 2005, 505, 510, der eine Nebenpflicht eines Kioskbesitzers für möglich hält, die vor seinem Laden verlorene Geldbörse eines Kunden zu sichern.

1929 Die Frage stellt sich indes, ob auch die rechtspraktische Funktion einer solchen Nebenpflicht gegeben wäre. Außer dem Ladeninhaber war hier niemand in der Lage dazu, den Schaden (sinnvoll) zu verhindern. Die Schadensvermeidungskosten - erhöhte Wachsamkeit bei Zusammenbrüchen von Kunden und gegebenenfalls Verständigung eines Notfalldienstes - sind für den Inhaber zudem gering und unterschreiten in jedem Fall den Schadenserwartungswert. Damit wäre der Ladeninhaber hier cheapest cost avoider und somit aus Sicht der Ökonomik grundsätzlich sinnvoller Schuldner einer entsprechenden Nebenpflicht. Aus einer systematischen Perspektive muss man sich aber fragen, ob die Regel des $\S 323 \mathrm{c}$ StGB hier abschließend das notwendige Maß an Tätigwerden bei plötzlichen Gefahren für Dritte regelt. Das gilt umso mehr, als der BGH die Schutzgesetzqualität der Norm - und damit die Transformation in einen zivilrechtlichen Verhaltensstandard zum Individualschutz - mittlerweile explizit festgestellt hat, BGH, Urt. v. 14.5.2013 - VI ZR 255/11, Rn. 7 (BGHZ 197, 225, 227f.); dagegen MüKo-BGB/Wagner, 7. Aufl. 2017, § 823 Rn. 417. Verpflichtet man den Ladeninhaber mit einer reinen Fahrlässigkeitshaftung auch über diesen Maßstab hinaus, so werden zumindest die Grenzen der verhaltenssteuernden Wirkung von $\S \S 823$ II BGB, 323c StGB erheblich aufgeweicht. Da der wirtschaftliche Schaden bei einer den Gläubiger plötzlich ereilenden Erkrankung ganz beträchtlich sein kann, setzt eine zivilrechtliche Fahrlässigkeitshaftung womöglich sogar noch stärkere Verhaltensanreize als die relativ milde Strafdrohung des $\S 323 \mathrm{c}$ StGB. Mit Blick hierauf und die teleologische Subsidiarität des $\S 241$ II BGB ist die rechtspraktische Funktion - und demnach eine Nebenpflicht insgesamt - zu verneinen.

1930 Das Schuldverhältnis verpflichtet den Schuldner schließlich nur „,nach seinem Inhalt“ aus $\S 241$ II BGB. Das „,nach seinem“ lässt sich im Rahmen der Auslegung nach dem Normzweck auch als „mit Rücksicht auf den“ deuten. Dann wird klar, dass aus § 241 II BGB nur dann eine angemessene Risikoverteilung abgeleitet werden kann, wenn der erkennbare Zweck des konkreten Schuldverhältnisses nicht im Einzelfall entgegensteht, näher hierzu s.o., S. 200ff. sowie insbesondere S. 202. 


\section{Zwischenergebnis: Transaktionsbezug als Gegenstück zur rechtspraktischen Funktion von $\$ 241$ II BGB}

Um die rechtspraktische Funktion einer Nebenpflicht an das individuelle Schuldverhältnis zu koppeln, wird sie sinnvollerweise durch die schuldverhältnisspezifische Funktion ergänzt. Diese wird sinnvoll durch den Begriff des Transaktionsbezuges ausgefüllt. Danach ist für jeden Einzelfall zu ermitteln, welchem Zweck das jeweilige Schuldverhältnis dient. Dieser Zweck basiert auf einer wie auch immer gearteten, nicht zwingend rechtsgeschäf(sähn)lichen Transaktion. Nur wenn sich die auf der rechtspraktischen Funktion fußende Verhaltensanforderung konkret in Bezug zu diesem Interessenaustausch bringen lässt, erfüllt die Nebenpflicht auch eine schuldverhältnisspezifische Funktion.

\section{Ergebnis: Sinnvolle Konturierung von $§ 241$ II BGB durch ökonomische Analyse}

Als Folge der teleologischen Subsidiarität schuldverhältnisbedingter Nebenpflichten ist die Funktion von $\S 241$ II BGB in einen rechtspraktischen und einen schuldverhältnisspezifischen Aspekt zu unterteilen. Die rechtspraktische Funktion von $\S 241$ II BGB bezieht sich dabei auf den Ausgleich haftungsrechtlicher Lücken des Jedermannsrecht im Bereich des Vermögensschutzes, der Haftung für das Verhalten Dritter sowie im Bereich der Beweislastverteilung für das Verschulden und hält sinnvolle Maßstäbe für eine entsprechende Lückenfüllung durch die Annahme von Nebenpflichten bereit. Die schuldverhältnisspezifische Funktion gewährleistet unter Rückgriff auf den Gedanken des Transaktionsbezugs, dass die entsprechende Nebenpflicht auch der Zwecksetzung des individuellen Schuldverhältnisses dient. Im Einzelnen lässt sich die sinnvolle Reichweite von Vermögensschutz unter Rückgriff auf Gedanken der ökonomischen Analyse des Rechts mit der Rekonstruktion des vollständigen Schuldverhältnisses und Aspekten ökonomischen Vertrauensschutzes konturieren. Mit den aufeinander abgestimmten Kriterien des cheapest cost avoider und des cheapest cost insurer sowie dem Element der Vertrauensprämie - welches konzeptionell sicherstellen soll, dass der Schuldner für die Belastung mit einer Nebenpflicht auch entschädigt wird - lässt sich die Reichweite vermögensschützender Nebenpflichten sinnvoll abstecken. Die Reichweite sinnvoller Haftung für das Verhalten Dritter wird sinnvollerweise durch das Kriterium der Gefahrerhöhung für die Integrität des Geschädigten durch die Einschaltung des Erfüllungsgehilfen bestimmt. Die 
Reichweite der Beweislastumkehr des $§ 280$ I 2 BGB ist schließlich unter Rückgriff auf die Abgrenzung der Verantwortungsbereiche zwischen Schuldner und Gläubiger zu bestimmen. Um sicherzustellen, dass die Verteilung der Beweislast nicht entgegen dem Haftungsgrund der Nebenpflicht - im Regelfall ein Kostenvorteil des Schuldners bei der Schadensvermeidung - erfolgt, ist die Nebenpflicht in ihrer Formulierung entsprechend an dem jeweiligen Haftungsgrund auszurichten.

Open Access Dieses Kapitel wird unter der Creative Commons Namensnennung 4.0 International Lizenz (http://creativecommons.org/licenses/by/4.0/deed.de) veröffentlicht, welche die Nutzung, Vervielfältigung, Bearbeitung, Verbreitung und Wiedergabe in jeglichem Medium und Format erlaubt, sofern Sie den/die ursprünglichen Autor(en) und die Quelle ordnungsgemäß nennen, einen Link zur Creative Commons Lizenz beifügen und angeben, ob Änderungen vorgenommen wurden.

Die in diesem Kapitel enthaltenen Bilder und sonstiges Drittmaterial unterliegen ebenfalls der genannten Creative Commons Lizenz, sofern sich aus der Abbildungslegende nichts anderes ergibt. Sofern das betreffende Material nicht unter der genannten Creative Commons Lizenz steht und die betreffende Handlung nicht nach gesetzlichen Vorschriften erlaubt ist, ist für die oben aufgeführten Weiterverwendungen des Materials die Einwilligung des jeweiligen Rechteinhabers einzuholen.

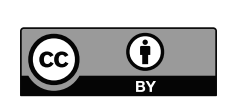

